\author{
UNIVERSIDADE DE SÃO PAULO \\ INSTITUTO DE QUÍMICA \\ Programa DE PÓS-GRAduAÇÃo EM QuímicA
}

Ana Paula Mangoni

\begin{abstract}
Materiais híbridos baseados em argilas catiônicas e espécies com potencial terapêutico
\end{abstract}

Versão corrigida da Dissertação defendida

Durante o desenvolvimento deste trabalho a autora recebeu auxílio financeiro do CNPq

São Paulo

Data do depósito na SPG:

$15 / 01 / 2014$

Ana Paula Mangoni 


\section{Materiais híbridos baseados em argilas catiônicas e espécies com potencial terapêutico}

Esta versão da dissertação contém as correções e alterações sugeridas pela Comissão Julgadora durante a defesa da versão original do trabalho, realizada em 12/02/2014. Uma cópia da versão original está disponível no Instituto de Química da Universidade de São Paulo.

Comissão Julgadora:

- $\operatorname{Prof}^{\mathrm{a}}$. Dr ${ }^{\mathrm{a}}$. Vera Leopoldo Constantino (orientadora) - IQ - USP

- Prof. Dr. Francisco Rolando Valenzuela Diaz - EP - USP

- Prof $^{\mathrm{a}}$. Dra . Dalva Lúcia Araújo de Faria - IQ-USP 
Ficha Catalográfica

Elaborada pela Divisão de Biblioteca e

Documentação do Conjunto das Químicas da USP.

Mangoni, Ana Paula

M277m Materiais híbridos baseados em argilas cationicas e espécies com potencial terapêutico / Ana Paula Mangoni. -- São Paulo, 2014.

$164 \mathrm{p}$.

Dissertação (mestrado) - Instituto de Química da Universidade de São Paulo. Departamento de Química Fundamental.

Orientador: Constantino, Vera Regina Leopoldo

1. Composto inorgânico lamelar 2. Química de materiais 3. Química de intercalação 4. Argila 5. Aminoácidos I. T. II. Constantino, Vera Regina Leopoldo, orientador.

$$
546 \text { CDD }
$$



Dedico esta dissertação às pessoas mais importantes da minha vida, meus pais, Marques e Marilene, minhas irmãs, Josiane e Andréia, e ao Allan, pelo amor incondicional e por acreditarem em mim. 


\section{AGRADECIMENTOS}

Aos meus pais, Marilene Carme Marafon Mangoni e Marques Delci Mangoni, por todo o amor incondicional e o imenso carinho que sempre me deram e também por sempre me proporcionarem condições psicológicas e financeiras para minha formação pessoal e acadêmica. Por entenderem e aceitarem minha ausência em suas vidas.

Às minhas irmãs, Josiane Mangoni e Andréia Fernanda Mangoni, por todo amor me oferecido, mesmo eu estando sempre ausente de suas vidas. Pelas várias horas passadas ao telefone e internet, tentando amenizar a saudade de alguma forma...

À professora Vera R. L. Constantino por "abrir as portas" do seu laboratório, me deixar fazer parte do seu grupo de pesquisa, pela orientação acadêmica e pessoal e pela paciência e carinho durante a realização deste trabalho.

Ao Allan, pelo carinho, amizade e companheirismo em todas as horas. Por passar fins de semanas no IQ me fazendo companhia, por aceitar minhas ausências, angústias e meu estresse. Por passar horas e horas me ajudando a formatar este trabalho.

Ao mais que amigo George, por todo o amor e pela amizade incondicional, por todos os momentos partilhados, tanto em casa, quanto no IQ, além de todos os momentos de lazer vividos nesses muitos anos "grudados". Além da ajuda científica (ideias, leitura e correções desta dissertação). Muito obrigada por fazer meus dias mais alegres, com suas gargalhadas estridentes, por me esperar inúmeras vezes até tarde no IQ, por se preocupar com o meu bem estar, por ouvir meus desabafos e por tantas outras coisas que só um grande amigo como ele poderia ter feito por mim!

À Queite, que desde os meus primeiros dias em São Paulo foi uma grande amiga e fez com que minha mudança para essa cidade fosse menos difícil. Companheira para TODOS os momentos, inclusive madrugadas passadas no IQ. Obrigada também por ler e corrigir meus trabalhos científicos. Obrigada por fazer parte diariamente da minha vida nesses dois belos anos.

Aos meus amigos do IQ, Cléia, Kassio, Rute, Marco Aurélio e Adriana por toda amizade, dentro e fora do IQ, pelos inúmeros momentos divertidos que vocês me proporcionaram. À Adriana, obrigada por ler esta dissertação e dar sugestões.

Às minhas amigas e colegas Michele e Vanessa, que me acolheram tão bem em nosso grupo de pesquisa e fora dele. Obrigada também por todos os conselhos e ajuda nos 
trabalhos científicos, por lerem e ajudarem a corrigir minha dissertação. Obrigada por me ensinarem, com tanta paciência, a usar os vários equipamentos do grupo. Por todos os momentos agradáveis, inclusive com muitas gargalhadas, que tivemos na salinha e fora dela. Obrigada por fazerem parte desses anos de SP.

Aos meus colegas e amigos de laboratório Ana Lucia, Alfredo, Gustavo, Rafael, Danilo, Vanessinha, Carol, Paulo e Vaeudo, por toda a ajuda nos experimentos e pelos vários momentos de descontração... Ao Alfredo que desde o início sempre se mostrou tão prestativo e preocupado em ajudar.

Aos meus amigos de longa data, Fabi, André e Miguel, Marciani, Pepé e Laurinha, por todo o amor, incentivo e por fazerem com que minha adaptação no Sudeste fosse muito mais fácil. Por todas as horas, quase que semanais, passadas ao telefone, sempre tão preocupados comigo. Por todo o esforço feito para me ver e continuar fazendo parte da minha vida.

Aos meus amigos que estão longe, Estela (e toda a família da madrinha), Luiz, Barbara, Jorge, Mariele, Angela, Nelson, Geovana Terra e Karen, que mesmo distante estiveram tão presentes em meus pensamentos e em meu coração.

Aos meus amigos de apartamento, Leo e Phablo, pela amizade, pela paciência, momentos de descontração e por me aturar ao longo desses anos.

Aos nossos vizinhos de laboratório e amigos, Rute, Iguatinã, Douglas, Rodrigo, Luis e Marcus Vinicius, por todos os momentos alegres, por todas as conversas, cientificas ou não, por todo o carinho.

Aos técnicos Cida e Ricardo, sempre tão prestativos e que além da grande ajuda na parte burocrática e nos equipamentos, também são amigos dentro e fora do IQ.

Aos técnicos Efigênia e Armando pela ajuda no laboratório.

Ao Filipe e à professora Helena Petrilli (Instituto de Física da USP), pelos cálculos computacionais que em muito auxiliaram na interpretação dos resultados experimentais.

Aos técnicos administrativos do IQ, em especial, à Cibele, Milton, Paulo e Marlene, por toda a ajuda e paciência na parte burocrática.

À Professora Marcia Fantini e aos técnicos Antonio Carlos e Társis, que abriram as portas do Laboratório de Cristalografia do IF-USP, permitindo o registro dos difratogramas de raios $\mathrm{X}$ para amostras presentes neste trabalho.

À Professora Maria Teresa Machini (IQ-USP) e ao técnico de laboratório Cleber, por realizarem o teste de quantificação de aminoácido e o teste qualitativo com ninidrina.

Ao Professor Marcos Bizeto e à Professora Maria Teresa Machini pelas discussões e sugestões no Exame de Qualificação.

À Professora Ana Maria da Costa Ferreira (IQ-USP) por emprestar os áminoácidos (Llisina e L-arginina) utilizados durante a realização desse trabalho e por sempre "emprestar" seu laboratório, caso fosse preciso.

Ao Laboratório de Espectroscopia Molecular (IQ-USP) e ao Claudio Hanashiro e à 
Nathália pelo registro e ajuda na interpretação dos espectros Raman.

À Vânia Bueno Silva, da Central Analítica (IQ-USP), por ser tão prestativa e realizar a análise elementar de carbono de forma tão rápida quando foi preciso.

Ao $\mathrm{CNPq}$, pela bolsa de Mestrado e apoio financeiro para que a realização deste trabalho fosse possível.

À Rede Nanobiomed-CAPES (Avanços, Benefícios e Riscos da Nanobiotecnologia Aplicada à Saúde) pelo auxílio financeiro.

À FAPESP pelo apoio financeiro indispensável à realização de trabalho de pesquisa desenvolvido pelo nosso grupo.

Ao Instituto de Química da Universidade de São Paulo pela disponibilidade das suas instalações para a realização deste trabalho.

A todos que contribuíram, de forma direta ou indireta, para a realização deste trabalho.

Muito Obrigada! 
De tudo, ficaram três coisas: a certeza de que ele estava sempre começando, a certeza de que era preciso continuar e a certeza de que seria interrompido antes de terminar. Fazer da interrupção um caminho novo. Fazer da queda um passo de dança, do medo uma escada, do sono uma ponte, da procura um encontro.

Fernando Sabino 


\section{RESUMO}

MANGONI, A. P. Materiais híbridos baseados em argilas catiônicas e espécies com potencial terapêutico. 2014. 164 f. Dissertação (Mestrado) - Programa de PósGraduação em Química - Instituto de Química, Universidade de São Paulo, São Paulo.

Os argilominerais são empregados na área farmacêutica e cosmética tanto como excipientes quanto ingredientes ativos. Esses compostos inorgânicos são inertes quimicamente, apresentam estruturas definidas e alta estabilidade térmica, o que contribui para o uso nessas áreas. Atualmente a indústria farmacêutica busca modificações no sistema de entrega de drogas (melhorias no tempo, local e taxa de liberação), objetivando um aumento na estabilidade das drogas e a prevenção e diminuição de efeitos colaterais. Nesse sentido, surge a necessidade de desenvolver novas formulações farmacêuticas, novos métodos de preparação e novos materiais. Considerando o fato dos argilominerais incorporarem espécies diversas entre suas lamelas, é interessante explorar a possibilidade de uso dessas matrizes inorgânicas como carregadores de espécies bioativas. O principal objetivo do presente trabalho foi preparar e caracterizar argilas de uso farmacêutico e/ou cosmético intercaladas com espécies que apresentam potencial terapêutico. Para tanto, usou-se duas argilas esmectitas naturais do tipo montmorilonita (Cloisita Sódica e Veegum HS) e uma esmectita sintética do tipo hectorita (Laponita RD). Os aminoácidos L-lisina, L-arginina e L-ornitina, e o dipeptídeo L-carnosina foram imobilizados em argilas catiônicas, por meio de reação de troca iônica. Na preparação dos materiais híbridos, alguns parâmetros experimentais foram avaliados: concentração hidrogeniônica $(\mathrm{pH})$ da suspensão de reação, proporção argila/aminoácido e tempo de reação. As argilas precursoras e os materiais híbridos obtidos foram caracterizados por difratometria de raios X, espectroscopia vibracional na região do infravermelho e Raman, análise termogravimétrica acoplada à espectrometria de massas e análise química de carbono. Os valores de distância inter-

lamelar $\left(d_{(001)}\right)$ dos materiais sugerem que a cadeia carbônica das espécies orgânicas se orienta paralelamente em relação às lamelas de baixa densidade de carga dos argilominerais. Nos espectros vibracionais na região do infravermelho há predominância das bandas características da estrutura inorgânica, mas as bandas entre 1800 e $1400 \mathrm{~cm}^{-1}$ relativas aos grupos funcionais do aminoácido permitem inferir sobre o seu grau de protonação no material híbrido. A acidez de Brönsted gerada pela polarização das moléculas de água 
associadas à argila foi observada para as montmorilonitas empregadas neste estudo. Amostras preparadas em suspensões nas quais o valor do $\mathrm{pH}$ era maior que o valor da primeira constante ácida $\left(p K_{a 1}\right)$ dos aminoácidos apresentam bandas atribuídas ao estiramento $\mathrm{C}=\mathrm{O}$ de grupo carboxilato protonado. Os espectros Raman foram obtidos apenas para a argila sintética, uma vez que as naturais apresentam luminescência. O espectro Raman da L-carnosina imobilizada em Laponita indica a presença preponderante da espécie zwitteriônica; o deslocamento das bandas atribuídas aos grupos amida e carboxílico do dipeptídeo para região de menor energia sugere a formação de ligações de hidrogênio com os grupos silanol da Laponita. Os resultados de análise termogravimétrica acoplada à espectrometria de massas dos materiais híbridos são distintos daqueles observados para os aminoácidos livres. A temperatura de início de decomposição das espécies orgânicas não é praticamente modificada após imobilização nas argilas, mas os processos térmicos se estendem até regiões de maior temperatura, evidenciando a influência da estrutura inorgânica sobre a decomposição térmica dos aminoácidos. Através dos dados de quantidade de carbono e de água nas amostras, calculou-se a concentração de aminoácidos nos materiais híbridos (massa de aminoácido / 100 gramas de material). As maiores concentrações de aminoácido (entre seis e oito por cento) foram observadas para as amostras de Cloisita e Veegum HS, isoladas em condições nas quais predomina a interação eletrostática entre as lamelas e os aminoácidos com carga positiva. Nas condições experimentais empregadas neste trabalho não foi observada a saturação das argilas com os aminoácidos, ou seja, as cargas das lamelas não foram totalmente neutralizadas pelos íons orgânicos.

Palavras-chave: montmorilonita, hectorita, aminoácidos, carnosina, lisina, materiais lamelares. 


\section{ABSTRACT}

\section{MANGONI, A. P. Hybrid materials based on cationic clays and species with}

therapeutic potential. 2014. 164 p. Masters Thesis - Graduate Program in Chemistry Instituto de Química, Universidade de São Paulo, São Paulo.

Clay minerals are used as excipients or active ingredients in the pharmaceutical and cosmetic fields. These inorganic compounds are chemically inert, have defined structures and high thermal stability, which make them useful for these areas. Currently the pharmaceutical industry seeks modifications in the drug delivery systems (improvements in the time, place and rate of release), aiming an increase in the stability of the drugs and also the prevention and reduction of side effects. In this way, it is a need to develop new pharmaceutical formulations, new preparation methods and new materials. Considering the fact that clay minerals incorporate various species between their layers, it is interesting to explore the possibility of using these inorganic matrices as carriers of bioactive species. The main aim of this work was to prepare and characterize clays of pharmaceutical and/or cosmetic usage intercalated with species of therapeutic potential. Two natural smectite clays of montmorillonite type (Sodium Cloisite and Veegum HS) and one synthetic smectite of hectorite type (Laponita RD) were employed. The amino acids L-lysine, L-arginine and L-ornithine, and the L-carnosine dipeptide were immobilized on cationic clays by ion exchange reaction. Some experimental parameters were evaluated in the preparation of hybrid materials: hydrogen ion concentration $(\mathrm{pH})$ of reaction suspension, clay/amino acid proportion and reaction time. Pristine clays and hybrid materials were characterized by X-ray diffraction, infrared and Raman vibrational spectroscopies, thermogravimetric analyses coupled to mass spectrometry and chemical analysis of carbon. The materials values of interlayer distance $\left(d_{(001)}\right)$ suggest that the carbon chain of the organic species is oriented parallel to the layers of clay minerals. The infrared vibrational spectra are dominated by the inorganic structure bands; however the bands between 1800 and $1400 \mathrm{~cm}^{-1}$ related to the functional groups of the amino acid allow to infer about the protonation degree in the hybrid material. The Brönsted acidity generated by the polarization of water molecules associated with the clay was observed for montmorillonite samples used in this study. Materials prepared in suspensions in which the $\mathrm{pH}$ value was greater than the value of the first acid constant $\left(p K_{a 1}\right)$ show bands assigned to the $\mathrm{C}=\mathrm{O}$ 
stretching of protonated carboxylate group. Raman spectra were obtained only for the synthetic clay, since the natural ones luminesce. Raman spectrum of L-carnosine immobilized on Laponita indicates the presence of mostly zwitterionic species; the displacement of bands assigned to amide and carboxylic groups of the dipeptide to the lower energy region suggests the formation of hydrogen bonds with the Laponita silanol groups. The results of thermogravimetric analyses coupled to mass spectrometry of hybrid materials are different from those observed for the free amino acids. The onset temperature of the organic species decomposition is practically unmodified after the immobilization on clays, but thermal processes are postponed up to higher temperature, revealing the inorganic structure influence on the amino acids thermal decomposition. Data on the carbon and water amounts in the samples were used to calculate the concentration of amino acids in the hybrid materials (mass of amino acid / 100 grams of material). The highest concentrations of amino acid (between six and eight percent) was observed for Cloisite and Veegum HS samples, isolated under conditions in which the electrostatic interaction between the layers and the positively charged amino acids are predominant. Under the experimental conditions employed in this study no saturation of clay with amino acids was observed, i.e. the layer charges were not completely neutralized by the organic ions.

Keywords: montmorillonite, hectorite, amino acid, carnosine, lysine, layered materials. 


\section{LISTA DE FIGURAS}

1.1 Azul Maia, material híbrido formado entre o pigmento orgânico índigo e a argila paligorsquita. (Adaptado de $[1,3,6]$ ). . . . . . . . . . . . . 28

1.2 Representação (a) de um tetraedro formando uma (b) folha tetraédrica e (c) de um octaedro formando uma (d) folha octaédrica. . . . . . . . . . . . 31

1.3 (A) Forma trioctaédrica e (B) Forma dioctaédrica. (Adaptado de [20]). . . 32

1.4 Filossilicatos com camadas do tipo $2: 1$ (folha tetraédrica + folha octaé-



1.5 Cargas deslocalizadas e localizadas na superfície de argilominerais. (Adaptada de [23]). . . . . . . . . . . . . . . . . . . . . . . . . . . . . . . . . . 34

1.6 a) Dimensões da lamela de Laponita e b) comparação do tamanho de uma lamela de Laponita com o de outras argilas. (Adaptado de [28]). . . . . . . 36

1.7 Esquema do processo de intercalação de moléculas orgânicas na região interlamelar das argilas. . . . . . . . . . . . . . . . . . . 37

1.8 Sítios ativos dos argilominerais 2:1: superfície de grupos siloxano. . . . . . 39

1.9 Sítios ativos dos argilominerais: cátions metálicos trocáveis e cátions estruturais expostos contendo esfera de coordenação insaturada. . . . . . . . . . 40

1.10 Sítios ativos dos argilominerais: moléculas de água polarizadas ao redor de cátions trocáveis e cátions nas arestas. . . . . . . . . . . . . . . . . . . 41

1.11 Sítios ativos dos argilominerais: sítios hidrofóbicos. . . . . . . . . . . . . 42

1.12 Sítios ativos dos argilominerais: sítios nas arestas ou bordas. . . . . . . . . 42

1.13 Acidez dos sítios das arestas ou bordas de esmectitas (三 representa a aresta do cristal). . . . . . . . . . . . . . . . . . . . . . . . 4 43

1.14 Esquema idealizado para a imobilização de drogas em argilas e os mecanismos de liberação de fármaco in vivo (argila com carga superficial (-); cations compensadores $\left(a^{+}\right)$; fármaco catiônico $\left(X^{+}\right)$; ânions associados ao fármaco (contra-íon) $\left(Y^{-}\right)$; contra-íons in vivo $\left(A^{+}\right)$e ânions associados aos contra-íons $\left.\left(B^{-}\right)\right)$. (Adaptado de [42]). . . . . . . . . . . . . . 48

1.15 Estrutura geral dos aminoácidos. . . . . . . . . . . . . . . . 50

1.16 Estrutura do dipeptídeo L-Carnosina: a) Representação em forma de bastão e b) Representação tridimensional. . . . . . . . . . . . . . . . . . . . 51 
1.17 Equações químicas referentes à desprotonação da L-Carnosina. . . . . . . . . 52

1.18 Estrutura do aminoácido L-Ornitina: a) Representação em forma de bastão e b) Representação tridimensional. . . . . . . . . . . . . . . . . . . . . . . 53

1.19 Equações químicas referentes à desprotonação da L-Ornitina. . . . . . . . . . 53

1.20 Ciclo da ureia. . . . . . . . . . . . . . . . . . . . . . 54

1.21 Estrutura do aminoácido L-Arginina: a) Representação em forma de bastão e b) Representação tridimensional. . . . . . . . . . . . . . . . . . . . . . 54

1.22 Equações químicas referentes à desprotonação da L-Arginina. . . . . . . . . . 55

1.23 Estrutura do aminoácido L-Lisina: a) Representação em forma de bastão e b) Representação tridimensional. . . . . . . . . . . . . . . . . . . . . 55

1.24 Equações químicas referentes à desprotonação da L-Lisina. . . . . . . . . . . 56

4.1 Difratogramas de raios X da Cloisita $\mathrm{Na}^{+}$e dos produtos das reações da Cloisita $\mathrm{Na}^{+}$com o Cloridrato de L-Lisina. (Código: Identidade da amostra; pH final de reação; proporção molar de argila:aminoácido; tempo de reação). . . . . . . . . . . . . . . . . . . . 70

4.2 Possibilidades dos arranjos da L-Lisina entre as lamelas da Cloisita. . . . . 72

4.3 Espectros vibracionais na região do Infravermelho do Cloridrato de L-Lisina (preto), Cloisita $\mathrm{Na}^{+}$(vermelho) em suas formas originais e dos produtos de reação. (Código: Identidade da amostra; pH final de reação; proporção molar de argila:aminoácido; tempo de reação)

4.4 Espectros vibracionais entre 1900 e $1300 \mathrm{~cm}^{-1}$ do Cloridrato de L-Lisina (preto), Cloisita $\mathrm{Na}^{+}$(vermelho) em suas formas originais e dos produtos de reação. (Código: Identidade da amostra; pH final de reação; proporção molar de argila:aminoácido; tempo de reação)

4.5 Curvas TGA (preto), DTG (verde oliva) e MS (fragmentos $m / z=18$ (preto) e $m / z=44$ (vermelho)) da Cloisita $N a^{+}$. . . . . . . . . . . . 77

4.6 Curvas TGA (preto), DTG (verde oliva) e MS (fragmentos $m / z=18$ (preto) e $m / z=44$ (vermelho)) do Cloridrato de L-Lisina. . . . . . . . . . 78

4.7 Curvas TGA (preto), DTG (verde oliva) e MS (fragmentos $\mathrm{m} / \mathrm{z}=18$ (preto) e $m / z=44$ (vermelho)) da amostra CloLys1. . . . . . . . . . . .

4.8 Curvas TGA (preto), DTG (verde oliva) e MS (fragmentos $m / z=18$ (preto) e $m / z=44$ (vermelho)) da amostra CloLysp6.

4.9 Difratogramas de raios $\mathrm{X}$ da Cloisita $\mathrm{Na}^{+}$e dos produtos das reações da Cloisita $\mathrm{Na}^{+}$com L-Arginina. (Código: Identidade da amostra; $\mathrm{pH}$ final de reação; proporção molar de argila:aminoácido; tempo de reação). . . . . . . . . 
4.10 Espectros vibracionais na região do Infravermelho da L-Arginina (preto), Cloisita $\mathrm{Na}^{+}$(vermelho) em suas formas originais e dos produtos de reação. (Código: Identidade da amostra; pH final de reação; proporção molar de argila:aminoácido; tempo de reação) . . . . . . . . . . . . . . . . . . . 83

4.11 Espectros vibracionais na região do Infravermelho da L-Arginina (preto), Cloisita $\mathrm{Na}^{+}$(vermelho) em suas formas originais e dos produtos de reação. (Código: Identidade da amostra; pH final de reação; proporção molar de argila:aminoácido; tempo de reação). . . . . . . . . . . . . . . . . . 84

4.12 Curvas TGA (preto), DTG (verde oliva) e MS (fragmentos $m / z=18, m / z$ $=30, m / z=46$ e $m / z=44)$ da L-Arginina. . . . . . . . . . . 86

4.13 Curvas TGA (preto), DTG (verde oliva) e MS (fragmentos $m / z=18$ (preto) e $m / z=44$ (vermelho)) da amostra CloArg2 . . . . . . . . . 87

4.14 Curvas TGA (preto), DTG (verde oliva) e MS (fragmentos $m / z=18$ (preto) e $m / z=44$ (vermelho)) da amostra CloArgp4. . . . . . . . . . 88

4.15 Difratogramas de raios $\mathrm{X}$ da Cloisita $\mathrm{Na}^{+}$e dos produtos das reações da Cloisita $\mathrm{Na}^{+}$com L-Carnosina. (Código: Identidade da amostra; pH final de reação; proporção molar de argila: aminoácidos; tempo de reação). . . . 89

4.16 Espectros vibracionais na região do Infravermelho da L-Carnosina (preto) e da Cloisita $\mathrm{Na}^{+}$(vermelho) em suas formas originais e dos produtos de reação. (Código: Identidade da amostra; pH final de reação; proporção molar de argila:aminoácido; tempo de reação) . . . . . . . . . . . . . . . . . 90

4.17 Espectros vibracionais na região do Infravermelho da L-Carnosina (preto), Cloisita $\mathrm{Na}^{+}$(vermelho) em suas formas originais e dos produtos de reação. (Código: Identidade da amostra; pH final de reação; proporção molar de argila:aminoácido; tempo de reação) . . . . . . . . . . . . . . . . 91

4.18 Espectros vibracionais na região do Infravermelho calculados da L-Carnosina em diferentes graus de protonação. . . . . . . . . . . . . . . . 92

4.19 Curvas TGA (preto), DTG (verde oliva) e MS (fragmentos $m / z=18$ (preto) e $m / z=44$ (vermelho)) da L-Carnosina. . . . . . . . . . . . . . 94

4.20 Curvas TGA (preto), DTG (verde oliva) e MS (fragmentos $\mathrm{m} / \mathrm{z}=18$ (preto) e $m / z=44$ (vermelho)) da amostra CloCar1. . . . . . . . . . 95

4.21 Difratogramas de raios X da Cloisita $\mathrm{Na}^{+}$e dos produtos das reações da Cloisita $\mathrm{Na}^{+}$com L-Ornitina. (Código: Identidade da amostra; pH final de reação; proporção molar de argila:aminoácido; tempo de reação) . . . . . . . 97

4.22 Espectros vibracionais na região do Infravermelho do Cloridrato de LOrnitina (preto), Cloisita $\mathrm{Na}^{+}$(vermelho) em suas formas originais e dos produtos de reação. (Código: Identidade da amostra; pH final de reação; proporção molar de argila:aminoácido; tempo de reação) . . . . . . . . . . 98 
4.23 Espectros vibracionais na região do Infravermelho do Cloridrato de LOrnitina (preto) e da Cloisita $\mathrm{Na}^{+}$(vermelho) em suas formas originais e dos produtos de reação. (Código: Identidade da amostra; pH final de reação; proporção molar de argila:aminoácido; tempo de reação). . . . . . . 99

4.24 Curvas TGA (preto), DTG (verde oliva) e MS (fragmentos $m / z=18$ (preto) e $m / z=44$ (vermelho)) do Cloridrato de L-Ornitina. . . . . . . . . 100

4.25 Curvas TGA (preto), DTG (verde oliva) e MS (fragmentos $m / z=18$ (preto) e $m / z=44$ (vermelho)) da amostra CloOrt1. . . . . . . . . . . . . 101

4.26 Difratogramas de raios X da Veegum HS e dos produtos das reações da Veegum HS com L-Lisina. (Código: Identidade da amostra; pH final de reação; proporção molar de argila:aminoácido; tempo de reação). . . . . . . . 102

4.27 Espectros vibracionais na região do Infravermelho do Cloridrato de L-Lisina (preto), Veegum HS (vermelho) em suas formas originais e dos produtos de reação. (Código: Identidade da amostra; pH final de reação; proporção molar de argila:aminoácido; tempo de reação) . . . . . . . . . . . . . . . . . 103

4.28 Espectros vibracionais na região do Infravermelho do Cloridrato de L-Lisina (preto), Veegum HS (vermelho) em suas formas originais e dos produtos de reação. (Código: Identidade da amostra; pH final de reação; proporção molar de argila:aminoácido; tempo de reação). . . . . . . . . . . . . . . . . 104

4.29 Curvas TGA (preto), DTG (verde oliva) e MS (fragmentos $m / z=18$ (preto) e $m / z=44$ (vermelho)) da Veegum HS. . . . . . . . . . . . . . . 105

4.30 Curvas TGA (preto), DTG (verde oliva) e MS (fragmentos $m / z=18$ (preto) e $m / z=44$ (vermelho)) da amostra VegLysS. . . . . . . . . . . . 106

4.31 Difratogramas de raios X da Veegum HS e dos produtos das reações da Veegum HS com L-Arginina. (Código: Identidade da amostra; pH final de reação; proporção molar de argila:aminoácido; tempo de reação). . . . . . . . 107

4.32 Espectros vibracionais na região do Infravermelho da L-Arginina (preto), Veegum HS (vermelho) em suas formas originais e dos produtos de reação. (Código: Identidade da amostra; pH final de reação; proporção molar de argila:aminoácido; tempo de reação) . . . . . . . . . . . . . . . . . . . 108

4.33 Espectros vibracionais na região do Infravermelho da L-Arginina (preto), Veegum HS (vermelho) em suas formas originais e dos produtos de reação. (Código: Identidade da amostra; pH final de reação; proporção molar de argila:aminoácido; tempo de reação) . . . . . . . . . . . . . . . . . . . . 109

4.34 Curvas TGA (preto), DTG (verde oliva) e MS (fragmentos $m / z=18$ (preto) e $m / z=44$ (vermelho)) da amostra VegArgS. . . . . . . . . . . . . 110

4.35 Difratogramas de raios $\mathrm{X}$ da Veegum HS e dos produtos das reações da Veegum HS com L-Carnosina. (Código: Identidade da amostra; pH final de reação; proporção molar de argila:aminoácido; tempo de reação). . . . . . . . 111 
4.36 Espectros vibracionais na região do Infravermelho da L-Carnosina (preto), Veegum HS (vermelho) em suas formas originais e dos produtos de reação. (Código: Identidade da amostra; pH final de reação; proporção molar de argila:aminoácido; tempo de reação). . . . . . . . . . . . . . . . . . . . . 112

4.37 Espectros vibracionais na região do Infravermelho da L-Carnosina (preto), Veegum HS (vermelho) em suas formas originais e dos produtos de reação. (Código: Identidade da amostra; pH final de reação; proporção molar de argila:aminoácido; tempo de reação) . . . . . . . . . . . . . . . . 113

4.38 Curvas TGA (preto), DTG (verde oliva) e MS (fragmentos $m / z=18$ (preto) e $m / z=44$ (vermelho)) da amostra VegCar6. . . . . . . . . . . 114

4.39 Difratogramas de raios $\mathrm{X}$ da Veegum HS e dos produtos das reações da Veegum HS com L-Ornitina. (Código: Identidade da amostra; pH final de reação; proporção molar de argila:aminoácido; tempo de reação) . . . . . . . . 115

4.40 Espectros vibracionais na região do Infravermelho do Cloridrato de Lornitina (preto), Veegum HS (vermelho) em suas formas originais e dos produtos de reação. (Código: Identidade da amostra; pH final de reação; proporção molar de argila:aminoácido; tempo de reação). . . . . . . . . . . 116

4.41 Espectros vibracionais na região do Infravermelho do Cloridrato de Lornitina (preto), Veegum HS (vermelho) em suas formas originais e dos produtos de reação. (Código: Identidade da amostra; pH final de reação; proporção molar de argila:aminoácido; tempo de reação). . . . . . . . . . . 117

4.42 Curvas TGA (preto), DTG (verde oliva) e MS (fragmentos $m / z=18$ (preto) e $m / z=44$ (vermelho)) da amostra VegOrtp4. . . . . . . . . . 118

4.43 Difratogramas de raios X da Laponita $\mathrm{RD}$ e dos produtos das reações da Laponita RD com L-Lisina. (Código: Identidade da amostra; pH final de reação; proporção molar de argila:aminoácido; tempo de reação) . . . . . . . . 121

4.44 Espectros vibracionais na região do infravermelho do Cloridrato de L-Lisina (preto), Laponita RD (vermelho) em suas formas originais e dos produtos de reação. (Código: Identidade da amostra; pH final de reação; proporção molar de argila:aminoácido; tempo de reação). . . . . . . . . . . . . . . . . 122

4.45 Curvas TGA (preto), DTG (verde oliva) e MS (fragmentos $m / z=18$ (preto) e $m / z=44$ (vermelho)) da Laponita RD. . . . . . . . . . . . . 123

4.46 Curvas TGA (preto), DTG (verde oliva) e MS (fragmentos $m / z=18$ (preto) e $m / z=44$ (vermelho)) da amostra LapLysS. . . . . . . . . . . . . 124

4.47 Difratogramas de raios $\mathrm{X}$ da Laponita $\mathrm{RD}$ e dos produtos das reações da Laponita RD com L-Arginina. (Código: Identidade da amostra; pH final de reação; proporção molar de argila:aminoácido; tempo de reação). . . . . 126 
4.48 Espectros vibracionais na região do Infravermelho da L-Arginina (preto), Laponita RD (vermelho) em suas formas originais e dos produtos de reação. (Código: Identidade da amostra; pH final de reação; proporção molar de argila:aminoácido; tempo de reação).

4.49 Curvas TGA (preto), DTG (verde oliva) e MS (fragmentos $m / z=18$ (preto) e $m / z=44$ (vermelho)) da amostra LapArgS. . . . . . . . . . . . . 128

4.50 Difratogramas de raios $\mathrm{X}$ da Laponita $\mathrm{RD}$ e dos produtos das reações da Laponita RD com L-Carnosina. (Código: Identidade da amostra; pH final de reação; proporção molar de argila:aminoácido; tempo de reação)

4.51 Espectros vibracionais na região do Infravermelho da L-Carnosina (preto), Laponita RD (vermelho) em suas formas originais e dos produtos de reação. (Código: Identidade da amostra; pH final de reação; proporção molar de argila:aminoácido; tempo de reação).

4.52 Espectros Raman do dipeptídeo L-Carnosina, da Laponita RD e da amostra LapCar2. .

4.53 Espectros Raman calculados do dipeptídeo L-Carnosina em diferentes graus de protonação e espectro experimental da L-Carnosina sólida (forma zwiteriônica).

4.54 Espectros Raman do dipeptídeo L-Carnosina e da amostra LapCar2. . . . . 133

4.55 Curvas TGA (preto), DTG (verde oliva) e MS (fragmentos $m / z=18$ (preto) e $m / z=44$ (vermelho)) da amostra LapCar2. . . . . . . . . . . . . 134

4.56 Difratogramas de raios X da Laponita $\mathrm{RD}$ e dos produtos das reações da Laponita RD com Cloridrato de L-Ornitina. (Código: Identidade da amostra; pH final de reação; proporção molar de argila:aminoácido; tempo de reação)

4.57 Espectros vibracionais na região do Infravermelho do Cloridrato de LOrnitina (preto), Laponita RD (vermelho) em suas formas originais e dos produtos de reação. (Código: Identidade da amostra; pH final de reação; proporção molar de argila:aminoácido; tempo de reação) . . . . . . . . . . . 136

4.58 Curvas TGA (preto), DTG (verde) e MS (fragmentos $m / z=18$ (preto) e $m / z=44$ (vermelho)) da amostra LapOrt2. . . . . . . . . . . . . 137

B.1 Curvas TGA (preto), DTG (verde oliva) e MS (fragmentos $m / z=18$ (preto) e $m / z=44$ (vermelho)) das amostras: A) CloLys2; B) CloLysS; C) CloLysp4; D) CloLysp5. . . . . . . . . . . . . . . . . . . . 152

B.2 Curvas TGA (preto), DTG (verde oliva) e MS (fragmentos $m / z=18$ (preto) e $m / z=44$ (vermelho)) das amostras: A) CloArg1; B) CloArgS; C) CloArgp5; D) CloArgp6. 
B.3 Curvas TGA (preto), DTG (verde oliva) e MS (fragmentos $m / z=18$ (preto) e $m / z=44$ (vermelho)) das amostras: A) CloCarp4; B) CloCarp5; C) CloCarp6. . . . . . . . . . . . . . . . . . . . . . . . 154

B.4 Curvas TGA (preto), DTG (verde oliva) e MS (fragmentos $m / z=18$ (preto) e $m / z=44$ (vermelho)) das amostras: A) CloOrtp4; B) CloOrtp5; C) CloOrtp6. . . . . . . . . . . . . . . . . . . . . . . . 155

B.5 Curvas TGA (preto), DTG (verde oliva) e MS (fragmentos $m / z=18$ (preto) e $m / z=44$ (vermelho)) das amostras: A) VegLysp4; B) VegLysp5; C) VegLysp6. . . . . . . . . . . . . . . . . . . . . . . . 156

B.6 Curvas TGA (preto), DTG (verde oliva) e MS (fragmentos $m / z=18$ (preto) e $m / z=44$ (vermelho)) das amostras: A) VegArgp4; B) VegArgp5; C) VegArgp6. . . . . . . . . . . . . . . . . . . . . . . . 157

B.7 Curvas TGA (preto), DTG (verde oliva) e MS (fragmentos $m / z=18$ (preto) e $m / z=44$ (vermelho)) das amostras: A) VegCar4; B) VegCar5; C) VegCar7; D) VegCar8. . . . . . . . . . . . . . . . . . . . . . . 158

B.8 Curvas TGA (preto), DTG (verde oliva) e MS (fragmentos $\mathrm{m} / \mathrm{z}=18$ (preto) e $m / z=44$ (vermelho)) das amostras: A) VegCarp4; B) VegCarp5; C) VegCarp6. . . . . . . . . . . . . . . . . . . . . . . . 159

B.9 Curvas TGA (preto), DTG (verde oliva) e MS (fragmentos $m / z=18$ (preto) e $m / z=44$ (vermelho)) das amostras: A) VegOrtp5; B) VegOrtp6; C) VegOrt1. . . . . . . . . . . . . . . . . . . . . . . . . 160

B.10 Curvas TGA (preto), DTG (verde oliva) e MS (fragmentos $m / z=18$ (preto) e $m / z=44$ (vermelho)) das amostras: A) LapLysp2; B) LapLysp7. 160

B.11 Curvas TGA (preto), DTG (verde oliva) e MS (fragmentos $m / z=18$ (preto) e $m / z=44$ (vermelho)) das amostras: A) LapArgp2; B) LapArgp9. 161

B.12 Curvas TGA (preto), DTG (verde oliva) e MS (fragmentos $m / z=18$ (preto) e $m / z=44$ (vermelho)) das amostras: A) LapCar1; B) LapCar3; C) LapCar4. . . . . . . . . . . . . . . . . . . . . . . . . . . 161

B.13 Curvas TGA (preto), DTG (verde oliva) e MS (fragmentos $m / z=18$ (preto) e $m / z=44$ (vermelho)) das amostras: A) LapOrtp2; B) LapOrtp7. 162

A.1 Mapa de potencial eletrostático para as possíveis formas protonadas do dipeptídeo L-Carnosina. . . . . . . . . . . . . . . . . . 166

A.2 Dimensões calculadas do dipeptídeo: A) L-Carnosina; e dos aminoácidos: B) L-Ornitina; C) L-Arginina; D) L-Lisina. . . . . . . . . . . . . . . . . . . 167

B.1 Mecanismo do teste da ninidrina. . . . . . . . . . . . . . . . 169

B.2 Teste da ninidrina. . . . . . . . . . . . . . . . . . . . . . . . . . . . 169 


\section{LISTA DE TABELAS}

1.1 Fórmulas estruturais ideais dos argilominerais do grupo das esmectitas. . . 35

1.2 Valores de constante de equilíbrio ácido $\left(p K_{a}\right)$ e do ponto isoelétrico (pI) do dipeptídeo L-Carnosina e dos aminoácidos L-Ornitina, L-Arginina e L-Lisina. 57

3.1 Argilas utilizadas nos experimentos de imobilização do dipeptídeo e dos aminoácidos. . . . . . . . . . . . . . . . . . . . . . . . 59

3.2 Reagentes utilizados nos experimentos de imobilização do dipeptídeo e dos aminoácidos com argilas. . . . . . . . . . . . . . . . . . . 60

3.3 Resumo das condições experimentais empregadas para os sistemas com a Cloisita $\mathrm{Na}^{+*}$. . . . . . . . . . . . . . . . . . . . . . . . . 61

3.4 Resumo das condições experimentais empregadas para os sistemas com a Veegum HS* . . . . . . . . . . . . . . . . . . . . . 63

3.5 Resumo das condições experimentais empregadas para os sistemas com a Laponita RD . . . . . . . . . . . . . . . . . . . . . . . . . 65

4.1 Distância interplanar $d_{(h k l)}$ e valores de $2 \theta$ da argila Cloisita Sódica, obtidos dos dados de difratometria de raios X. . . . . . . . . . . . . . . . . . . 71

4.2 Distância interplanar $d_{(001)}$ dos materiais obtidos pela reação de imobilização do Cloridrato de L-Lisina em Cloisita. . . . . . . . . . . . . . . . . . . 72

4.3 Bandas de absorção e atribuições de alguns modos vibracionais dos grupos funcionais do Cloridrato de L-Lisina [74] . . . . . . . . . . . . . . . . . 74

4.4 Regiões de modificações e atribuições dos possíveis modos vibracionais de alguns grupos orgânicos nos produtos da imobilização do Cloridrato de L-Lisina em Cloisita. . . . . . . . . . . . . . . . . . . . 76

4.5 Distância interplanar $d_{(001)}$ dos materiais obtidos pela reação de imobilização de L-Arginina em Cloisita. . . . . . . . . . . . . . . . . . . . . . . . . 83

4.6 Distância interplanar $d_{(001)}$ dos materiais obtidos pela reação de imobilização de L-Carnosina em Cloisita. . . . . . . . . . . . . . . . . . . . . . . . . 88

4.7 Bandas de absorção e atribuições de alguns modos vibracionais calculados para a L-Carnosina em diferentes graus de protonação. 
4.8 Distância interplanar $d_{(001)}$ dos materiais obtidos pela reação de imobilização de L-Ornitina em Cloisita. . . . . . . . . . . . . . . . . . . . . . . 96

4.9 Distância interplanar $d_{(001)}$ dos materiais obtidos pela reação de imobilização de L-Lisina em Veegum HS. . . . . . . . . . . . . . . . . . . . . . . . . 102

4.10 Distância interplanar $d_{(001)}$ dos materiais obtidos pela reação de imobilização de L-Arginina em Veegum HS. . . . . . . . . . . . . . . . . . . . 106

4.11 Distância interplanar $d_{(001)}$ dos materiais obtidos pela reação de imobilização de L-Carnosina em Veegum HS. . . . . . . . . . . . . . . . . . . . . . . 112

4.12 Distância interplanar $d_{(001)}$ dos materiais obtidos pela reação de imobilização de L-Ornitina em Veegum HS. . . . . . . . . . . . . . . . . . . . . . . . 115

4.13 Distância interplanar $d_{(001)}$ dos materiais obtidos pela reação de imobilização de L-Lisina em Laponita RD. . . . . . . . . . . . . . . . . . . . . . . . 121

A.1 Resumo das condições experimentais para a preparação de amostras com a argila Cloisita $\mathrm{Na}^{+*}$. . . . . . . . . . . . . . . . . . . . . . . . . . . . . . 149

A.2 Resumo das condições experimentais para a preparação de amostras com a argila Veegum HS* . . . . . . . . . . . . . . . . . . . . . . 150

A.3 Resumo das condições experimentais para a preparação de amostras com a argila Laponita RD. . . . . . . . . . . . . . . . . . . . . . . 150

C.1 Dados de análise elementar dos materiais híbridos argila/L-Lisina. . . . . . 163

C.2 Dados de análise elementar dos materiais híbridos argila/L-Arginina. . . . 163

C.3 Dados de análise elementar dos materiais híbridos argila/L-Carnosina. . . . 164

C.4 Dados de análise elementar dos materiais híbridos argila/L-Ornitina. . . . 164 


\section{LISTA DE ABREVIATURAS}

CTC Capacidade de troca catiônica.

DRX Difratometria de raios X.

DTG Curva referente à primeira derivada da curva TGA.

FTIR Espectroscopia vibracional no infravermelho com transformada de Fourier.

MS Espectrometria de Massas.

PDI Índice de Polidispersibilidade.

TGA Análise termogravimétrica.

TOT Folha Tetraédrica + Folha Octaédrica + Folha Tetraédrica. 


\section{SUMÁRIO}

LISTA DE FIGURAS

LISTA DE TABELAS $\quad 22$

1 INTRODUÇÃO $\quad 27$

1.1 Materiais híbridos inorgânico-orgânicos . . . . . . . . . . . . . . . 27

1.2 Argilas e Argilominerais . . . . . . . . . . . . . . . . . . . 30

1.3 Sítios ativos predominantes nos argilominerais . . . . . . . . . . 38

1.3.1 Superfície neutra de siloxano . . . . . . . . . . . . . . . 38

1.3.2 Sítios de substituição isomórfica . . . . . . . . . . . . . . 39

1.3.3 Cátions metálicos trocáveis e cátions estruturais . . . . . . . . . . . 40

1.3.4 Moléculas de água ao redor do cátion trocável . . . . . . . . . . . . 40

1.3.5 Sítios hidrofóbicos . . . . . . . . . . . . . . . . 41

1.3.6 Sítios nas bordas ou arestas das lamelas com exposição dos grupos silanol e aluminol . . . . . . . . . . . . . . . . . . . 42

1.4 Aplicações de argilas nas áreas farmacêutica e médica . . . . . . . . . . . . 44

1.5 Estudos de sistemas argila/aminoácidos . . . . . . . . . . . . . . 49

1.6 Aminoácidos . . . . . . . . . . . . . . . . . . . . . . 50

1.6.1 L-Carnosina . . . . . . . . . . . . . . . . . . . 51

1.6.2 L-Ornitina . . . . . . . . . . . . . . . . . . . . 52

1.6 .3 L-Arginina . . . . . . . . . . . . . . . . 54

1.6.4 L-Lisina . . . . . . . . . . . . . . . . . 55

2 OBJETIVOS $\quad 58$

3 MATERIAIS E MÉTODOS $\quad 59$

3.1 Materiais e Reagentes . . . . . . . . . . . . . . . . . . . . . . . . 59

3.2 Intercalação de aminoácidos em Cloisita Sódica . . . . . . . . . . . . . . . 60

3.3 Intercalação de aminoácidos em Veegum HS . . . . . . . . . . . . . . . . . 62

3.4 Intercalação de aminoácidos em Laponita RD . . . . . . . . . . . . . . . . 63

3.5 Técnicas de caracterização . . . . . . . . . . . . . . . . 65

3.5.1 Difratometria de raios X . . . . . . . . . . . 65 
3.5.2 Espectroscopia Vibracional no Infravermelho . . . . . . . . . . . . 66

3.5.3 Espectroscopia Raman . . . . . . . . . . . . . . . . . . . . 66

3.5.4 Análise Térmica acoplada à Espectrometria de Massas . . . . . . . 66

3.5.5 Análise Elementar . . . . . . . . . . . . . . . . . . . 67

3.5.6 Medidas de Potencial Zeta e tamanho de partículas . . . . . . . . . 67

3.5.7 Outros Equipamentos . . . . . . . . . . . . . . . . 67

4 RESULTADOS E DisCUSSÃO

4.1 Imobilização de aminoácidos em Cloisita Sódica . . . . . . . . . . . . . . . 69

4.1.1 L-Lisina em Cloisita Sódica . . . . . . . . . . . . . . . . . . 70

4.1 .2 L-Arginina em Cloisita Sódica . . . . . . . . . . . . . . . . . . 82

4.1.3 L-Carnosina em Cloisita Sódica . . . . . . . . . . . . . . . . . . 88

4.1.4 L-Ornitina em Cloisita Sódica . . . . . . . . . . . . . . . . . . . 96

4.2 Imobilização de aminoácidos em Veegum HS . . . . . . . . . . . . . . . . . 101

4.2 .1 L-Lisina em Veegum HS . . . . . . . . . . . . . . . . . . . . . . 101

4.2 .2 L-Arginina em Veegum HS . . . . . . . . . . . . . . . . . . 106

4.2 .3 L-Carnosina em Veegum HS . . . . . . . . . . . . . . . . . . . . . . 111

4.2.4 L-Ornitina em Veegum HS . . . . . . . . . . . . . . . . . . 115

4.3 Imobilização de aminoácidos em Laponita RD . . . . . . . . . . . . . . . . 119

4.3 .1 L-Lisina em Laponita RD . . . . . . . . . . . . . . . . . . . . 120

4.3.2 L-Argina em Laponita RD . . . . . . . . . . . . . . . . . . . . 125

4.3 .3 L-Carnosina em Laponita RD . . . . . . . . . . . . . . . . . . . 128

4.3.4 L-Ornitina em Laponita RD . . . . . . . . . . . . . . . . . . . . . 135

5 CONCLUSÕES $\quad 138$

6 PERSPECTIVAS FUTURAS 141

7 REFERÊNCIAS BIBLIOGRÁFICAS 142

Apêndice A Condições experimentais empregadas nos testes de imobilização de aminoácidos em argila

Apêndice B Dados de Análise Térmica acoplados a Espectrometria de Massas

Apêndice C Dados de análise elementar dos materiais híbridos argila/aminoácido

Anexo A Métodos Computacionais 



\section{Capítulo 1}

\section{INTRODUÇÃO}

\subsection{Materiais híbridos inorgânico-orgânicos}

Materiais híbridos são constituídos por moléculas orgânicas ou redes (como os polímeros orgânicos) intimamente misturados (em nível molecular) com componentes inorgânicos (óxidos de metais, entre outros) [1]. O termo "materiais híbridos O-I" foi evocado por volta dos anos 1990. Essa década foi muito produtiva para essa nova área da ciência e desde então foram criados muitos eventos científicos para discuti-la [1].

Os materiais inorgânico-orgânicos possuem propriedades mecânicas, ópticas e térmicas diferentes das dos materiais que os originaram e apresentam uma diversidade de novas aplicações em várias áreas, como por exemplo, nas áreas automobilística e odontológica, entre outras [2]. Dessa forma o estudo das propriedades, aplicações e métodos de síntese de novos materiais híbridos, principalmente através de rotas "limpas" e sustentáveis, é um campo promissor e em constante desenvolvimento. Essa classe de novos materiais merece especial atenção e está cada vez mais difundida. Materiais híbridos também ocorrem na natureza, como por exemplo, conchas de moluscos (constituídas de proteínas e carbonato de cálcio), ossos (constituídos de colágeno e de hidroxiapatita) e dentes (constituídos de fibras de colágeno e hidroxiapatita) [1].

Muitas substâncias podem ser combinadas na formação de materiais híbridos. Na classe dos compostos orgânicos podemos citar os polímeros e os corantes orgânicos, e na dos inorgânicos, as argilas, os óxidos metálicos, os carbonatos, os fosfatos etc. [1]. O interesse 
em utilizar materiais naturais para formar os materiais híbridos de interesse comercial é devido à sua durabilidade, suas propriedades mecânicas, densidade, permeabilidade, cor, hidrofobia, entre outras propriedades $[1,2]$.

Os materiais híbridos contendo argilas como o componente inorgânico são utilizados pela humanidade há muito tempo e por isso presume-se que elas eram um dos constituintes dos primeiros materiais híbridos. Os precursores das cerâmicas chinesas são um exemplo clássico desses materiais, nos quais a urina (que contém ureia, composto orgânico) era misturada à argila (composto inorgânico) formando um material híbrido que quando calcinado gerava uma cerâmica com características especiais. Pode-se citar também, o pigmento azul Maia (Figura $1.1[3,4,5]$ ), utilizado pela civilização pré-colombiana, obtido quando o corante natural azul índigo (orgânico) era misturado à argila do tipo paligorsquita (inorgânica) e submetido posteriormente ao aquecimento [1, 3, 6].

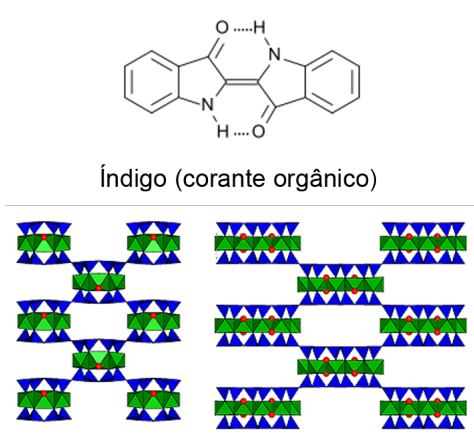

Paligorsquita (composto inorgânico)

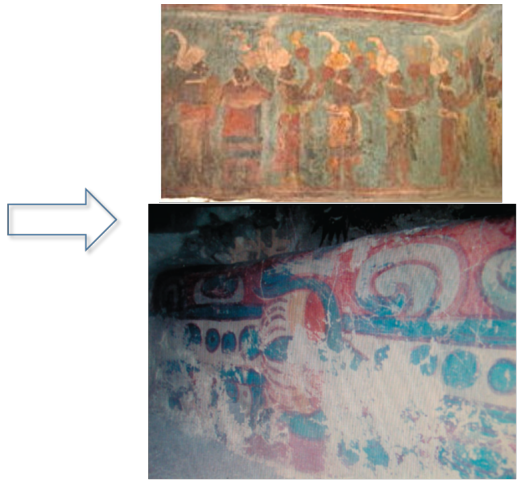

Afrescos Maias (azul Maia, material híbrido)

Figura 1.1: Azul Maia, material híbrido formado entre o pigmento orgânico indigo e a argila paligorsquita. (Adaptado de [1, 3, 6]).

O pigmento azul Maia é um material híbrido que merece destaque, uma vez que forma uma paleta de cores que vai desde o azul turquesa até o azul esverdeado, com uma elevada estabilidade frente a ataques ácidos, básicos e de reagentes orgânicos [3]. Esse pigmento já era utilizado pelos povos da mesoamérica há pelo menos 8 séculos. O corante índigo é extraído da Indigofera suffruticosa e forma um material nanoestruturado com a argila paligorsquita que é um filossilicato fibroso.

Se por um lado tanto a natureza como os povos antigos já produziam esses materiais, a indústria só começou a desenvolver materiais híbridos mais tarde, na década de 1940 
[1], principalmente com a mistura de polímeros orgânicos em matrizes inorgânicas. Como exemplos desses materiais podemos citar as tintas, papéis, agentes de acoplamento (silanos, silicones) etc. Foi nessa década também que Gieseking e Hendricks [6] relataram pela primeira vez a substituição dos cátions trocáveis das argilas pertencentes à família das esmectitas por cátions orgânicos através de reações de troca iônica. Esse grupo de materiais são chamados geralmente de "argilas organofílicas".

As argilas organofílicas se dispersam em líquidos orgânicos formando géis tixotrópi$\cos ^{1}$ e, por isso, são importantes na fabricação de lubrificantes [6]. Elas também podem ser usadas como agentes espessantes para tintas, pois apresentam compatibilidade com meios orgânicos pouco polares. Há a aplicação tradicional das argilas organofílicas como cargas ou enchimentos para diversos polímeros (como as tintas, a borracha, os plásticos, as graxas industriais, o polipropileno - o produto formados é usado no interior e exterior de veículos)[8]. As argilas, principalmente bentonitas organofílicas, também são usadas como adsorventes seletivos para poluentes.

A família das argilas esmectitas estão sendo estudadas para a aplicação em diversas áreas, como a ambiental e a biomédica. Esses materiais apresentam estrutura cristalina organizada, morfologia e composição química que lhes conferem características únicas como as de elevada área superficial, capacidade de troca iônica, estabilidade térmica, mecânica e química, além da versatilidade nos mecanismos de reações com diferentes moléculas orgânicas [6].

Devido à versatilidade desses materiais híbridos, com as argilas como parte inorgânica, do baixo custo da matéria-prima e de sua longa utilização pela humanidade, há diversas aplicações ambientais para esses materiais, como por exemplo: para o tratamento de água (remoção de poluentes), na formulação e como carregadores de pesticidas (para reduzir ou evitar a lixiviação e decomposição do pesticida), como revestimento de solos, para a elaboração de sensores, entre outras [6].

Há uma nova geração de materiais híbridos, os biomaterirais que podem ser nanoestruturados e chamados de bionanocompósitos [9]. Esses materiais são nanocompósitos

\footnotetext{
${ }^{1}$ Tixotropia: propriedade de alguns fluidos em modificar sua viscosidade em função do tempo e pressão aplicada [7].
} 
formados entre um biopolímero (polímero que ocorre naturalmente) e uma matriz inorgânica, que possui pelo menos uma dimensão na escala nanométrica [9].

Os bionanocompósitos podem ser biocompatíveis e biodegradáveis [2, 9], podendo desta forma reduzir a quantidade de resíduos e a poluição ambiental e favorecer o desenvolvimento sustentável, já que os micro-organismos são capazes de decompor esses materiais. Bionanocompósitos também podem ser encontrados na natureza: pérolas e conchas, marfim, ossos, esmalte e dentina dos dentes são alguns exemplos $[9,10]$.

Biomateriais já são usados na medicina regenerativa como os implantes para a regeneração de tecidos, principalmente a regeneração óssea. A maioria dos trabalhos publicados sobre reparação óssea é sobre materiais híbridos formados pela combinação de hidroxiapatita com colágeno. O biomaterial também pode carregar, em sua estrutura, medicamentos, para ser utilizado tanto no crescimento dos tecidos, quanto na liberação controlada do fármaco [6]. Uma das vantagens desses materiais é a sua matriz inorgânica, que aumenta a estabilidade e proteção desses materiais a longo prazo [9]. Esse aspecto possui grade importância, justificando sua abordagem em diversos tópicos da literatura pertinente a materiais híbridos.

O nosso grupo de pesquisa tem uma vasta experiência na caracterização de materiais híbridos formados a partir de argilas catiônicas e compostos orgânicos. Entre alguns desses estudos estão os materiais híbridos formados pela polimerização de aminas aromáticas e diaminas intercaladas em argilas [11]. Também já se estudou os materiais resultantes da intercalação de corantes naturais em argilas [12], entre outros compostos orgânicos [13, 14].

\subsection{Argilas e Argilominerais}

Em 1956, Agricola oficializou pela primeira vez uma definição para argila [15]. Ela é definida classicamente como um material natural, terroso, com granulação fina, constituída por partículas de tamanho médio inferior a $2 \mu \mathrm{m}$, e que apresenta plasticidade ao ser umedecida e endurece quando é seca $[15,16]$. Seus principais constituintes minerais são os argilominerais, cuja definição é dada a seguir. No presente trabalho, o termo argila será usado para se referir aos argilominerais para simplificação. 
Os argilominerais são silicatos hidratados de alumínio ou magnésio, da família dos filossilicatos (do grego phyllos: folhas), de estrutura lamelar ou fibrosa [16]. Os argilominerais com estrutura lamelar são constituídos de camadas em forma de folhas de tetraedros de silício e oxigênio, e folhas de octaedros de alumínio (ou magnésio), oxigênio e hidroxilas como demonstrado na Figura 1.2.

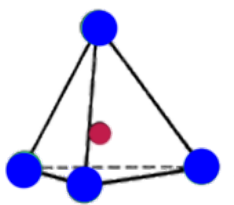

(a)

$\mathrm{O}$

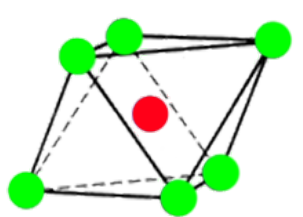

(c)

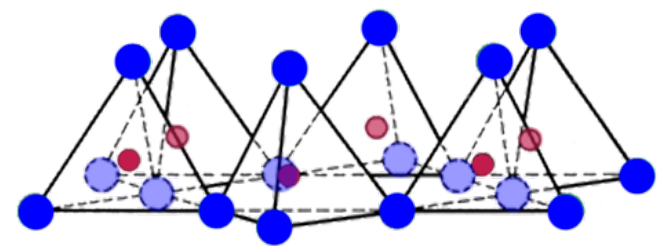

(b)

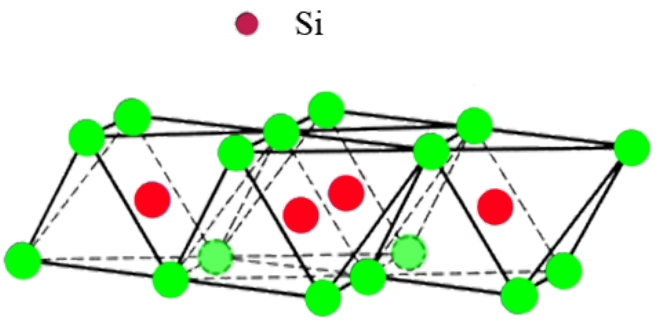

(d)

$\mathrm{OH}$

Figura 1.2: Representação (a) de um tetraedro formando uma (b) folha tetraédrica e (c) de um octaedro formando uma (d) folha octaédrica.

Nas folhas constituídas por tetraedros de silício cada unidade $\left(\mathrm{SiO}_{4}\right)$, compartilha, em duas dimensões, três dos quatro átomos de oxigênio com os tetraedros vizinhos, formando anéis de seis tetraedros (anéis hexagonais); essa camada é denominada de "folha siloxano" ou simplesmente "folha tetraédrica $(\mathrm{T})$ " [17, 18]. Essas folhas podem estar ligadas a outras folhas, formadas por octaedros (e denominada "folha octaédrica (O)"), através do compartilhamento dos átomos de oxigênio.

Podemos classificar os argilominerais de acordo com a natureza do átomo central dos octaedros [18, 19]. Quando esse átomo é divalente, todos os sítios octaédricos estão ocupados (como na brucita $\left[\mathrm{Mg}(\mathrm{OH})_{2}\right]$ ), e as argilas são classificadas como trioctaédricas. Já quando o cátion é trivalente, só $2 / 3$ dos octaedros estão ocupados (como na gibsita $\left.\left[\mathrm{Al}(\mathrm{OH})_{3}\right]\right)$ e a argila é classificada como dioctaédrica. Os dois tipos de folhas podem ser observados na Figura 1.3 [20]. Os argilominerais apresentam uma clivagem paralela a essas camadas. Argilominerais podem apresentar diferentes composições químicas e 
propriedades, dependendo da natureza e da quantidade de cátions dentro dessas folhas tetraédricas e octaédricas.

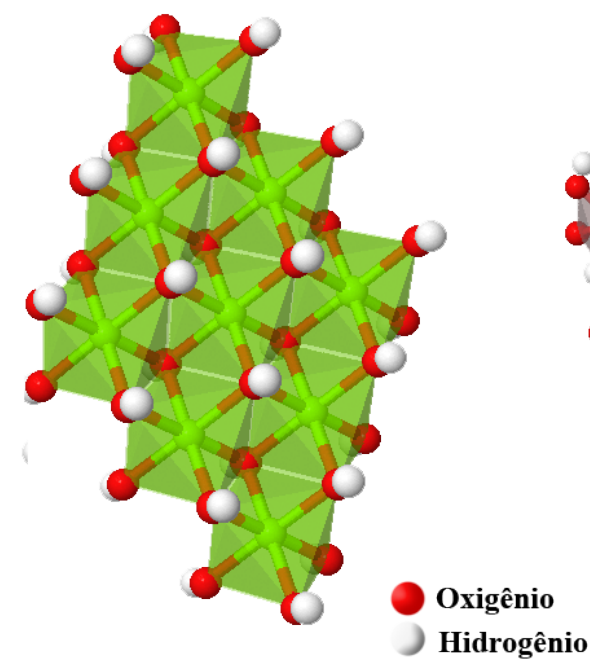

(A)

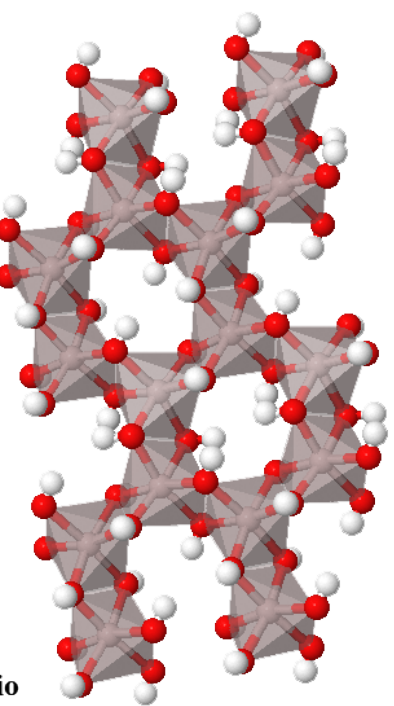

(B)

Figura 1.3: (A) Forma trioctaédrica e (B) Forma dioctaédrica. (Adaptado de [20]).

Nos argilominerais podem ocorrer substituições isomórficas [17, 18], isto é, substituições sem alterar a estrutura das folhas tanto nos tetraedros $\left(S i^{4+}\right.$ por $A l^{3+}$, por exemplo) quanto nos octaedros $\left(A l^{3+}\right.$ por $\mathrm{Fe}^{2+}$ ou $\mathrm{Mg}^{2+}$ por $\mathrm{Li}^{+}$, por exemplo). Essas substituições por cátions de menor valência são responsáveis pela carga negativa das camadas dos argilominerais, que são compensadas pela presença de íons positivos entre as lamelas [19]. Esses cátions interlamelares podem ser substituídos, de forma reversível, por outros cátions metálicos ou moléculas carregadas positivamente; por isso, são chamados de "cátions trocáveis". Devido ao desbalanceamento de carga causado pelas substituições isomórficas, esses cátions estão fixos eletrostaticamente ao longo das faces externas e entre as lamelas.

As substituições isomórficas geralmente ocorrem durante a formação das argilas, devido à presença de outros íons favoráveis à essa substituição no ambiente geoquímico [17]. O tamanho do íon, sua carga elétrica e identidade química determinam se a substituição é no sítio octaédrico ou no tetraédrico.

A capacidade de troca catiônica (CTC) é a quantidade de cátions necessários para neutralizar as cargas negativas nas camadas das argilas. Ela pode ser expressa em milie- 
quivalentes do cátion por $100 \mathrm{~g}$ de argila ou em mmol de carga por $100 \mathrm{~g}$ de argila, sendo que esse último é mais comumente usado atualmente.

Os argilominerais também são classificados quanto à razão de camadas tetraédricas e octaédricas que formam as lamelas. Argilominerais de camada $1: 1$ apresentam uma folha octaédrica e uma folha tetraédrica. Já argilominerais de camada $2: 1$ apresentam uma camada octaédrica entre duas camadas tetraédricas, como pode ser observado na Figura 1.4 [19]. Nos argilominerais do tipo $2: 1$ o elemento central das folhas octaédricas está coordenado aos átomos de oxigênio das folhas tetraédricas [21].

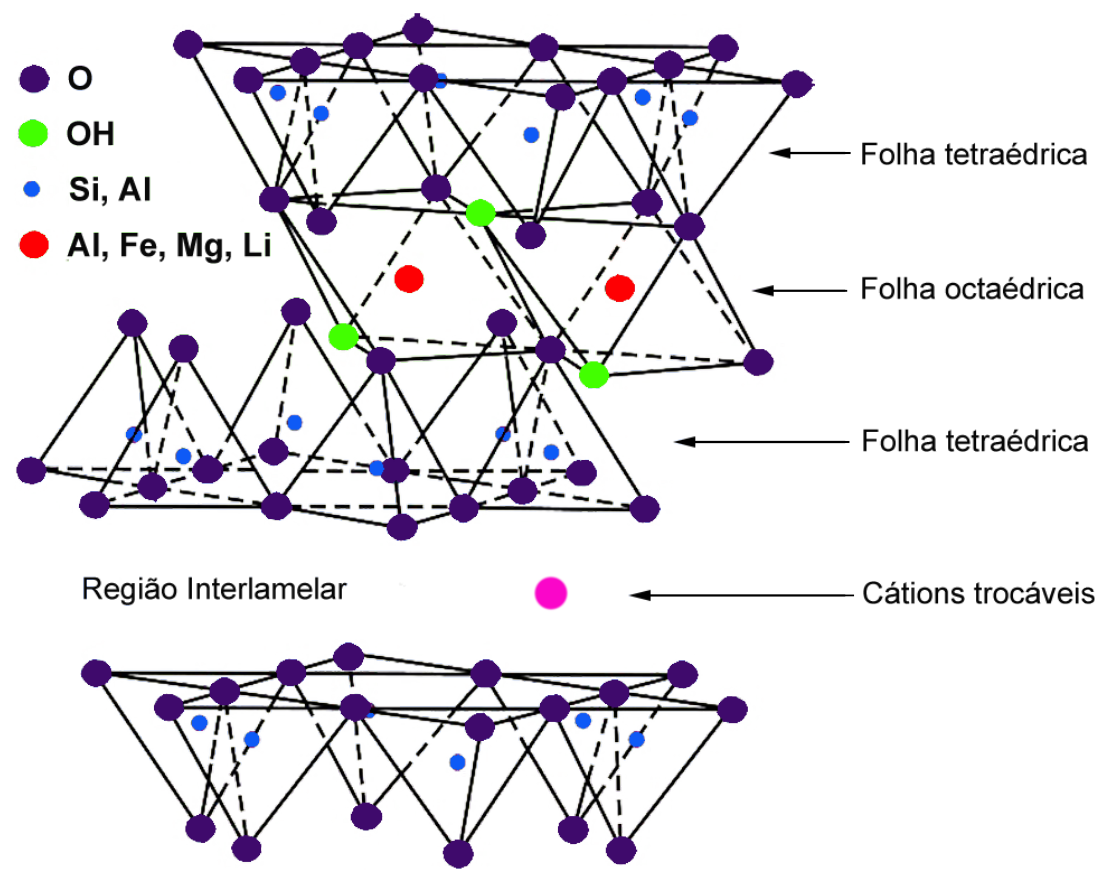

Figura 1.4: Filossilicatos com camadas do tipo $2: 1$ (folha tetraédrica + folha octaédrica + folha tetraédrica $=$ TOT).

As forças que agem sobre as espécies catiônicas próximas às folhas com deficiência de carga são forças eletrostáticas e obedecem à lei de Coulomb². Substituições na folha octaédrica causam uma deficiência de cargas deslocalizadas na superfície das camadas. Já as substituições nos tetraedros fazem com que a distribuição de carga negativa seja localizada na superfície das camadas, conforme ilustra a Figura 1.5 [23]. Outras forças atrativas que as espécies próximas às lamelas carregadas podem sofrer são as forças íon-dipolo e

\footnotetext{
${ }^{2}$ Também conhecida como Energia Eletrostática (E), surge das interações entre partículas carregadas e é diretamente proporcional às cargas positivas e negativas $\left(Z^{+} Z^{-} e^{2}\right)$ e inversamente proporcional à distância entre elas (d), ou seja, $E=Z^{+} Z^{-} e^{2} / 4 \pi \epsilon_{0} d$, onde $e$ é a carga do elétron e $\epsilon_{0}$ é a permissividade do meio [22].
} 
íon-dipolo induzido $[24,25]$. Porém, essas forças são mais fracas que aquela citada anteriormente porque a energia de interações íon-dipolo é inversamente proporcional à distância ao quadrado, e a energia de interação íon-dipolo induzido é inversamente proporcional à distância elevado à quarta potência ${ }^{3}$.

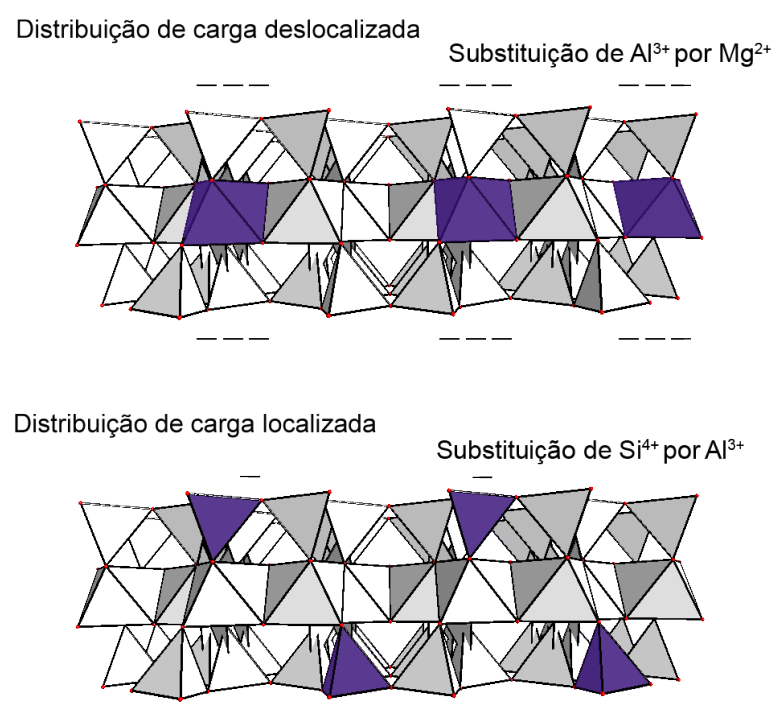

Figura 1.5: Cargas deslocalizadas e localizadas na superfície de argilominerais. (Adaptada de [23]).

O estudo dos sítios de interação das argilas é de grande valia para se entender a reatividade de moléculas orgânicas com argilas [23] e serão melhor explorados adiante.

Um dos grupos de argila mais abundantes é o das esmectitas. Ela pertence à família dos filossilicatos $2: 1$ e compreende os seguintes argilominerais: montmorilonita, nontronita, beidelita, saponita, hectorita e sauconita. Na Tabela 1.1 [16] são apresentadas as fórmulas estruturais ideais desses argilominerais. Entre colchetes estão representados os sítios octaédricos, entre parênteses os sítios tetraédricos e entre chaves os cátions interlamelares com as moléculas de águas de hidratação [21].

A grande variedade de argilominerais pertencentes à família das esmectitas é devida à possibilidade de substituições isomórficas. Essas substituições geram uma carga superficial média de 0,2 a 0,6 elétrons por unidade $\mathrm{O}_{10}(\mathrm{OH})_{2}$ nos argilominerais pertencentes a esse grupo [16]. A CTC das argilas esmectitas do tipo montmorilonitas e hectoritas está entre 40 e $150 \mathrm{mmol}_{c} / 100 \mathrm{~g}$ de argila. A diferença nos valores de CTC entre as argilas

\footnotetext{
${ }^{3} \mathrm{~A}$ energia potencial de uma interação íon-dipolo é dada por $\mathrm{E}=\left|Z^{ \pm}\right| \mu e / 4 \pi \epsilon_{0} d^{2}$, onde $\mu$ é o momento de dipolo e a energia potencial de uma interação íon-dipolo induzido é $E=-Z^{2} \alpha e^{2} / 2 d^{4}$
} 
Tabela 1.1: Fórmulas estruturais ideais dos argilominerais do grupo das esmectitas.

\begin{tabular}{|c|c|}
\hline \multirow{4}{*}{ Dioctaédrica } & $\begin{array}{c}\text { Montmorilonita } \\
\left\{M_{x+y / n}^{n+} y H_{2} O\right\}\left[A 1_{4-y} M g_{y}\right]\left(S i_{8-x} A 1_{x}\right) O_{20}(O H)_{4}\end{array}$ \\
\hline & $\begin{array}{c}\text { Beidelita } \\
\left\{M_{x+y / n}^{n+} y H_{2} O\right\}\left[A 1_{4-y}\right]\left(S i_{8-x} A 1_{x}\right) O_{20}(O H)_{4}\end{array}$ \\
\hline & $\begin{array}{c}\text { Nontronita } \\
\left\{M_{x / n}^{n+} y H_{2} O\right\}\left[F e_{4}\right]\left(S i_{8-x} A 1_{x}\right) O_{20}(O H)_{4}\end{array}$ \\
\hline & $\begin{array}{c}\text { Volconscoíta } \\
\left\{M_{x+y / n}^{n+} y H_{2} O\right\}\left[A 1_{4-y} F e_{y}\right]\left(S i_{8-x} A 1_{x}\right) O_{20}(O H)_{4} \\
\end{array}$ \\
\hline \multirow[t]{3}{*}{ Trioctaédrica } & $\begin{array}{c}\text { Saponita } \\
\left\{M_{x / n}^{n+} y H_{2} O\right\}\left[M g_{6}\right]\left(S i_{8-x} A 1_{x}\right) O_{20}(O H)_{4}\end{array}$ \\
\hline & $\begin{array}{c}\text { Sauconita } \\
\left\{M_{x+y / n}^{n+} y H_{2} O\right\}\left[M g_{6-y} Z n_{y}\right]\left(S i_{8-x} A 1_{x}\right) O_{20}(O H)_{4}\end{array}$ \\
\hline & $\begin{array}{c}\text { Hectorita } \\
\left\{M_{x / n}^{n+} y H_{2} O\right\}\left[M g_{6-x} L i_{x}\right]\left(S i_{8}\right) O_{20}(O H, F)_{4}\end{array}$ \\
\hline
\end{tabular}

está relacionada com o grau de substituição isomórfica nas lamelas (que gera diferentes quantidades de carga elétrica por unidade de área), a carga e o raio do cátion interlamelar.

Como há a possibilidade de variar a distância basal, ou seja, a distância entre as lamelas, os agilominerais do grupo das esmectitas são chamados de "argilominerais com basal expansível reversívelmente" e, devido a essa propriedade, há uma grande aplicação desse grupo de argilominerais [8] já comentados anteriormente no item 1.1 (sobre Materiais híbridos inorgânico-orgânicos).

A argila do tipo montmorilonita foi descoberta em 1847 em Montmorillon, no sul da França, por Damour e Savelt [26]. É uma argila que apresenta, em sua célula unitária, composição química ideal $M_{0,67}^{+}\left(A l_{3,33} M g_{0,67}\right) S i_{8} O_{20}(O H)_{4}$, onde $M^{+}$representa um cátion monovalente. Ocorre usualmente substituição isomórfica dos cátions $A l^{3+}$ por íons $M g^{2+}$ da folha octaédrica $[8,16]$. Atualmente a montmorilonita é uma das argilas mais amplamente utilizadas. Neste trabalho, utilizou-se como matriz inorgânica duas amostras de montmorilonitas naturais, Veegum HS e Cloisita Sódica, que apresentam capacidade de troca catiônica de $80 \mathrm{mmol}_{c} / 100 \mathrm{~g}$ e $92 \mathrm{mmol}_{c} / 100 \mathrm{~g}$, respectivamente [27].

A argila sintética Laponita RD do grupo das esmectitas, é do tipo hectorita, com substituição isomórfica de magnésio por lítio em sua folha octaédrica; portanto sua folha octaédrica é do tipo trioctaédrica. A célula unitária da Laponita RD apresenta composição química ideal $\mathrm{Na}_{0,7}^{+}\left[\left(\mathrm{Mg}_{5,45} \mathrm{Li}_{0,4}\right) \mathrm{Si}_{8} \mathrm{O}_{20}(\mathrm{OH})_{4}\right]^{-0,7}$. Possui o íon $\mathrm{Na}^{+}$entre suas camadas 
para balancear a carga negativa. A capacidade de troca catiônica da Laponita RD é de $50 \mathrm{mmol}_{c} / 100 \mathrm{~g}$, valor usado para os cálculos das reações de intercalação [28].

A Laponita é uma hectorita sintética, livre de impurezas minerais, formada por lamelas na forma de discos com menos de $1 \mathrm{~nm}$ de espessura e aproximadamente $25 \mathrm{~nm}$ de diâmetro. As dimensões da lamela de Laponita e uma comparação do tamanho dela com a de outras argilas encontram-se na Figura 1.6 [29].

a)

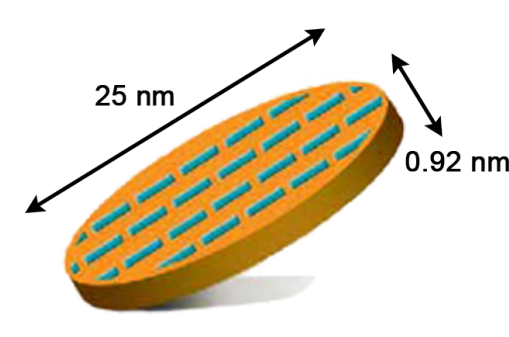

b)

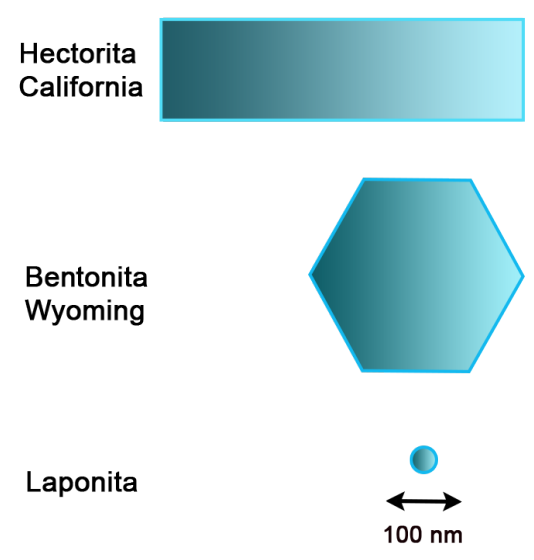

Figura 1.6: a) Dimensões da lamela de Laponita e b) comparação do tamanho de uma lamela de Laponita com o de outras argilas. (Adaptado de [28]).

As propriedades dos argilominerais dependem muito da sua estrutura e composição, e podem influenciar de maneira significativa na interação com moléculas orgânicas, levando à formação de complexos com diferentes propriedades. As interações entre as argilas e os compostos orgânicos dependem do comprimento da cadeia carbônica, da massa molar, dos grupos funcionais presentes (por exemplo: grupos hidrofóbicos), dos grupos carregados positivamente e negativamente (por exemplo: $-\mathrm{NH}_{3}^{+},-\mathrm{COO}^{-}$), dos grupos oxigenados (por exemplo: carbonila, hidroxila, C-O-C) e da configuração das moléculas orgânicas [30].

Como as argilas apresentam pequeno tamanho de partícula e grande área superficial, suas propriedades de superfície são muito interessantes. Elas também apresentam ótimas propriedades mecânicas e têm sido usadas nos últimos anos para a síntese de materiais híbridos, possibilitando a formação de nanocompósitos, pois apresentam uma dimensão na escala nanométrica.

No contexto do estudo desenvolvido nesta Dissertação, a palavra "intercalação" é usada 
para designar a introdução reversível de íons ou moléculas (espécies convidadas) em uma matriz inorgânica (estrutura cristalina chamada também de hospedeira) que apresenta vazios estruturais [8, 31]. A Figura 1.7 ilustra o processo de intercalação de moléculas orgânicas na região interlamelar das argilas.

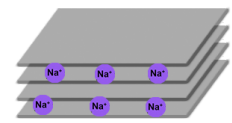

Argila no estado sólido

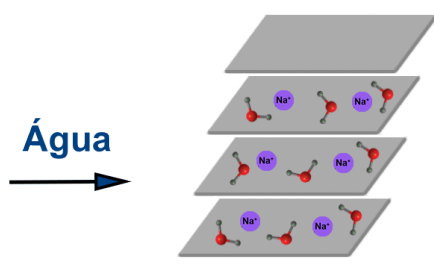

Hidratação das camadas de argila em água

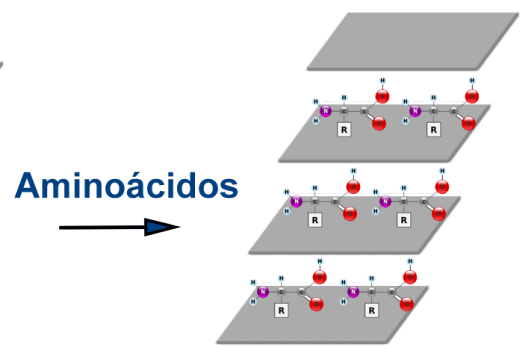

Argila modificada

Figura 1.7: Esquema do processo de intercalação de moléculas orgânicas na região interlamelar das argilas.

As argilas do tipo montmorilonitas formam tactóides, isto é, ficam empilhadas "face a face". Arranjos desse tipo favorecem primeiramente a interação da molécula orgânica com as superfícies externas da partícula de argila e só depois de certo tempo as moléculas orgânicas migram para a região interlamelar [21]. Já a Laponita RD, fica totalmente dispersa em suspensão aquosa, ou seja, suas partículas se separam em camadas individuais ou em tactóides com poucas lamelas empilhadas.

A migração de alta quantidade de moléculas de água para a região interlamelar pode provocar um distanciamento tal entre as lamelas, que as mesmas se separam. Esse processo é conhecido como esfoliação ou delaminação. Forma-se uma dispersão coloidal de argila em água. A esfoliação é promovida em suspensões diluídas em água. Observa-se que a concentração na qual a Laponita forma dispersões coloidais é maior que aquela reportada para outras argilas esmectitas (como as montmorilonitas). Esse fato está relacionado com o menor tamanho de partículas de Laponita, que favorece o inchamento osmótico. 


\subsection{Sítios ativos predominantes nos argilominerais}

A acidez do solo é amplamente estudada. Antigamente se atribuía a acidez à acumulação de ácidos orgânicos. Em 1913 Loew [32] propôs que a acidez dos solos era devida à existência de ácidos aluminossilícicos altamente insolúveis.

As propriedades da superfície das argilas dependem de muitos fatores, entre eles da composição química, da natureza dos átomos da superfície, do tipo dos sítios de interações, e da natureza dos cátions trocáveis [18]. Os sítios ativos predominantes nos argilominerais são [23]: I) superfície neutra de siloxano; II) sítios de substituição isomórfica; III) cátions metálicos trocáveis e cátions estruturais; IV) moléculas de água ao redor do cátion trocável; V) sítios hidrofóbicos; VI) sítios nas bordas ou arestas das lamelas com exposição dos grupos silanol e aluminol.

\subsubsection{Superfície neutra de siloxano}

A superfície menos reativa encontrada em argilominerais é a folha formada pelos tetraedros de silício (siloxano) que é neutra em argilas sem substituições isomórficas [18, 33]. As argilas 2:1 sem substituição isomórfica, como o talco e a pirofilita, são exemplos de tipo de material. Como cada átomo de oxigênio faz ligações covalentes com dois átomos de silício, esses átomos de oxigênio da superfície externa (camada de siloxano) tornam-se doadores fracos de elétrons, não sendo capazes de fazer fortes interações com moléculas de água, por exemplo. Essa superfície neutra comporta-se como uma base de Lewis fraca e tem característica predominantemente hidrofóbica. Usualmente, o átomo de silício não forma ligações $p \pi-p \pi$, pois seus orbitais atômicos são grandes e difusos, não permitindo uma interação efetiva, mas, como pode ser observado na Figura 1.8, o silício pode utilizar os orbitais d para formar ligações $d \pi-p \pi$ com o átomo de oxigênio, o que fortalece a ligação Si-O [34]. 




Figura 1.8: Sitios ativos dos argilominerais 2:1: superfície de grupos siloxano.

\subsubsection{Sítios de substituição isomórfica}

As substituições isomórficas conferem às argilas uma superfície basal carregada com carga negativa permanente. Em sistemas naturais essa deficiência de cargas é compensada pela presença de um cátion trocável. O grau de intumescimento e a acessibilidade da região interlamelar são influenciados pelo tipo de substituição isomórfica. Quando o silício é substituído pelo alumínio na folha tetraédrica das argilas, ocorrem distorções locais devido à diferença no comprimento das ligações entre o Si-O (0,162 nm) e o Al-O (0,177 nm) $[18,23]$. Se considerarmos a eletronegatividade de Pauling dos átomos que compõem os tetraedros que formam a folha tetraédrica (uma vez que a ionicidade de uma ligação é proporcional à diferença de eletronegatividade dos átomos envolvidos na ligação), a carga sobre o oxigênio é maior quando ele está ligado ao alumínio do que ao átomo de silício, pois a diferença de eletronegatividade é maior entre os átomos em uma ligação Al-O do que em uma ligação Si-O.

As substituições de silício por alumínio aumentam a reatividade da superfície. Quanto maior for esse grau de substituição, maior o caráter básico de Lewis (doador de elétrons) e maior a possibilidade de moléculas orgânicas polares estabelecerem ligações de hidrogênio diretamente com a superfície da argila [33].

Quando a substituição isomórfica ocorre na folha octaédrica, a carga negativa é mais 
deslocalizada, pois a carga está deslocalizada sobre dez átomos de ogênios basais e o caráter de base de Lewis da superfície é reforçado. Já a substituição isomórfica que ocorre nos tetraedros é mais localizada, pois ocorre sobre três oxigênios basais [23].

\subsubsection{Cátions metálicos trocáveis e cátions estruturais}

Os cátions do interior dos tetraedros e octaedros também são chamados de "sítios metálicos estruturais" [23]. A natureza do cátion e o teor de água influenciam significativamente a acidez de Lewis na superfície dos argilominerais, tanto para os cátions metálicos trocáveis como para os cátions estruturais presentes nas bordas ou arestas das lamelas. As moléculas de água ocupam as posições de coordenação ao redor do cátion estrutural que está com sua esfera de coordenação incompleta. Quando ocorrem reações com espécies orgânicas, que possuem caráter de base de Lewis, elas podem se coordenar a esses metais, nesses dois sítios, e não necessariamente substituir o cátion metálico trocável, conforme pode ser observado na Figura 1.9.



Figura 1.9: Sítios ativos dos argilominerais: cátions metálicos trocáveis e cátions estruturais expostos contendo esfera de coordenação insaturada.

\subsubsection{Moléculas de água ao redor do cátion trocável}

Há dois ambientes distintos de sorção de água nas argilas: a) moléculas de água coordenadas diretamente ao cátion metálico trocável e b) moléculas de água sorvidas nos poros intersticiais, nos espaços interlamelares entre os cátions metálicos trocáveis ou nos sítios polares na superfície externa [23]. Nesses dois ambientes essas moléculas de água são fontes de acidez de Brönsted, pois a água pode doar próton, como pode ser visto na Figura 
1.10. Essa acidez de Brönsted na superfície dos argilominerais pode ser bastante elevada e depende da natureza do cátion metálico trocável e da quantidade de água presente. Observa-se que quanto maior a razão carga/raio do íon metálico no espaço interlamelar, maior o caráter ácido de Brönsted da argila. Quanto menor o grau de hidratação da argila, maior a sua acidez.

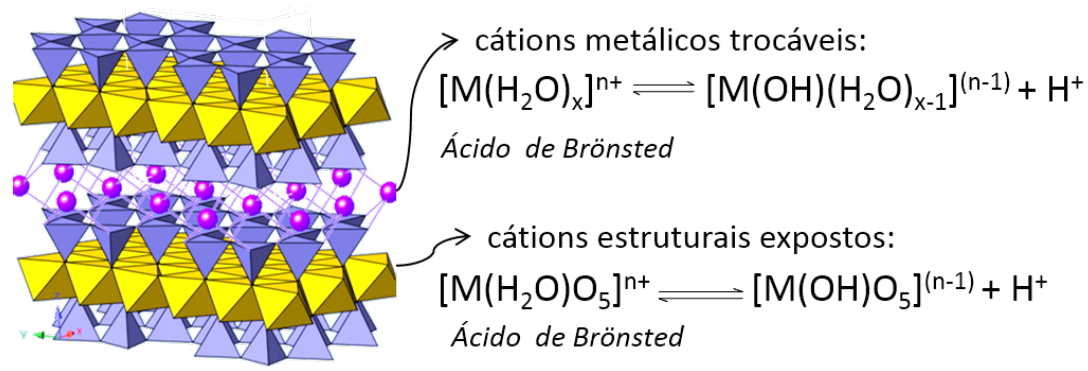

Figura 1.10: Sítios ativos dos argilominerais: moléculas de água polarizadas ao redor de cátions trocáveis e cátions nas arestas.

\subsubsection{Sítios hidrofóbicos}

Os sítios hidrofóbicos surgem das reações das argilas com cátions orgânicos, que geram as chamadas "argilas organofílicas", tornando-as hidrofóbicas, como ilustrado na Figura 1.11. Os íons quaternário de amônio de cadeias longas são exemplos de espécies usualmente empregadas na produção de argilas organofílicas. Esses sítios são responsáveis pela sorção de moléculas orgânicas. As argilas organofílicas são "solventes" eficientes de compostos orgânicos. Elas podem também agir como pilares moleculares, permitindo a adsorção seletiva de solutos orgânicos, devido à não saturação da lamela com o cátion orgânico e a criação de poros. 


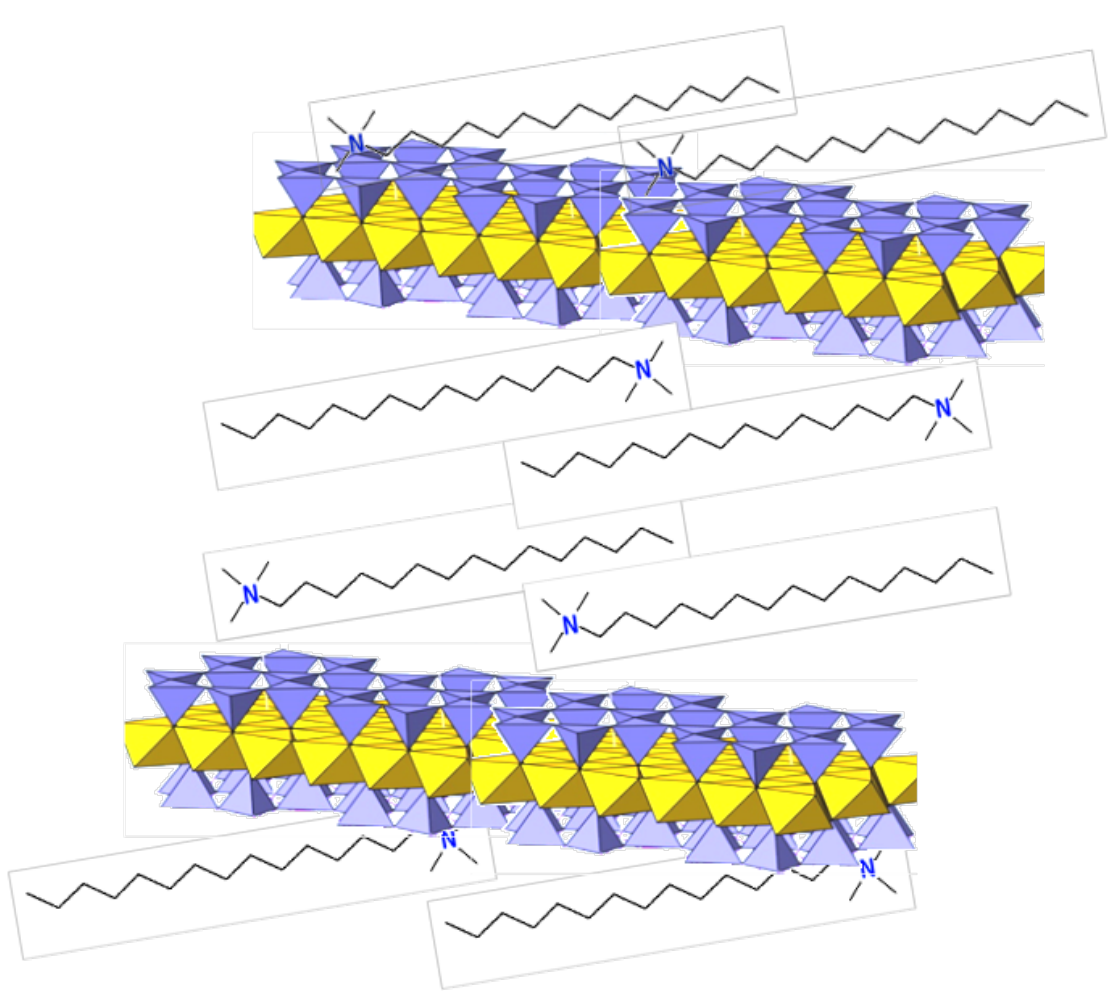

Figura 1.11: Sítios ativos dos argilominerais: sitios hidrofóbicos.

\subsubsection{Sítios nas bordas ou arestas das lamelas com exposição dos grupos silanol e aluminol}

Os sítios silanol e aluminol são gerados a partir dos grupos hidroxila localizados nas bordas quebradas das lamelas; por isso são os sítios reativos mais abundantes [18, 33]. Os sítios Al-O-H e Si-O-H podem interagir através de ligações de hidrogênio para adsorver moléculas acumuladas nas interfaces. Nesses grupos $\mathrm{OH}$ pode haver a dissociação do íon $H^{+}$, gerando carga negativa nas arestas; essas cargas geradas são dependentes do pH do meio, como ilustrado na Figura 1.12 [35].

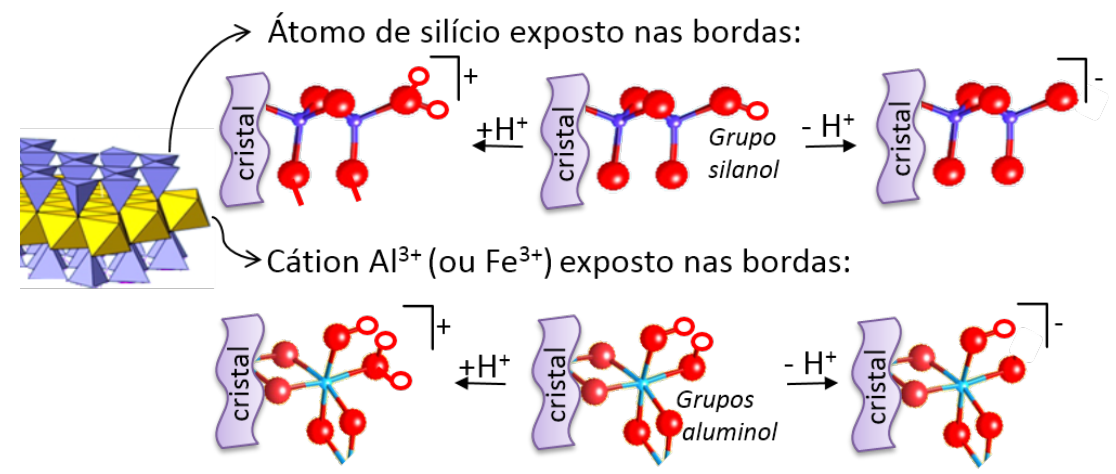

Figura 1.12: Sitios ativos dos argilominerais: sitios nas arestas ou bordas. 
Liu et al. [36] reportaram recentemente o emprego de dinâmica molecular de primeiro princípio (first principles molecular dynamics - FPMD) para calcular as contantes ácidas dos grupos presentes nas arestas do plano (010) de uma montmorilonita de composição $L i_{0,5}\left[\mathrm{Al}_{3,5} \mathrm{Mg}_{0,5}\right]\left[\mathrm{Si}_{8}\right] \mathrm{O}_{20}(\mathrm{OH})_{4}$. As propriedades da superfície lateral dos argilominerais são dependentes do pH. Os estudos de modelagem realizados pelos autores foram comparados com os valores de $p K_{a}$ obtidos experimentalmente através de técnicas como a titulação potenciométrica. Contudo, os ensaios experimentais não permitem avaliar os valores dos pKs dos grupos individuais presentes nas arestas dos cristais das argilas (e os valores reportados variam de um trabalho para outro utilizando a mesma argila). De um modo geral, observa-se que as argilas montmorilonita SWy-1 e SWy-2 (procedentes da coleção da Clay Minerals Society) sofrem processos de desprotonação no intervalo de pH entre 5,5 e 8,3, segundo as reações mostradas na Figura 1.13. Os resultados de valores de $p K_{a}$ obtidos através de cálculos teóricos por Liu et al. estão em boa concordância com os resultados experimentais.

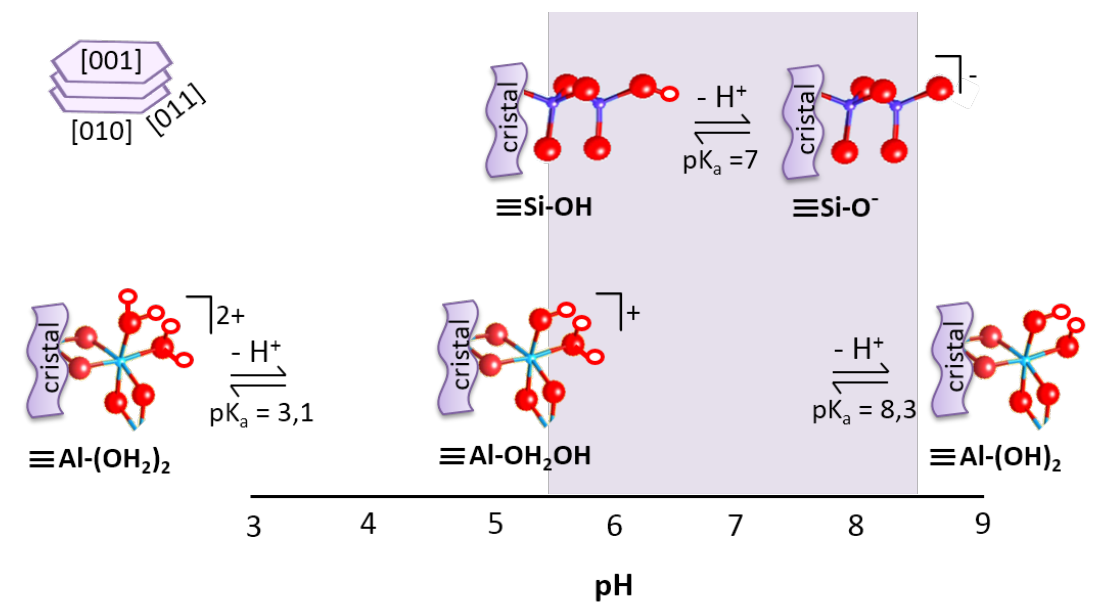

Figura 1.13: Acidez dos sítios das arestas ou bordas de esmectitas (三 representa a aresta do cristal).

Na faixa usual de pH empregada nos trabalhos com argila em laboratório (isto é, entre 3 e 9), os grupos nas arestas se encontram preponderantemente nas formas $\equiv S i-O H$, $\equiv \mathrm{Si}-\mathrm{O}^{-} \mathrm{e} \equiv \mathrm{Al}-\mathrm{OH}_{2} \mathrm{OH}$ ( $\equiv$ representa a aresta do cristal). A forma sinalol protonado (isto é, $\left.\equiv \mathrm{Si}-\mathrm{OH}_{2}^{+}\right)$só ocorre em meio altamente ácido $\left(p K_{a}\right.$ experimentais entre -8 e -4) [36]. Os cálculos teóricos revelaram que as propriedades ácido-base do grupo silanol mudam quando ligado a um octaedro de magnésio (e não de alumínio). Nesse caso, a 
presença do íon $M^{2+}$ diminui a acidez do grupo silanol, de modo que o valor do $p K_{a}$ aumenta para 10,8 .

Cabe ressaltar que medidas exatas de constantes ácidas de argilas são difíceis de serem determinadas porque outras reações podem ocorrer além da protonação/desprotonação dos grupos sinalol e aluminol. Por exemplo, em valores de $\mathrm{pH}$ inferiores a 4 e superiores a 11, observa-se a solubilização do alumínio enquanto em pH superior a 9-10, os tetraedros de silício começam a solubilizar gerando íons silicato em solução [37]. À medida que o pH diminui, o próton começa a competir com o cátion na região interlamelar, promovendo reação de troca iônica.

A carga elétrica superficial das argilas é de fundamental importância nos processos de troca iônica, adsorção e estabilização coloidal, entre outros [37]. A carga elétrica nas argilas esmectitas tem duas origens: (i) na substituição isomórfica nas folhas que compõem as lamelas (cargas estruturais, que independem do meio no qual a argila se encontra) e (ii) nos grupos (ligantes oxo e/ou hidróxido ligados a $\mathrm{Si}, \mathrm{Al}, \mathrm{Mg}$ etc.) expostos nas arestas das lamelas (cargas que dependem do meio no qual a argila se encontra).

Em virtude da morfologia 2D das partículas das argilas, 90-95 \% da carga total é devida às cargas estruturais e somente 5-10\%, às cargas das arestas. Os métodos eletrocinéticos permitem obter informações sobre a carga elétrica superficial das argilas. As medidas de potencial Zeta de suspensões de argilas esmectitas no intervalo de pH igual a 2-12 revelam valores de potencial negativo $(-30 \mathrm{a}-50 \mathrm{mV}$ ) e a ausência de um ponto isoelétrico ( $\mathrm{pH}$ no qual o potencial Zeta é zero). Logo, a carga elétrica das partículas de argila é dominada pela carga elétrica estrutural.

\subsection{Aplicações de argilas nas áreas farmacêutica e mé- dica}

Desde a pré-história os minerais têm sido utilizados para fins medicinais [38]. Atualmente os minerais desempenham um importante papel na área da saúde, na qual são utilizados como matéria-prima para compor formulações farmacêuticas, pois eles geralmente 
são termicamente estáveis e quimicamente inertes, apresentam estruturas bem definidas e preços baixos [39, 40, 41].

A prática de comer "terra", em que a composição é alta em argila, é denominada "geofagia" e há várias hipóteses para tentar explicar esse comportamento observado em homens e animais [42]. Por exemplo, sugere-se o consumo de "terra" para finalidade de desintoxicação, para amenizar a diarreia causada por infecções gastrointestinais, para a suplementação de minerais e para a redução da acidez do trato digestivo. As argilas bentonitas, ricas em montmorilonitas cálcicas e sódicas, são usadas há muito tempo em nutrição animal, pois são bons agentes adsorventes de micro-organismos patogênicos e de toxinas.

Há cerca de 4500 minerais conhecidos, mas somente cerca de 30 são utilizados na indústria farmacêutica e cosmética. A maioria dos excipientes na indústria farmacêutica é análogos sintéticos aos naturais, mas no caso das argilas, devido ao fato de sua síntese ser complexa e dispendiosa, usam-se as argilas naturais [39].

Os minerais têm fins farmacêuticos clássicos, como excipientes ou como ingredientes ativos. Excipientes são substâncias inertes que conferem volume, consistência e forma aos medicamentos. Eles podem ter propriedades organolépticas, ajudar na conservação da droga ou proporcionar a liberação da substância ativa dentro do organismo. Além dessas utilizações, os argilominerais podem ser empregados para transportar e modificar os sistemas de entrega de drogas no organismo devido à sua capacidade de interagir com fármacos, tanto pela adsorção quanto através de reações de troca iônica [39]. As esmectitas por incharem ao serem dispersas em água, e dependendo do tempo de exposição e da temperatura, podem favorecer a liberação do princípio ativo. A influência dos excipientes minerais sobre a biodisponibilidade da droga está relacionada com a estabilidade que podem conferir e o processo de liberação. Os excipientes minerais podem ser benéficos ou prejudiciais em relação à liberação das drogas, isso depende do grau de interação do argilomineral com o princípio ativo [38].

Os argilominerais empregados na área farmacêutica devem apresentar as seguintes propriedades: alto poder de adsorção, grande área superficial, propriedades tixotrópicas, 
plasticidade, entre outras. Sua composições químicas, propriedades toxicológicas e físicoquímicas devem atender às leis regulatórias vigentes em relação à indústria farmacêutica.

Uma característica muito interessante das dispersões de argila é a sua estabilidade. Entre as argilas do grupo das esmectitas, a montmorilonita, a saponita e a hectorita são as espécies mais utilizadas em preparações farmacêuticas, pois elas agem como: a) desintegrantes (preparações farmacêuticas como os comprimidos precisam se desintegrar no estômago do paciente para que o fármaco seja liberado); b) emulsificantes, espessantes e antiaglomerantes (em medicamentos líquidos administrados oral ou topicamente, precisa-se evitar a segregação dos componentes); c) corretores de sabor (em medicamentos administrados via oral também se utiliza algumas substâncias para mascarar o sabor desagradável de determinados ingredientes ativos); d) cápsula para liberação de ingredientes ativos (a interação entre os argilominerais e as moléculas orgânicas pode ser utilizada para controlar a liberação de fármacos, melhorando assim suas propriedades terapêuticas) [38]. O aprisionamento das moléculas do fármaco em partículas é uma estratégia útil para protege-la contra a degradação química e enzimática [43]. A liberação controlada de drogas é de especial interesse, por proporcionar níveis de fármaco adequados ao longo do tratamento (manutenção da dose terapêutica); se possível, a liberação deve ocorrer no local desejado para a ação do fármaco, evitando efeitos colaterais [6].

Muitas argilas com grande capacidade de sorção e área específica, como as esmectitas, são utilizadas como protetores gastrointestinais. Esses minerais aumentam a viscosidade e estabilidade do muco gástrico, diminuem a degradação das glicoproteínas do muco e a irritação e secreção gástrica. Por mais que esses argilominerais se liguem rapidamente à mucosa gástrica, elas não fornecem proteção a longo prazo. Estudos realizados em ratos mostram que esse efeito de proteção das esmectitas diminui em 10 min após a ingestão $[38,44]$.

Um tema de interesse na área médica é a entrega de biomoléculas e fármacos através da membrana celular, pois, atualmente, essa entrega é ineficaz e as biomoléculas sofrem degradação enzimática no organismo. A busca por carregadores eficientes de drogas ainda é um desafio. As nanopartículas inorgânicas, como os argilominerais, já empregados na 
área farmacêutica, por apresentarem baixa toxicidade e capacidade de intercalação/desintercalação, são uma alternativa para o transporte e liberação controlada de drogas [45].

A nanotecnologia ${ }^{4}$ tem ganhado cada vez mais destaque, principalmente na área médica, fazendo surgir o campo da nanomedicina. As nanopartículas empregadas com fins farmacêuticos são usadas tanto como ingredientes ativos, quanto como vetores. Ao serem usadas como vetores, elas introduzem o princípio ativo no organismo, desempenhando papel de transportadoras [40]. Há uma evolução nos produtos farmacêuticos quanto à modificação no sistema de entrega da droga, que envolve o controle do tempo, do local e da taxa de liberação, de modo a promover a prevenção e a diminuição dos efeitos colaterais. Tais mudanças são possíveis através de modificações nas formulações farmacêuticas, nos métodos de preparação e no uso de novos materiais [41, 43].

O principal conceito envolvido em entrega modificada de drogas é que a formulação farmacêutica deve proporcionar níveis terapêuticos da droga no local de ação e mantêla ao longo do tratamento, visando reduzir os efeitos tóxicos, entre outras finalidades terapêuticas. Há estudos que demonstram as várias vantagens de nanocompósitos carregadores de fármacos (material híbrido formado por polímeros biocompatíveis, partículas de argila e o princípio ativo), pois eles protegem os compostos do $\mathrm{pH}$ agressivo do fluido gástrico, permitem um melhor ajuste da cinética de liberação, melhoram a estabilidade da dispersão e suas propriedades mecânicas, quando comparados aos materiais produzidos a partir da combinação do polímeros e do fármaco [43].

A argilas também apresentam a vantagem de poderem ter o caráter de sua superfície alterada de hidrofílico para hidrofóbico através da modificação com cátion orgânico (argilas organofílicas), e com esse aumento da hidrofobicidade da superfície, espera-se aumentar e atingir a liberação prolongada em suspensões aquosas [43].

Entre as várias propostas para a realização da liberação controlada, o processo de troca iônica tem recebido destaque nos últimos anos [43], pois sistemas trocadores de íons (veículos) podem substituir seus íons por moléculas de fármaco na forma iônica e ao

\footnotetext{
${ }^{4}$ Nanotecnologia: estudo e desenvolvimento de novos materiais na escala nanométrica (de 1 a 100 nanometros, aproximadamente).
} 
entrarem em contato com os fluidos biológicos, esses íons podem ser extraídos do veículo e ser entregues no organismo. O carregador deve ser eliminado ou biodegradado. Na Figura 1.14 [43], pode-se observar esse esquema idealizado de adsorção/dessorção.

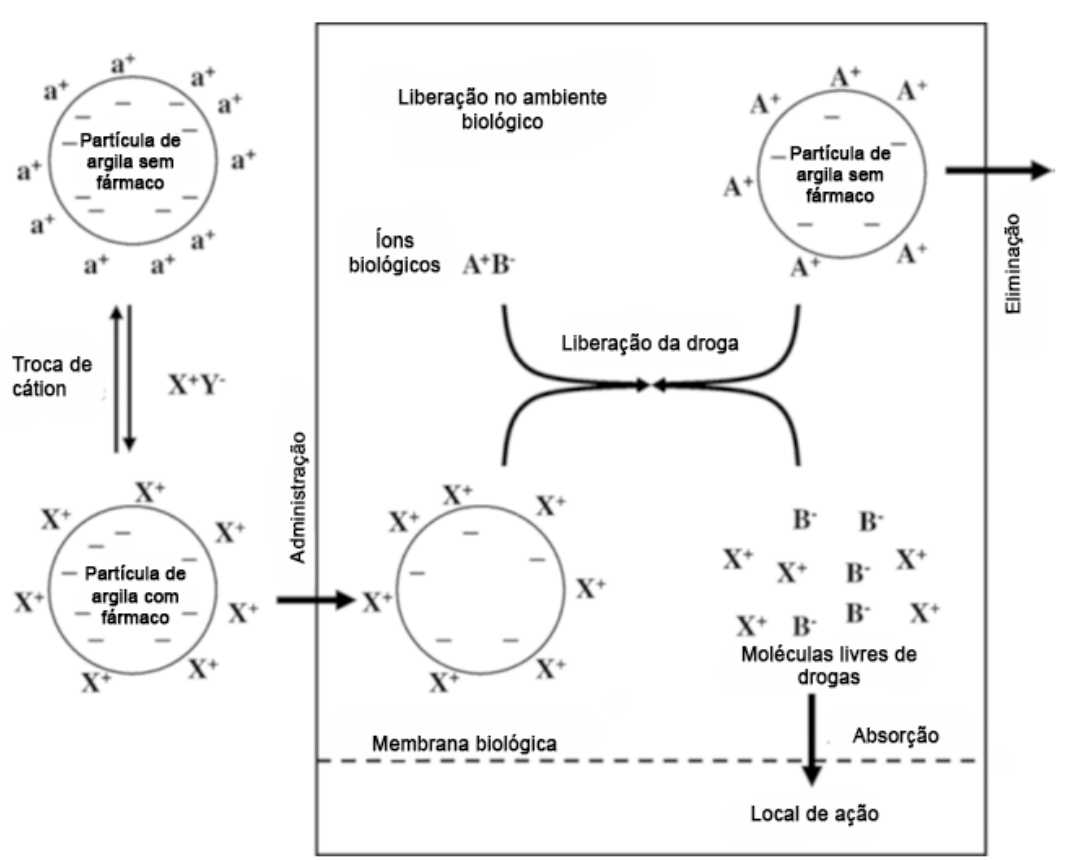

Figura 1.14: Esquema idealizado para a imobilização de drogas em argilas e os mecanismos de liberação de fármaco in vivo (argila com carga superficial (-); cations compensadores $\left(a^{+}\right)$; fármaco catiônico $\left(X^{+}\right)$; ânions associados ao fármaco (contra-ion) $\left(Y^{-}\right)$; contra-ions in vivo $\left(A^{+}\right)$e ânions associados aos contra-ions $\left(B^{-}\right)$). (Adaptado de [42]).

Os argilominerais mais estudados para esse tipo de sistema são as montmorilonitas e as saponitas, por apresentarem capacidade de troca iônica elevada, se comparadas com outras argilas (por exemplo: talco e caulinita) [43]. Melhorar a dissolução de fármacos pouco solúveis em água também é um desafio para a área farmacêutica. Entre algumas alternativas está a adsorção das moléculas do fármaco em superfícies sólidas finamente divididas, como as argilas. A liberação do fármaco a partir da superfície da argila é promovida pela fraca ligação entre eles juntamente com o aumento da disponibilidade da droga. A dispersibilidade da droga na região interlamelar é dada pela quebra das interações moleculares existentes entre eles quando isolados. 


\subsection{Estudos de sistemas argila/aminoácidos}

Estudos das interações de biomoléculas, como os aminoácidos, com matrizes inorgânicas são realizados com diferentes intuitos, que podem abranger desde o transporte dessas moléculas no solo até os estudos com o objetivo de se entender a origem da vida na Terra. Há teorias de que os polipeptídeos podem ter sido formados no espaço intersticial de matrizes inorgânicas, como as argilas e zeólitas, pela ativação catalítica da matéria orgânica, como os aminoácidos [1].

Os aminoácidos podem resistir por milhões de anos (dependendo da profundidade, do tempo e das condições ambientais) em solos e sedimentos, e, por isso, eles podem ser usados como um indicador de paleossolos (solos antigos) [46]. A redução acentuada da concentração de aminoácido abaixo do solo reflete uma redução de húmus, bem como de biomassa e atividade microbiana. Os aminoácidos nos horizontes mais profundos podem ser considerados como uma parte integral da matéria orgânica fóssil ou inerte que resistiu à ação microbiana. Certos aminoácidos são adsorvidos preferencialmente por argilas: quanto maior a cadeia carbônica do aminoácido, menor a força de interação com a argila [46]. Os aminoácidos também podem sofrer transformações, convertendo-se em outros aminoácidos nesse ambiente ao longo dos séculos.

Os processos de interações (adsorção/dessorção) da matéria orgânica com superfícies sólidas como as argilas influencia o transporte, o acúmulo e a disponibilidade de matéria orgânica [47]. Tais processos podem explicar a decomposição seletiva e a conservação do carbono em diferentes ambientes. Essas interações são importantes para o ciclo biogeoquímico do carbono em ambiente aquático. Estudos mostram, por exemplo, que proteínas são fortemente e rapidamente adsorvidas por minerais e sedimentos marinhos [47].

Há estudos [48] para o uso de aminoácidos carregados positivamente, como a lisina e a arginina, como modificadores orgânicos para as montmorilonitas. Como esses aminoácidos se assemelham na estrutura química com os cátions alquilamônio, modificadores convencionais [49], esses estudos esperam compreender o mecanismo de interação dos aminoácidos com a lamela da argila. Como os dipeptídeos são as unidades formadoras das proteínas, se eles (os dipeptídeos com grupos funcionais específicos) forem usados para modificar as 
argilas, pode-se esperar uma compatibilidade da argila com as proteínas e futuramente ajudar na concepção de sensores.

Os estudos da interação entre as argilas e os aminoácidos básicos, como a lisina, são mais amplamente relatados $[50,51]$. Esses estudos apontam para uma interação eletrostática entre a superfície da argila e os grupos funcionais do aminácido [47].

\subsection{Aminoácidos}

Os aminoácidos são pequenas moléculas orgânicas constituintes de macromoléculas com importantes funções biológicas, como as proteínas, que apresentam potencial terapêutico e podem interagir com argilas. Existem vinte aminoácidos codificados pelo código genético e mais de 300 aminoácidos de ocorrência natural [52].

Nos aminoácidos um grupo carboxila e um grupo amino estão ligados ao mesmo carbono. O que difere um aminoácido de outro são suas cadeias laterais ou grupos R (Figura 1.15). Esses grupos R são diferentes quanto à estrutura, ao tamanho, à carga elétrica e influenciam na solubilidade em água do aminoácido [52].

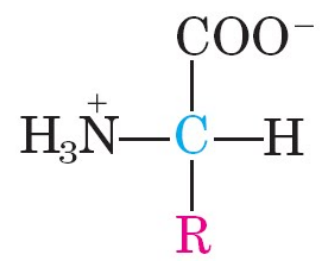

Figura 1.15: Estrutura geral dos aminoácidos.

Em 1891, Emil Fischer propôs duas configurações absolutas para os quatro substituintes no átomo de carbono assimétrico, sistema D e L, com base na configuração do gliceraldeído. Todas as proteínas são formadas pelo conjunto dos 20 aminoácidos, sendo todos $\alpha$-aminoácidos e L-estereoisômeros [52].

A seguir serão apresentados brevemente os aminoácidos e o dipeptídeo usados no presente trabalho. 


\subsubsection{L-Carnosina}

A L-carnosina é um dipeptídeo de ocorrência natural, constituído pelos aminoácidos L-histidina e $\beta$-alanina, sendo de grande importância biológica e farmacológica [53]. Sua estrutura está representada na Figura 1.16. Esse dipeptídeo foi identificado pela primeira vez pelo bioquímico Vladimir Gulevich, em 1900, no extrato de carne, quando procurava compostos nitrogenados ainda não conhecidos nessa matriz [54]. A carnosina é ausente em plantas e invertebrados.
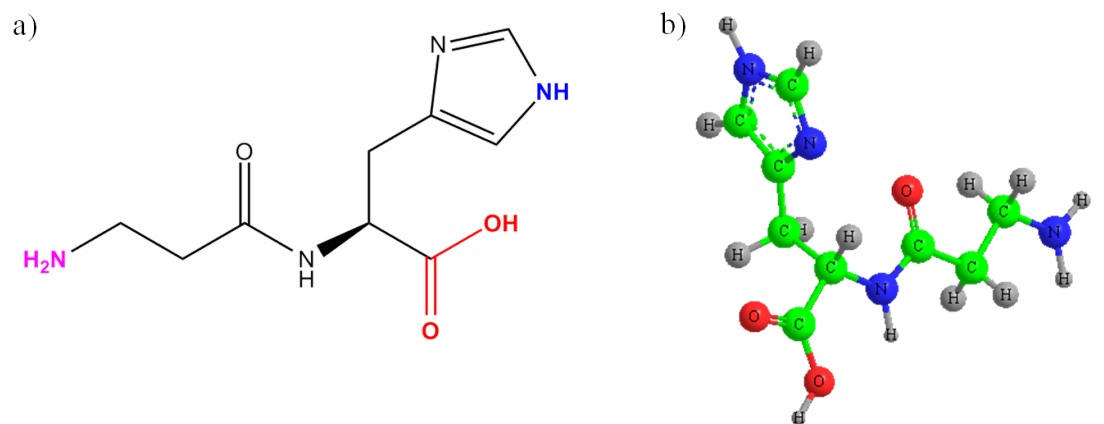

Figura 1.16: Estrutura do dipeptídeo L-Carnosina: a) Representação em forma de bastão e b) Representação tridimensional.

Essa molécula é encontrada em elevada concentração nos tecidos do corpo, como os músculos esquelético e cardíaco, os tecidos nervosos, o estômago e o cérebro. Seu papel biológico exato ainda não é bem compreendido. Estudos apontam que esse aminoácido é um importante antioxidante, protege enzimas e pode inativar as espécies livres de oxigênio e metais pró-oxidantes. Além dessas propriedades inibe a glicosilação não enzimática de proteínas, desempenha papel como neurotransmissor, na modulação enzimática e na quelação de metais pesados $[54,55,56,57]$. A L-carnosina também melhora a função do coração, possui notáveis propriedades cicatrizantes, atenua a isquemia e possui ação protetora contra a nefrotoxicidade [56, 58].

Estudos têm demonstrado uma relação inversa entre idade e concentração de Lcarnosina nos músculos de humanos [59]. A perda de massa muscular está relacionada à deterioração da coordenação motora, o que resulta no aumento da frequência de quedas, que levam a ferimentos e até a morte de idosos. Há estudos que demonstram que a carnosina também atua de forma significativa contra a lesão renal aguda induzida pela 
cisplatina [56].

Esse dipeptídeo também é importante para a manutenção do pH intracelular, uma vez que possui ação tamponante; sua quantidade nos músculos é um fator determinante para o desempenho em exercícios de alta intensidade [59]. O produto DDM Carnosina ${ }^{\circledR}$ (Omeopiacenza, Pharma Group) foi desenvolvido para se ter uma liberação controlada da carnosina ao longo de 8 h. A maior liberação de carnosina ocorre durante a contração muscular, e ela é imediatamente hidrolisada no soro pela enzima carnosinase, sugerindo assim que atletas precisam ingerir maior quantidade de carnosina [54].

A carnosina apresenta três valores de constante de equilíbrio ácido $\left(p K_{a}\right): p K_{a 1}=$ 2,$64 ; p K_{a 2}=6,83 ; p K_{a 3}=9,51$ [53]. As estruturas em equilíbrio estão representadas na Figura 1.17.<smiles>NCCC(=O)NC(Cc1c[nH]cn1)C(=O)O</smiles><smiles>CC(C)O</smiles>

$\mathrm{H}^{+}$

$$
\frac{\mathrm{H}^{+}}{\mathrm{pK}_{\mathrm{a} 3}}
$$<smiles>NCCC(=O)NC(Cc1c[nH]c[nH+]1)C(=O)[O-]</smiles><smiles></smiles><smiles>NCCC(=O)NC(Cc1c[nH]cn1)C(=O)[O-]</smiles>

Figura 1.17: Equações químicas referentes à desprotonação da L-Carnosina.

\subsubsection{L-Ornitina}

A L-ornitina é um aminoácido de grande importância para o organismo. Sua estrutura está ilustrada na Figura 1.18.

A L-ornitina apresenta três valores de constante de equilíbrio ácido $\left(p K_{a}\right): p K_{a 1}=$ 1,$94 ; p K_{a 2}=8,65 ; p K_{a 3}=10,76$ [53]. Pode-se observar na Figura 1.19 as estruturas em equilíbrio ácido-base.

A L-ornitina desempenha papel central no ciclo da ureia, permitindo a liberação do 
<smiles>NCCC[C@H](N)C(=O)O</smiles>

b)

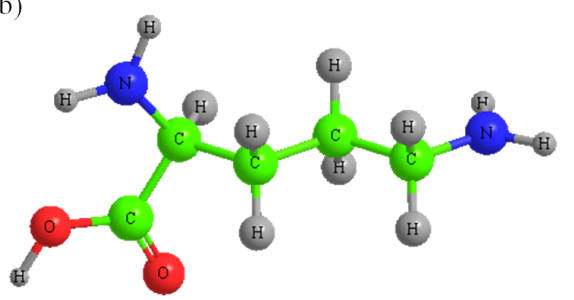

Figura 1.18: Estrutura do aminoácido L-Ornitina: a) Representação em forma de bastão e b) Representação tridimensional.<smiles>NCCC[C@H](N)C(=O)O</smiles><smiles></smiles><smiles>NCCC[C@H]([NH3+])C(=O)O</smiles>
$\mathrm{H}^{+} \| \mathrm{pK} \mathrm{a}_{\mathrm{a} 2}$<smiles>NCCC[C@H](N)C(=O)O</smiles><smiles>NCCC[C@H](N)C(=O)O</smiles>

Figura 1.19: Equações químicas referentes à desprotonação da L-Ornitina.

excesso de nitrogênio; essa molécula também promove a liberação do hormônio de crescimento ao estimular a glândula pituitária. A L-ornitina é gerada na ação da enzima arginase sobre a L-arginina [60], como pode ser observada na Figura 1.20 [61]. Esse aminoácido já é comercializado como suplemento dietético e empregado na prática clínica para o tratamento de encefalopatia hepática [62]. 


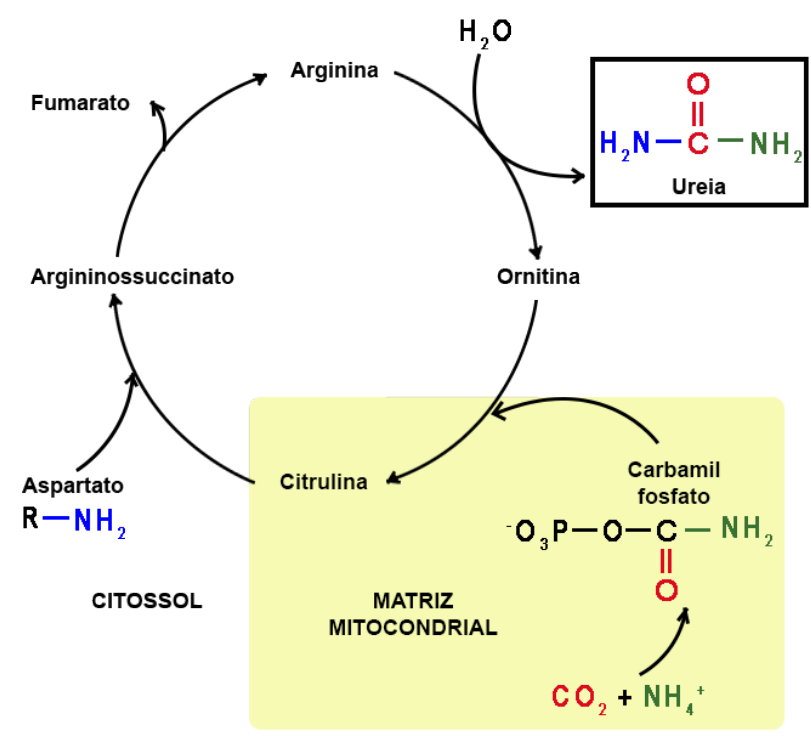

Figura 1.20: Ciclo da ureia.

\subsubsection{L-Arginina}

Um dos aminoácidos mais versáteis metabolicamente é a L-arginina [63], cuja estrutura pode ser observada na Figura 1.21. Ela pode formar o óxido nítrico, a L-citrulina, a L-ornitina, ureia e dióxido de carbono, entre outras moléculas bioativas. Desempenha também papel importante na aprendizagem e no desempenho da memória, mas pode ser neurotóxico em quantidades excessivas. O envelhecimento altera os níveis de L-arginina e seus metabólitos, e também diminui sua interação nas subregiões do hipocampo, do cortéx entorrinal, do cortéx perirrinal e do córtex pré-frontal [63].
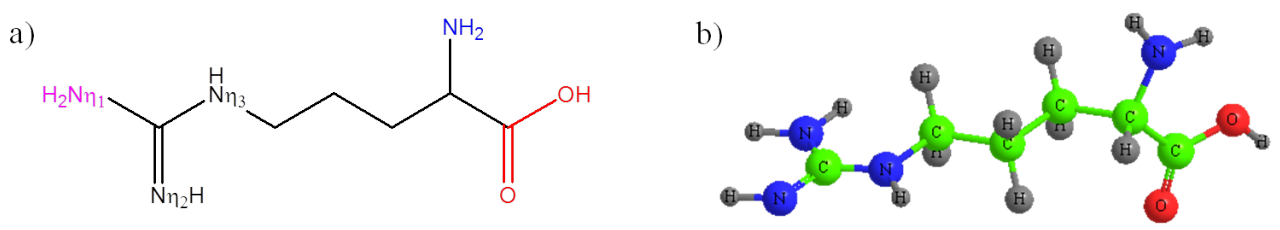

Figura 1.21: Estrutura do aminoácido L-Arginina: a) Representação em forma de bastão e b) Representação tridimensional.

A L-arginina é um aminoácido que possui o grupo R (grupo guanidina) carregado positivamente em meio fisiológico. Esse aminoácido apresenta três valores de constante de equilíbrio ácido: $p K_{a 1}=2,17 ; p K_{a 2}=9,04 ; p K_{a 3}=12,48$ [52]. Seus equilíbrios ácidos-base podem ser observados na Figura 1.22. 


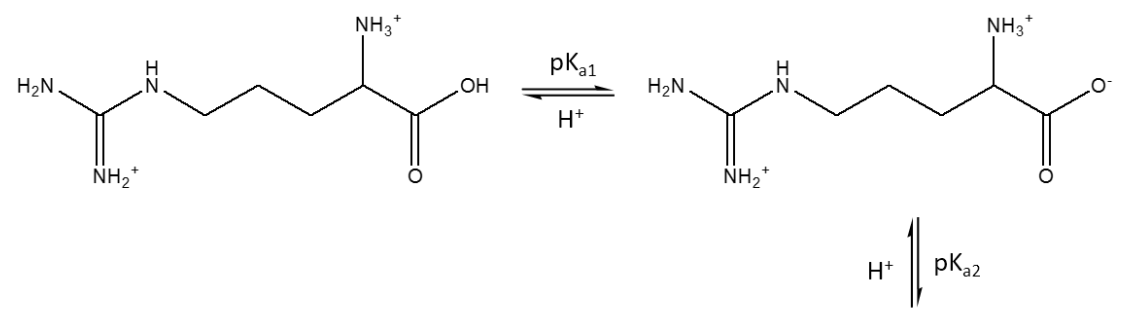<smiles>N=C(N)NCCCC(N)C(=O)O[14c]1[14cH][14cH][14cH][14cH][14cH]1</smiles>

Figura 1.22: Equações químicas referentes à desprotonação da L-Arginina.

Há estudos sobre a melhora do desempenho físico ao se incluir na dieta do atleta a L-arginina [64]. Ela também desempenha um importante papel na desintoxicação de amônia, através do ciclo da ureia, transformando-a em ureia. As principais fontes desse aminoácido são as proteínas da dieta [65].

\subsubsection{L-Lisina}

A L-Lisina, representada na Figura 1.23, é um aminoácido hidrofílico devido à sua cadeia lateral muito polar (sua cadeia lateral e a da arginina são as mais longas no conjunto dos vinte aminoácidos codificados). É um aminoácido essencial, encontrado na constituição de enzimas e proteínas, essencial para o crescimento normal de crianças e na manutenção do equilíbrio de nitrogênio no corpo. Além de ajudar o organismo a absorver e a conservar o cálcio, a L-lisina é um dos componentes dos ossos, cartilagens e outros tecidos conectivos. Esse aminoácido também pode prevenir acidentes vasculares cerebrais, entre outros estresses induzidos por patologias [66, 67, 68].
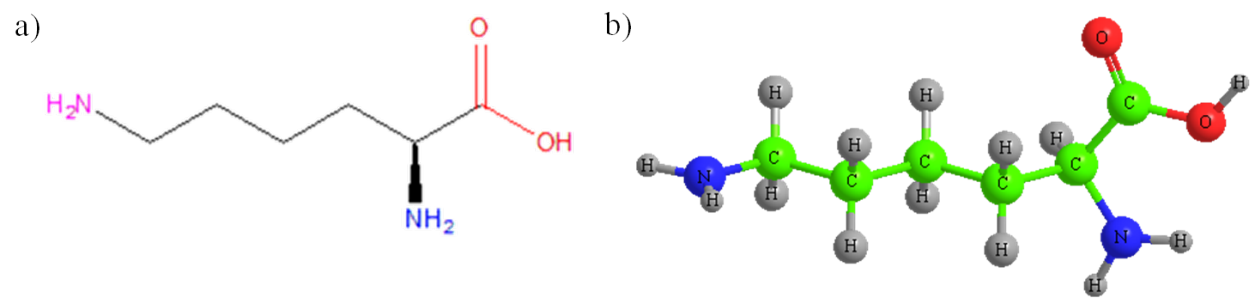

Figura 1.23: Estrutura do aminoácido L-Lisina: a) Representação em forma de bastão e b) Representação tridimensional.

A L-lisina também tem um potencial terapêutico para a profilaxia de herpes. A herpes 
simplex vírus l (HSV-1) é uma das doenças virais mais comuns entre os humanos, mas ainda não existe tratamento que impeça sua recorrência. Inúmeros estudos têm sugerido a lisina e a arginina como possíveis agentes terapêuticos contra o HSV-1.

A L-lisina apresenta três valores de constante de equilíbrio ácido $\left(p K_{a}\right): p K_{a 1}=2,18$; $p K_{a 2}=8,95 ; p K_{a 3}=10,5$ [52]. As espécies totalmente protonadas da L-lisina , com carga líquida positiva igual a 2, exitem em pH menor que 2. À medida que o pH aumenta, o primeiro passo de desprotonação ocorre no grupo ácido carboxílico $\left(p K_{a 1}=2,18\right)$, fazendo com que o aminoácido fique com uma carga total igual a +1 . Em $\mathrm{pH}$ fisiológico, esse aminoácido tem carga positiva. A segunda desprotonação $\left(p K_{a 2}=8,95\right)$ leva à formação da sua forma zwitteriônica. A terceira desprotonação $\left(p K_{a 3}=10,5\right)$ deixa a L-lisina com carga líquida negativa. As equações químicas envolvendo esses equilíbrios podem ser observadas na Figura 1.24.<smiles>NCCCC[C@H](N)C(=O)O</smiles><smiles>NCCCC[C@H](N)C(=O)OC=CNCCCC[C@H](N)C(=O)O</smiles>

Figura 1.24: Equações químicas referentes à desprotonação da L-Lisina.

Na Tabela 1.2 encontram-se os valores de $p K_{a} s$ das quatro espécies em foco neste trabalho e seu ponto isoelétrico, pH em que o aminoácido encontra-se com carga líquida igual a zero. 
Tabela 1.2: Valores de constante de equilíbrio ácido $\left(p K_{a}\right)$ e do ponto isoelétrico (pI) do dipeptídeo L-Carnosina e dos aminoácidos L-Ornitina, L-Arginina e L-Lisina.

\begin{tabular}{cccccc}
\hline \multirow{2}{*}{ Aminoácido } & $\begin{array}{c}p K_{a 1} \\
\text { Grupo Carboxílico }\end{array}$ & $\begin{array}{c}p K_{a 2} \\
\text { Imidazol }\end{array}$ & $\begin{array}{c}p K_{a 2} \\
\text { Grupo } \alpha \text {-Amino }\end{array}$ & $\begin{array}{c}p K_{a 3} \\
\text { Grupo Cadeia Lateral (R) }\end{array}$ & pI \\
\hline \hline L-Carnosina & 2,64 & 6,83 & & 9,51 & 6,33 \\
\hline L-Ornitina & 1,94 & & 8,65 & 10,76 & 7,11 \\
\hline L-Arginina & 2,17 & & 9,04 & 12,48 & 10,76 \\
\hline L-Lisina & 2,18 & & 8,95 & 10,5 & 9,74 \\
\hline
\end{tabular}




\section{Capítulo 2}

\section{OBJETIVOS}

O principal objetivo do presente trabalho é preparar e caracterizar argilas de uso farmacêutico e/ou cosmético, como a Laponita RD, Veegum HS e Cloisita Sódica, intercaladas com espécies que apresentam potencial terapêutico como o dipeptídeo L-carnosina e os aminoácidos L-lisina, L-arginina e L-ornitina.

Os objetivos específicos são os seguintes:

(i) Investigar condições experimentais para a imobilização do dipeptídeo e dos aminoácidosdas em argilas de uso farmacêutico e/ou cosmético;

(ii) Caracterizar os materiais híbridos através de análise química, análise térmica, difratometria de raios X, espectroscopia vibracional no infravermelho e Raman e medidas de tamanho de partículas e de potencial Zeta. 


\section{Capítulo 3}

\section{MATERIAIS E MÉTODOS}

\subsection{Materiais e Reagentes}

Os materiais e os reagentes utilizados nos procedimentos experimentais estão listados nas Tabelas 3.1 e 3.2. Nenhum reagente foi purificado previamente.

Tabela 3.1: Argilas utilizadas nos experimentos de imobilização do dipeptídeo e dos aminoácidos.

\begin{tabular}{|c|c|c|c|c|}
\hline Argila & Procedência & $\begin{array}{c}\mathrm{CTC} / \\
\mathrm{mmol}_{c} / 100 \mathrm{~g}\end{array}$ & $\begin{array}{c}\text { Composição Química / } \\
\text { \% em massa }\end{array}$ & Ref \\
\hline Cloisita $\mathrm{Na}^{+}$ & Bentonit União Nordeste & 92 & $\begin{array}{c}\mathrm{SiO}_{2}=60,14 \\
\mathrm{Al}_{2} \mathrm{O}_{3}=23,34 \\
\mathrm{Fe}_{2} \mathrm{O}_{3}=4,10 \\
\mathrm{MgO}=2,05 \\
\mathrm{Na}_{2} \mathrm{O}=2,37\end{array}$ & {$[69]$} \\
\hline Veegum HS & R.T. Vanderbilt Company ${ }^{\circledR}$ & 80 & $\begin{array}{c}\mathrm{SiO}_{2}=64,8 \\
\mathrm{Al}_{2} \mathrm{O}_{3}=15,2 \\
\mathrm{Fe}_{2} \mathrm{O}_{3}=2 \\
\mathrm{MgO}=2,2 \\
\mathrm{Na}_{2} \mathrm{O}=2,28\end{array}$ & {$[70]$} \\
\hline Laponita RD & Bentonit União Nordeste & 50 & $\begin{array}{c}\mathrm{SiO}_{2}=66,2 \\
\mathrm{MgO}=30,2 \\
\mathrm{Na}_{2} \mathrm{O}=2,9 \\
\mathrm{Li}_{2} \mathrm{O}=0,7\end{array}$ & {$[71]$} \\
\hline
\end{tabular}

Embora a L-carnosina seja um dipeptídeo, a seguir esse composto será classificado neste trabalho como um aminoácido para simplificar o texto escrito. 
Tabela 3.2: Reagentes utilizados nos experimentos de imobilização do dipeptídeo e dos aminoácidos com argilas.

\begin{tabular}{cccc}
\hline Reagente & Composição & Procedência & Grau de Pureza $/ \%$ \\
\hline \hline L-carnosina & $\mathrm{C}_{9} \mathrm{H}_{14} \mathrm{~N}_{4} \mathrm{O}_{3}$ & Sigma-Aldrich & ${ }^{\circledR}$ \\
\hline L-arginina & $\mathrm{C}_{6} \mathrm{H}_{14} \mathrm{~N}_{4} \mathrm{O}_{2}$ & Sigma-Aldrich $^{\circledR}$ & 99 \\
\hline Cloridrato de L-lisina & $\mathrm{C}_{6} \mathrm{H}_{14} \mathrm{~N}_{2} \mathrm{O}_{2} \cdot \mathrm{HCl}$ & Merck $^{\circledR}$ & 98 \\
\hline Cloridrato de L-ornitina & $\mathrm{C}_{5} \mathrm{H}_{12} \mathrm{~N}_{2} \mathrm{O}_{2} \cdot \mathrm{HCl}$ & Sigma-Aldrich $^{\circledR}$ & 99 \\
\hline Nitrato de Prata & $\mathrm{AgNO}$ & Merck $^{\circledR}$ & 99 \\
\hline Ácido Clorídrico & $\mathrm{HCl}$ & Synth $^{\circledR}$ & $>99,8$ \\
\hline
\end{tabular}

\subsection{Intercalação de aminoácidos em Cloisita Sódica}

Para a preparação dos materiais híbridos com a argila natural Cloisita $\mathrm{Na}^{+}$, realizouse inicialmente um teste em uma estação de trabalho com um carrossel para doze tubos de ensaio de $50 \mathrm{~mL}$. Usou-se a proporção molar argila:aminoácido de $1: 1$ para todas as amostras, considerando-se a CTC da Cloisita $\mathrm{Na}^{+}\left(92 \mathrm{mmol}_{c} / 100 \mathrm{~g}\right)$. Foram feitas dispersões de $0,200 \mathrm{~g}$ de argila em $20,0 \mathrm{~mL}$ de água deionizada (logo, a concentração da suspensão era $1 \%(\mathrm{~m} / \mathrm{v}))$, essa dispersão foi deixada por 1 hora sub agitação mecânica, sendo que o pH foi ajustado para 6,5 e 4 pela adição de solução de $\mathrm{HCl}$ (cada pH representa um sistema). Em paralelo, foi dissolvida a massa correspondente ao valor estequiométrico de cada aminoácido em 20,0 $\mathrm{mL}$ de água deionizada. Depois foi feita a adição da solução de aminoácido à dispersão de argila. O sistema foi mantido sob agitação por $24 h$ à temperatura ambiente; o sólido foi isolado com a ajuda de centrífuga.

A partir desse teste continuaram-se os experimentos com a Cloisita e os aminoácidos que apresentaram melhores resultados. Em um béquer, 1, $000 \mathrm{~g}$ de argila Cloisita $\mathrm{Na}^{+}$foi suspensa em 150, $0 \mathrm{~mL}$ de água deionizada e foi mantida sob agitação até que a argila estivesse totalmente dispersa. $\mathrm{O}$ valor de $\mathrm{pH}$ para essa suspensão foi de aproximadamente 8,9. Após a adição de $50 \mathrm{~mL}$ da solução do aminoácido à dispersão da argila, houve a adição de ácido clorídrico para o ajuste do pH ao valor desejado. Após isso, os sistemas foram deixados sob agitação por 24 ou $48 h$ à temperatura ambiente. Todos os valores das variáveis experimentais encontram-se na Tabela 3.3.

A abreviação dada aos materiais obtidos está de acordo com a ordem cronológica de 
Tabela 3.3: Resumo das condições experimentais empregadas para os sistemas com a Cloisita $N a^{+*}$.

\begin{tabular}{ccccc}
\hline \multirow{2}{*}{ Amostra } & \multirow{2}{*}{ Aminoácido } & \multicolumn{2}{c}{ Proporção } & $\mathrm{pH}$ (final \\
& & Argila $/$ Aminoácido & da suspensão) & $\begin{array}{c}\text { Tempo de Agitação } \\
\text { (horas) }\end{array}$ \\
\hline \hline CloLys1 & Lisina & $1: 1$ & 2,66 & 24 \\
\hline CloLys2 & Lisina & $1: 2$ & 2,67 & 24 \\
\hline CloLysp4 & Lisina & $1: 1$ & 4,09 & 24 \\
\hline CloLyp6 & Lisina & $1: 1$ & 6,63 & 24 \\
\hline CloLysS & Lisina & $1: 2$ & 7,52 & 24 \\
\hline CloArg1 & Arginina & $1: 1$ & 3,25 & 24 \\
\hline CloArg2 & Arginina & $1: 2$ & 3,32 & 24 \\
\hline CloArgp4 & Arginina & $1: 1$ & 9,60 & 48 \\
\hline CloArgS & Arginina & $1: 2$ & 9,54 & 24 \\
\hline CloCar1 & Carnosina & $1: 1$ & 3,46 & 24 \\
\hline CloCarp5 & Carnosina & $1: 1$ & 8,12 & 24 \\
\hline CloOrtp4 & Ornitina & $1: 1$ & 4,81 & 48 \\
\hline CloOrtp6 & Ornitina & $1: 1$ & 6,99 & 4,25 \\
\hline CloOrt1 & Ornitina & $1: 2$ & & \\
\hline
\end{tabular}

*Todos os experimentos foram realizados à temperatura ambiente.

preparação. A primeira parte da abreviação está relacionada ao nome da argila (Clo: Cloisita, Veg: Veegum, Lap: Laponita), a segunda parte é a abreviação do aminoácido usado (Lys: lisina, Arg: arginina, Car: carnosina, Ort: ornitina), os números e a letra S que se seguem estão relacionados, respectivamente, à ordem cronológica e ao procedimento realizado sem o ajuste do valor do $\mathrm{pH}$ (ou seja, S significa que não houve ajuste). Para as amostras feitas como teste, usou se a letra "p" e um número após a abreviação do aminoácido para indicar o valor do pH inicial da reação de troca iônica.

No caso da L-lisina e da L-arginina, que se encontram na forma catiônica quando dissolvidas em água, também realizou-se um experimento sem ajuste de pH. Para isso 1, $000 \mathrm{~g}$ de argila foi disperso em 150, $0 \mathrm{~mL}$ de água deionizada e em seguida foi adicionado 50, $0 \mathrm{~mL}$ de solução do aminoácido, de modo a se obter a relação 1:2 de argila:aminoácido. O sistema foi deixado sob agitação mecânica por $48 h$ à temperatura ambiente.

Todas as suspensões foram centrifugadas a $15.000 \mathrm{rpm}$ durante $7 \mathrm{~min}$ e o sobrenadante foi descartado. O sólido foi lavado com $20 \mathrm{~mL}$ de água deionizada e então separado mais uma vez por centrifugação. Repetiu-se esse procedimento por três vezes, até que o teste para íons cloreto desse negativo. O sólido separado foi seco à pressão reduzida na presença 
de sílica gel.

O resumo de todas as condições experimentais empregadas durante a preparação dos materiais híbridos com Cloisita $\mathrm{Na}^{+}$se encontra na Tabela A.1 (Apêndice A).

\subsection{Intercalação de aminoácidos em Veegum HS}

Com a argila natural Veegum HS também se fez um estudo em batelada utilizando a estação de trabalho com um carrossel para doze tubos de ensaio de 50,0 $\mathrm{mL}$. Da mesma forma, usou-se a proporção argila:aminoácido de 1:1 para todas as amostras (proporção em relação à CTC da Veegum HS, $80 \mathrm{mmol}_{c} / 100 \mathrm{~g}$ ). Foram feitas dispersões de $0,200 \mathrm{~g}$ de argila em 20, 0 mL de água deionizada, logo, a concentração da suspensão era 1 \% (m/v), essa dispersão foi deixada por 1 hora sub agitação mecânica, sendo que os valores de pH foram ajustados para 6, 5 e 4 (cada $\mathrm{pH}$ representa um sistema). Em paralelo, foi dissolvido o correspondente estequiométrico (argila:aminoácido) de massa de cada aminoácido em 20, $0 \mathrm{~mL}$ de água deionizada. Depois foi feita então a mistura da solução de aminoácido à dispersão de argila, a mistura foi agitada por $24 h$ à temperatura ambiente.

O estudo experimental com o dipeptídeo L-carnosina foi mais extenso com essa argila e está descrito a seguir. Em um béquer, 1,000 g de argila Veegum HS foi suspensa em 150, 0 mL de água deionizada e mantida sob agitação. $\mathrm{O}$ pH da dispersão de argila foi ajustado com uma solução de $\mathrm{HCl} 0,1$ mol. $L^{-1}$. Em outro béquer, a massa de carnosina correspondente a proporção 1:2 argila:aminoácido foi dissolvida em 50, $0 \mathrm{~mL}$ de água deionizada e seu pH também foi ajustado. Após à adição da solução de aminoácido à dispersão de argila, também foi necessário a adição da solução de ácido para ajustar o pH ao valor desejado. Após isso, os sistemas foram deixados sob agitação por 24 ou $48 h$. Todos os valores das variáveis experimentais empregadas encontram-se na Tabela 3.4.

Os sistemas L-lisina e L-arginina seguiram o mesmo procedimento descrito acima para a argila Cloisita $\mathrm{Na}^{+}$. Dispersou-se $1,000 \mathrm{~g}$ de argila em 150, $0 \mathrm{~mL}$ de água deionizada e em seguida foi adicionado o aminoácido, na relação 1:2 de argila:aminoácido em relação à CTC da argila. O sistema foi deixado sob agitação mecânica por $48 h$. Todos os experimentos foram realizados à temperatura ambiente. 
Para as suspensões com a argila Veegum HS também usou-se centrifugação como método de separação. As amostras foram lavadas três vezes com $20 m L$ de água deionizada, após cada lavagem centrifugou-se a $15.000 \mathrm{rpm}$ durante $7 \mathrm{~min}$; o sobrenadante foi descartado. Em seguida a amostra foi seca à pressão reduzida na presença de sílica gel.

Os valores dos diferentes parâmetros experimentais utilizados para as reações entre Veegum HS e os aminoácidos encontram-se na Tabela 3.4.

Tabela 3.4: Resumo das condições experimentais empregadas para os sistemas com a Veegum $H S^{*}$.

\begin{tabular}{ccccc}
\hline Amostra & Aminoácido & $\begin{array}{c}\text { Proporção } \\
\text { Argila }\end{array}$ & $\begin{array}{c}\mathrm{pH} \text { (final } \\
\text { da suspensão) }\end{array}$ & $\begin{array}{c}\text { Tempo de Agitação } \\
\text { (horas) }\end{array}$ \\
\hline \hline VegLysp4 & Lisina & $1: 1$ & 4,32 & 24 \\
\hline VegLysp6 & Lisina & $1: 1$ & 5,55 & 24 \\
\hline VegLysS & Lisina & $1: 2$ & 7,39 & 48 \\
\hline VegArgp4 & Arginina & $1: 1$ & 9,64 & 24 \\
\hline VegArgS & Arginina & $1: 2$ & 9,93 & 48 \\
\hline VegCar4 & Carnosina & $1: 2$ & 4,50 & 24 \\
\hline VegCar6 & Carnosina & $1: 2$ & 3,15 & 42 \\
\hline VegCar7 & Carnosina & $1: 2$ & 5,02 & 24 \\
\hline VegCarp4 & Carnosina & $1: 1$ & 8,07 & 24 \\
\hline VegOrtp4 & Ornitina & $1: 1$ & 4,17 & 24 \\
\hline VegOrtp5 & Ornitina & $1: 1$ & 4,95 & 48 \\
\hline VegOrt1 & Ornitina & $1: 2$ & 4,18 & \\
\hline
\end{tabular}

*Todos os experimentos foram realizados à temperatura ambiente.

O resumo de todas as condições experimentais empregadas durante a preparação dos materiais híbridos com Veegum HS se encontra na Tabela A.2 (Apêndice A).

\subsection{Intercalação de aminoácidos em Laponita RD}

Uma parte dos experimentos com a argila sintética Laponita RD foi feita em batelada utilizando a estação de trabalho com um carrossel para doze tubos de ensaio de 50, $0 \mathrm{~mL}$. Assim como para as argilas Cloisita $\mathrm{Na}^{+}$e Veegum HS, nesse estudo em batelada, usou-se a proporção argila:aminoácido de 1:1 para todas as amostras, considerando-se a CTC da Laponita RD $\left(50 \mathrm{mmol}_{c} / 100 \mathrm{~g}\right)$. Foram feitas dispersões de $0,200 \mathrm{~g}$ de argila em $20,0 \mathrm{~mL}$ de água deionizada (logo, a concentração da suspensão era de $1 \%(\mathrm{~m} / \mathrm{v})$ ), essa dispersão foi deixada por 30 hora sub agitação mecânica; o valor de pH foi ajustado para 2 ou 7, 
mas esses valores não ficaram estáveis em função do tempo, havia um consumo de prótons ao longo do experimento e os valores de $\mathrm{pH}$ aumentaram (os valores dos $\mathrm{pH}$ de reação encontram-se na Tabela 3.5). Logo após, foi dissolvido o correspondente estequiométrico de massa de cada aminoácido em 20, $0 \mathrm{~mL}$ de água deionizada. Foi feita então a mistura da solução de aminoácido à dispersão de argila. O sistema precisou ser deixado por $96 h$ sob agitação, pois nas primeiras $24 h$ houve separação de fases nos tubos. Para a remoção dos íons cloreto, provenientes da solução de $\mathrm{HCl}$ utilizada para modificar o pH, usou-se uma membrana de diálise, seamless cell com faixa de corte de massa molecular entre 12.000 e 14.000 da Viskase Corporation.

O estudo experimental com o dipeptídeo L-carnosina e o aminoácido L-ornitina com a argila Laponita RD foi mais extenso, conforme mencionado a seguir.

Dispersou-se 1, $000 \mathrm{~g}$ de argila Laponita RD em 150, $0 \mathrm{~mL}$ de água deionizada sob agitação até que a argila estivesse totalmente dispersa. A solução de 50, $0 \mathrm{~mL}$ do dipeptídeo L-carnosina (ou do aminoácido L-ornitina) foi acrescentado à dispersão de argila e o pH do sistema foi ajustado com uma solução de $\mathrm{HCl}$ 0,1 mol. $L^{-1}$. Os sistemas foram deixados sob agitação por 24 ou $48 h$. Todos os valores das variáveis experimentais encontram-se na Tabela 3.5. Para uma amostra com L-Carnosina foi realizado um estudo com aumento de temperatura. Para isso 1, $000 \mathrm{~g}$ de argila foi dispersa em 150, $0 \mathrm{~mL}$ de água deionizada sob agitação, e o pH foi ajustado para 6,57. Em outro béquer, a massa de carnosina correspondente a proporção 1:2 argila:aminoácido foi dissolvida em $50,0 \mathrm{~mL}$ de água deionizada e o pH da solução também foi ajustado para 6,63. Misturou-se a solução do aminoácido à dispersão da argila e começou-se o aquecimento a $60{ }^{\circ} \mathrm{C}$. O sistema foi deixado sob aquecimento e agitação mecânica por $6 h$.

Da mesma forma que para as argilas anteriores, realizou-se um experimento com a L-lisina e L-arginina sem ajuste de $\mathrm{pH}$, seguindo o mesmo procedimento usado com a argila Cloisita $\mathrm{Na}^{+}$. Dispersou-se 1, $000 \mathrm{~g}$ de argila em 150, $0 \mathrm{~mL}$ de água deionizada e em seguida foi adicionado 50,0 $\mathrm{mL}$ da solução do aminoácido, de modo a se obter a relação 1:2 de argila:aminoácido. O sistema foi deixado sob agitação mecânica por $48 h$.

As suspensões foram colocadas em membrana de diálise submersa em água deionizada. 
Está água foi trocada até que o teste para íons cloreto desse negativo. Congelaram-se essas suspensões e, por liofilização, secaram-se as amostras.

Os valores dos diferentes parâmetros experimentais utilizados para as reações entre Laponita RD e os aminoácidos encontram-se na Tabela 3.5.

Tabela 3.5: Resumo das condições experimentais empregadas para os sistemas com a Laponita $R D$.

\begin{tabular}{cccccc}
\hline Amostra & Aminoácido & $\begin{array}{c}\text { Proporção } \\
\text { Argila / Aminoácido }\end{array}$ & $\begin{array}{c}\mathrm{pH} \text { (final } \\
\text { da suspensão) }\end{array}$ & $\begin{array}{c}\text { Tempo de Agitação } \\
\text { (horas) }\end{array}$ & Temperatura \\
\hline \hline LapLysp2 & Lisina & $1: 1$ & 6,82 & 96 & Ambiente \\
\hline LapLysp7 & Lisina & $1: 1$ & 7,61 & 96 & Ambiente \\
\hline LapLysS & Lisina & $1: 2$ & 8,31 & 48 & Ambiente \\
\hline LapArgp2 & Arginina & $1: 1$ & 6,84 & 96 & Ambiente \\
\hline LapArgp9 & Arginina & $1: 1$ & 8,91 & 96 & Ambiente \\
\hline LapArgS & Arginina & $1: 2$ & 10,18 & 48 & Ambiente \\
\hline LapCar1 & Carnosina & $1: 1$ & 6,00 & 24 & Ambiente \\
\hline LapCar2 & Carnosina & $1: 3$ & 6,10 & 24 & Ambiente \\
\hline LapCar4 & Carnosina & $1: 3$ & 6,90 & 6 & $60{ }^{\circ} \mathrm{C}$ \\
\hline LapOrtp2 & Ornitina & $1: 1$ & 6,86 & 96 & Ambiente \\
\hline LapOrtp7 & Ornitina & $1: 1$ & 7,71 & 96 & Ambiente \\
\hline LapOrt2 & Ornitina & $1: 2$ & 6,50 & 48 & Ambiente \\
\hline
\end{tabular}

O resumo de todas as condições experimentais empregadas durante a preparação dos materiais híbridos com Laponita RD se encontra na Tabela A.3 (Apêndice A).

As argilas precursoras e os produtos contendo os aminoácidos imobilizados nas argilas, foram caracterizados por difratometria de raios X, espectroscopia vibracional na região do infravermelho e análise térmica acoplada à espectrometria de massas. Para algumas amostras foram realizadas análise elementar $(\mathrm{CHN})$, medidas de potencial Zeta e de tamanho médio de partículas. Para a amostra LapCar2 foi possível registrar o espectro Raman.

\subsection{Técnicas de caracterização}

\subsubsection{Difratometria de raios $\mathrm{X}$}

Nas análises de difratometria de raios X com amostras na forma de pó (DRXP) foi utilizado um difratômetro Rigaku, modelo Miniflex, com comprimento de onda $\lambda$ de $1,54056 \AA$ gerados por um ânodo de $\mathrm{Cu}\left(K_{\alpha}\right)$, empregando tensão de $30 \mathrm{kV}$, corrente de $15 \mathrm{~mA}$ e filtro de Ni. Usou-se faixa de varredura $(2 \theta)$ de 1,5 a $70^{\circ}$ com passo de $0,03^{\circ}$ a cada 
segundo.

Os difratogramas para os materiais utilizando a Laponita RD como matriz inorgânica foram obtidos no Laboratório de Cristalografia do Instituto de Física da USP (IF-USP). Utilizou-se um difratômetro da marca Rigaku, modelo Ultima Plus, geometria BraggBrentano e monocromador de cristal de grafite. Para as medidas, utilizou-se uma tensão de $40 k V$ e corrente de $30 m A$, radiação $K \alpha$ de cobre. O ângulo $2 \theta$ foi variado de 1,5 a $70^{\circ}$, empregando tempo de contagem de $8 \mathrm{~s}$ a cada passo de $0,02^{\circ}$.

\subsubsection{Espectroscopia Vibracional no Infravermelho}

Para o registro dos espectros vibracionais na região do infravermelho, utilizou-se um aparelho FTIR-Bomem, modelo-MB, série 102. Os espectros foram obtidos na região de 4000 a $400 \mathrm{~cm}^{-1}$, com resolução de $4 \mathrm{~cm}^{-1}$, usando-se $\mathrm{KBr}$ para dispersar as amostras no acessório de reflectância difusa. Os dados foram fornecidos pelo equipamento como porcentagem de transmitância.

\subsubsection{Espectroscopia Raman}

Os espectros Raman foram registrados em um espectrômetro FT-Raman Bruker modelo RFS100/S, do Laboratório de Espectroscopia Molecular (IQ-USP), utilizando a linha de 1064 nm de um laser Nd:YAG.

\subsubsection{Análise Térmica acoplada à Espectrometria de Massas}

As análises térmicas foram realizadas em aparelho TGA-DSC modelo 490 PC Luxx, da Netzsch, acoplado a um espectrômetro de massas QMS 403C Aeolos. Como porta amostra foi utilizado cadinho de $\mathrm{Al}_{2} \mathrm{O}_{3}$. A análise foi realizada nas seguintes condições: ar sintético (marca Oxigás) como gás de purga a uma vazão de $50 \mathrm{~mL} \cdot \mathrm{min}^{-1}$, razão de aquecimento de $10{ }^{\circ} \mathrm{C} \cdot \mathrm{min}^{-1}$, partindo-se da temperatura ambiente até $1000{ }^{\circ} \mathrm{C}, N_{2}$ (marca Oxigás) como gás de proteção para a balança TGA-DSC a uma vazão de 20 mL.min ${ }^{-1}$. Para as amostras obtidas no teste (código com a letra p após a abreviação do nome da argila e do aminoácido), a razão de aquecimento foi $20{ }^{\circ} \mathrm{C} \cdot \mathrm{min}^{-1}$. 


\subsubsection{Análise Elementar}

As análises elementares $(\mathrm{CHN})$ foram realizadas na Central Analítica do Instituto de Química da Universidade de São Paulo em um equipamento Perkin Elmer modelo 2400.

\subsubsection{Medidas de Potencial Zeta e tamanho de partículas}

Os valores do potencial Zeta e tamanho médio de partículas foram determinados usando o equipamento ZetaSizer NanoZs da Malvern Instruments, Worcestershire, UK. As medidas foram realizadas a $25^{\circ} \mathrm{C}$.

Foram feitas suspensões de $0,1 \%(\mathrm{~m} / \mathrm{v})$. As suspensões foram tratadas por $30 \mathrm{~min}$ em equipamento de ultrassom modelo 8893 da Cole-Parmer e deixadas em repouso por $24 h$ antes das medidas. Retirou-se o sobrenadante de cada suspensão para efetuar a análise. Para as medidas de potencial Zeta da Laponita RD, preparou-se uma suspensão $1 \%(\mathrm{~m} / \mathrm{v})$, essa suspensão foi deixada por 30 minutos no Ultrassom e em repouso por somente 2 h. Para efetuar a medida foi coletado o sobrenadante.

\subsubsection{Outros Equipamentos}

Para a remoção da água dos produtos da reação de intercalação Laponita/aminoácido utilizou-se um liofilizador da Thermo Savant. O equipamento multitarefa para liofilização ("freeze drying") é constituído pelas seguintes partes: sistema de vácuo LyoPump VLP 195 FD, bomba de alto vácuo VLP 200, sistema de drenagem em aço inox Dda $110 G$, recirculador e filtro de óleo da bomba VPOF 110, filtro de gotículas de óleo da bomba EMF 10, sistema de retorno Gas Ballast GBORK. No equipamento há uma torre com 16 entradas, com válvulas e sistema de vedação.

Para a separação do sólido em suspensão, usou-se uma centrífuga Bench Top Centrifuge Z 383, Hermle Labortechnik GmbH, com rotor angular 220.78 VO2 (velocidade máxima: $15.000 \mathrm{rpm}$ ou $26.000 \mathrm{xg}$ ), volume: $6 x 85 \mathrm{~mL}$, massa: $140 \mathrm{~g}$ por cavidade, raio $10,3 \mathrm{~cm}$. A Ultra centrífuga refrigerada da Hermle de Alta Velocidade Z36HK, também foi utilizada para a separação do sólido das suspensões. 
Para as medidas de pH, utilizou-se um pHmetro Digimed - DM 20. A água deionizada utilizada nos procedimentos experimentais foi obtida em um deionizador Elga Purelab Máxima, resistividade de aproximadamente $18 \mathrm{M} \Omega \mathrm{x} \mathrm{cm}$. Para pesagem de reagentes e amostras, utilizou-se a balança Digital Marte AL-500, semi-analítica com precisão 0, $001 \mathrm{~g}$. 


\section{Capítulo 4}

\section{RESULTADOS E DISCUSSÃO}

\subsection{Imobilização de aminoácidos em Cloisita Sódica}

As condições experimentais empregadas nas preparações das amostras Cloisita/aminoácidos visavam promover a interação eletrostática entre a matriz inorgânica e a espécie orgânica através da reação de troca iônica, isto é, o cátion que ocupa a região interlamelar da argila é substituído pelo aminoácido na forma catiônica, como ilustra a Figura 1.7. Para a realização dos experimentos utilizou-se uma faixa de pH em que os aminoácidos estivessem protonados (valores na Tabela 1.2) com pelo menos uma carga positiva, possibilitando a interação eletrostática dos aminoácidos com as lamelas da argila.

Sabe-se que as cargas na superfície das argilas dependem do valor de pH da suspensão na qual elas se encontram dispersas. A Figura 1.13 ilustra as modificações (processos de protonação e desprotonação) que ocorrem em argilas esmectitas em função da alteração nos valores do $\mathrm{pH}$. Pode-se observar que embora os grupos silanol e aluminol sofram modificações quando o valor do pH é modificado, a carga elétrica das lamelas será negativa. Assim sendo, os valores de $\mathrm{pH}$ escolhidos nos experimentos contemplam, praticamente somente os equilíbrios ácido-base dos aminoácidos.

Tanto para as medidas de tamanho de partículas, quanto para as medidas de potencial Zeta prepararam-se suspensões aquosas estoque, de concentração igual a $0,1 \%(\mathrm{~m} / \mathrm{v})$. Para efetuar as medidas foi coletado o sobrenadante das suspensões. O valor do potencial Zeta da suspensão de Cloisita $0,1 \%(\mathrm{~m} / \mathrm{v})$ é - 42,5 $\mathrm{mV}(\sigma= \pm 1,40)$ para um valor de $\mathrm{pH}$ 
da suspensão de 8,9. Suspensões coloidais estáveis apresentam valores de potencial Zeta superior a $\pm 30 \mathrm{mV}$. Logo, o valor encontrado para a suspensão de Cloisita Sódica indica que se trata de um sistema estável. O diâmetro médio dessas partículas é igual a $183 \mathrm{~nm}$ $(\sigma= \pm 2,56$ e $P D I=0,33)$.

\subsubsection{L-Lisina em Cloisita Sódica}

A caracterização inicial da argila pristina e dos materiais híbridos foi feita por difratometria de raios X. A Figura 4.1 apresenta os difratogramas obtidos. O primeiro pico corresponde ao espaçamento basal $d_{(001)}$ da argila e o seu valor pode ser determinado aplicando a Equação de Bragg ${ }^{1}$. Quando há um aumento na distância entre as lamelas das argilas, o pico de difração se desloca para a região de menor ângulo.

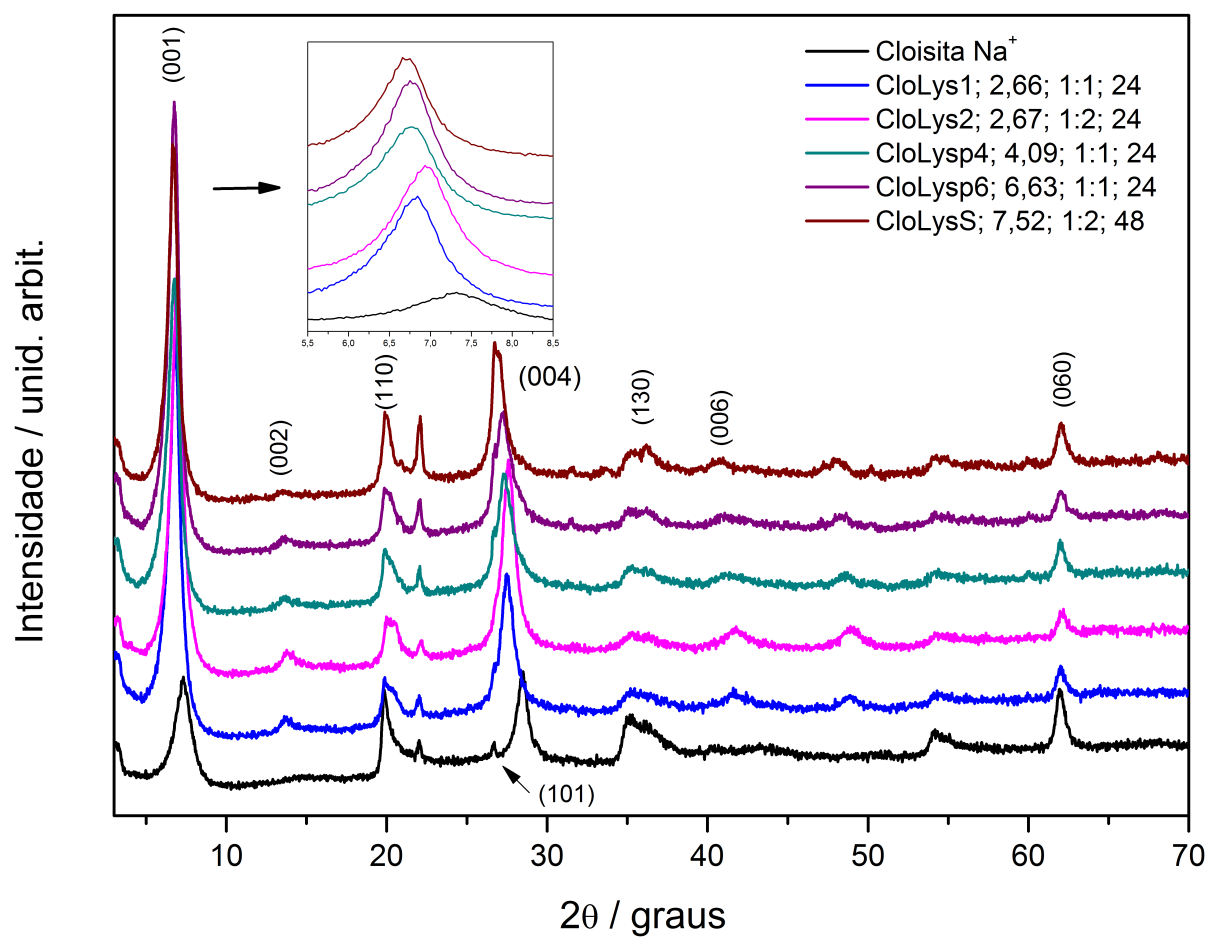

Figura 4.1: Difratogramas de raios $\mathrm{X}$ da Cloisita $\mathrm{Na}^{+}$e dos produtos das reaçôes da Cloisita $\mathrm{Na}^{+}$com o Cloridrato de L-Lisina. (Código: Identidade da amostra; pH final de reação; proporção molar de argila:aminoácido; tempo de reação).

\footnotetext{
${ }^{1} \mathrm{~A}$ Equação de Bragg é dada por $2 d \sin \theta=n \lambda$, onde $\mathrm{n}$ é um número inteiro, $\lambda$ é o comprimento de onda da radiação incidente, $d$ é a distância entre planos atômicos e $\theta$ é o ângulo de difração.
} 
Pelos difratogramas de raios X, observa-se que os picos da argila precursora são mantidos, isso significa que a estrutura mineralógica da Cloisita $\mathrm{Na}^{+}$é mantida. Observa-se também o surgimento de novos picos referente aos harmônicos (001). Na Tabela 4.1 estão os valores dos picos de difração de raios X da Cloisita Sódica e suas atribuições [72].

Tabela 4.1: Distância interplanar $d_{(h k l)}$ e valores de $2 \theta$ da argila Cloisita Sódica, obtidos dos dados de difratometria de raios $X$.

\begin{tabular}{ccc}
\hline $2 \theta /$ graus & $d / \AA$ & $($ hkl $)$ \\
\hline \hline 7,30 & 12,1 & $(001)$ \\
\hline 13,47 & 6,44 & $(002)$ \\
\hline 20,06 & 4,43 & $(110)$ \\
\hline 26,68 & 3,42 & $(101)$ \\
\hline 28,46 & 3,13 & $(004)$ \\
\hline 35,41 & 2,53 & $(130)$ \\
\hline 41,73 & 2,16 & $(006)$ \\
\hline 62,03 & 1,49 & $(060)$ \\
\hline
\end{tabular}

A partir dos cálculos teóricos das dimensões dos aminoácidos (calculadas pelo doutorando e mestre em Física, Filipe Dalmatti Lima, do Instituto de Física da USP (IF-USP), aluno da Professora Doutora Helena Maria Petrilli, a partir da estrutura de menor energia com o programa Accelrys Discovery Studio Visualizer 3.5., vide Figura A.2 do Anexo A) as dimensões calculadas para a L-lisina na forma neutra são 3,6 x 6,3 x 7,3 A. As dimensões para as formas protonadas ou desprotonadas do aminoácido não são modificadas de modo significativo, segundo cálculos teóricos (DFT). O difratograma de raios X da argila natural mostrou um valor de espaçamento interplanar $d_{(001)}$ de 12,1 $\AA$. Após a reação de imobilização com os aminoácidos, esses valores variaram entre 12,8 e 13,2 A (Tabela 4.2). O aumento no valor de $d_{(001)}$ indica que pode ter ocorrido a expansão da estrutura cristalina da montmorilonita devido à introdução do aminoácido, já que a menor dimensão do aminoácido L-lisina é $3,6 \AA$ e a espessura da camada TOT é 9,6 $\AA$ [8, 73]. Pode-se observar também que os novos materiais apresentam esse pico com maiores intensidades, isso é um indicativo de que os materiais formados estão melhor organizados, em relação ao empilhamento, do que a argila pristina.

A menor área ocupada por uma espécie de L-lisina com carga +1 é $23 \AA^{2}(3,6$ x 6,3 $=23)$ enquanto a maior área é $46 \AA^{2}(6,3 \times 7,3)$. Sabe-se que para as argilas montmori- 
Tabela 4.2: Distância interplanar $d_{(001)}$ dos materiais obtidos pela reação de imobilização do Cloridrato de L-Lisina em Cloisita.

\begin{tabular}{ccc}
\hline Amostra & $2 \theta /$ graus & $d_{(001)} / \AA$ \\
\hline \hline Cloisita & 7,30 & 12,1 \\
\hline CloLys1 & 6,84 & 12,9 \\
\hline CloLys2 & 6,93 & 12,8 \\
\hline CloLysp4 & 6,75 & 13,1 \\
\hline CloLysp6 & 6,75 & 13,1 \\
\hline CloLysS & 6,70 & 13,2 \\
\hline
\end{tabular}

lonitas, 1 elétron ocupa aproximadamente $130 \AA^{2}$ [12], logo um cátion monovalente desse aminoácido pode adotar um arranjo tanto paralelo quanto perpendicular em relação às lamelas. Duas das possibilidades de orientação da L-lisina entre as lamelas são ilustras na Figura 4.2. Considerando os valores de espaçamento basal calculados através dos dados de DRX (Tabela 4.2), pode-se inferir que o aminoácido está orientado paralelamente em relação às lamelas.



Figura 4.2: Possibilidades dos arranjos da L-Lisina entre as lamelas da Cloisita.

Na Figura 4.3 estão mostrados os espectros vibracionais na região do infravermelho (FTIR) de todas as amostras isoladas relativas ao sistema Cloisita/L-lisina. Para a melhor interpretação dos resultados, foram adicionados os espectros do aminoácido L-lisina 
e da argila Cloisita $\mathrm{Na}^{+}$. A espectroscopia na região do infravermelho é uma técnica analítica usada extensivamente, pois é uma técnica econômica e rápida e é um método complementar à difração de raios X para investigar argilas.

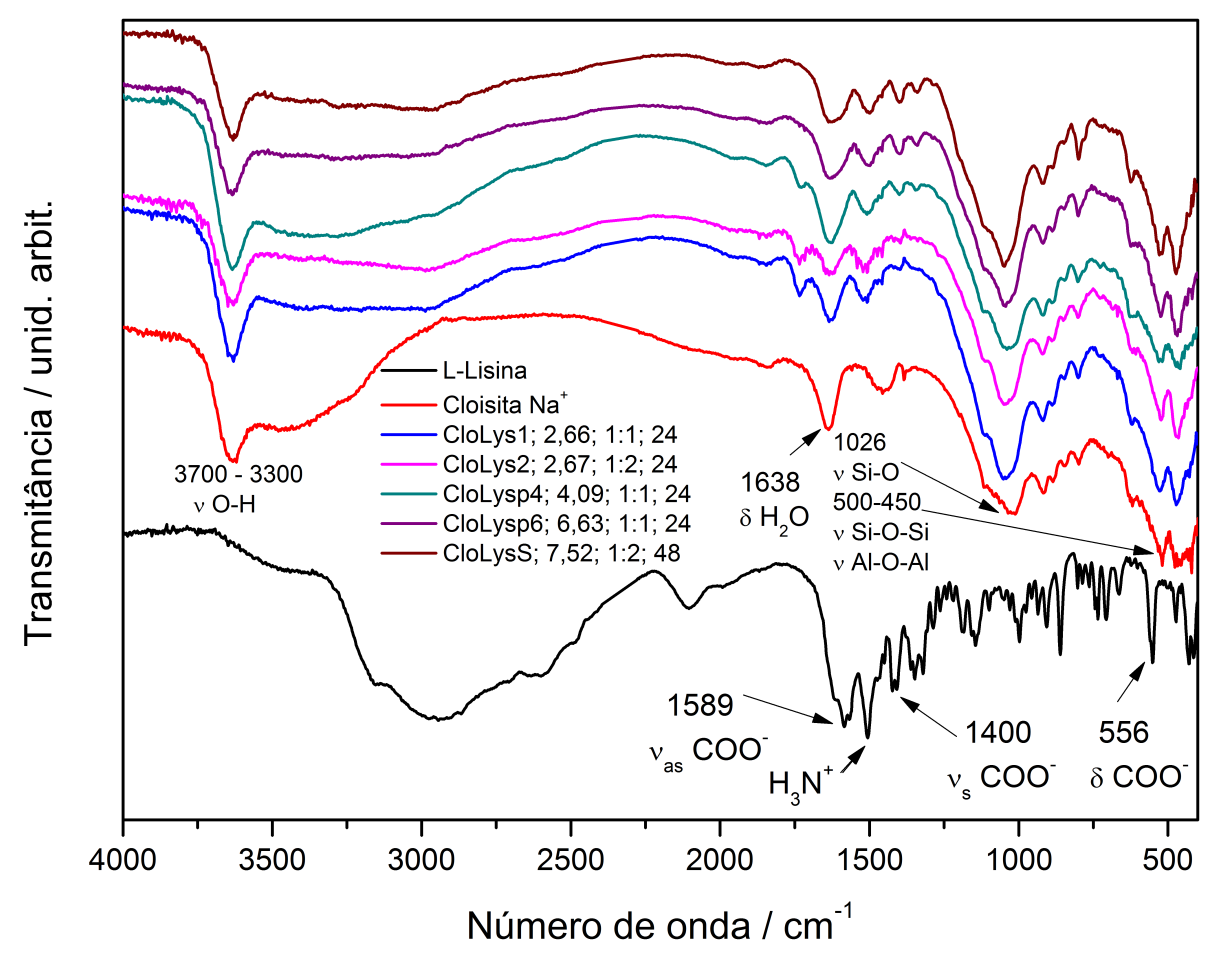

Figura 4.3: Espectros vibracionais na região do Infravermelho do Cloridrato de L-Lisina (preto), Cloisita $\mathrm{Na}^{+}$(vermelho) em suas formas originais e dos produtos de reação. (Código: Identidade da amostra; pH final de reação; proporção molar de argila:aminoácido; tempo de reação).

No espectro vibracional da L-lisina, observa-se uma banda larga entre 3300 e $2200 \mathrm{~cm}^{-1}$ que pode ser atribuída aos seguintes modos vibracionais: estiramento, simétrico e antissimétrico, do grupo $\mathrm{NH}_{3}^{+}$e ao estiramento simétrico e antissimétrico do grupo C-H [66]. Observa-se também a banda de combinação na região de $2100-2020 \mathrm{~cm}^{-1}$, que é atribuída à combinação da $\delta N H_{3}^{+}$e $\tau N H_{3}^{+}$, sendo portanto uma banda importante para confirmar a presença do grupo amino protonado. O grupo carboxilato $\left(\mathrm{COO}^{-}\right)$apresenta estiramento antissimétrico em $1589 \mathrm{~cm}^{-1}$, simétrico em $1400 \mathrm{~cm}^{-1}$ e a banda em $556 \mathrm{~cm}^{-1}$ correspondente à deformação angular. Na Tabela 4.3 encontram-se as atribuições de alguns modos vibracionais dos grupos funcionais do aminoácido L-lisina (na forma cloridrato) e suas 
respectivas regiões de absorção [74].

Tabela 4.3: Bandas de absorção e atribuições de alguns modos vibracionais dos grupos funcionais do Cloridrato de L-Lisina [74].

\begin{tabular}{cc}
\hline $\begin{array}{c}\text { Região de absorção } \\
c m^{-1}\end{array}$ & Modos Vibracionais \\
\hline \hline $3350-2200$ & $\begin{array}{c}\text { Estiramento simétrico e antissimétrico } \nu C H_{2}, \\
\text { Estiramento simétrico e antissimétrico } \mathrm{NH}_{3}\end{array}$ \\
\hline 2100 & Sobretons e combinações de bandas \\
\hline 1589 & Estiramento antissimétrico $\nu_{a s} C O O^{-}$ \\
\hline 1564 & Deformação antissimétrica $\tau \mathrm{NH}_{3}^{+}$ \\
\hline 1505 & Deformação $\mathrm{NH}_{3}^{+}$ \\
\hline 1400 & Estiramento simétrico $\nu_{s} C O O^{-}$ \\
\hline $1350-1360$ & Deformação angular simétrica $\tau C H_{2}$ \\
\hline 1190 & Deformação $\tau N H_{3}^{+}$ \\
\hline 1146 & Deformação angular antissimétrica do $\mathrm{N} \mathrm{do} \mathrm{C \alpha}$ \\
\hline 1000 & Deformação fora do plano $C O O^{-}$ \\
\hline 909 & Estiramento $\nu C-C$ \\
\hline 858 & Estiramento simétrico $\nu_{s} C-C-N$ \\
\hline 739 & Estiramento $\nu C-C$ \\
\hline 702 & Deformação angular simétrica no plano $\rho C H_{2}$ \\
\hline 456 & Deformação angular simétrica no plano $\delta_{s} O-C-O$ \\
\hline 414 & Torsão $N H_{3}^{+}$ \\
\hline$\nu=$ estiramento; $\tau=$ torção; $\rho=$ rocking $; \delta=$ deformação angular.
\end{tabular}

Nos espectros vibracionais das amostras contendo argila há uma banda larga na região de $3700-3300 \mathrm{~cm}^{-1}$ atribuída ao estiramento $\mathrm{O}-\mathrm{H}$ das moléculas de água (tanto de hidratação do sódio e adsorvidas na lamela, quanto das hidroxilas das lamelas). Em aproximadamente $1638 \mathrm{~cm}^{-1}$, há a uma banda atribuída à deformação angular da água. As bandas mais intensas em $1026 \mathrm{~cm}^{-1}$ e $500-450 \mathrm{~cm}^{-1}$ são atribuídas, respectivamente, ao estiramento Si-O-Si das folhas tetraédricas e à deformação Al-O das folhas octaédricas (bandas características da Cloisita) [75].

Observa-se que nos espectros de todos os produtos há modificações na região entre 1750 e $1400 \mathrm{~cm}^{-1}$. Como todas as amostras foram isoladas em condições de $\mathrm{pH}$ nos quais o grupo amina da L-lisina estivessem protonados, a banda em aproximadamente $1500 \mathrm{~cm}^{-1}$, atribuída à deformação do grupo $-\mathrm{NH}_{3}^{+}$, é observada no espectro de todas as amostras de Cloisita com L-lisina. Na Tabela 4.4 encontra-se o resumo das regiões de modificações e atribuições dos possíveis modos vibracionais de alguns grupos orgânicos nos produtos da 
imobilização da L-lisina em Cloisita, ou seja, amostras CloLys1, CloLys2 e CloLysp4. O espectro FTIR da amostra CloLysp4 também apresenta banda em $1400 \mathrm{~cm}^{-1}$ referente ao grupo $\mathrm{COO}^{-}$. Assim sendo, essa amostra parece conter tanto as espécies $\mathrm{Lis}^{2+}$ quanto as espécies $\mathrm{Lis}^{+}$. Nas amostras CloLysp6 e CloLysS, espera-se que a espécie imobilizada seja a Lys $^{+}$(L-lisina com carga +1 ), uma vez que foram preparadas suspensões com valores de $\mathrm{pH}$ inferiores ao valor de $p K_{a 2}$ (aproximadamente 9 ). Os espectros vibracionais dessas duas amostras não apresentam a banda em aproximadamente $1750 \mathrm{~cm}^{-1}(\nu C=O)$, mas mostram bandas em 1590 e $1400 \mathrm{~cm}^{-1}$ atribuída $\nu_{a s s}$ e $\nu_{s}$ do grupo $-C O O^{-}$, respectivamente, confirmando a imobilização da espécie $\mathrm{Lys}^{+}$.

A Figura 4.4 mostra o espectro vibracional entre as regiões 1900 e $1300 \mathrm{~cm}^{-1}$ para a melhor visualização das modificações observadas.

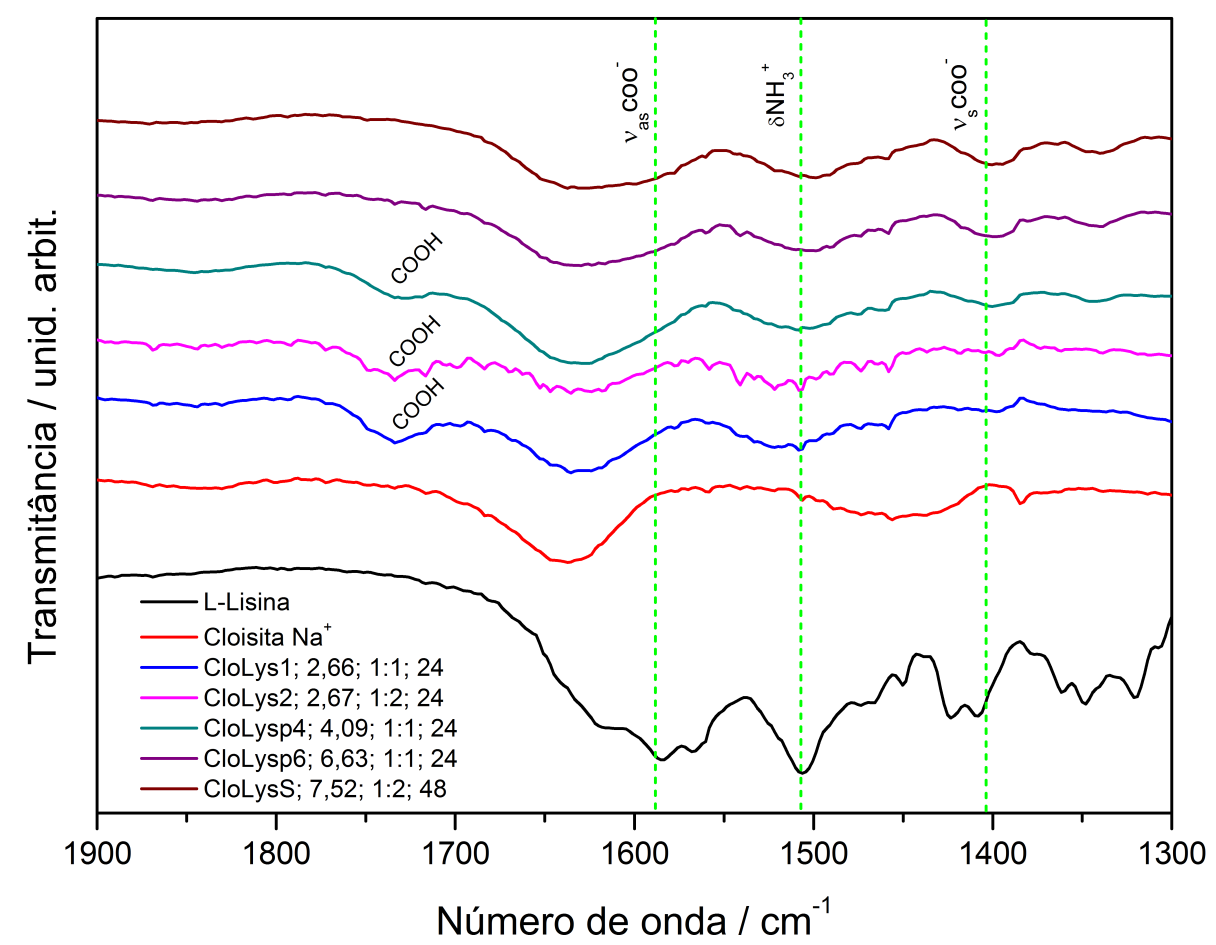

Figura 4.4: Espectros vibracionais entre 1900 e $1300 \mathrm{~cm}^{-1}$ do Cloridrato de L-Lisina (preto), Cloisita $\mathrm{Na}^{+}$(vermelho) em suas formas originais e dos produtos de reação. (Código: Identidade da amostra; pH final de reação; proporção molar de argila:aminoácido; tempo de reação).

Nos espectros FTIR das amostras CloLys1 e CloLys2, observa-se uma banda em apro- 
Tabela 4.4: Regiões de modificações e atribuições dos possiveis modos vibracionais de alguns grupos orgânicos nos produtos da imobilização do Cloridrato de L-Lisina em Cloisita.

\begin{tabular}{cc}
\hline $\begin{array}{c}\text { Região de absorção } / \\
\mathrm{cm}^{-1}\end{array}$ & Modos vibracionais \\
\hline \hline 1733 & Estiramento $\nu \mathrm{C}=\mathrm{O}$ \\
\hline 1590 & Estiramento antissimétrico $\nu_{a s s} C O O^{-}$ \\
\hline 1500 & Deformação $\delta \mathrm{NH}_{3}^{+}$ \\
\hline 1400 & Estiramento simétrico $\nu_{s} \mathrm{COO}^{-}$ \\
\hline
\end{tabular}

ximadamente $1750 \mathrm{~cm}^{-1}$ que não está presente no espectro do cloridrato de L-lisina. Essa banda pode ser atribuída ao $\nu \mathrm{C}=\mathrm{O}$ do grupo $-\mathrm{COOH}$, sugerindo que a L-lisina está imobilizada na Cloisita na forma $\mathrm{H}_{3} \mathrm{~N}^{+}\left(\mathrm{CH}_{2}\right)_{4} \mathrm{CH}\left(\mathrm{N}^{+} \mathrm{H}_{3}\right) \mathrm{COOH}\left(\mathrm{Lys}^{2+}\right)$. Para essas duas amostras, a banda referente ao modo vibracional $\nu_{a s} C O O^{-}$é praticamente inexistente, indicando que a forma do carboxilato protonado é preferencialmente intercalado. É interessante lembrar que as argilas possuem propriedades ácidas provenientes da polarização das moléculas de $\mathrm{H}_{2} \mathrm{O}$ ao redor de cátions no espaço interlamelar (Figura 1.9). Do ponto de vista eletrostático, a interação com a forma $\mathrm{H}_{3} \mathrm{~N}^{+}\left(\mathrm{CH}_{2}\right)_{4} \mathrm{CH}\left(\mathrm{N}^{+} \mathrm{H}_{3}\right) \mathrm{COOH}$ é mais forte em relação à forma $\mathrm{H}_{3} \mathrm{~N}^{+}\left(\mathrm{CH}_{2}\right)_{4} \mathrm{CH}\left(\mathrm{N}^{+} \mathrm{H}_{3}\right) \mathrm{COO}^{-}$, uma vez que a primeira possui carga $(+2)$ e a segunda, carga $(+1)$.

Segundo os resultados de FTIR, nas amostras CloLys1, CloLys2 e CloLysp4 (produtos de reações realizadas em pH 2,66, 2,67 e 4,09, respectivamente), algumas moléculas de L-lisina apresentam o grupo carboxilato protonado. Sabendo-se que o $p K_{a}$ do grupo carboxilato da L-lisina é 2,2, nas duas primeiras amostras a L-lisina estaria com aproximadamente metade de suas moléculas com o grupo carboxilato protonado nas condições de síntese. Considerando o pH do meio de preparação da amostra CloLysp4 e o valor da primeira constante ácida da L-lisina, a concentração da espécie $L y s^{+}$é 66 vezes superior àquela da $\operatorname{Lys}^{2+}$ (L-lisina com carga +2$)$. Portanto, o fato da espectroscopia vibracional na região do infravermelho mostrar que a L-lisina se encontra preponderantemente com carga +2 na superfície da Cloisita atesta o caráter ácido da argila. Já o grupo amino encontra-se protonado em todas as amostras, uma vez que as bandas largas em aproximadamente $1500 \mathrm{~cm}^{-1}$ estão presentes nos espectros FTIR de todas as amostras.

Na Figura 4.5 são apresentados os resultados referentes à análise térmica da argila 
Cloisita $\mathrm{Na}^{+}$. Ao observar a curva DTG, pode-se dividir o processo de perda de massa em duas etapas. Na primeira etapa (da temperatura ambiente até aproximadamente $156{ }^{\circ} \mathrm{C}$ ) ocorre a perda das moléculas de água ligadas superficialmente nas lamelas e, também, presentes na região interlamelar (ou seja, moléculas de água adsorvidas na argila). A identidade da espécie volátil é atestada pela curva proveniente dos espectros de massas, que indica a liberação de um fragmento com $m / z$ igual a 18. Esse processo de perda de massa corresponde a aproximadamente $5,6 \%$ da massa total da Cloisita $\mathrm{Na}^{+}$.

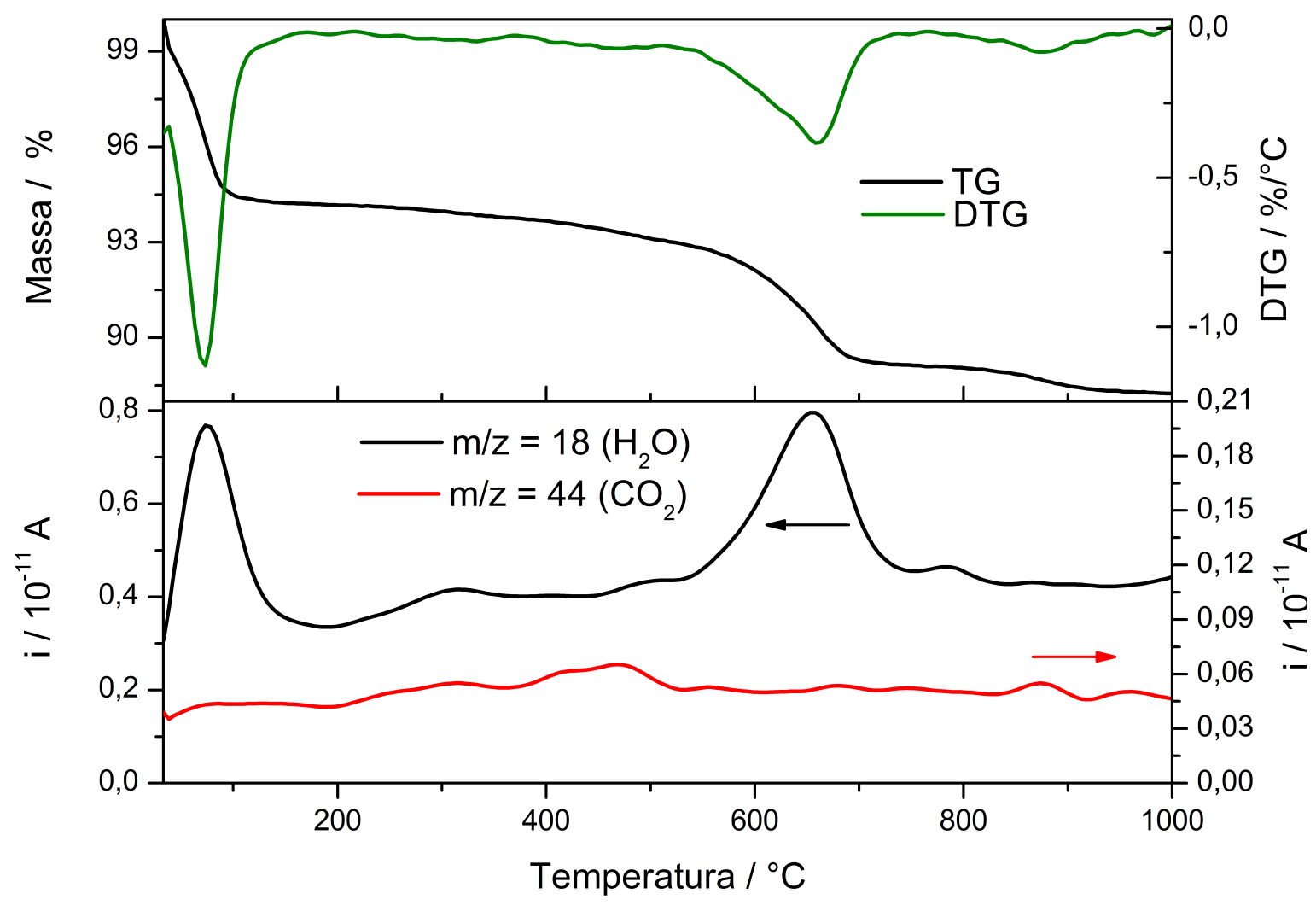

Figura 4.5: Curvas TGA (preto), DTG (verde oliva) e $M S$ (fragmentos $m / z=18$ (preto) $e$ $\mathrm{m} / z=44$ (vermelho)) da Cloisita $\mathrm{Na}^{+}$.

A segunda etapa, que apresenta um mínimo na curva DTG em $660{ }^{\circ} \mathrm{C}$, corresponde ao processo de desidroxilação (eliminação de $\mathrm{H}_{2} \mathrm{O}$ ) das lamelas da Cloista $\mathrm{Na}^{+}$. Através da curva TGA, observa-se que esse processo se estende até a temperatura de $900{ }^{\circ} \mathrm{C}$, a partir da qual não se observa mais perda de massa.

Na Figura 4.6 são apresentados os resultados referentes à análise térmica do Cloridrato 
de L-lisina. Pode-se observar quatro mínimos na curva DTG, que correspondem a quatro fenômenos de perda de massa. Na primeira etapa (de 255 até aproximadamente $370{ }^{\circ} \mathrm{C}$ ) ocorre a perda do fragmento $\mathrm{m} / \mathrm{z}$ igual a 18 em maior quantidade e em menor quantidade do fragmento com $m / z$ igual a 44 (atribuído ao dióxido de carbono). Nas segunda e terceira etapas de perda de massa, com picos DTG em 450 e $505{ }^{\circ} \mathrm{C}$, observa-se a saída do fragmento $m / z$ igual a 18 com maior intensidade.

Na quarta etapa (aproximadamente $535{ }^{\circ} \mathrm{C}$ ), ocorre principalmente a perda do fragmento $m / z$ igual a 44 . Em $660{ }^{\circ} \mathrm{C}$ já não se observa mais variação de massa e a curva indica que toda a massa de L-lisina foi oxidada a produtos voláteis. Nas condições instrumentais empregadas, não foram detectados fragmentos com $m / z$ igual a $36(\mathrm{HCl})$ ou 35 (Cl), relacionados à liberação de $\mathrm{HCl}$.

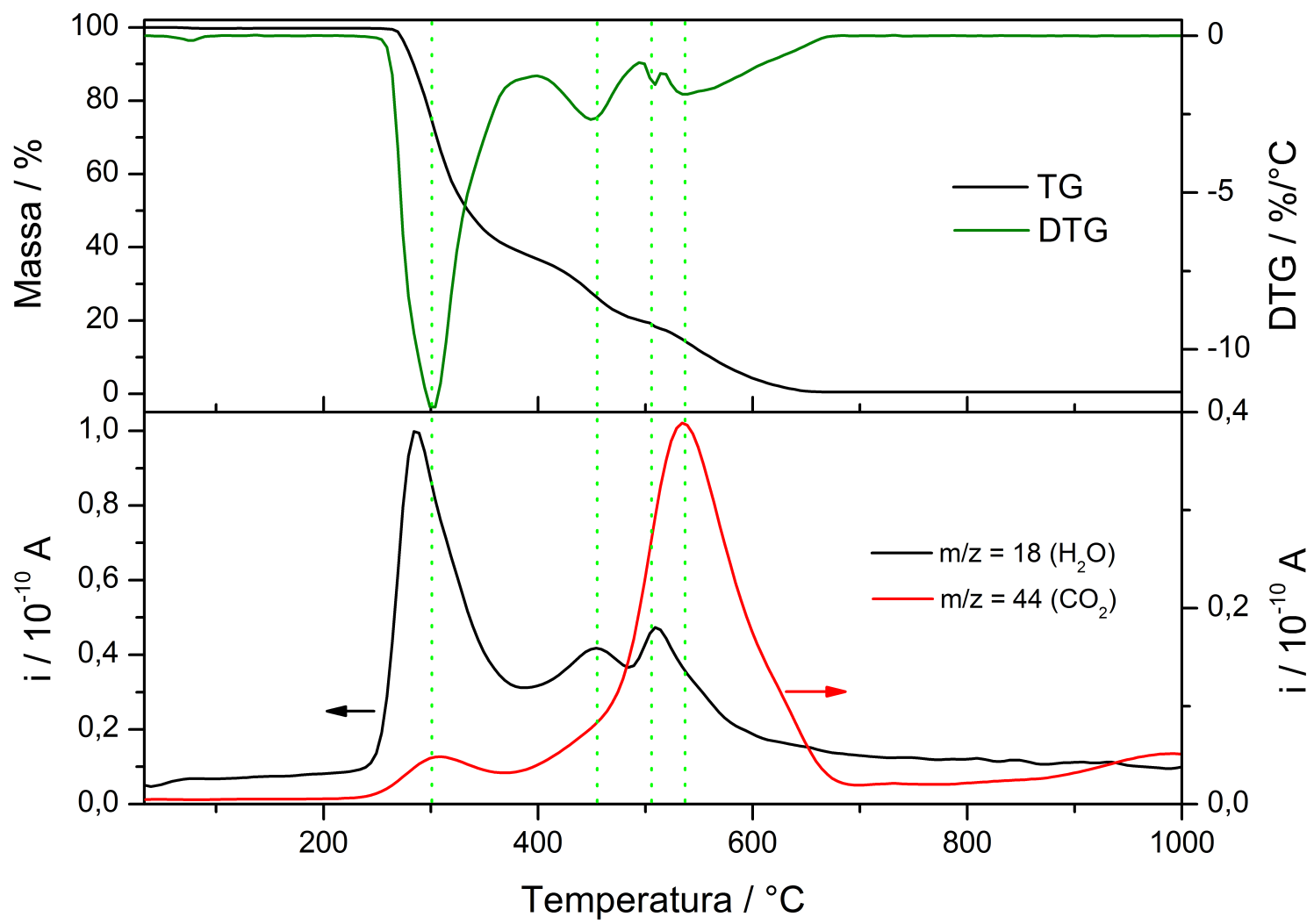

Figura 4.6: Curvas TGA (preto), DTG (verde oliva) e $M S$ (fragmentos $m / z=18$ (preto) e $m / z=44$ (vermelho)) do Cloridrato de L-Lisina.

Na Figura 4.7 é apresentada a curva temogravimétrica de um dos produtos das rea- 
ções de imobilização do aminoácido L-lisina na argila Cloisita $\mathrm{Na}^{+}$(amostra CloLys1). Pela curva DTG identificam-se três etapas de perda de massa, diferentemente da argila precursora, para a qual só se observa dois eventos. Pela curva MS, observa-se que o fragmento com $\mathrm{m} / \mathrm{z}$ igual a 44 começa a ser liberado na temperatura em torno de $220{ }^{\circ} \mathrm{C}$ e termina em $870{ }^{\circ} \mathrm{C}$. Para as amostra CloLysS e CloLys2 a análise térmica apresentou resultados semelhantes à amostra CloLys1 (Figura B.1, Apêndice B). Esses dados indicam uma maior estabilidade térmica da L-lisina quando imobilizada na argila Cloisita. Esse fato pode estar relacionado com o fato do oxigênio molecular difundir com maior dificuldade entre as lamelas ou mesmo com uma possível influência da interação com a argila na estrutura do aminoácido.

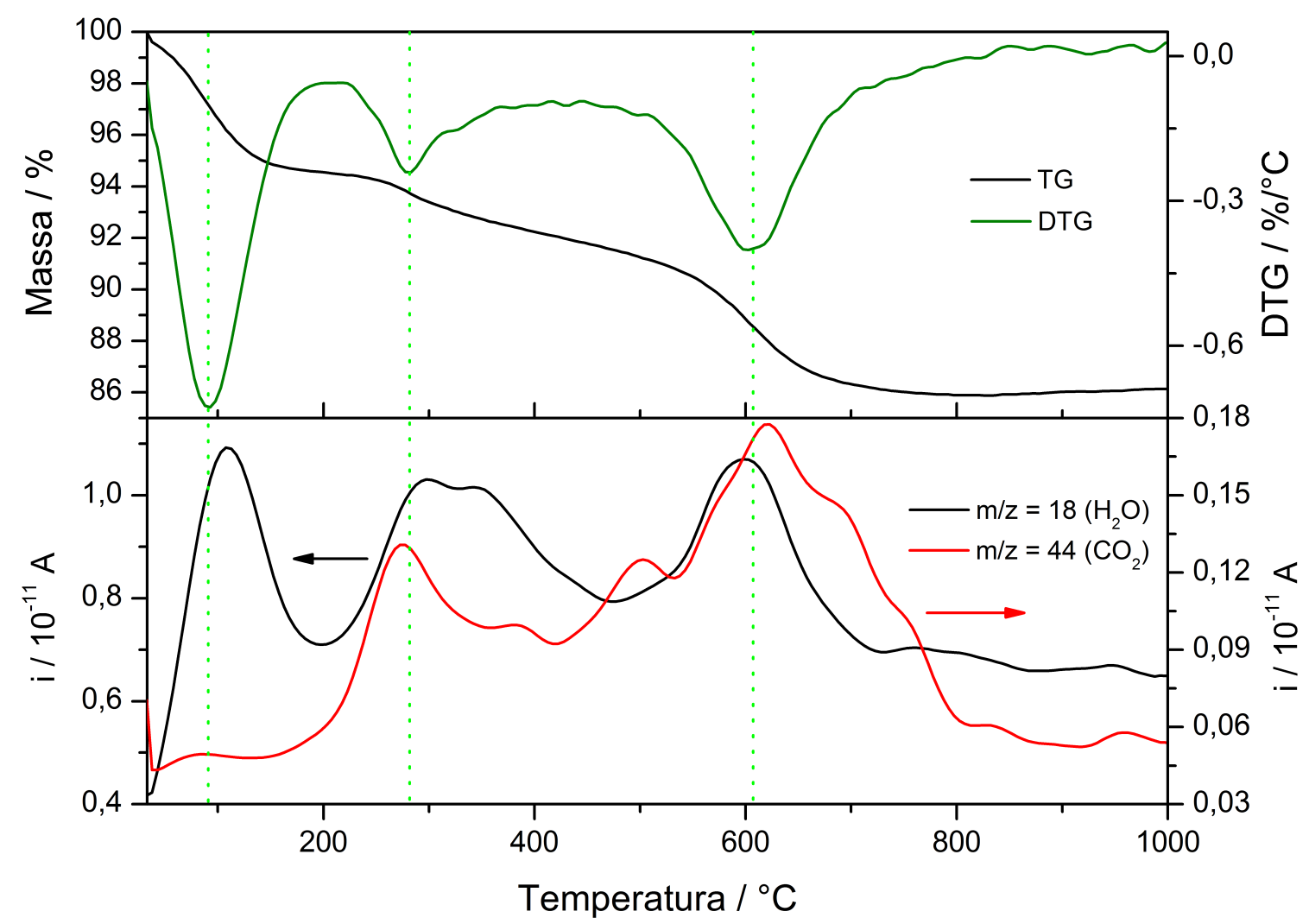

Figura 4.7: Curvas TGA (preto), DTG (verde oliva) e $M S$ (fragmentos $m / z=18$ (preto) e $m / z=44$ (vermelho)) da amostra CloLys1.

A Figura 4.8 mostra os resultados de análise térmica da amostra CloLysp6. O perfil de decomposição do aminoácido no intervalo de 300 - $700{ }^{\circ} \mathrm{C}$ é um pouco distinto daquele 
observado para a amostra CloLys1, quando se compara as curvas MS para os fragmentos com $m / z$ igual a 18 e 44 . Tais mudanças podem estar relacionadas com o fato dessas duas amostras apresentarem o aminoácido com diferentes graus de protonação e cargas elétricas. As amostras CloLysp4 e CloLysp5 apresentam perfis de decomposição térmica semelhantes a da amostra CloLysp6 (cujos resultados de análise térmica encontram-se no Apêndice B. O fato do comportamento térmico da amostra CloLysp4 se assemelhar ao das amostras CloLysp5 e CloLysp6 parece confirmar que essa amostra possui espécies Lys $^{+}$, além das espécies $\operatorname{Lys}^{2+}$.

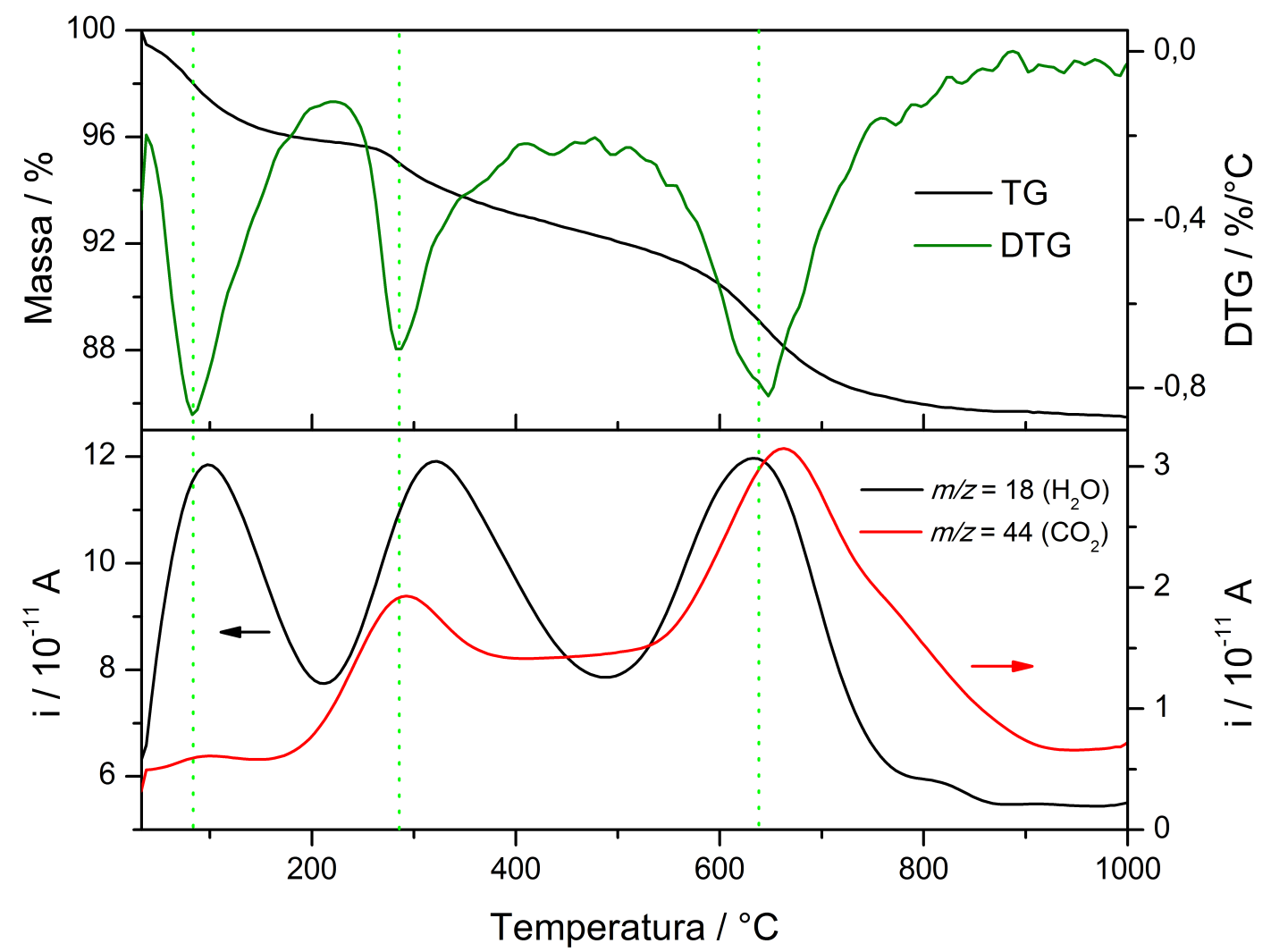

Figura 4.8: Curvas TGA (preto), DTG (verde oliva) e $M S$ (fragmentos $m / z=18$ (preto) e $m / z=44$ (vermelho)) da amostra CloLysp6.

A argila precursora não sofre mudanças significativas (perda de massa) no intervalo de temperatura de 160 a $500{ }^{\circ} \mathrm{C}$, logo essa mudança observada nos dados de análise térmica das amostras com L-lisina se deve à decomposição do aminoácido. Observa-se ainda que o perfil de decomposição da espécie orgânica foi modificado, o que evidencia a interação com 
a argila (isto é, o perfil de decomposição das amostras argila/L-lisina não são a somatória dos perfis das duas fases isoladas).

A massa residual dessa análise é aproximadamente a mesma observada para as amostras CloLys1, CloLys2 (em torno de 87 \%). O uso do dobro de massa de L-lisina no experimento de preparação da amostra CloLys2 em relação à amostra CloLys1 não resultou em uma maior quantidade de aminoácido imobilizado na Cloisita.

As amostras CloLys1, CloLys2 e CloLysS foram submetidas à análise química elementar de carbono, hidrogênio e nitrogênio (CHN), que forneceu os seguintes valores de porcentagem em massa de carbono, respectivamente: 2,15, 2,28 e 3,84 \%. Os dados de CHN corroboram com os dados de análise térmica: as quantidades de L-lisina imobilizadas nas amostras CloLys1 e CloLys2 são semelhantes.

A partir das porcentagens de carbono nas amostras e considerando-se que esse elemento é proveniente somente do aminoácido, a concentração de L-lisina nas amostras CloLys1 e CloLysS é respectivamente: 4,40\% (ou $30 \mathrm{mmol} / 100 \mathrm{~g}$ ) e 7,84 \% (ou 53,3 mmol/100 g). A amostra CloLys1 possui 4,40 \% de L-lisina, 6 \% de água de hidratação e, portanto, 89,6 \% de argila. Considerando-se a CTC da Cloisita (92 mmol de carga positiva / $100 \mathrm{~g}$ ) e a presença preponderante de espécie $\operatorname{Lys}^{2+}$ (conforme dados de FTIR), o aminoácido está neutralizando aproximadamente $73 \%$ das cargas elétricas da argila. Já a amostra CloLysS possui 7,84 \% de L-lisina, $3 \%$ de água e, portanto, 89,2 \% de argila. Considerando-se a presença de espécies $\mathrm{Lys}^{+}$nessa amostra, o aminoácido está neutralizando $65 \%$ das cargas negativas da Cloisita. Como 65 e $73 \%$ de CTC foram neutralizadas ${ }^{2}$, as moléculas de L-lisina devem estar intercaladas, já que a carga da superfície externa das argilas é responsável apenas por 5 - $10 \%$ da CTC [37].

Realizou-se o teste com ninidrina para a amostra CloLysS, o qual resultou em uma coloração azulada, característica para reações de ninidrina com aminoácidos. Para essa mesma amostra mediu-se o valor de potencial Zeta que foi igual a - 41,1 $\mathrm{mV}(\sigma= \pm 0,56)$, em uma suspensão $0,1 \%(\mathrm{~m} / \mathrm{v})$ e valor de $\mathrm{pH}=8,31$. O tamanho médio de partícula é

\footnotetext{
${ }^{2}$ A porcentagem de CTC neutralizada (X) é calculada considerando-se o valor da CTC de cada argila como $100 \%$ e o valor em mmol de carga positiva proveniente do aminoácido nas amostras (calculadas a partir da \% de carbono) sendo X \%. X\% = mmol de aminocido.100/CTC
} 
igual a $156,3 \mathrm{~nm}(\sigma= \pm 1,39$ e $P D I=0,25)$.

\subsubsection{L-Arginina em Cloisita Sódica}

As reações de imobilização com o aminoácido L-arginina foram feitas com variações nos mesmos parâmetros utilizados para o aminoácido L-lisina, apresentados anteriormente.

Os difratogramas de raios $\mathrm{X}$ da argila pristina e dos produtos das reações encontram-se na Figura 4.9. Observa-se que as amostras de L-arginina em Cloisita apresentam valores de espaçamento interplanar $d_{(001)}$ que variam entre 12,7 e 13,1 $\AA$ (Tabela 4.5). O aumento dos valores de $d_{(001)}$ para essas amostras também foi pequeno, porém considerando-se um arranjo da L-arginina paralelo às lamelas, o espaçamento esperado é 13,2 $\AA(9,6 \AA+3,6$ A). As dimensões teóricas da L-arginina também foram calculadas a partir da estrutura de menor energia (Figura A.2, Anexo A).

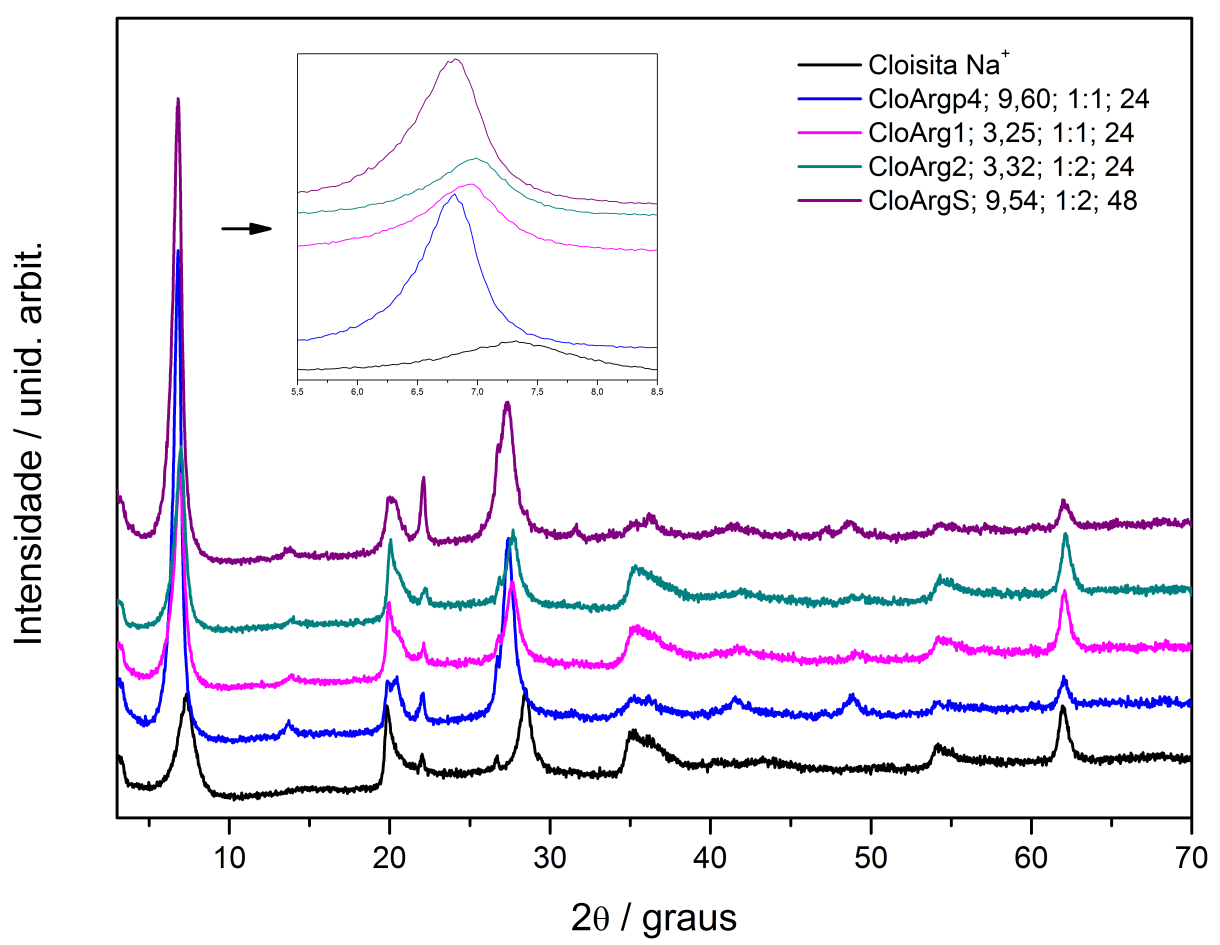

Figura 4.9: Difratogramas de raios $\mathrm{X}$ da Cloisita $\mathrm{Na}^{+}$e dos produtos das reações da Cloisita $\mathrm{Na}^{+}$com L-Arginina. (Código: Identidade da amostra; $p H$ final de reação; proporção molar de argila:aminoácido; tempo de reação). 
Tabela 4.5: Distância interplanar $d_{(001)}$ dos materiais obtidos pela reação de imobilização de L-Arginina em Cloisita.

\begin{tabular}{ccc}
\hline Amostra & $2 \theta /$ graus & $d_{(001)} / \AA$ \\
\hline \hline Cloisita & 7,30 & 12,1 \\
\hline CloArg1 & 6,94 & 12,7 \\
\hline CloArg2 & 6,98 & 12,7 \\
\hline CloArgp4 & 6,77 & 13,1 \\
\hline CloArgS & 6,80 & 13,0 \\
\hline
\end{tabular}

Os espectros vibracionais FTIR das amostras isoladas, da argila pristina e da Larginina encontram-se na Figura 4.10.

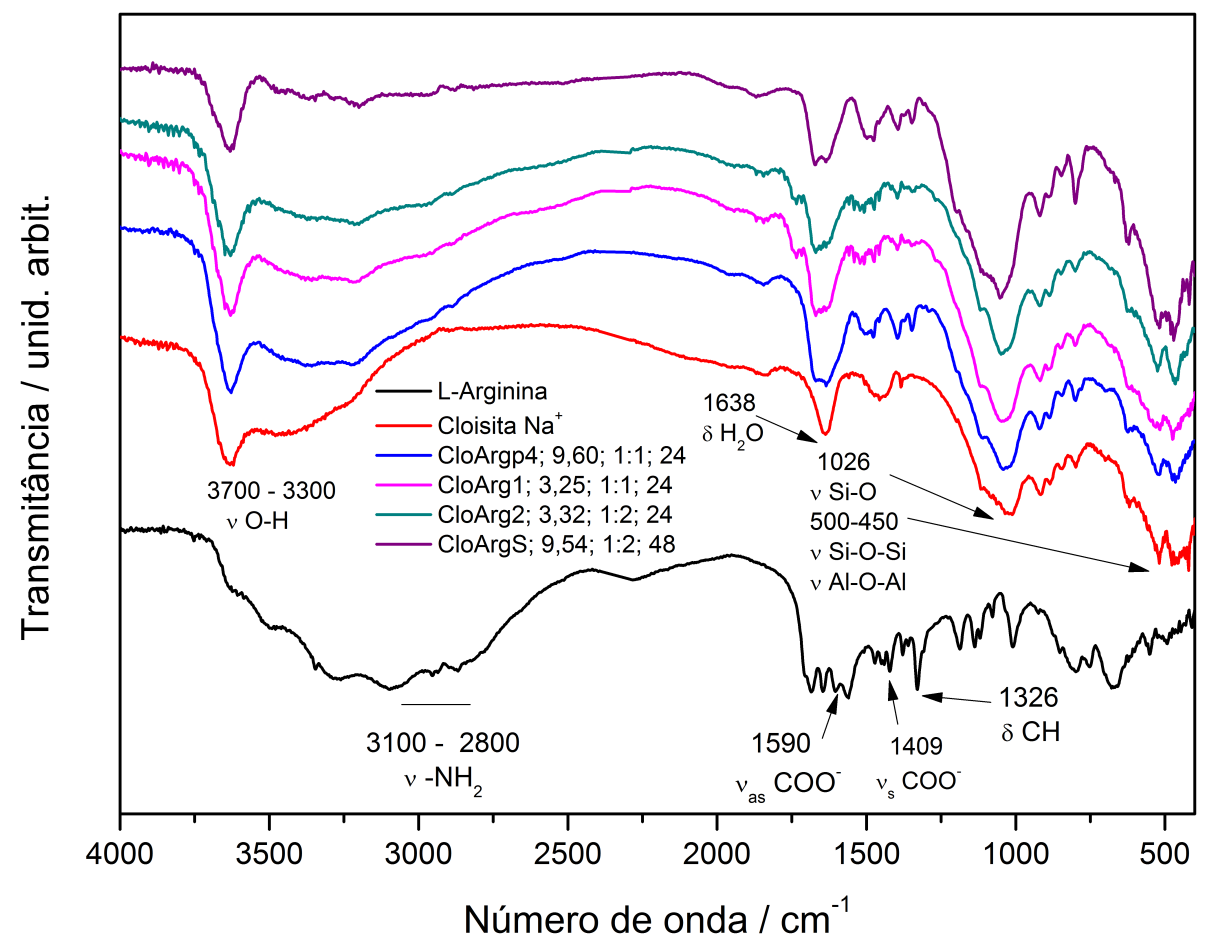

Figura 4.10: Espectros vibracionais na região do Infravermelho da L-Arginina (preto), Cloisita $\mathrm{Na}^{+}$(vermelho) em suas formas originais e dos produtos de reação. (Código: Identidade da amostra; pH final de reação; proporção molar de argila:aminoácido; tempo de reação).

No espectro vibracional da L-arginina observam-se as bandas características dos grupos funcionais dos aminoácidos já mencionados na Tabela 4.3. Os espectros de todos os produtos de reações com a Cloisita também apresentam modificações na região entre 1700 e $1300 \mathrm{~cm}^{-1}$, que podem ser atribuídas aos grupos funcionais do aminoácido presente no material. Há também um alargamento da banda situada entre 1770 e $1570 \mathrm{~cm}^{-1}$. 
A Figura 4.11 mostra o espectro vibracional entre as regiões 1900 e $1300 \mathrm{~cm}^{-1}$ para uma melhor visualização.

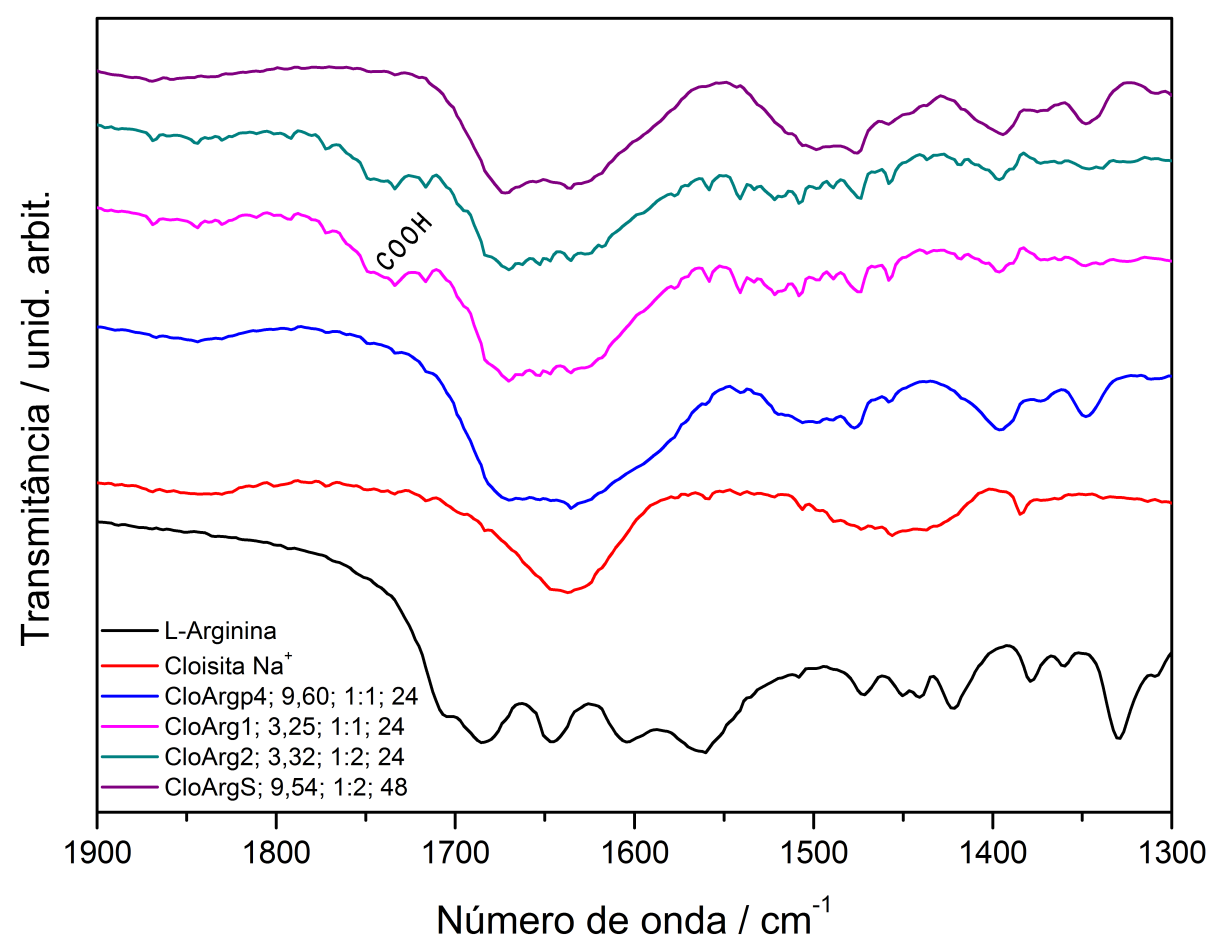

Figura 4.11: Espectros vibracionais na região do Infravermelho da L-Arginina (preto), Cloisita $\mathrm{Na}^{+}$(vermelho) em suas formas originais e dos produtos de reação. (Código: Identidade da amostra; $\mathrm{pH}$ final de reação; proporção molar de argila:aminoácido; tempo de reação).

Considerando-se os valores de $\mathrm{pH}$ das suspensões utilizadas para preparar as amostras CloArg1 e CloArg2 e os valores de $p K_{a}$ da L-arginina (Tabela 1.2), é esperada a imobilização da espécie $\left(\mathrm{NH}_{2}\right)_{2} \mathrm{CHN}^{+} \mathrm{H}\left(\mathrm{CH}_{2}\right)_{3} \mathrm{CH}\left(\mathrm{N}^{+} \mathrm{H}_{3}\right) \mathrm{COO}^{-}\left(\mathrm{Arg}^{+}\right)$na argila, já que a concentração da espécie $A r g^{+}$é 14 vezes superior a da concentração da $A r g^{2+}$. Nas Figuras 4.10 e 4.11 observa-se a presença da banda em aproximadamente $1740 \mathrm{~cm}^{-1}$ referente ao modo vibracional $\nu C=O$, indicando que o grupo carboxilato encontra-se protonado na presença da Cloisita (embora o valor de $p K_{a 1}(2,4)$ da L-arginina seja inferior ao valor do pH de preparação das amostras, isto é, 3,25).

No valor de pH das suspensões usadas na preparação das amostras CloArgp4 e CloArgS (aproximadamente 9,6), espera-se a presença predominante da espécie $A r g^{0}$, uma vez que o valor de $p K_{a 2}$ do aminoácido é 9,04. Os espectros de FTIR indicam que realmente as 
amostras CloArgp4 e CloArgS não possuem o grupo carboxilato protonado (ausência da banda $\nu C=O)$. Seria interessante procurar bandas referentes ao grupo $-\mathrm{NH}_{3}^{+}$nessas amostras, o que poderia indicar que na superfície da argila a forma $\mathrm{Arg}^{+}$estaria presente (em virtude da acidez da Cloisita). As bandas referentes ao grupo amino protonado no aminoácidos ocorrem em 1620 e $1520 \mathrm{~cm}^{-1}$, além daquelas em $1175\left(\rho N H_{3}^{+}\right)$e 560 $\left(\tau \mathrm{NH}_{3}^{+}\right) \mathrm{cm}^{-1}[76]$. Os espectros das amostras CloArgp4 e CloArgS apresentam absorção em $1520 \mathrm{~cm}^{-1}$, que sugerem a presença do grupo $-\mathrm{NH}_{3}^{+}$. Infelizmente as bandas em 1175 e $560 \mathrm{~cm}^{-1}$ são encobertas pelas bandas da Cloisita.

Na Figura 4.12 são apresentados os resultados referentes à análise térmica da Larginina. O processo de perda de massa pode ser dividido em duas etapas. Na primeira etapa (de $210{ }^{\circ} \mathrm{C}$ até aproximadamente $320{ }^{\circ} \mathrm{C}$ ) ocorre a perda com maior intensidade do fragmento $m / z$ igual a 18 e de menor quantidade do fragmento com $m / z$ igual a 44 . Esse processo de perda de massa corresponde a aproximadamente $40 \%$ da massa total da L-arginina.

Na segunda etapa $\left(\right.$ de $420{ }^{\circ} \mathrm{C}$ até aproximadamente $720{ }^{\circ} \mathrm{C}$ ) ocorre a perda principal do fragmento $m / z$ igual a 44 (dióxido de carbono). Como a arginina apresenta maior número de átomos de nitrogênio que os demais aminoácidos aqui empregados, foi possível observar a liberação de óxidos de nitrogênio. Ao término do experimento, não foi observada a presença de resíduo sólido no cadinho, o que indica que toda a massa de L-arginina foi oxidada a produtos voláteis.

Na Figura 4.13 são apresentados os dados de análise térmica do produto da reação de imobilização da L-arginina na argila Cloisita $\mathrm{Na}^{+}$(amostra CloArg2). Os dados de análise térmica da amostra CloArg1 apresentam perfil semelhante ao da CloArg2, mesmo dobrando-se a massa inicial de L-arginina. A amostra CloArg2 não apresenta quantidade significativamente maior do aminoácido (CloArg1 possui 2,44 \% de carbono e CloArg2 possui: 2,70 \%). Pela curva DTG, identificam-se quatro etapas de perda de massa. Pelos dados de espectrometria de massas, observa-se que o fragmento com $\mathrm{m} / \mathrm{z}$ igual a 44 na amostra CloArg2 começa a ser liberado em $190{ }^{\circ} \mathrm{C}$ e termina em aproximadamente $770{ }^{\circ} \mathrm{C}$. O fragmento com $\mathrm{m} / \mathrm{z}$ igual a 18 é observado durante todo o processo de aquecimento da 


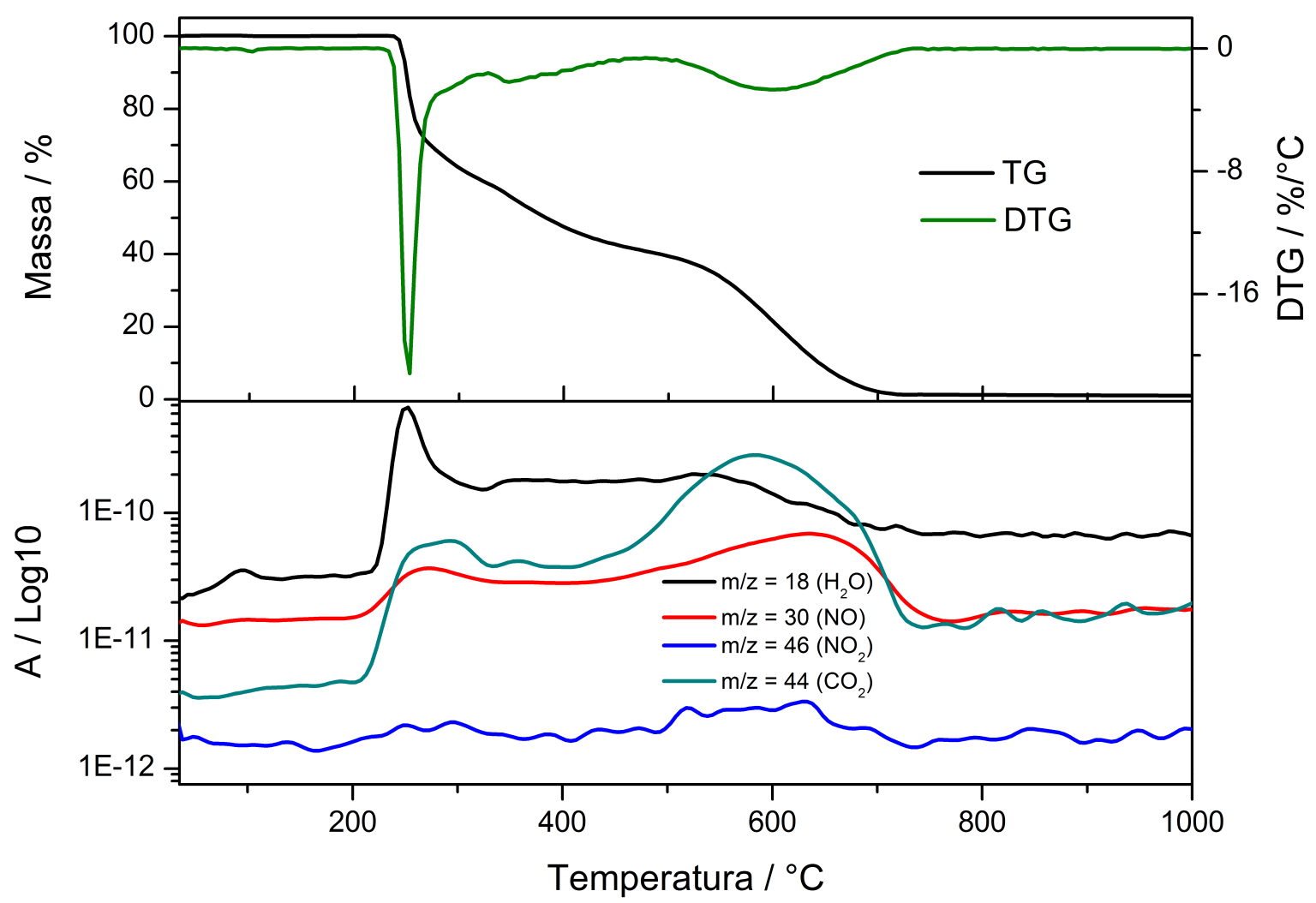

Figura 4.12: Curvas TGA (preto), DTG (verde oliva) e $M S$ (fragmentos $m / z=18, m / z=$ $30, m / z=46$ e $m / z=44)$ da L-Arginina.

amostra. A massa residual dessa análise foi de $82,5 \%$.

Na Figura 4.14 são apresentados os dados de análise térmica da amostra CloArgp4 (que são semelhantes aos da amostra CloArgp5, Apêndice B). Mais uma vez, observa-se que o perfil das curvas TGA, DTG e MS não são a soma das curvas da Cloisita e da L-arginina, indicando que há interações entre as fases, de modo a modificar o perfil de decomposição do aminoácido. As diferenças nos dados das amostras CloArg1 (e CloArg2) e CloArgp4 (e CloArgp5) se devem às espécies de natureza distintas imobilizadas na Cloisita.

A partir da análise de CHN da amostra CloArgS (considerando-se que esse elemento é proveniente somente do aminoácido), a concentração de L-arginina na amostras é 8,1 \% (ou $46 \mathrm{mmol} / 100 \mathrm{~g}$ ). Considerando-se a CTC da Cloisita e a presença preponderante da espécie $\mathrm{Arg}^{+}$(devido ao valor de $\mathrm{pH}$ de síntese igual a 9,54), o aminoácido está neutralizando aproximadamente $50 \%$ das cargas elétricas da argila. 


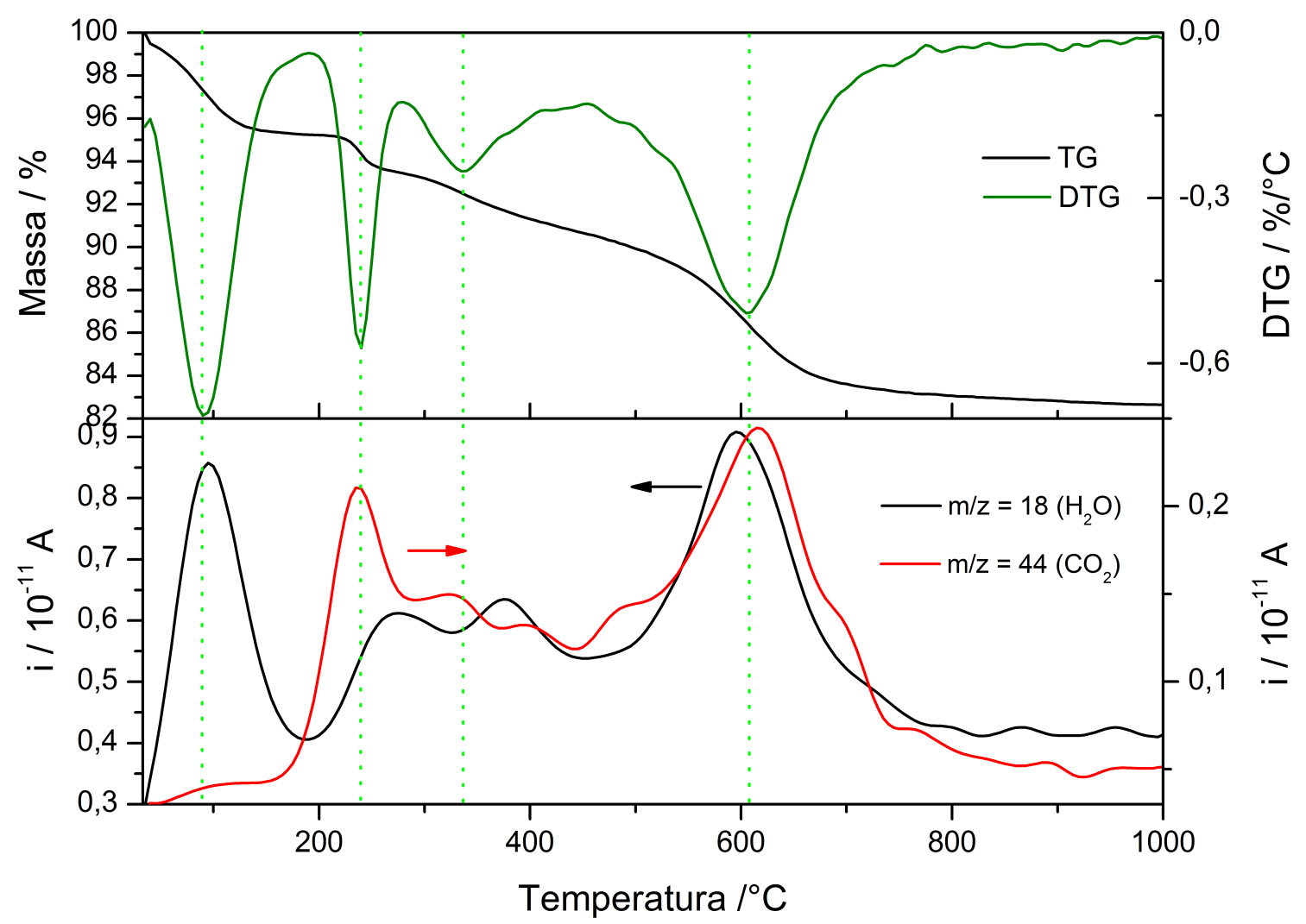

Figura 4.13: Curvas TGA (preto), DTG (verde oliva) e $M S$ (fragmentos $m / z=18$ (preto) $e$ $m / z=44$ (vermelho)) da amostra CloArg2.

Para a amostra CloArgS foi feito o teste qualitativo com o reagente ninidrina, que apresentou resultado positivo (coloração azulada, mostrada na Figura B.2 do Anexo B), confirmando que há aminoácido na amostra. O valor de potencial Zeta de uma suspensão $0,1 \%(\mathrm{~m} / \mathrm{v})$ e de $\mathrm{pH}$ igual a 8,95 da amostra CloArgS, é - 38,9 mV $(\sigma= \pm 1,18)$; a suspensão possui partículas com tamanho médio igual a 214,4 nm $(\sigma= \pm 4,48$ e $P D I=$ 0,30). Observa-se que a interação com o aminoácido praticamente manteve a estabilidade do sistema e que o tamanho médio das partículas aumentou (possivelmente devido a um maior grau de agregação das partículas). 


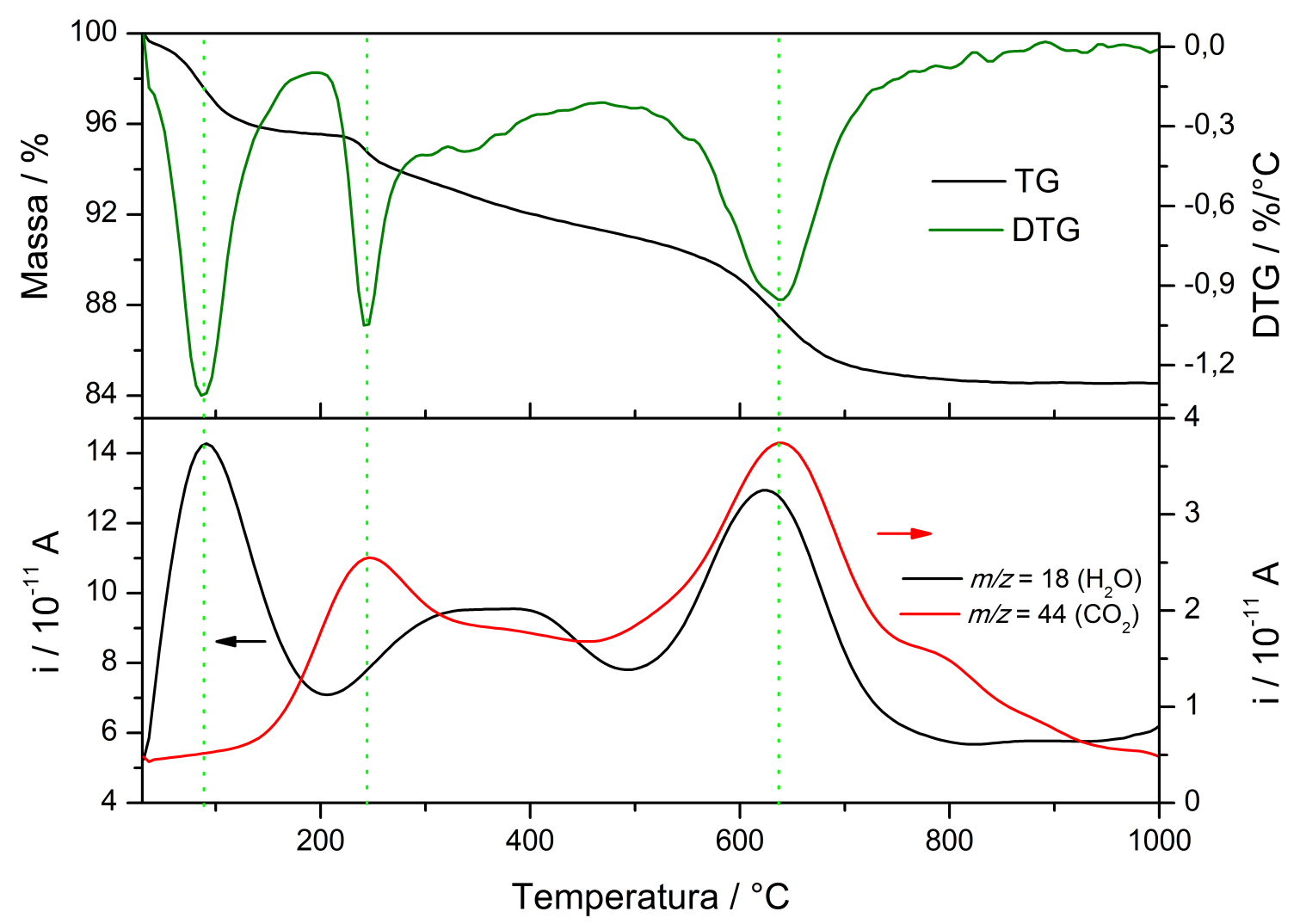

Figura 4.14: Curvas TGA (preto), DTG (verde oliva) e $M S$ (fragmentos $m / z=18$ (preto) e $m / z=44$ (vermelho)) da amostra CloArgp 4 .

\subsubsection{L-Carnosina em Cloisita Sódica}

Para a reação de imobilização da L-carnosina em argila Cloisita $\mathrm{Na}^{+}$, usou-se a razão molar 1:1 (argila:aminoácido) e 24 h de agitação. A Figura 4.15 apresenta os difratogramas da argila Cloisita e dos produtos das reações de intercalação com o aminoácido L-carnosina. Os valores de espaçamento interplanar $d_{(001)}$ para esses produtos variam entre 12,7 e $12,9 \AA$ (Tabela 4.6).

Tabela 4.6: Distância interplanar $d_{(001)}$ dos materiais obtidos pela reação de imobilização de L-Carnosina em Cloisita.

\begin{tabular}{ccc}
\hline Amostra & $2 \theta /$ graus & $d_{(001)} / \AA$ \\
\hline \hline Cloisita & 7,30 & 12,1 \\
\hline CloCar1 & 6,94 & 12,7 \\
\hline CloCarp5 & 6,86 & 12,9 \\
\hline
\end{tabular}

As dimensões teóricas da L-carnosina neutra foram calculadas e são 4,5 x 7,4 x 10,6 $\AA$ 


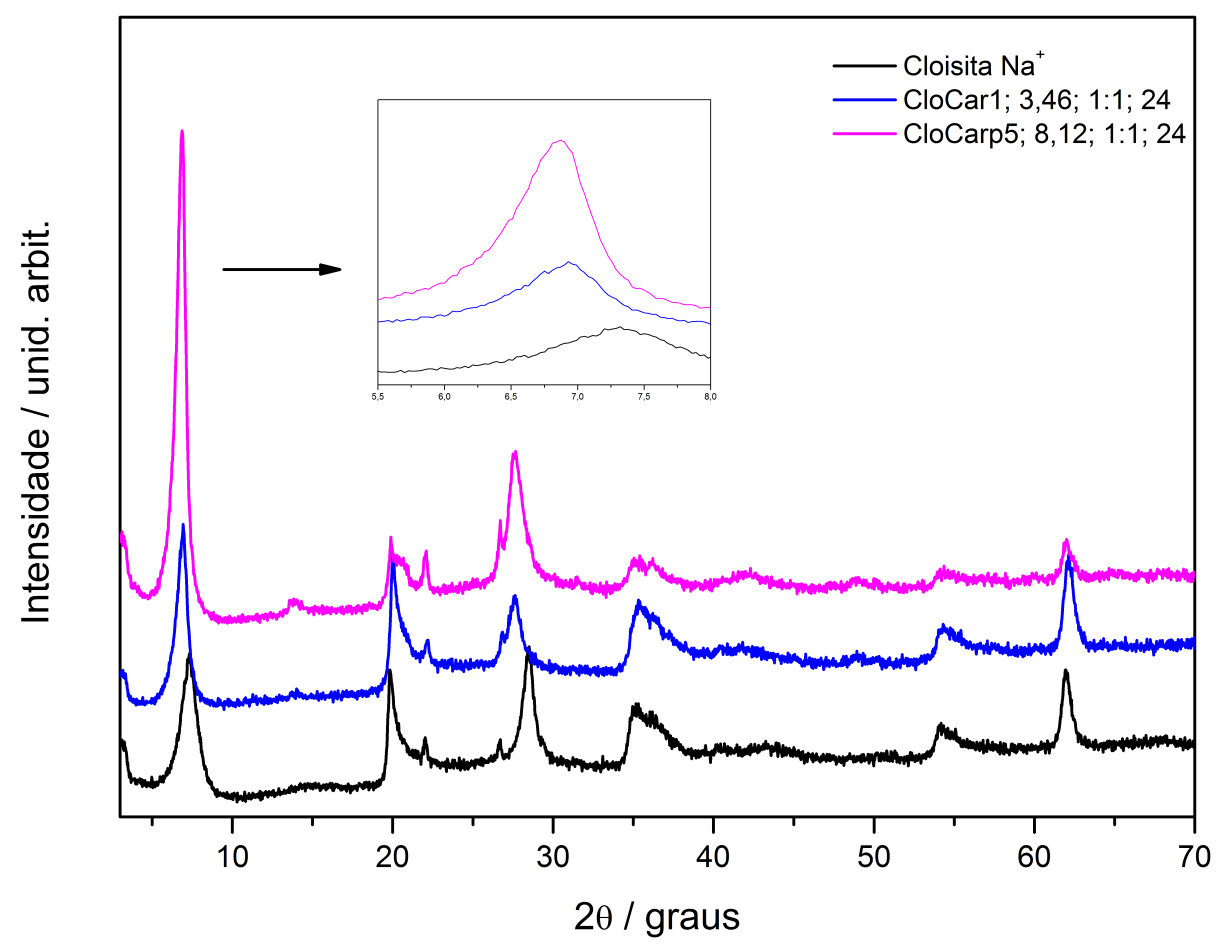

Figura 4.15: Difratogramas de raios $X$ da Cloisita $\mathrm{Na}^{+}$e dos produtos das reações da Cloisita $\mathrm{Na}^{+}$com L-Carnosina. (Código: Identidade da amostra; $p H$ final de reação; proporção molar de argila: aminoácidos; tempo de reação).

(Figura A.2, Anexo A). Diferentemente dos resultados já apresentados para os sistemas de Cloisita com os aminoácidos L-lisina e L-arginina, os dados de DRX para os sistemas Cloisita/L-carnosina parecem indicar que não ocorreu a intercalação do aminoácido na argila, pois a menor dimensão da L-carnosina é de 4,5 , que somado ao valor da espessura da TOT $(9,6 \AA)$ resulta no valor de $d_{(001)}$ igual a $14,1 \AA$. Para uma espécie de L-carnosina com carga +1 a menor área ocupada é $33 \AA^{2}(4,5 \times 7,4)$ e a maior área é $78 \AA^{2}(7,4$ x 10,6), não sendo esse o motivo da possível não intercalação. Os demais resultados de caracterização da amostra devem auxiliar na confirmação ou não dessa proposta.

Na Figura 4.16 estão mostrados os espectros vibracionais na região do infravermelho das amostras isoladas da Cloisita e do aminoácido L-carnosina.

Segundo Durmus [77], no espectro vibracional da L-carnosina, observam-se bandas na região $3230 \mathrm{~cm}^{-1}$ referentes ao estiramento $\mathrm{N}-\mathrm{H}$ do grupo $\mathrm{NH}_{3}^{+}$. A banda na região de aproximadamente $2850 \mathrm{~cm}^{-1}$ é atribuída ao estiramento simétrico e antissimétrico 


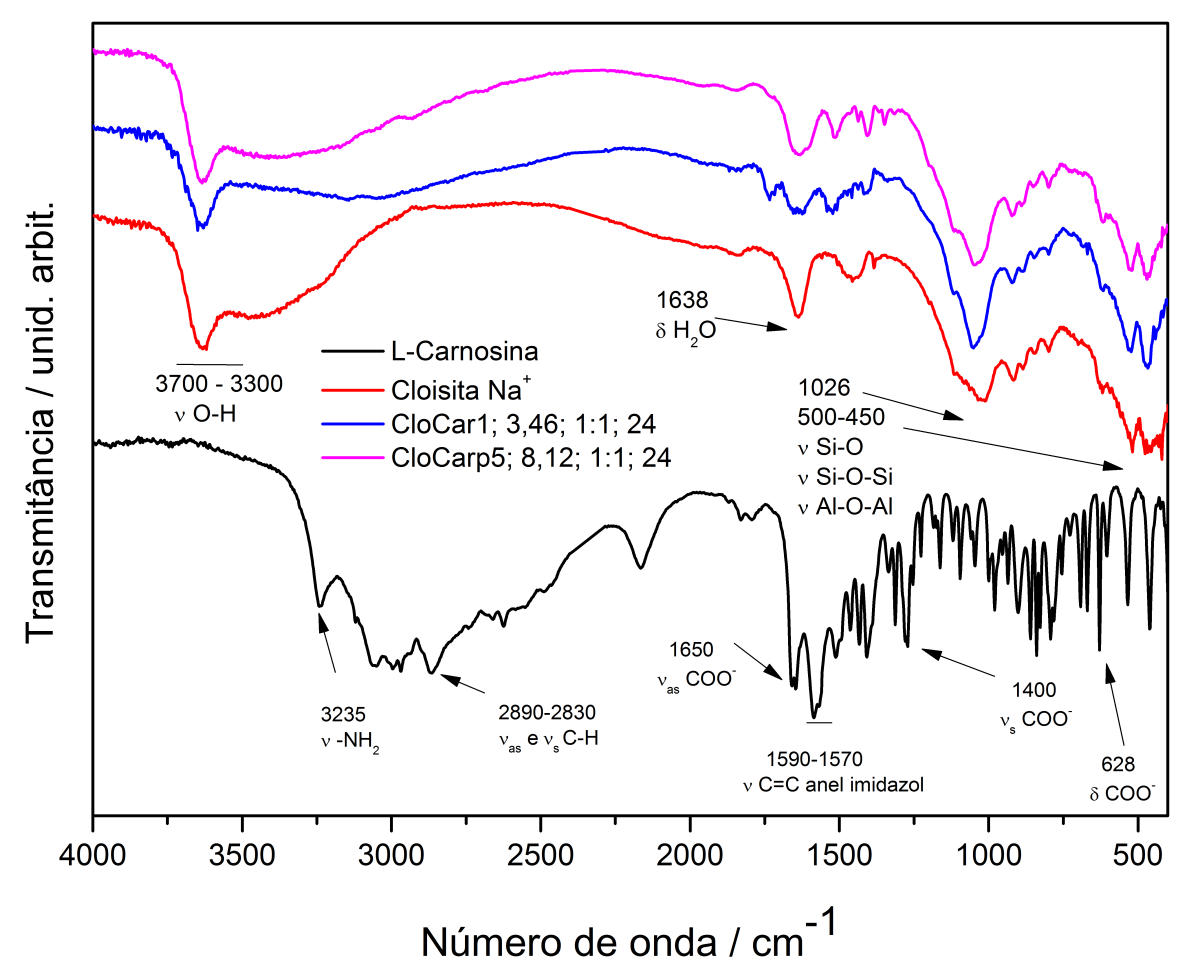

Figura 4.16: Espectros vibracionais na região do Infravermelho da L-Carnosina (preto) e da Cloisita $\mathrm{Na}^{+}$(vermelho) em suas formas originais e dos produtos de reação. (Código: Identidade da amostra; pH final de reação; proporção molar de argila:aminoácido; tempo de reação).

do grupo C-H. O grupo carboxilato $\left(\mathrm{COO}^{-}\right)$apresenta estiramento antissimétrico em $1650 \mathrm{~cm}^{-1}$ e simétrico em $1400 \mathrm{~cm}^{-1}$ e deformação angular em $628 \mathrm{~cm}^{-1}$. Há uma banda em $1630 \mathrm{~cm}^{-1}$ atribuída à deformação angular da água absorvida. As bandas referentes ao estiramento C-C do imidazol encontram-se na região de $1590-1570 \mathrm{~cm}^{-1}$.

Assim como os outros produtos, as amostras com L-carnosina apresentam modificações no espectro FTIR na região entre 1300 e $1700 \mathrm{~cm}^{-1}$. A Figura 4.17 mostra o espectro vibracional entre as regiões 1900 e $1300 \mathrm{~cm}^{-1}$ para uma melhor interpretação dos resultados.

O pH de síntese da amostra CloCar1 foi de aproximadamente 3,5. Logo, considerando o valor de $p K_{a 1}$, a espécie em maior concentração em solução seria aquela com a Lcarnosina com carga $+1\left(\mathrm{Car}^{+}\right)$. Porém, no espectro FTIR há a banda relacionada ao modo vibracional $\nu \mathrm{C}=\mathrm{O}$, sugerindo a presença da espécie em que a L-carnosina está com 


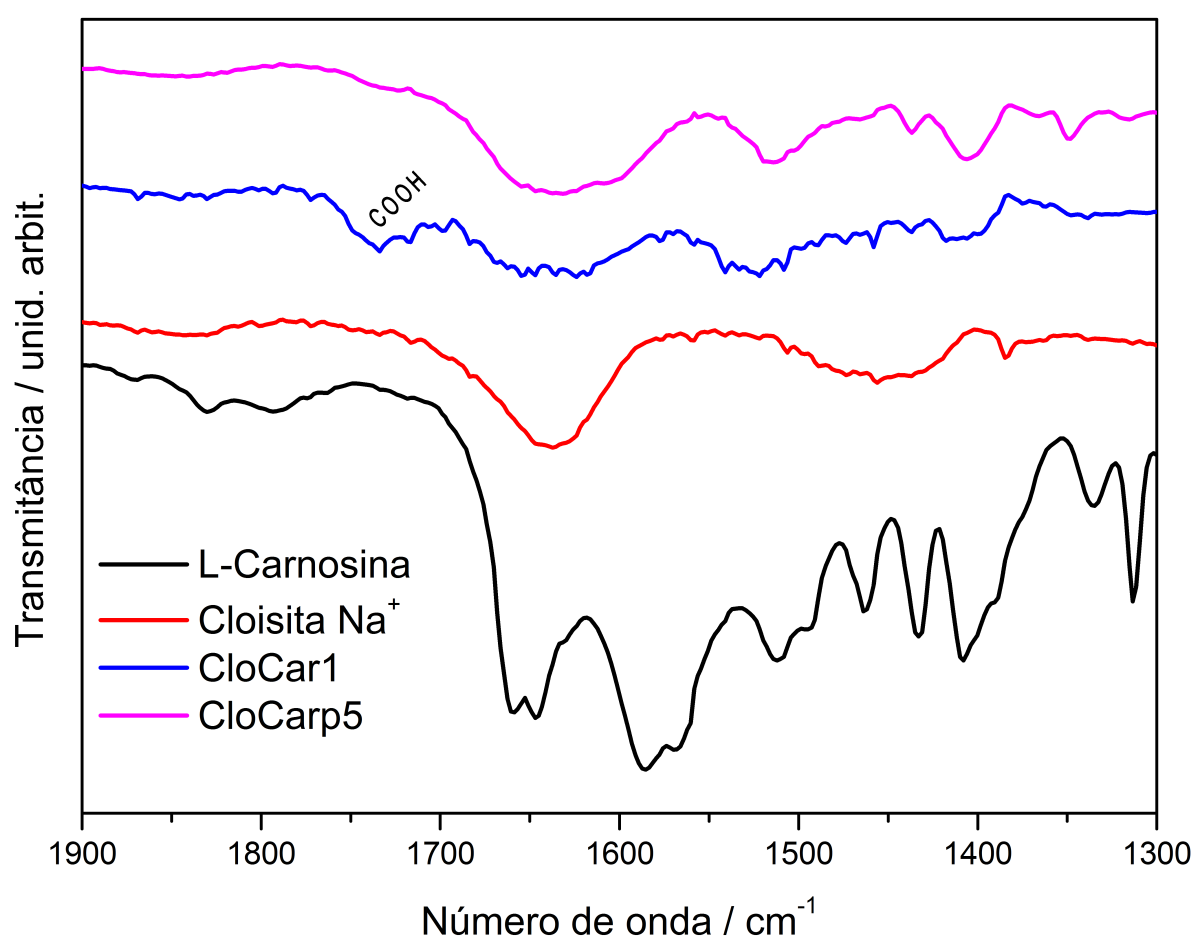

Figura 4.17: Espectros vibracionais na região do Infravermelho da L-Carnosina (preto), Cloisita $\mathrm{Na}^{+}$(vermelho) em suas formas originais e dos produtos de reação. (Código: Identidade da amostra; pH final de reação; proporção molar de argila:aminoácido; tempo de reação).

carga $+2\left(\mathrm{Car}^{2+}\right)$. Para a amostra CloCarp5, considerando-se o valor do $p K_{a 2}$, a espécie preponderante no valor de $\mathrm{pH}$ do meio de preparação da amostra é a L-carnosina com carga zero $\left(\operatorname{Car}^{0}\right)$, na qual os grupos carboxilato e imidazol se encontram desprotonados e o grupo amina está protonado. No espectro da amostra CloCarp5, não se observa banda relacionada ao modo vibracional $\nu \mathrm{C}=\mathrm{O}$ de carboxilato protonado e se observa banda de deformação do grupo $\mathrm{NH}_{3}^{+}$em aproximadamente $1520 \mathrm{~cm}^{-1}$.

Na Figura 4.18 são apresentados os espectros FTIR teóricos calculados para a Lcarnosina através da teoria do funcional da densidade (DFT) [78] no esquema de KohnSham [79], implementados no código computacional Gaussian 09 [80], pelo doutorando e mestre em Física, Filipe Dalmatti Lima, do Instituto de Física da USP (IF-USP), aluno da Professora Doutora Helena Maria Petrilli. As bandas e as atribuições dos modos vibracionais da L-carnosina em diferentes graus de protonação encontram-se na Tabela 4.7. 


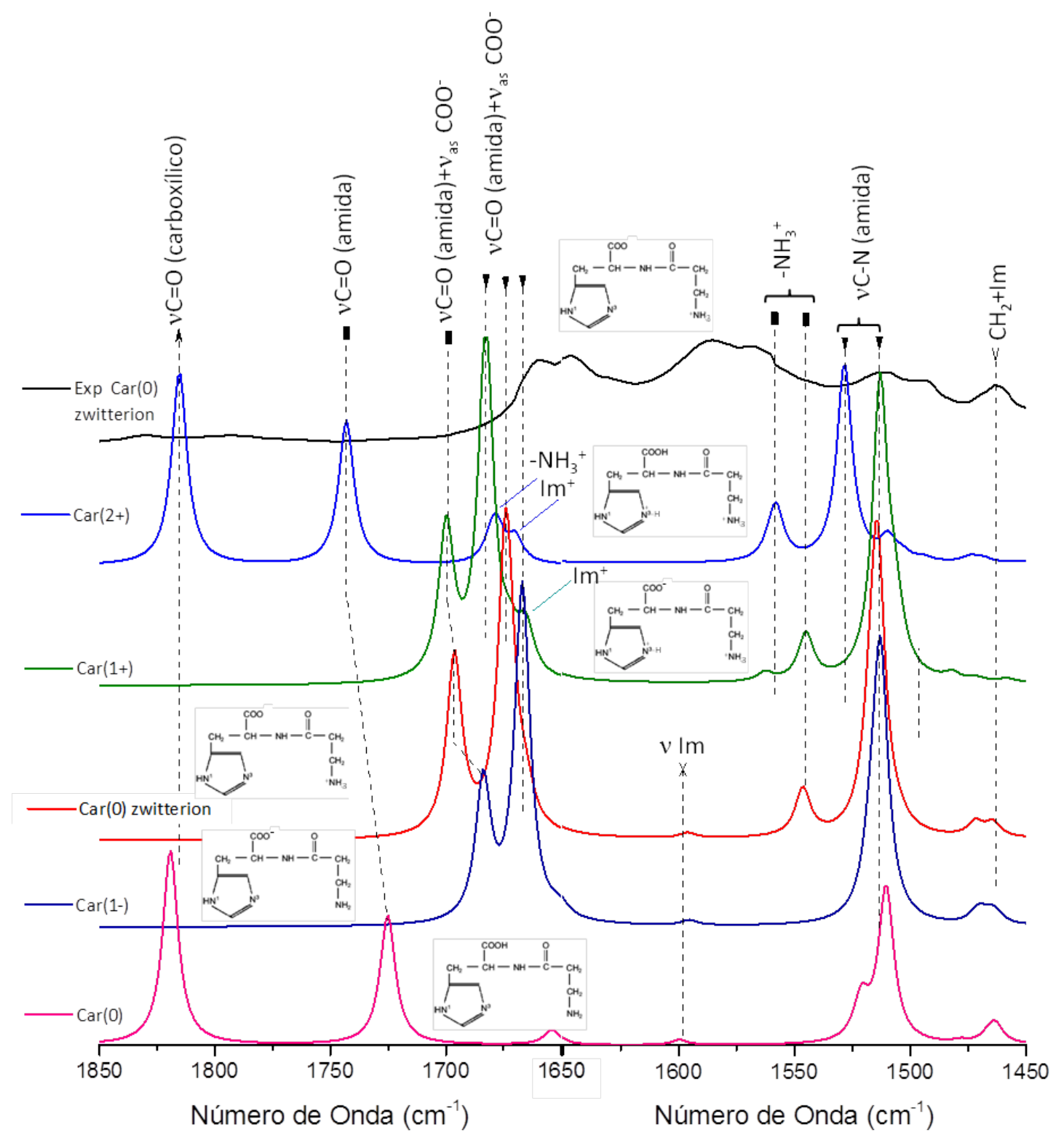

Figura 4.18: Espectros vibracionais na região do Infravermelho calculados da L-Carnosina em diferentes graus de protonação.

As bandas que permitem distinguir o anel imidazólico protonado e desprotonado encontram-se em aproximadamente 1670 e $1600 \mathrm{~cm}^{-1}$, respectivamente (Figura 4.18). Infelizmente a resolução do espectro da CloCarp5 não é alta o suficiente para permitir inferir sobre o grau de protonação do imidazol na amostra e, consequentemente, concluir sobre a presença da espécies $\operatorname{Car}(1+)$ ou Car(0) na amostra com Cloisita.

A Figura 4.19 mostra os resultados referentes à análise térmica da L-Carnosina. O processo de perda de massa pode ser dividido em duas etapas. Na primeira etapa ocorre 
Tabela 4.7: Bandas de absorção e atribuições de alguns modos vibracionais calculados para a L-Carnosina em diferentes graus de protonação.

\begin{tabular}{cc}
\hline $\begin{array}{c}\text { Bandas de absorção } \\
\mathrm{cm}^{-1}\end{array}$ & Modos vibracionais \\
\hline \hline 1820 & Estiramento $\nu C=O$ (carboxílico) \\
\hline $1750-1725$ & Estiramento $\nu C=O$ (amida) \\
\hline & Estiramento $\nu C=O$ (amida) \\
$1700-1650$ & Estiramento simétrico $\nu_{a s} C O O^{-}$ \\
& Deformação $N_{3}^{+}$ \\
& Estiramento anel imidazol \\
\hline 1600 & Estiramento $\nu$ imidazol \\
\hline $1575-1550$ & Deformação $N H_{3}^{+}$ \\
\hline $1525-1500$ & Estiramento simétrico $\nu_{s} C-N$ (amida) \\
\hline 1460 & Estiramento $\nu C H_{2}$ e $\nu$ imidazol
\end{tabular}

a perda do fragmento $\mathrm{m} / \mathrm{z}$ igual a 18 com maior intensidade e do fragmento com $\mathrm{m} / \mathrm{z}$ igual a 44 em menor quantidade. Essa etapa se inicia em $230{ }^{\circ} \mathrm{C}$ e se estende até $350{ }^{\circ} \mathrm{C}$, com perda de massa igual a $33 \%$ da massa total da L-carnosina.

Entre as temperaturas 440 e $730^{\circ} \mathrm{C}$, a perda do fragmento $m / z$ igual a 44 é preponderante, e corresponde a $67 \%$ de perda de massa. Em $800{ }^{\circ} \mathrm{C}$ a massa na curva TG é igual a zero, ou seja, toda a massa de L-carnosina foi transformada em produtos voláteis.

Na Figura 4.20 estão mostrados os dados de análise térmica da amostra CloCar1. Podemos constatar três mínimos mais acentuados na curva DTG. Ao observar os dados de espectrometria de massas, identificam-se também três picos para o fragmento com $\mathrm{m} / z$ igual a 18; já a curva do fragmento com $m / z$ igual a 44 apresenta apenas dois picos e com intensidade muito menor, indicando a perda de água nas temperaturas de 85, 320 e $600{ }^{\circ} \mathrm{C}$ e de $C O_{2(g)}$ em 300 e $615{ }^{\circ} \mathrm{C}$. A massa residual dessa análise foi de $82 \%$.

Os resultados de análise térmica para as demais amostras isoladas com Cloisita/Lcarnosina são apresentados no Apêndice B).

Para a amostra CloCar1 a concentração de L-carnosina foi 7,1% (ou $31 \mathrm{mmol} / 100 \mathrm{~g}$, conforme dados de CHN); o aminoácido está neutralizando aproximadamente $34 \%$ das cargas elétricas da argila.

Ainda não há relatos na literatura sobre o estudo da imobilização de L-carnosina em montmorilonitas. 


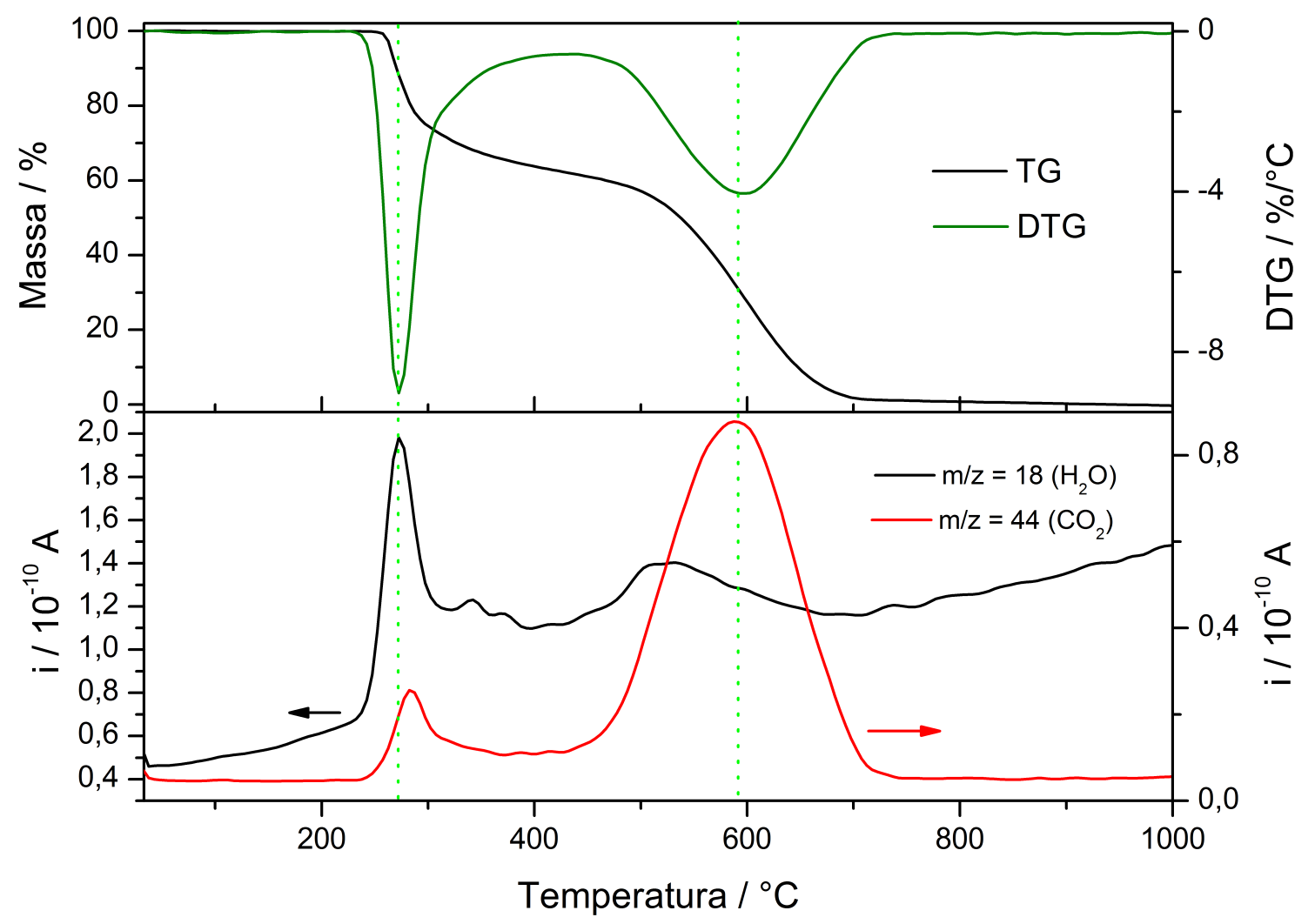

Figura 4.19: Curvas TGA (preto), DTG (verde oliva) e $M S$ (fragmentos $m / z=18$ (preto) e $m / z=44$ (vermelho)) da L-Carnosina. 


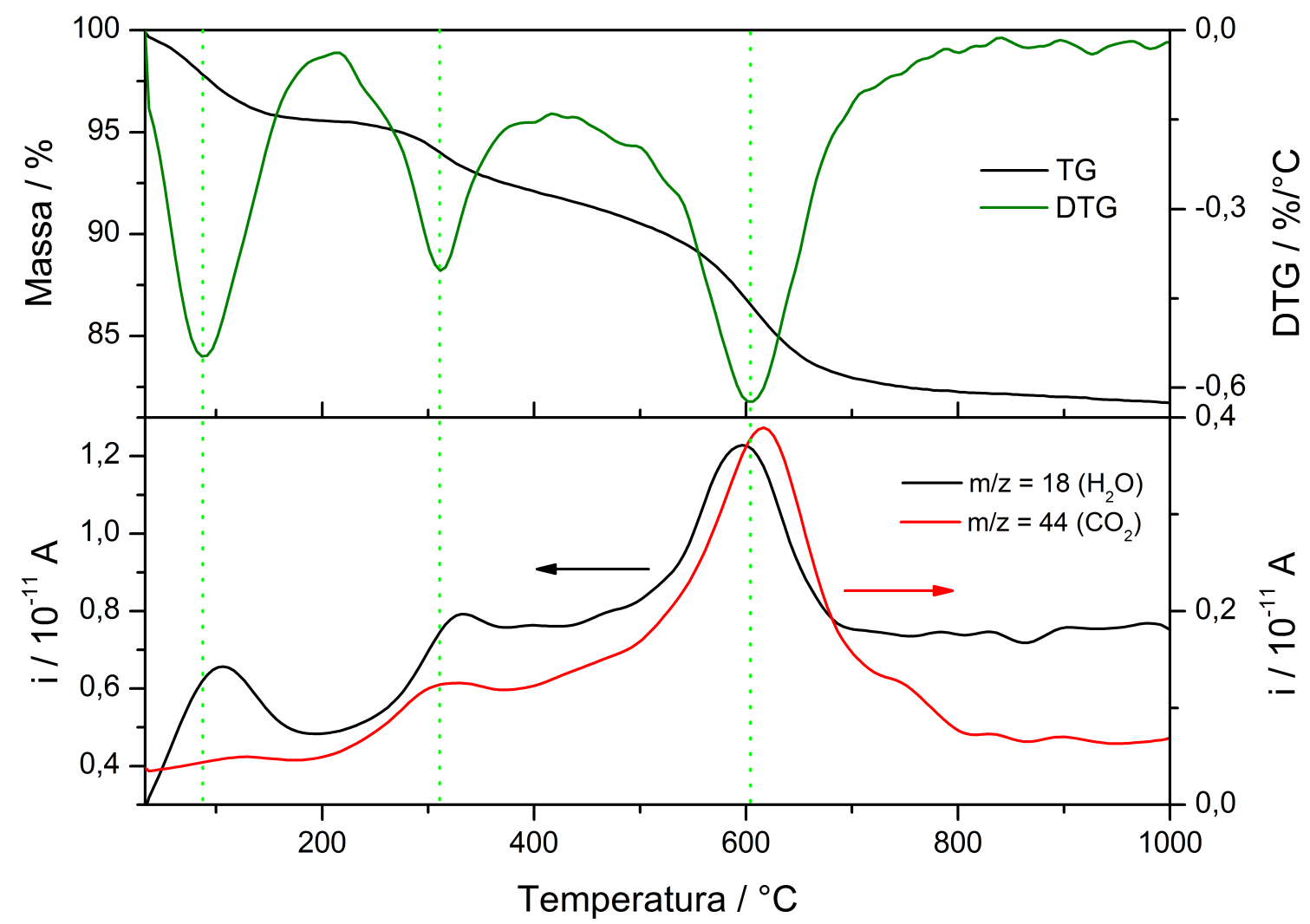

Figura 4.20: Curvas TGA (preto), DTG (verde oliva) e $M S$ (fragmentos $m / z=18$ (preto) e $m / z=44$ (vermelho)) da amostra CloCar1. 


\subsubsection{L-Ornitina em Cloisita Sódica}

O experimento com o aminoácido L-ornitina, amostra denominada CloOrt1, foi realizado com razão molar de 1:2 (argila:aminoácido), pH igual a 4,25 e deixou-se o sistema sob agitação por $48 \mathrm{~h}$. Os outros experimentos foram realizados com razão molar de 1:1 (argila:aminoácido) e com 24 h de agitação, e o valor do pH entre aproximadamente 5 e 7 .

Os difratogramas de raios $\mathrm{X}$ referentes às amostras isoladas nesses experimentos (Figura 4.21) apresentam perfil parecido, indicando que a argila não sofreu modificações em sua estrutura cristalina. Há uma pequena modificação no primeiro pico da Cloisita (20 $\left.=7,30^{\circ}\right)$ em relação ao primeiro pico das amostras CloOrtp4 e CloOrtp6 $\left(2 \theta=6,82^{\circ}\right.$ e $2 \theta=6,92^{\circ}$. Um pequeno aumento do espaçamento interlamelar foi observado, mas como a L-ornitina tem dimensões 3,6 x 6,4 x 5,8 $\AA$ (Figura A.2, Anexo A), os espaços $d_{(001)}$ observados (Tabela 4.8) não permitem inferir com certeza a intercalação de L-ornitina. Outros dados de caracterização devem ser considerados para melhor interpretação dos sistema Cloisita/L-ornitina.

Tabela 4.8: Distância interplanar $d_{(001)}$ dos materiais obtidos pela reação de imobilização de L-Ornitina em Cloisita.

\begin{tabular}{ccc}
\hline Amostra & $2 \theta /$ graus & $d_{(001)} / \AA$ \\
\hline \hline Cloisita & 7,30 & 12,1 \\
\hline CloOrtp4 & 6,82 & 12,9 \\
\hline CloOrtp6 & 6,92 & 12,8 \\
\hline CloOrt1 & 6,90 & 12,8 \\
\hline
\end{tabular}

O espectro vibracional na região do infravermelho do aminoácido L-ornitina (na forma cloridrato), da Cloisita e dos produtos das reações entre os dois materiais encontra-se na Figura 4.22. No espectro referente ao aminoácido, pode-se observar uma banda alargada entre 3200 e $2300 \mathrm{~cm}^{-1}$ referentes às sobreposições das vibrações do grupo N-H. A banda intensa em $1630 \mathrm{~cm}^{-1}$ é um indicativo da presença de grupos $-C O O^{-}$. O estiramento simétrico do grupo $-\mathrm{COO}^{-}$é observado pela banda em $1400 \mathrm{~cm}^{-1}$. Há uma banda em $1480 \mathrm{~cm}^{-1}$ e outra em aproximadamente $400 \mathrm{~cm}^{-1}$, o que confirma a presença do grupo $-\mathrm{NH}_{3}^{+}[81]$. 


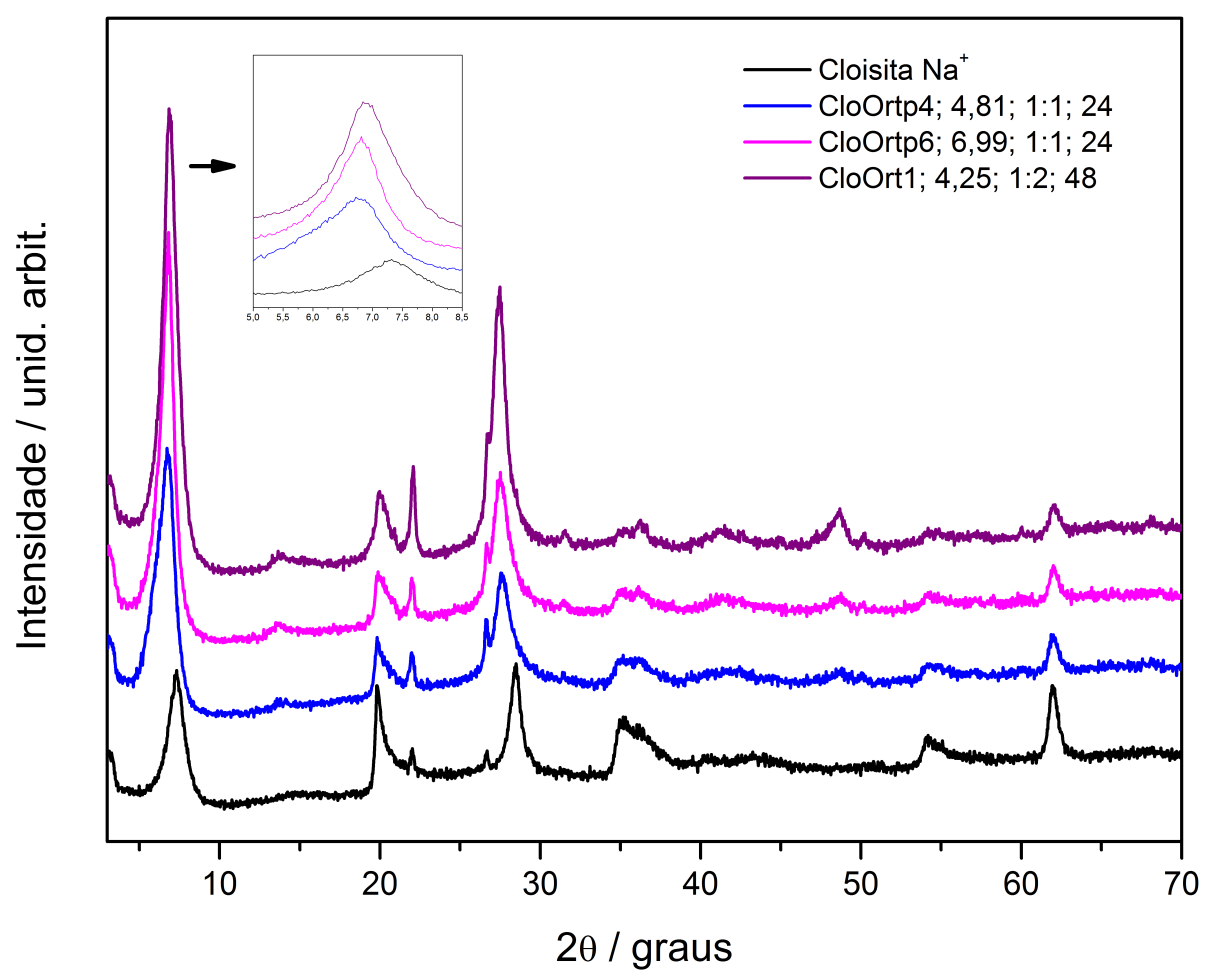

Figura 4.21: Difratogramas de raios $X$ da Cloisita $\mathrm{Na}^{+}$e dos produtos das reações da Cloisita $\mathrm{Na}^{+}$com L-Ornitina. (Código: Identidade da amostra; $p H$ final de reação; proporção molar de argila:aminoácido; tempo de reação).

Na Figura 4.23 é mostrado o espectro vibracional entre as regiões 1900 e $1300 \mathrm{~cm}^{-1}$, para melhor visualização das modificações observadas, comparando-se os espectros vibracionais dos produtos das reações e seus precursores.

Os espectros FTIR mostram que a L-ornitina não se encontra totalmente protonada nas amostras destacadas, uma vez que se observa banda referente ao estiramento $\nu C=O$ somente na amostra CloOrt1 (banda ausente no espectro do cloridrato de L-ornitina). Considerando-se o valor de pH de preparação da amostra CloOrt1 $(4,25)$ e o valor de $p K_{a 1}$ da L-ornitina $(1,94)$ a forma $\mathrm{H}_{3} \mathrm{~N}^{+}\left(\mathrm{CH}_{2}\right)_{3} \mathrm{CH}\left(\mathrm{N}^{+} \mathrm{H}_{3}\right) \mathrm{COO}^{-}$(L-ornitina com carga $\left.1+=\mathrm{Ort}^{+}\right)$é 200 vezes superior à forma $\operatorname{Ort}^{2+}$ (L-ornitina com carga 2+) comprovando que a protonação do grupo carboxilato é devido à acidez intrínseca da argila. As amostras CloOrt1 e CloOrtp4 foram preparadas em valores de $\mathrm{pH}$ abaixo do valor de $p K_{a 2}(8,65)$, de modo que a espécie em maior concentração em solução é a L-ornitina com carga $1+$. Na preparação da CloOrt1 foi usado o dobro de aminoácido em relação à preparação de 


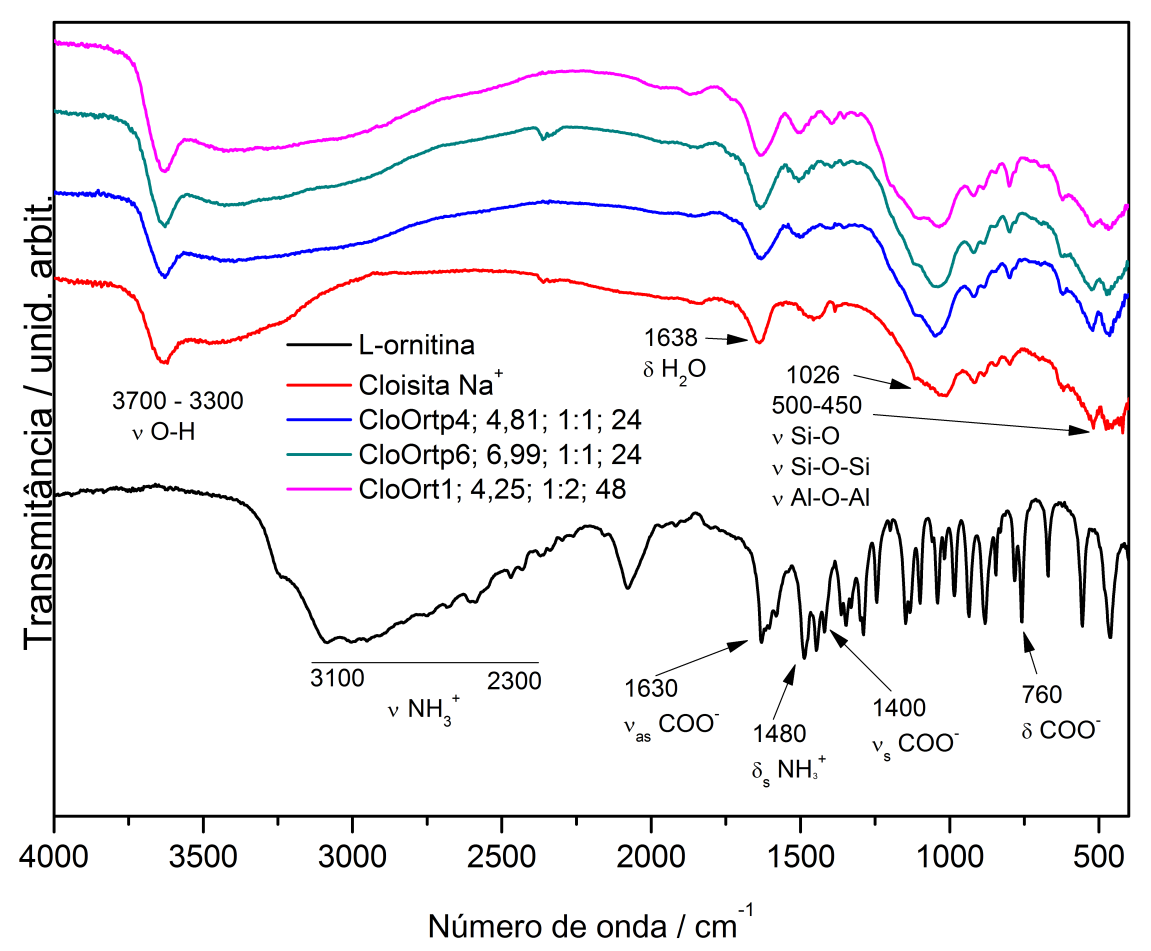

Figura 4.22: Espectros vibracionais na região do Infravermelho do Cloridrato de L-Ornitina (preto), Cloisita $\mathrm{Na}^{+}$(vermelho) em suas formas originais e dos produtos de reação. (Código: Identidade da amostra; pH final de reação; proporção molar de argila:aminoácido; tempo de reação).

CloOrtp4 e o tempo de reação foi também dobrado para promover uma maior extensão de intercalação do aminoácido na Cloisita. Os espectros dessas duas amostras apresentam intensidades diferentes nas regiões de $1700-1570 \mathrm{~cm}^{-1}$ (referentes à absorção de moléculas de água, dos grupos $-\mathrm{COO}^{-}, \nu \mathrm{C}=\mathrm{O}$ e dos grupos $\left.-\mathrm{NH}_{3}^{+}\right)$e de $1520-1450 \mathrm{~cm}^{-1}$ (referentes aos grupos $-\mathrm{COO}^{-} \mathrm{e}-\mathrm{NH}_{3}^{+}$). As intensidades parecem indicar que há maior conteúdo de material orgânico na amostra CloOrt1. Os dados de análise térmica apresentados a seguir poderão esclarecer tal proposta.

Os resultados referentes à análise térmica da L-ornitina estão apresentados na Figura 4.24. Observando a curva DTG, pode-se dividir o processo de perda de massa em duas etapas principais. Na primeira etapa, que ocorre entre 220 e $320{ }^{\circ} \mathrm{C}$, há a perda do fragmento $m / z$ igual a 18 , constatado pelo espectro de massas. Nesse primeiro processo, a perda de massa é igual a $66 \%$ da massa total da L-ornitina. Entre as temperaturas 500 e $630{ }^{\circ} \mathrm{C}$ 




Figura 4.23: Espectros vibracionais na região do Infravermelho do Cloridrato de L-Ornitina (preto) e da Cloisita $\mathrm{Na}^{+}$(vermelho) em suas formas originais e dos produtos de reação. (Código: Identidade da amostra; $p H$ final de reação; proporção molar de argila:aminoácido; tempo de reação).

ocorre também a perda do fragmento $\mathrm{m} / \mathrm{z}$ igual a 44 , além da perda do fragmento $\mathrm{m} / \mathrm{z}$ igual a 18. Em $630{ }^{\circ} \mathrm{C}$ toda a massa de L-ornitina foi convertida em produtos voláteis.

Na Figura 4.25 são apresentados os resultados referentes à análise térmica da amostra CloOrt1. Pela curva DTG, observa-se que há dois processos de perda de massa: o primeiro na temperatura em torno de $77^{\circ} \mathrm{C}$ e o segundo em torno de $610{ }^{\circ} \mathrm{C}$. A massa residual foi de $88 \%$. A perda do fragmento com $\mathrm{m} / \mathrm{z}$ igual a 18 ocorre em maior intensidade entre a temperatura inicial até $170{ }^{\circ} \mathrm{C}$ e de 500 a $730{ }^{\circ} \mathrm{C}$. Há perda com maior intensidade do fragmento com $\mathrm{m} / z$ igual a 44 entre as temperaturas de 230 e $850{ }^{\circ} \mathrm{C}$, mas muito menor em relação à água. Interessantemente, o evento em aproximadamente $280{ }^{\circ} \mathrm{C}$ observado para o cloridrato de L-ornitina é muito pouco pronunciado nas amostras de L-ornitina imobilizada em Cloisita. Os dados de análise térmica são semelhantes para as amostras CloOrt1 e CloOrtp4 (Apêndice B), evidenciando que o fato de dobrar a quantidade de 




Figura 4.24: Curvas TGA (preto), DTG (verde oliva) e $M S$ (fragmentos $m / z=18$ (preto) e $m / z=44$ (vermelho)) do Cloridrato de L-Ornitina.

L-ornitina na preparação da amostra CloOrt1 não resultou em maior conteúdo de aminoácido imobilizado em argila.

O conteúdo de matéria orgânica na amostra CloOrtp6 é semelhante às quantidades observadas para as amostras mencionadas acima e os resultados de análise térmica também encontram-se no Apêndice B.

A amostra CloOrt1 possui 2,80 \% de carbono. Considerando a imobilização da espécie $\mathrm{Ort}^{+}$, a porcentagem de L-ornitina é 6,2\% (ou 46,6 mmol/100 g de material), neutralizando 50,6 \% da CTC. Sendo assim, o aminoácido deve estar intercalado e não apenas adsorvido nas arestas da argila.

Assim como para a L-carnosina, para a L-ornitina imobilizada em montmorilonitas não se encontrou relatos na literatura sobre esse sistema. 


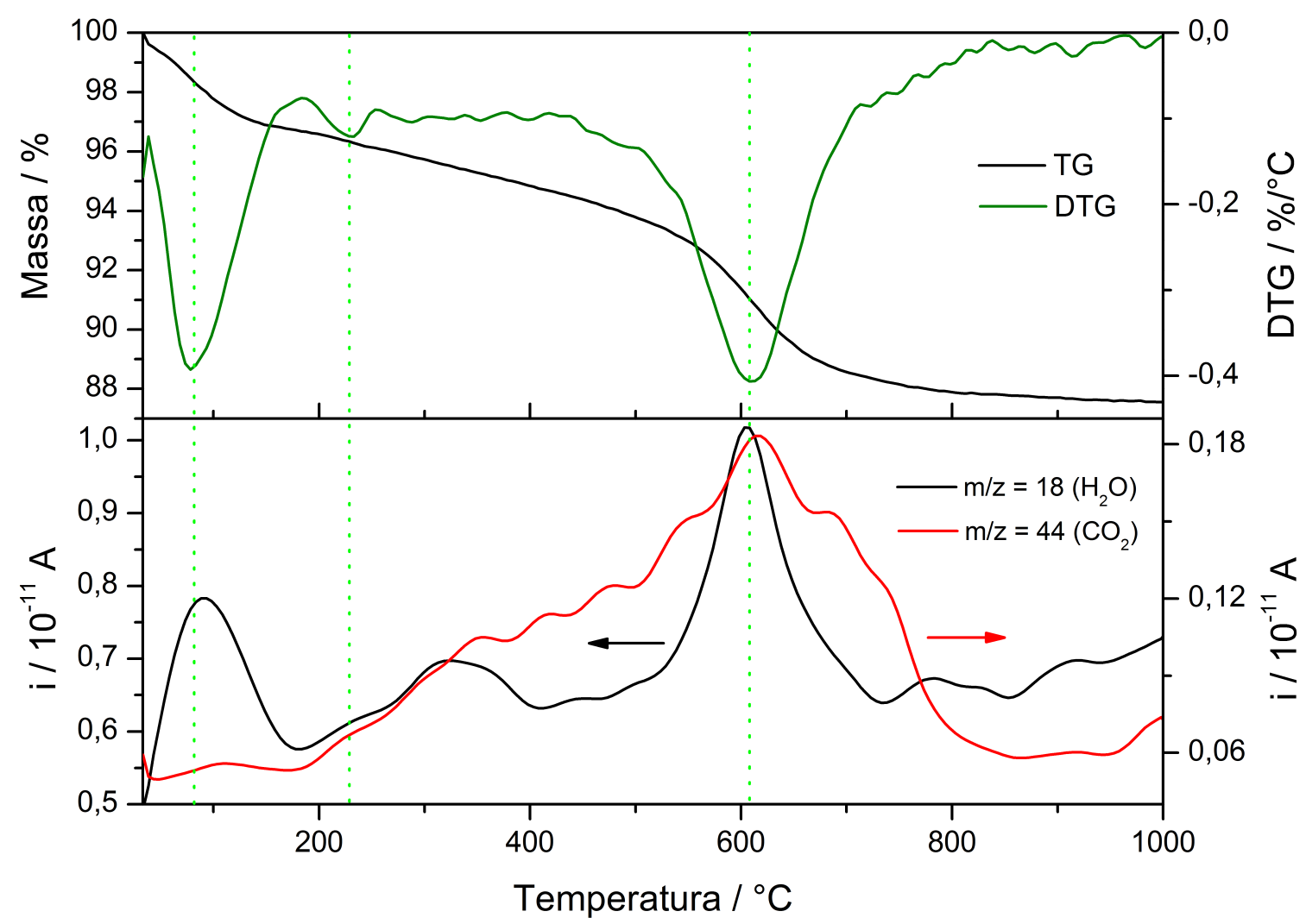

Figura 4.25: Curvas TGA (preto), DTG (verde oliva) e $M S$ (fragmentos $m / z=18$ (preto) e $m / z=44$ (vermelho)) da amostra CloOrt1.

\subsection{Imobilização de aminoácidos em Veegum HS}

O procedimento experimental para se realizar as medidas de diâmetro médio das partículas e de potencial Zeta foram os mesmos já descritos para a argila Cloisita. O potencial Zeta da suspensão de Veegum HS 0,1\% (m/v) é - 46,9 mV $(\sigma= \pm 1,27)$, indicando que a suspensão é estável, e o pH da suspensão é de aproximadamente 7,3. O diâmetro médio dessas partículas em suspensão é de $148 \mathrm{~nm}(\sigma= \pm 0,79$ e $P D I=0,26)$.

\subsubsection{L-Lisina em Veegum HS}

Ao se observar os difratogramas de raios X mostradas na Figura 4.26, constata-se que a estrutura cristalina da argila é preservada depois das reações de imobilização com a LLisina. Na Tabela 4.9 estão os valores de $2 \theta$ e da distância interplanar $d_{(001)}$ dos materiais obtidos pela reação de imobilização de L-lisina em Veegum HS. 


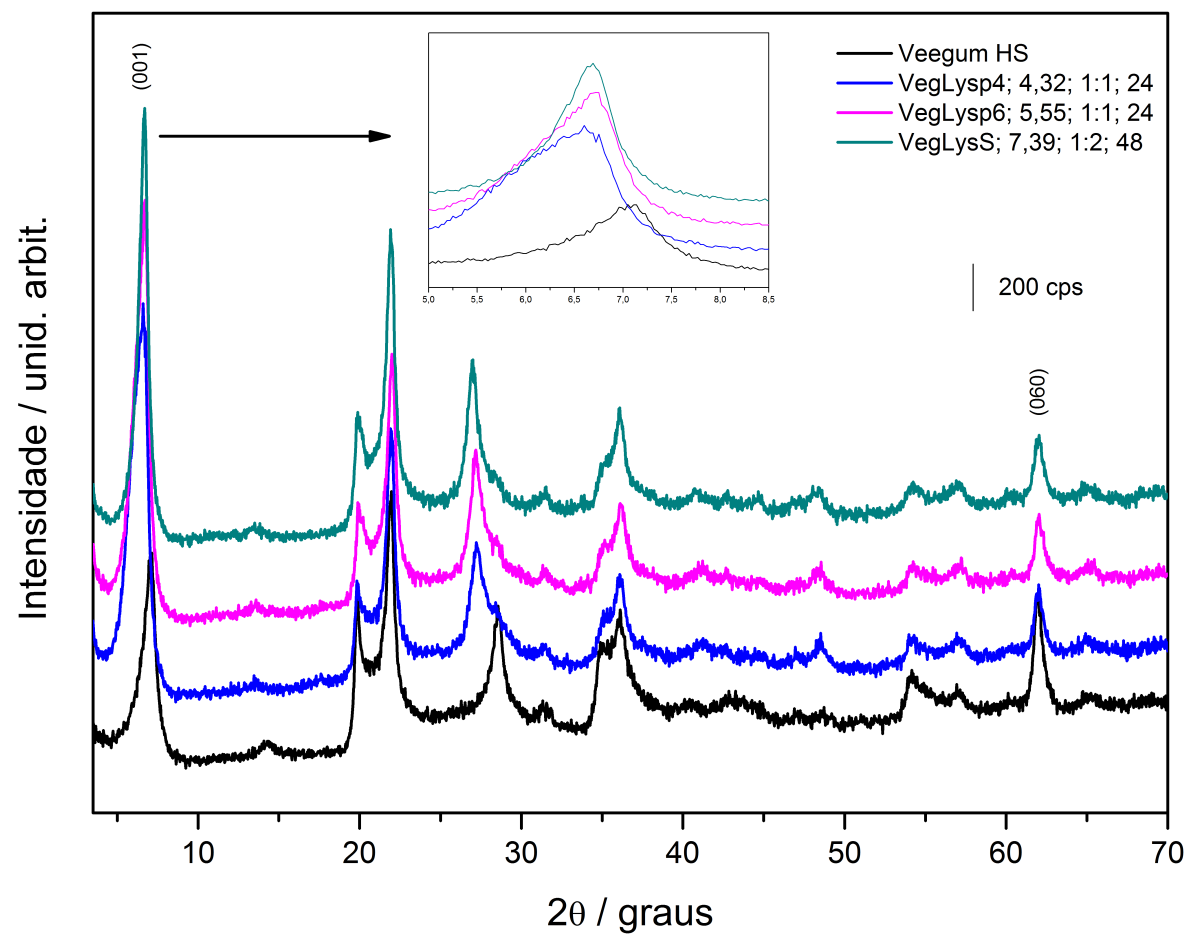

Figura 4.26: Difratogramas de raios $X$ da Veegum $H S$ e dos produtos das reações da Veegum HS com L-Lisina. (Código: Identidade da amostra; $p H$ final de reação; proporção molar de argila:aminoácido; tempo de reação).

Tabela 4.9: Distância interplanar $d_{(001)}$ dos materiais obtidos pela reação de imobilização de L-Lisina em Veegum HS.

\begin{tabular}{ccc}
\hline Amostra & $2 \theta /$ graus & $d_{(001)} / \AA$ \\
\hline \hline Veegum & 7,11 & 12,4 \\
\hline VegLysp4 & 6,62 & 13,3 \\
\hline VegLysp6 & 6,70 & 13,2 \\
\hline VegLysS & 6,68 & 13,2 \\
\hline
\end{tabular}

Conforme discussão realizada para o sistema Cloisita/L-lisina, os valores de espaçamento basal observado sugerem que o aminoácido se encontra em orientação paralela às lamelas da argila, uma vez que a menor dimensão da L-lisina é 3,6̊ (Anexo A) e a espessura da lamela é $9,6 \AA$.

No espectro FTIR da Veegum HS (Figura 4.27) há bandas características da argila, como a banda larga na região de $3700-3300 \mathrm{~cm}^{-1}$, atribuída ao estiramento O-H das moléculas de água (tanto de hidratação do cátion interlamelar ou adsorvidas na lamela, quanto das hidroxilas das lamelas). Na região próxima a $1630 \mathrm{~cm}^{-1}$ há uma banda atri- 
buída à deformação angular da molécula de água. As bandas em 1060, 780 e 550-450 $\mathrm{cm}^{-1}$ correspondem, respectivamente, aos estiramentos Si-O, Si-O-Si e Al-O-Al [75]. Como observado para os sistemas Cloisita/aminoácidos, os espectros FTIR são dominados pelas bandas do argilomineral.

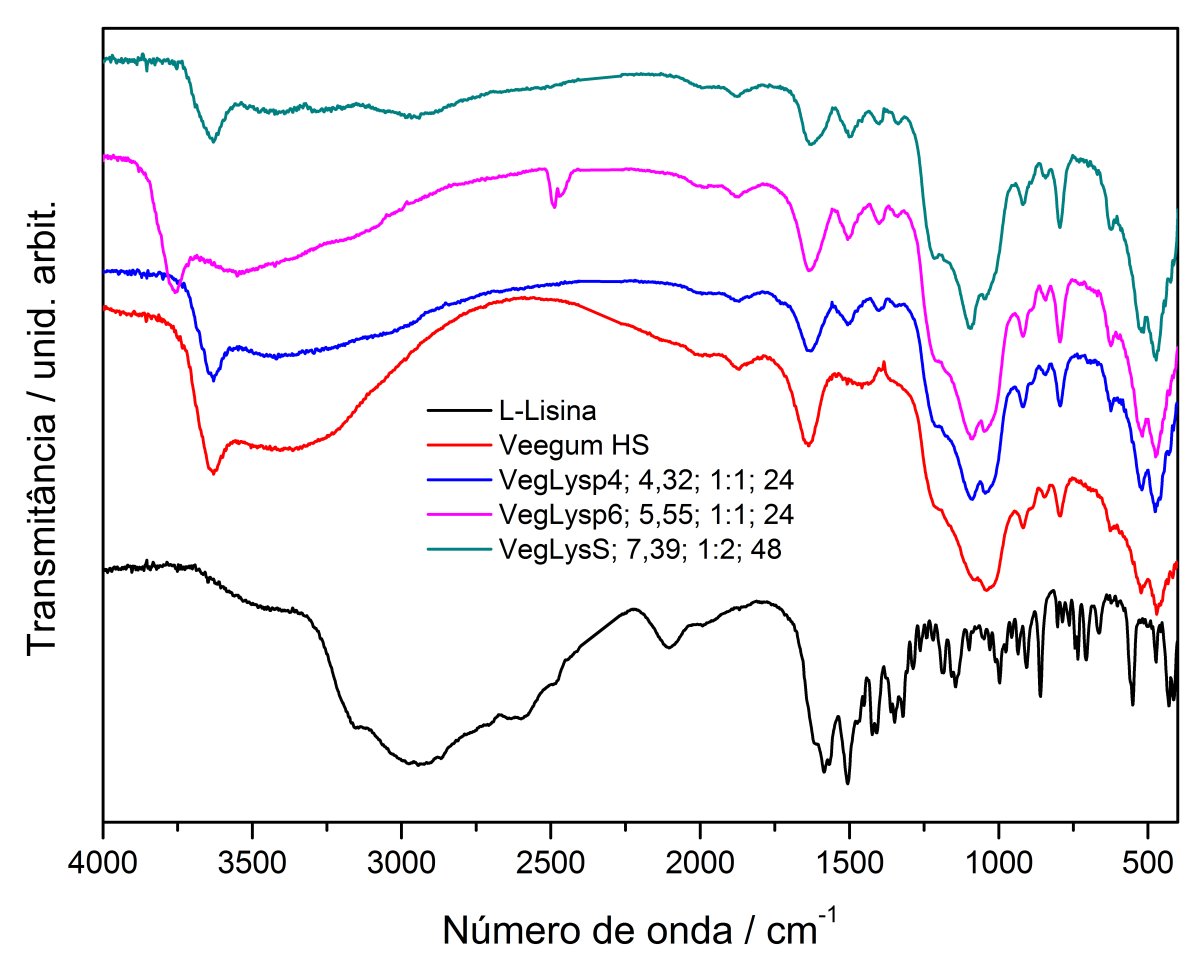

Figura 4.27: Espectros vibracionais na região do Infravermelho do Cloridrato de L-Lisina (preto), Veegum HS (vermelho) em suas formas originais e dos produtos de reação. (Código: Identidade da amostra; pH final de reação; proporção molar de argila:aminoácido; tempo de reação).

Há uma mudança no espectro do Cloridrato de L-lisina na região do infravermelho entre $1600-1300 \mathrm{~cm}^{-1}$ após imobilização em Veegum HS, como pode ser melhor visualizado na Figura 4.28.

Nos valores de pH em que as três amostras foram preparadas (VegLysp4, VegLysp5 e VegLysp6), espera-se que a L-lisina esteja na forma $\mathrm{H}_{3} \mathrm{~N}^{+}\left(\mathrm{CH}_{2}\right)_{4} \mathrm{CH}\left(\mathrm{N}^{+} \mathrm{H}_{3}\right) \mathrm{COO}^{-}$ $\left(\right.$ Lys $\left.^{+}\right)$. A amostra VegLysp4 (preparada em pH igual a 4,32) não apresenta a banda referente ao modo vibracional $\nu C=O$ observada para a amostra CloLysp4 (preparada em pH igual a 4,09). A diferença observada neste trabalho pode ser devido aos valores 




Figura 4.28: Espectros vibracionais na região do Infravermelho do Cloridrato de L-Lisina (preto), Veegum HS (vermelho) em suas formas originais e dos produtos de reação. (Código: Identidade da amostra; pH final de reação; proporção molar de argila:aminoácido; tempo de reação).

diferentes de $\mathrm{pH}$ ou a uma maior acidez da argila Cloisita em relação à Veegum HS conforme dados da literatura.

Na Figura 4.29 são apresentados os resultados referentes à análise térmica da Veegum HS. Pode-se dividir o processo de perda de massa em dois eventos principais. No primeiro evento, entre a temperatura ambiente e aproximadamente $160{ }^{\circ} \mathrm{C}$, ocorre a perda das moléculas de água ligadas superficialmente nas lamelas e, também, presentes na região interlamelar. Confirma-se a identidade da espécie volátil pela curva do espectro de massas, que indica a liberação de um fragmento com $m / z$ igual a 18 . O segundo principal evento de perda de massa, com um pico DTG em $670{ }^{\circ} \mathrm{C}$, é devido ao processo de desidroxilação (eliminação de $\mathrm{H}_{2} \mathrm{O}$ ) das lamelas da argila.

Diferentemente do resultado da análise térmica da argila precursora, o produto VegLysS (Figura 4.30) apresenta um evento de perda de massa adicional no intervalo de 


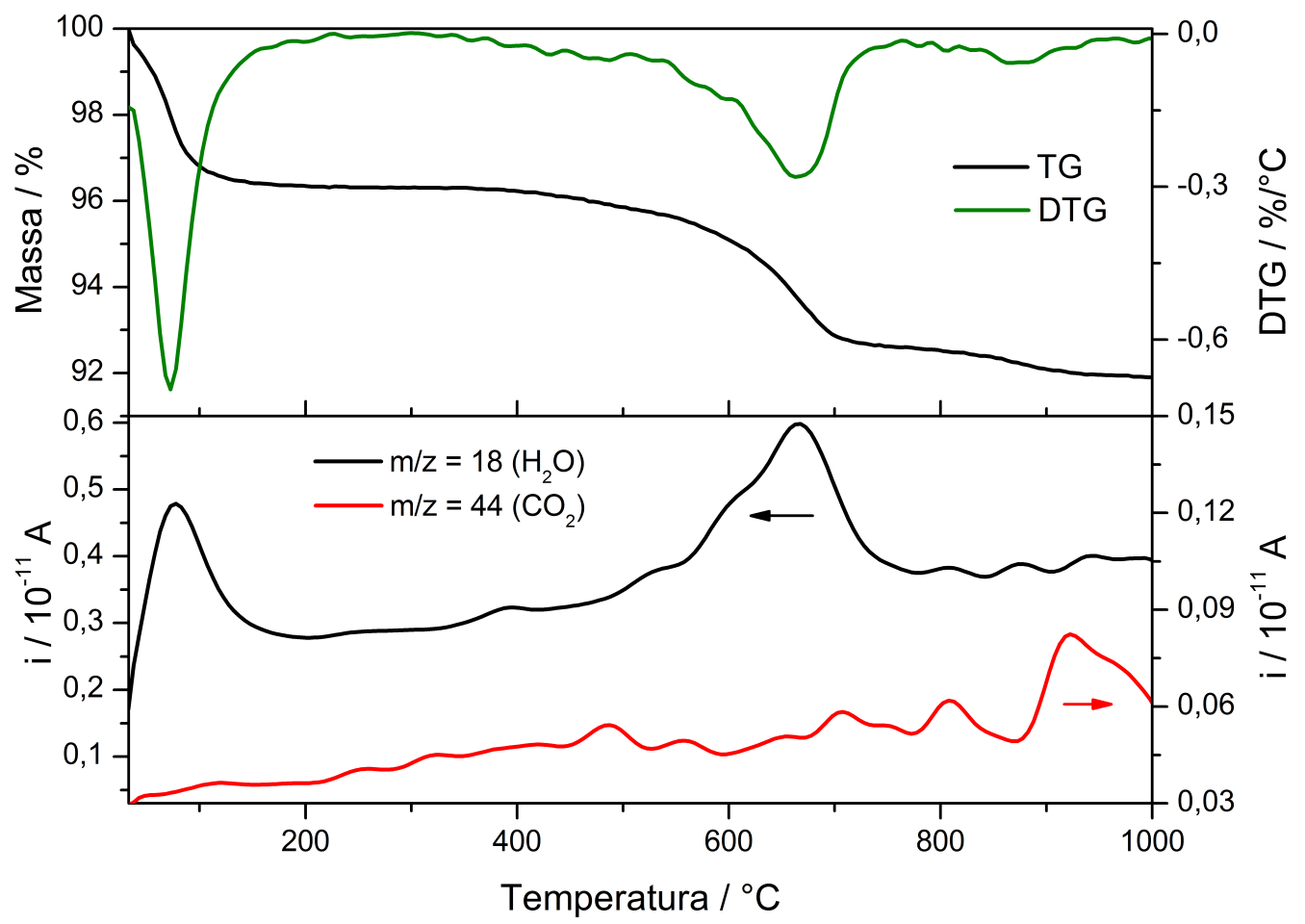

Figura 4.29: Curvas TGA (preto), DTG (verde oliva) e $M S$ (fragmentos $m / z=18$ (preto) e $m / z=44$ (vermelho)) da Veegum $H S$.

temperatura de 200 a $600{ }^{\circ} \mathrm{C}$, atribuído à presença de composto orgânico no material.

Mesmo em baixa quantidade (36,4 mmol / $100 \mathrm{~g}$ de amostra ou 5,8 \%), a interação com a argila está alterando o perfil de decomposição da L-lisina. Talvez o fato da L-lisina estar entre as lamelas dificulte o acesso do oxigênio molecular, de modo que a oxidação total do aminoácido ocorra em temperaturas mais elevadas que aquela observada para o cloridrato de L-lisina. 




Figura 4.30: Curvas TGA (preto), DTG (verde oliva) e $M S$ (fragmentos $m / z=18$ (preto) e $m / z=44$ (vermelho)) da amostra VegLysS.

\subsubsection{L-Arginina em Veegum HS}

Na Figura 4.31 estão apresentados os difratogramas de raios X da argila Veegum HS e dos produtos das reações de imobilização com o aminoácido L-arginina. Na Tabela 4.10 estão os valores de $2 \theta$ e da distância interplanar $d_{(001)}$ para o sistema Veegum HS/Larginina.

Tabela 4.10: Distância interplanar $d_{(001)}$ dos materiais obtidos pela reação de imobilização de L-Arginina em Veegum HS.

\begin{tabular}{ccc}
\hline Amostra & $2 \theta /$ graus & $d_{(001)} / \AA$ \\
\hline \hline Veegum & 7,11 & 12,4 \\
\hline VegArgp4 & 6,57 & 13,4 \\
\hline VegArgS & 6,84 & 12,9 \\
\hline
\end{tabular}

Os espaçamentos observados sugerem a intercalação da L-arginina em arranjo paralelo às lamelas da argila, visto que o somatório da menor dimensão do aminoácido $(3,6 \AA)$ com a espessura da camada TOT $(9,6 \AA)$ é igual a $13,2 \AA$.

Observando-se os espectros vibracionais da Figura 4.32, percebe-se que as mudanças 


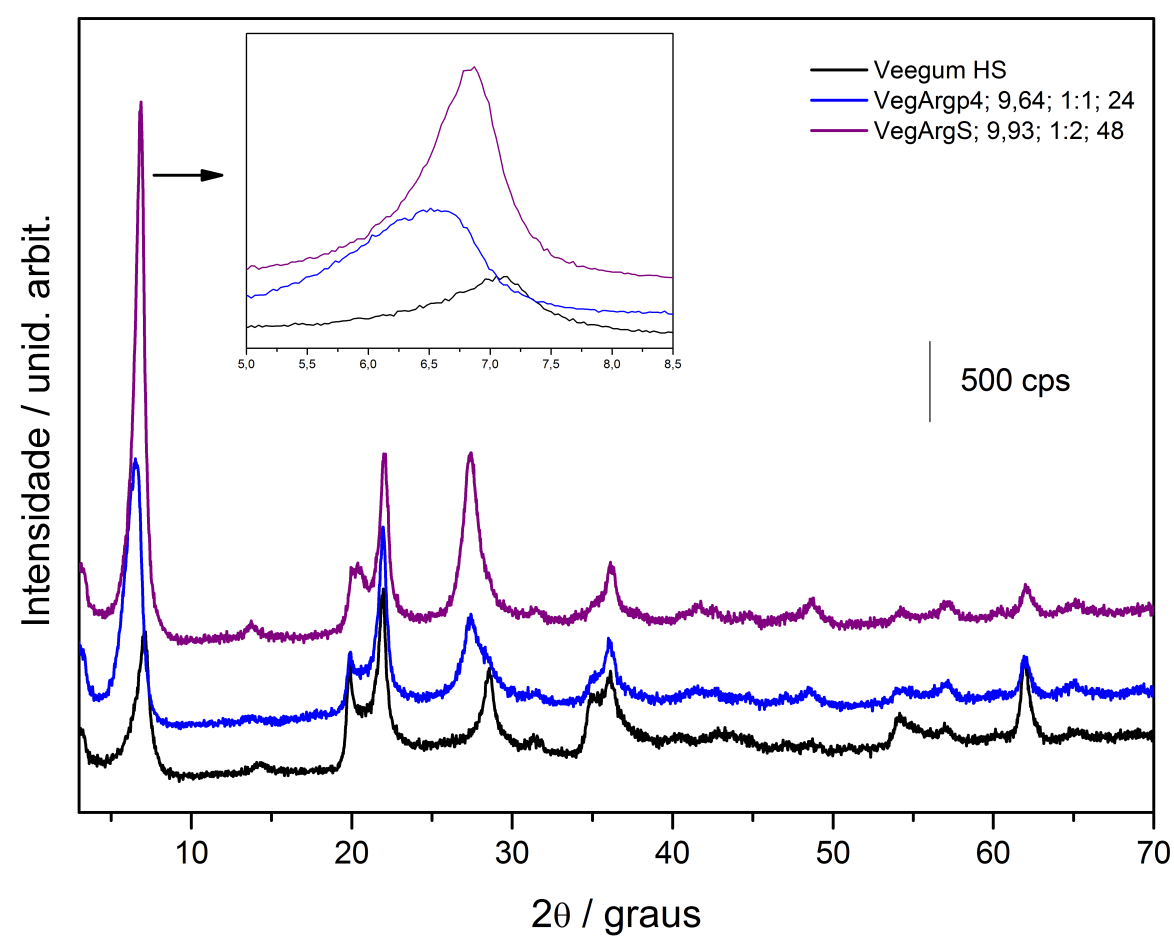

Figura 4.31: Difratogramas de raios $X$ da Veegum $H S$ e dos produtos das reaçôes da Veegum HS com L-Arginina. (Código: Identidade da amostra; $p H$ final de reação; proporção molar de argila:aminoácido; tempo de reação).

no espectro dos produtos das reações da argila com a L-arginina também ocorrem entre $1600-1300 \mathrm{~cm}^{-1}$, assim como os dos outros produtos com a Cloisita.

A Figura 4.33 mostra os espectros vibracionais entre as regiões 1900 e $1300 \mathrm{~cm}^{-1}$ para melhor visualização das modificações observadas.

As amostras VegArgp4 e VegArgS foram preparadas em suspensões com valores de $\mathrm{pH}$ superiores ao valor de $p K_{a 2}$ da L-arginina $(9,04)$. A espécie em solução em maior concentração é a $\operatorname{Arg}^{0}$ (L-arginina com carga zero).

Como podemos observar na Figura 4.34, há três eventos principais de perda de massa para a amostra VegArgS. No primeiro evento é liberado apenas o fragmento com $m / z$ igual a 18 e, entre 200 e $800{ }^{\circ} \mathrm{C}$, observa-se a perda, tanto de moléculas de água (fragmento com $m / z$ igual a 18), quanto de matéria orgânica na forma de dióxido de carbono (atribuída ao fragmento $m / z$ igual a 44$)$.

A massa residual dessa análise é em torno de 87 \%. Para as outras amostras (VegArgp4, 




Figura 4.32: Espectros vibracionais na região do Infravermelho da L-Arginina (preto), Veegum $H S$ (vermelho) em suas formas originais e dos produtos de reação. (Código: Identidade da amostra; $\mathrm{pH}$ final de reação; proporção molar de argila:aminoácido; tempo de reação).

VegArgp5 e VegArgp6) a perda de massa foi um pouco menor e os perfis das curvas TG, DTG e MS são semelhante as da amostra VegArgS (os resultados referentes à análise térmica dessas amostras encontram-se no Apêndice B).

O resultado de análise elementar para a amostra VegArgS demonstrou menor porcentagem em massa de carbono $(1,94 \%)$ que o sistema Cloisita/L-arginina. Essa amostra apresenta aproximadamente 4,71 \% de aminoácido ou 26,9 mmol de L-arginina / $100 \mathrm{~g}$ de material. 


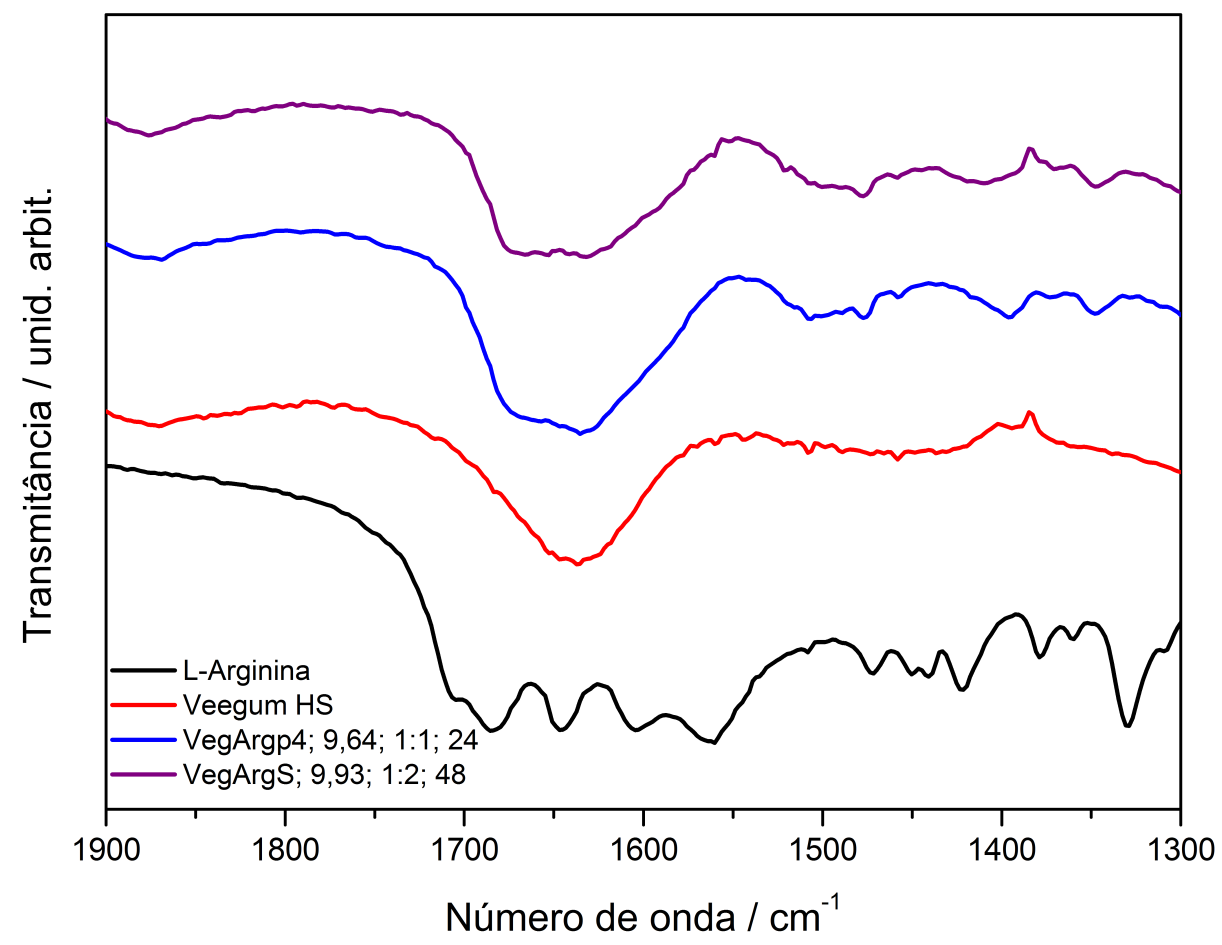

Figura 4.33: Espectros vibracionais na região do Infravermelho da L-Arginina (preto), Veegum $H S$ (vermelho) em suas formas originais e dos produtos de reação. (Código: Identidade da amostra; pH final de reação; proporção molar de argila:aminoácido; tempo de reação). 


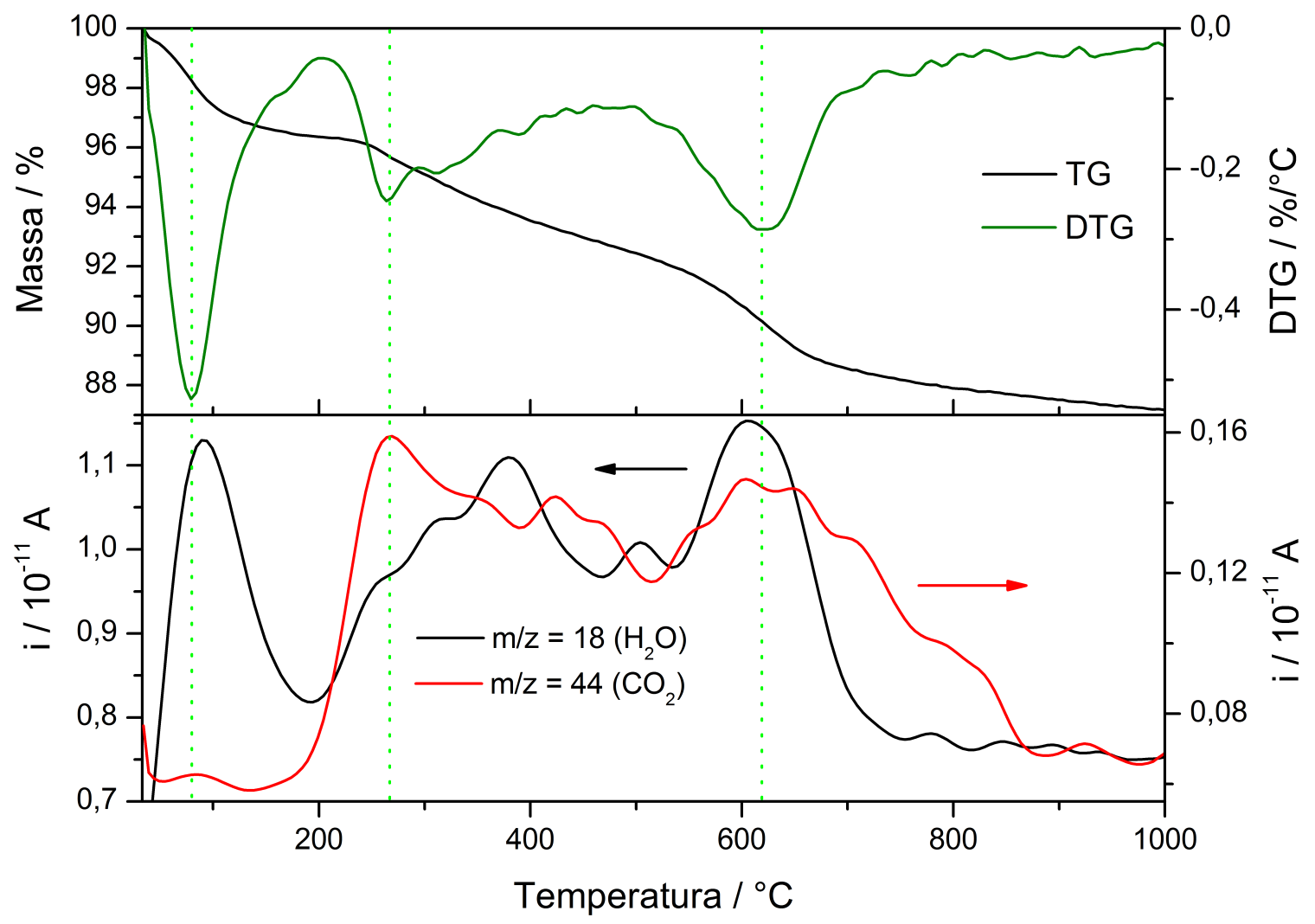

Figura 4.34: Curvas TGA (preto), DTG (verde oliva) e $M S$ (fragmentos $m / z=18$ (preto) e $m / z=44$ (vermelho)) da amostra VegArgS. 


\subsubsection{L-Carnosina em Veegum HS}

Para a intercalação da L-carnosina na argila farmacêutica Veegum HS, fez-se experimentos com variações no valor do pH, na proporção argila:aminoácido e no tempo de reação.

Ao se observar os difratogramas de raios X (Figura 4.35), nota-se que todos os produtos das reações de intercalação apresentam os picos em $2 \theta=7,11^{\circ}(\mathrm{d}=12,4 \AA)$, correspondendo ao plano (001), deslocados entre 13,0 e 13,7 $\AA$, o que pode ser um indício da intercalação do dipeptídeo em Veegum HS.

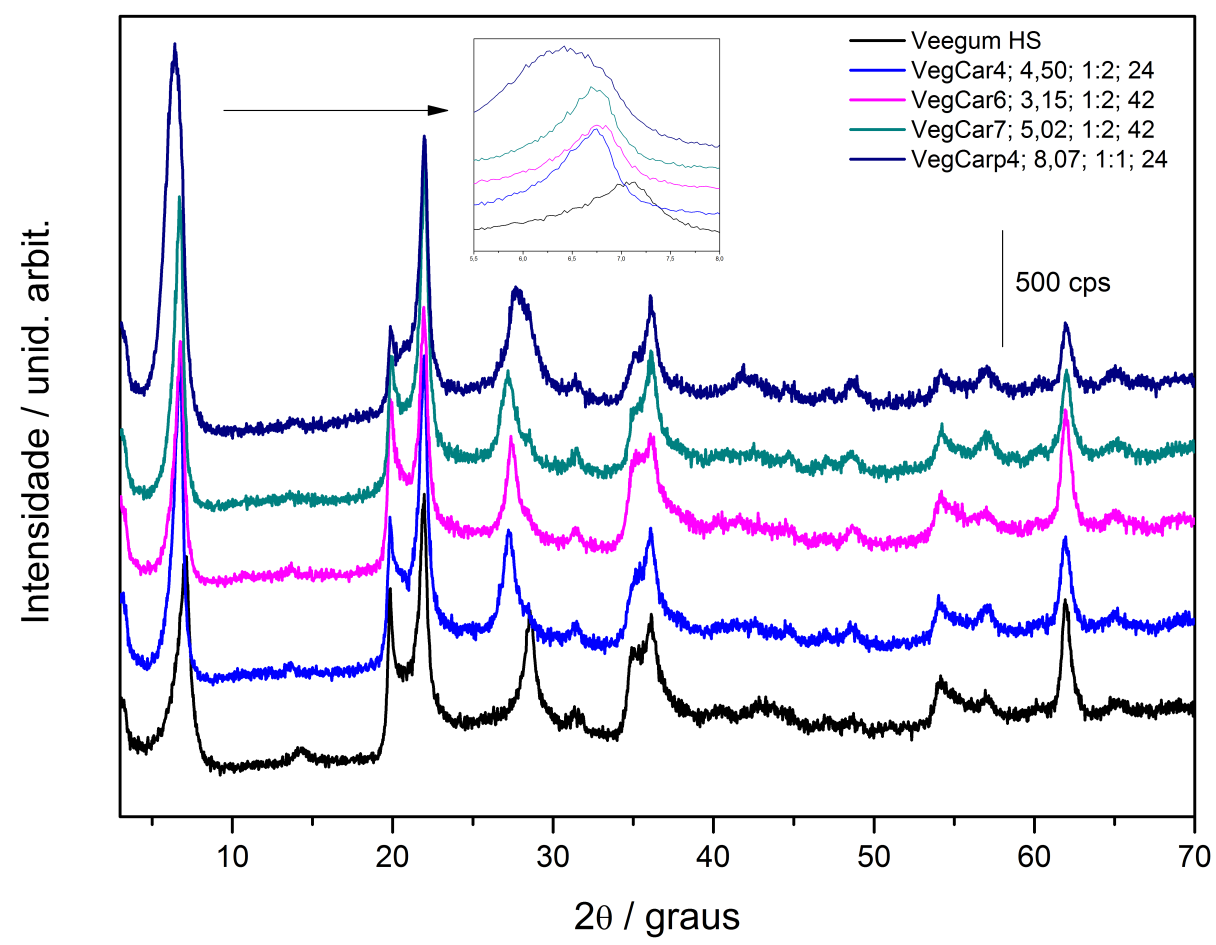

Figura 4.35: Difratogramas de raios $X$ da Veegum $H S$ e dos produtos das reações da Veegum $H S$ com L-Carnosina. (Código: Identidade da amostra; $p H$ final de reação; proporção molar de argila:aminoácido; tempo de reação).

Na Tabela 4.11 encontram-se os valores de $d_{(001)}$, calculados através da equação de Bragg. Se somarmos a dimensão com menor tamanho (dimensões calculadas através de simulações de dinâmica molecular) da L-carnosina $(4,5 \AA)$ ao tamanho da folha TOT de uma montmorilotina $(9,6 \AA)$, chega-se a um valor de $d_{(001)}$ igual a $14,1 \AA$. Considerandose o espaçamento $d_{(001)}$ das amostras VegCar4, VegCar6, VegCar7 e VegCarp4, pode- 
se sugerir a intercalação da L-carnosina no espaço interlamelar. Porém outros dados de caracterização devem ser considerados para corroborar tal interpretação.

Tabela 4.11: Distância interplanar $d_{(001)}$ dos materiais obtidos pela reação de imobilização de L-Carnosina em Veegum HS.

\begin{tabular}{ccc}
\hline Amostra & $2 \theta /$ graus & $d_{(001)} / \AA$ \\
\hline \hline Veegum & 7,11 & 12,4 \\
\hline VegCar4 & 6,74 & 13,1 \\
\hline VegCar6 & 6,71 & 13,2 \\
\hline VegCar7 & 6,77 & 13,1 \\
\hline VegCarp4 & 6,47 & 13,7 \\
\hline
\end{tabular}

A Figura 4.36 mostra o espectro vibracional do dipeptídeo, da Veegum HS e dos produtos de intercalação da argila com a L-carnosina. As mudanças nos espectros ocorrem na mesma região das amostras anteriormente discutidas para os sistemas com a argila Cloisita.



Figura 4.36: Espectros vibracionais na região do Infravermelho da L-Carnosina (preto), Veegum HS (vermelho) em suas formas originais e dos produtos de reação. (Código: Identidade da amostra; $p H$ final de reação; proporção molar de argila:aminoácido; tempo de reação).

Para melhor visualização das modificações ocorridas a Figura 4.37 mostra o espectro 
vibracional ampliado entre as regiões 1900 e $1300 \mathrm{~cm}^{-1}$.

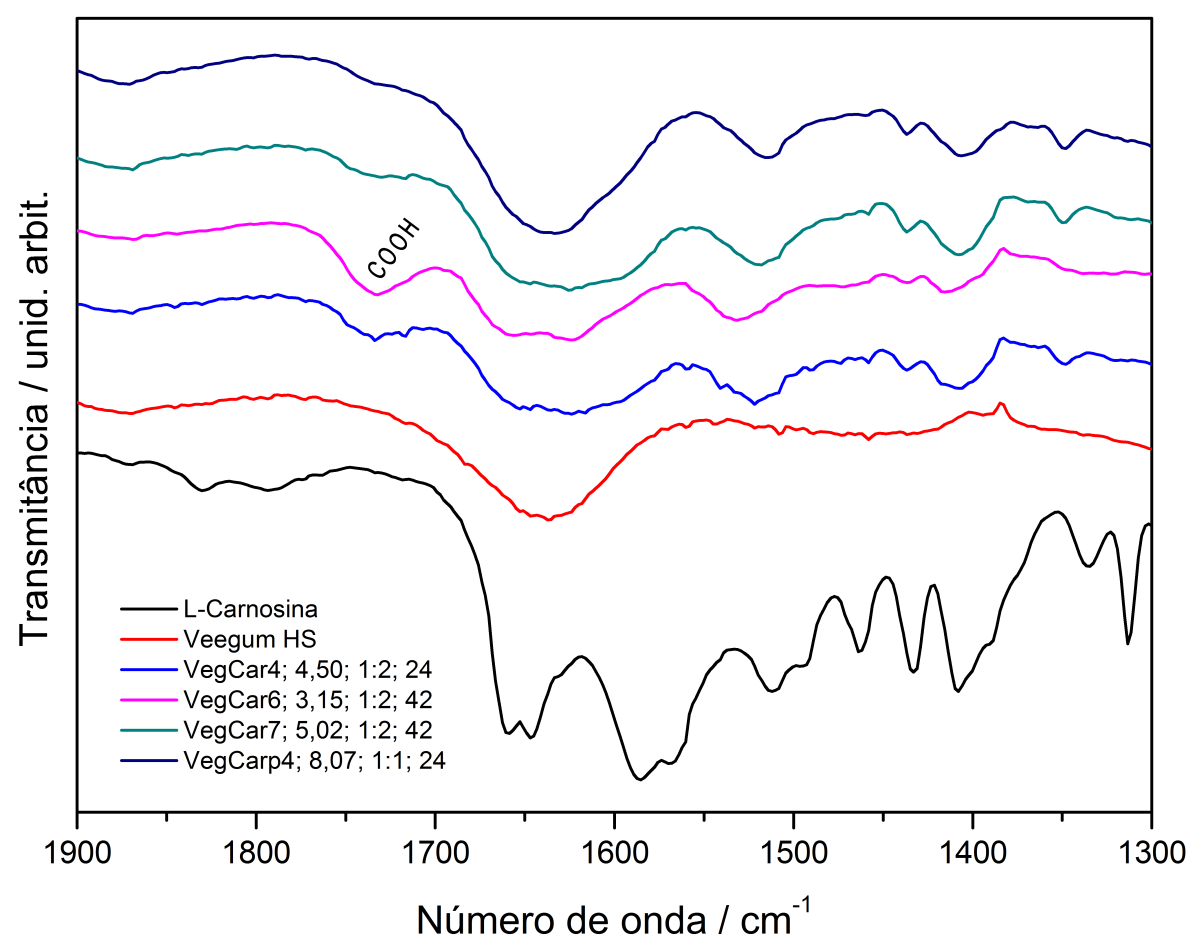

Figura 4.37: Espectros vibracionais na região do Infravermelho da L-Carnosina (preto), Veegum HS (vermelho) em suas formas originais e dos produtos de reação. (Código: Identidade da amostra; pH final de reação; proporção molar de argila:aminoácido; tempo de reação).

Pode-se observar, para as amostras VegCar4 e VegCar6, a banda de absorção atribuída ao estiramento $\nu C=O$ do grupo $-\mathrm{COOH}$ em aproximadamente $1700 \mathrm{~cm}^{-1}$. Considerando os valores de $p K_{a 1}$ e $p K_{a 2}$ da L-carnosina (2,64 e 6,83, respectivamente) e os valores de pH das suspensões de preparação dessas amostras, espera-se que para amostra VegCar4 $(p H=4,50)$ a concentração da espécie $\mathrm{Car}^{+}$seja 72 vezes superior à da $\mathrm{Car}^{2+}, \operatorname{logo}$ a acidez da argila contribui para o surgimento da banda em $1700 \mathrm{~cm}^{-1}$. Ja para amostra $\operatorname{Veg} \operatorname{Car6}(p H=3,15)$ a concentração da espécie $\mathrm{Car}^{+}$é aproximadamente quatro vezes superior a da espécie $\operatorname{Car}^{2+}$, podemos observar que para essa amostra a banda de absorção correspondente ao grupo carboxilato é menos intensa comparada a da amostra VegCar4. A presença da banda em $1400 \mathrm{~cm}^{-1}\left(\nu C O O^{-}\right)$sugere que a $\mathrm{Car}^{+}$também esteja presente nas amostras.

Na Figura 4.38 são apresentadas os dados de análise térmica de um dos produtos 
das reações de intercalação da argila Veegum HS com a L-carnosina. Pela curva DTG identificam-se três etapas de perda de massa. Diferentemente da argila precursora onde se observa somente dois eventos de perda de massa. Pelo espectro de massas observa-se que o fragmento com $m / z$ igual a 44 na amostra VegCar6 começa a ser liberado na temperatura de aproximadamente $240{ }^{\circ} \mathrm{C}$ e termina em aproximadamente $800{ }^{\circ} \mathrm{C}$. Esse fragmento não é observado no espectro de massas da argila pristina e no espectro de massas da L-carnosina esse fragmento não é mais liberado na temperatura de aproximadamente $720{ }^{\circ} \mathrm{C}$. Sugerese que nos materiais híbridos houve uma imobilização do aminoácido na argila. Para as outras amostras esse fragmento é liberado em menor quantidade e os resultados da análise térmica encontram-se no Apêndice B. A massa residual dessa análise foi de $86 \%$.

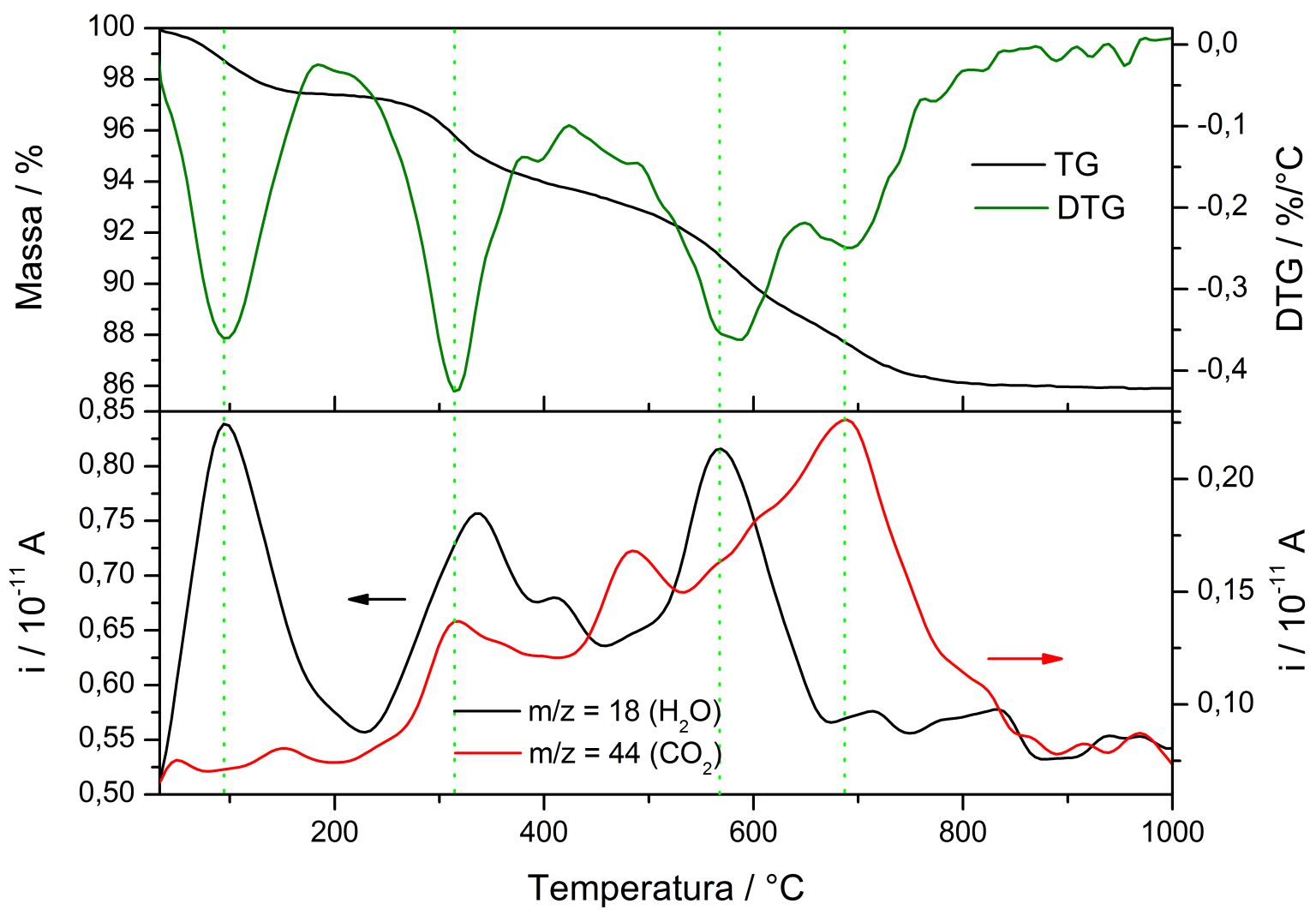

Figura 4.38: Curvas TGA (preto), DTG (verde oliva) e $M S$ (fragmentos $m / z=18$ (preto) $e$ $m / z=44$ (vermelho)) da amostra VegCar6. 


\subsubsection{L-Ornitina em Veegum HS}

A Figura 4.39 apresenta os difratogramas de raios X da Veegum HS e dos produtos resultantes da interação da argila com o aminoácido L-ornitina. Os valores calculados para $d_{(001)}$ desses produtos e da argila encontram-se na Tabela 4.12.

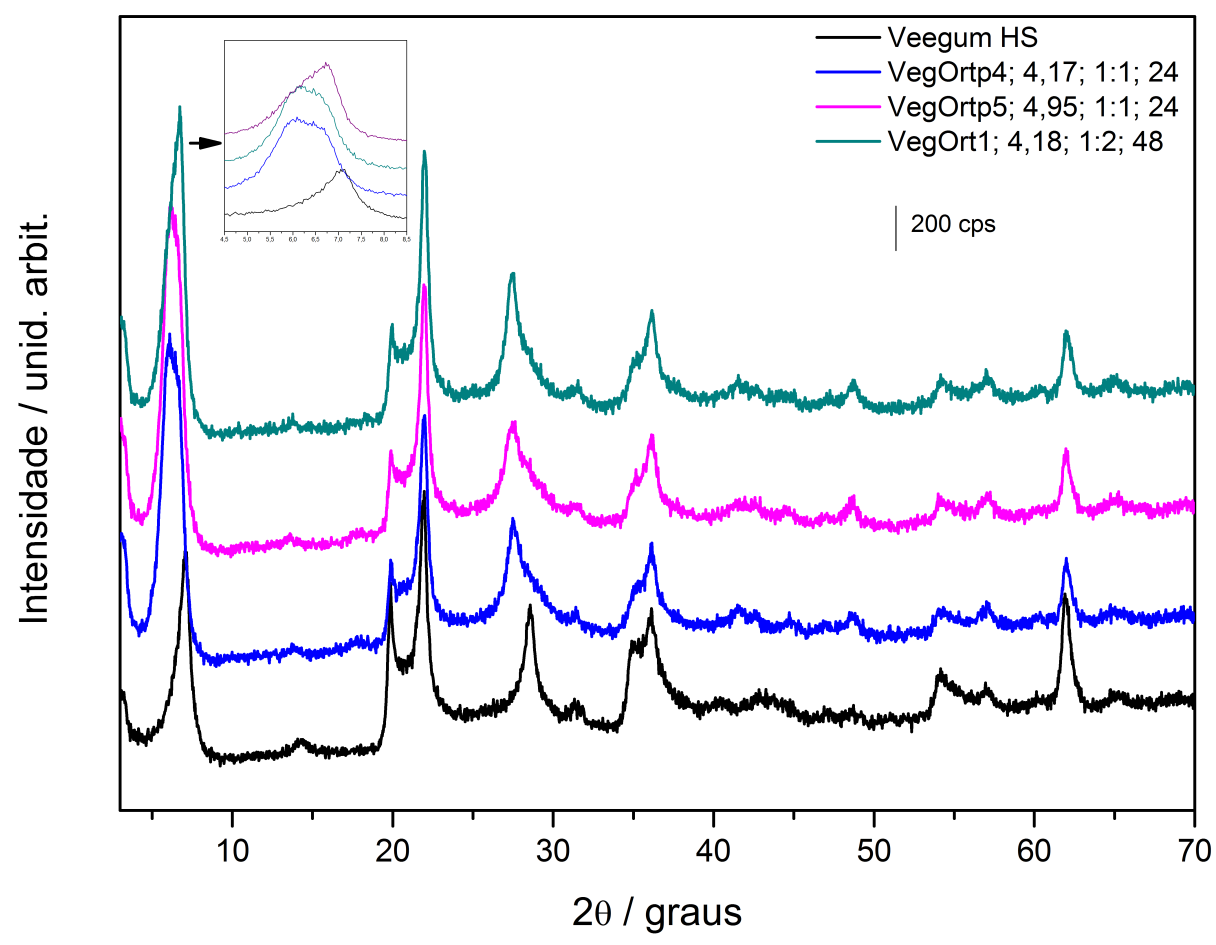

Figura 4.39: Difratogramas de raios $X$ da Veegum $H S$ e dos produtos das reações da Veegum HS com L-Ornitina. (Código: Identidade da amostra; $p H$ final de reação; proporção molar de argila:aminoácido; tempo de reação).

Tabela 4.12: Distância interplanar $d_{(001)}$ dos materiais obtidos pela reação de imobilização de L-Ornitina em Veegum HS.

\begin{tabular}{ccc}
\hline Amostra & $2 \theta /$ graus & $d_{(001)} / \AA$ \\
\hline \hline Veegum & 7,11 & 12,4 \\
\hline VegOrtp4 & 6,31 & 14,0 \\
\hline VegOrtp5 & 6,34 & 13,9 \\
\hline VegOrt1 & 6,62 & 13,3 \\
\hline
\end{tabular}

Os valores de espaçamento $d_{(001)}$ sugerem que o aminoácido se encontra em orientação paralela às lamelas da argila, assim como sugerido para os outros sistemas, pois o somatório da espessura da camada TOT $(9,6 \AA)$ com a menor dimensão da L-ornitina $(3,6 \AA)$ 
é igual a 13,2 Å. Kanamaru e Vand [82] estudaram a interação entre a argila Vermiculita e o ácido 6-amino-hexanóico pela técnica de DRX e propuseram que o grupo carboxilato mantém-se paralelo à camada de silicato e que as moléculas orgânicas interagem com a superfície da argila através de ligações de hidrogênio do tipo OHO e NHO. Para essa proposta, o valor $d_{(001)}$ do sistema Veegum/L-ornitina teria que ser igual a $16,1 \AA$.

Os espectros de absorção na região do infravermelho da Veegum HS, do cloridrato de L-Ornitina e os produtos de reação entre eles encontram-se na Figura 4.40. Para melhor visualização dos resultados, a Figura 4.41 mostra os espectros entre as regiões 1900 e $1300 \mathrm{~cm}^{-1}$. Como pode se observar há o surgimento de uma banda em $1746 \mathrm{~cm}^{-1}$ para a amostra VegOrt1 e VegOrtp4, que pode ser atribuída ao grupo $\mathrm{C}=\mathrm{O}$ (referente ao grupo carboxilato protonado) e uma banda em $1508 \mathrm{~cm}^{-1}$ para todas as amostras na região da vibração da deformação angular do grupo $\mathrm{NH}_{3}^{+}$.



Figura 4.40: Espectros vibracionais na região do Infravermelho do Cloridrato de L-ornitina (preto), Veegum HS (vermelho) em suas formas originais e dos produtos de reação. (Código: Identidade da amostra; $p H$ final de reação; proporção molar de argila:aminoácido; tempo de reação). 




Figura 4.41: Espectros vibracionais na região do Infravermelho do Cloridrato de L-ornitina (preto), Veegum HS (vermelho) em suas formas originais e dos produtos de reação. (Código: Identidade da amostra; $p H$ final de reação; proporção molar de argila:aminoácido; tempo de reação).

As três amostras Veegum/L-ornitina foram preparadas em suspensões cujo valor de $\mathrm{pH}$ era superior ao valor do $p K_{a 1}(1,94)$ e inferior ao $p K_{a 2}(8,65)$ do aminoácido. Espera-se que a espécie imobilizada na Veegum seja a $\mathrm{Ort}^{+}$. Contudo, a banda de absorção referente ao modo de vibração do grupo -COOH sugere que a argila possui acidez suficiente para protonar parte da L-ornitina, pois em solução de pH igual a 4,2 a concentração de $O r t^{+}$é aproximadamente 200 vezes superior àquela de $\mathrm{Ort}^{2+}$. Resultado semelhante foi observado para o sistema Cloisita/L-ornitina.

As curvas referentes à análise térmica da amostra VegOrtp4 são apresentados na Figura 4.42. Pode-se observar, pela curva DTG, dois processos principais de perda de massa: o primeiro na temperatura em torno de $100{ }^{\circ} \mathrm{C}$ e o segundo em torno de $630{ }^{\circ} \mathrm{C}$. A massa residual para essa amostra foi de aproximadamente $88 \%$. A perda do fragmento com $\mathrm{m} / \mathrm{z}$ igual a 18 ocorre em maior intensidade entre a temperatura inicial até $170{ }^{\circ} \mathrm{C}$ e de 550 
a $730{ }^{\circ} \mathrm{C}$. Há perda com maior intensidade do fragmento com $\mathrm{m} / z$ igual a 44 entre as temperaturas de 230 e $850{ }^{\circ} \mathrm{C}$, mas muito menor em relação à água. Os dados de análise térmica das amostras VegOrtp5 e VegOrtp6 encontram-se no Apêndice B e são semelhantes aos resultados para a amostra VegOrtp4. O perfil do espectro de MS da amostra VegOrt1 é diferente do das outras amostras do sistema Veegum/L-ornitina: a perda do fragmento com $\mathrm{m} / \mathrm{z}$ igual a 18 e 44 ocorre em menor intensidade comparando-se com as outras amostras, mesmo que a VegOrt1 tenha sido preparada com o dobro de aminoácido.

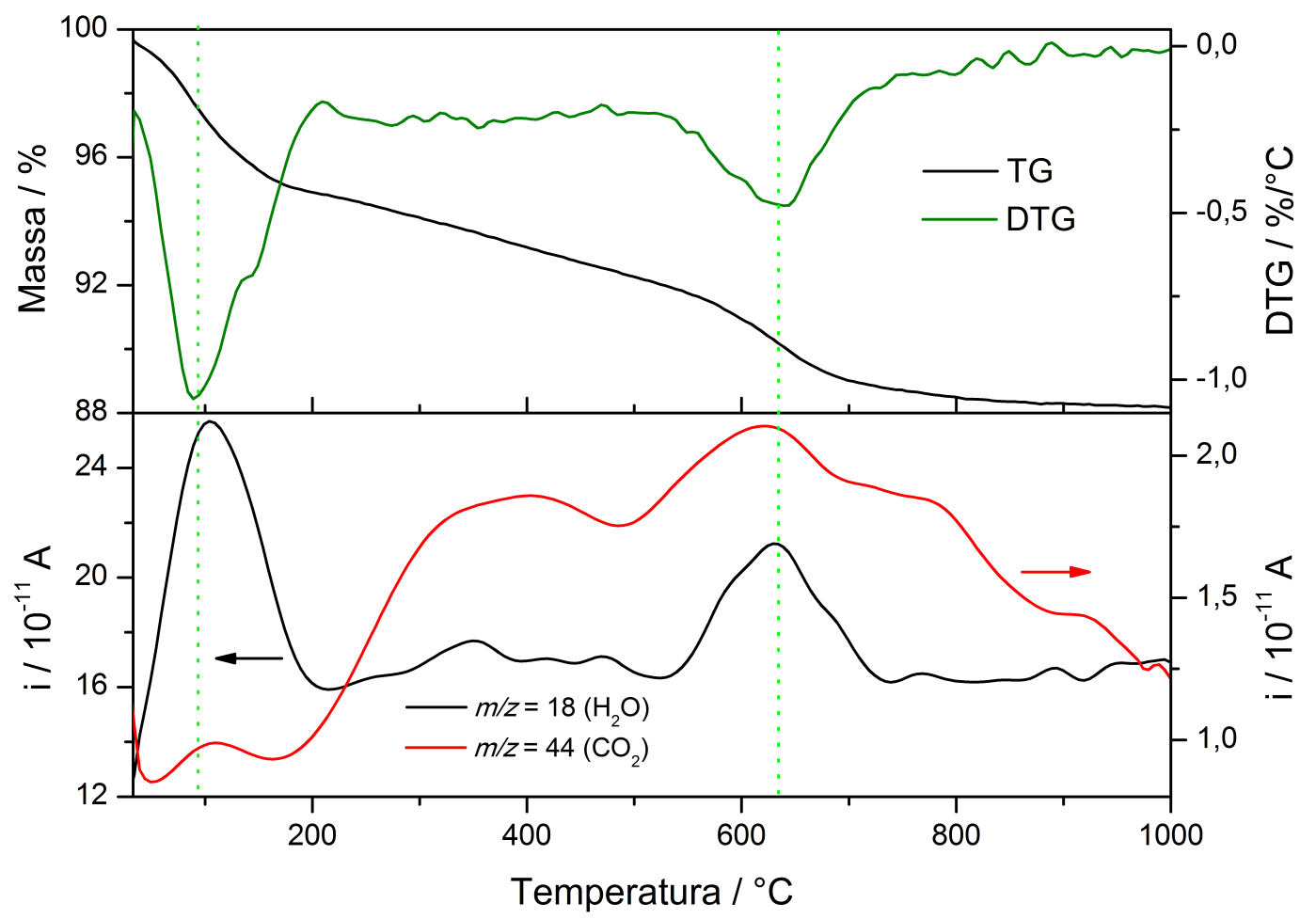

Figura 4.42: Curvas TGA (preto), DTG (verde oliva) e $M S$ (fragmentos $m / z=18$ (preto) e $m / z=44$ (vermelho)) da amostra VegOrtp 4 .

Assim como a Cloisita, a Veegum desloca o processo de oxidação da Ornitina para maiores valores de temperatura, pois ao se observar os resultados de análise térmica do cloridrato de L-ornitina, nota-se que o material já está totalmente decomposto em aproximadamente $630^{\circ} \mathrm{C}$.

Realizou-se análise elementar de carbono para a amostra VegOrt1 (1,69 \% de carbono). Considerando a imobilização da espécie $\mathrm{Ort}^{+}$, a porcentagem de L-ornitina é 3,75 \% (ou $28,1 \mathrm{mmol} / 100 \mathrm{~g})$, neutralizando $35,2 \%$ da CTC da Veegum HS. 
Nos experimentos com as argilas Cloisita e Veegum HS os menores valores de pH empregados foram de aproximadamente 2,6 (CloLys1) e 3,2 (VegCar6). Nessas condições, a troca de $\mathrm{Na}^{+}$por $\mathrm{H}^{+}$em montmorilonitas é de aproximadamente $5 \%$ da CTC [37], sugerindo que nas amostras mencionadas, os prótons foram consumidos na reação de troca iônica com o cátion interlamelar e que a extensão da troca foi pequena.

A análise por espectroscopia vibracional no região do infravermelho de argilominerais ativados com ácido mostra que montmorilonita não sofre mudanças significavas em sua estrutura após $4 \mathrm{~h}$ de contato com solução $6 \mathrm{~mol} \mathrm{~L}^{-1}$ de $\mathrm{HCl}$ a $95{ }^{\circ} \mathrm{C}$ [83]. Já a argila hectorita tratada por $8 \mathrm{~h}$ com solução de $\mathrm{HCl} 0,25$ mol $L^{-1}$ a $30{ }^{\circ} \mathrm{C}$ possui espectro de sílica amorfa, demostrando a maior solubilidade de argilas trioctaédricas em relação às dioctaédricas. Logo, pode-se inferir que nos estudos realizados neste trabalho a solubilização da Cloisita e Veegum HS é negligenciável.

\subsection{Imobilização de aminoácidos em Laponita RD}

Para os sistemas Laponita/aminoácidos não foi possível a separação do material híbrido por centrifugação, além do material precisar de uma rotação muito elevada para separar da parte líquida, também se perdia quase todo o produto ao se lavar a amostra, isso se deve ao pequeno tamanho das partículas da Laponita RD.

Diferentemente das argilas montmorilonitas, Cloisita e Veegum HS, mencionadas anteriormente, a Laponita RD é uma argila sintética e que pertence ao grupo das hectoritas. Essa argila não possui íons alumínio (os sítios octaédricos são preenchidos por íons $M g^{2+}$ em maior quantidade e os íons $\mathrm{Li}^{+}$em menor quantidade). Conforme mencionado na parte introdutória desta Dissertação, outra diferença da Laponita com as outras argilas empregadas neste estudo é o pequeno tamanho de partículas. Tais fatores se refletem em um comportamento distinto da Laponita em relação à Cloisita e à Veegum HS.

Segundo trabalhos relatados na literatura [83, 84], argilominerais do grupo das esmectitas são ativados por tratamento com ácidos para gerar produtos comerciais para uso como catalisadores e adsorventes industriais. Geralmente a ativação ácida requer o uso de soluções concentradas de ácidos minerais, aquecimento e horas de tratamento. O produto 
gerado é uma sílica hidratada, protonada, amorfa e porosa. Nesses processos, os íons $H^{+}$ substituem os cátions da região interlamelar e reagem com os grupos -OH da folha octaédrica. Posteriormente, os íons que compõem as folhas octaédricas (e os íons alumínio dos tetraedros) são removidos da estrutura das argilas. A extensão da solubilização de um argilomineral depende tanto da natureza do material quanto das condições experimentais. Observa-se que as argilas trioctaédricas (como as hectoritas) se dissolvem mais prontamente que as dioctaédricas (como as montmorilonitas). Isso se deve ao fato das primeiras apresentarem principalmente folhas do tipo brucita, $\mathrm{Mg}(\mathrm{OH})_{2}$, que são mais solúveis em meios ácidos que as folhas do tipo gibsita, $\mathrm{Al}(\mathrm{OH})_{3}$. Devido à constituição química da Laponita, não é possível diminuir muito o valor de $\mathrm{pH}$ das dispersões como foi feito no caso das argilas Cloisita e Veegum HS.

O diâmetro médio das partículas da Laponita RD é 14,06 nm $(\sigma= \pm 0,13$ e PDI = 0,33), para um valor de $\mathrm{pH}$ da suspensão de 9,38, uma valor bem menor comparado as outras argilas utilizadas no trabalho e já esperado, pois as partículas dessa argila são bem pequenas. O potencial Zeta igual a - 42,5 $\mathrm{mV}(\sigma= \pm 2,39)$, valor de suspensões estáveis.

\subsubsection{L-Lisina em Laponita RD}

Na Figura 4.43 pode-se observar os difratogramas de raios X da Laponita RD pristina e dos produtos de imobilização com L-lisina. A argila tem sua estrutura cristalina mantida nos produtos, pois seus picos são mantidos. Comparando-se os picos $d_{(001)}$ das montimorilonitas com a hectorita observa-se a diferença na largura dos picos, isso se deve ao tamanho das partículas da Laponita RD (14,06 nm) que leva à uma estrutura com baixa organização de empilhamento ao longo do eixo $c$ o que resulta em picos mais alargados.

O pico com $2 \theta=6,14^{\circ}$, correspondendo a um espaçamento basal de $14,4 \AA$, referese à difração do plano (001) e está coerente ao esperado para uma esmectita com uma monocamada de moléculas de água entre as lamelas. Na Tabela 4.13 encontram-se os valores de $d_{(001)}$ para os produtos das reações de imobilização da L-lisina em Laponita RD. Somando-se a espessura da camada TOT (9,6 A) à menor dimensão do aminoácido Llisina $(3,6 \AA)$, chega-se a um valor de $d_{(001)}$ igual a $13,2 \AA$. Como os difratogramas de raios 
X apresentaram valores entre 14,8 e $15,4 \AA$, pode-se considerar que houve a intercalação de moléculas de L-lisina.

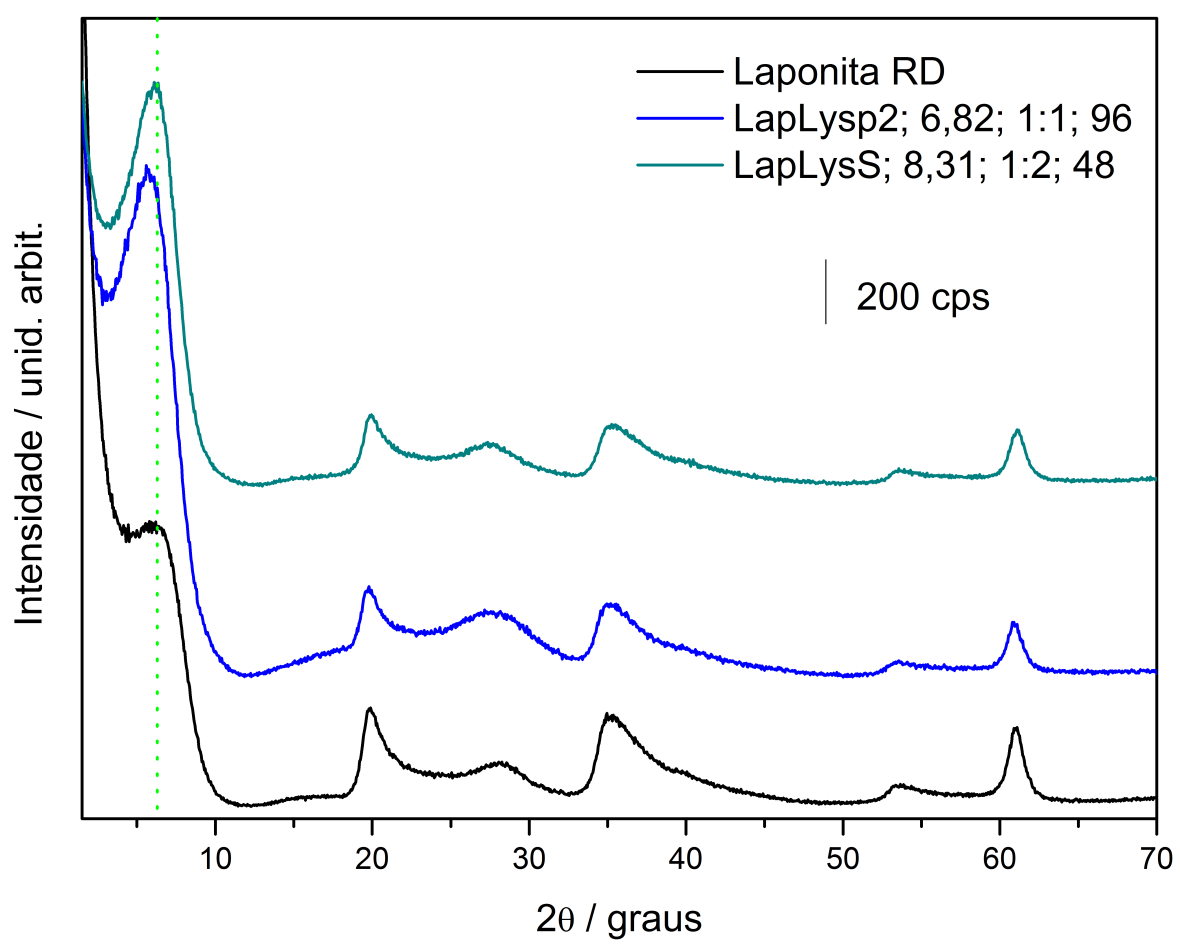

Figura 4.43: Difratogramas de raios $X$ da Laponita $R D$ e dos produtos das reações da Laponita $R D$ com L-Lisina. (Código: Identidade da amostra; $p H$ final de reação; proporção molar de argila:aminoácido; tempo de reação).

Tabela 4.13: Distância interplanar $d_{(001)}$ dos materiais obtidos pela reação de imobilização de L-Lisina em Laponita RD.

\begin{tabular}{ccc}
\hline Amostra & $2 \theta /$ graus & $d_{(001)} / \AA$ \\
\hline \hline Laponita RD & 6,14 & 14,4 \\
\hline LapLysS & 5,98 & 14,8 \\
\hline LapLysp2 & 5,75 & 15,4 \\
\hline
\end{tabular}

Os espectros vibracionais na região do infravermelho para os produtos das reações de imobilização da L-lisina na Laponita RD encontram-se na Figura 4.44. A amostra LapLysS é a que apresenta mudanças mais significativas. Nos valores de $\mathrm{pH}$ de síntese $(6,82 ; 7,61 ; 8,31)$, esperava-se imobilizar a forma $\mathrm{Lys}^{+}$.

Na Figura 4.45 são apresentados os resultados referentes à análise térmica da Laponita RD. Ao observar a curva DTG, pode-se dividir o processo de perda de massa em duas 




Figura 4.44: Espectros vibracionais na região do infravermelho do Cloridrato de L-Lisina (preto), Laponita RD (vermelho) em suas formas originais e dos produtos de reação. (Código: Identidade da amostra; $p H$ final de reação; proporção molar de argila:aminoácido; tempo de reação).

etapas. Na primeira etapa (da temperatura ambiente até aproximadamente $150{ }^{\circ} \mathrm{C}$ ) ocorre a perda das moléculas de água ligadas superficialmente nas lamelas e, também, presentes na região interlamelar. A identidade da espécie volátil é atestada pela curva MS, que indica a liberação de fragmento com $m / z$ igual a 18. Esse processo de perda de massa corresponde a aproximadamente $5,1 \%$ da massa total da Laponita RD. Não se observa a liberação de fragmento com $m / z$ igual a 44 durante o processo.

A segunda etapa de perda de massa, que apresenta um pico DTG em $726{ }^{\circ} \mathrm{C}$, corresponde ao processo de desidroxilação (eliminação de $\mathrm{H}_{2} \mathrm{O}$ ) das lamelas da Laponita RD. Nas argilas montmorilonitas, Cloisita e Veegum HS, a desidroxilação ocorre em temperatura inferior (aproximadamente $600{ }^{\circ} \mathrm{C}$ ) àquela observada para a Laponita RD (aproximadamente $700{ }^{\circ} \mathrm{C}$ ). Essa diferença se deve às composições químicas distintas das lamelas.

Na Figura 4.46 podemos observar as curvas da análise térmica da amostra LapLysS. 


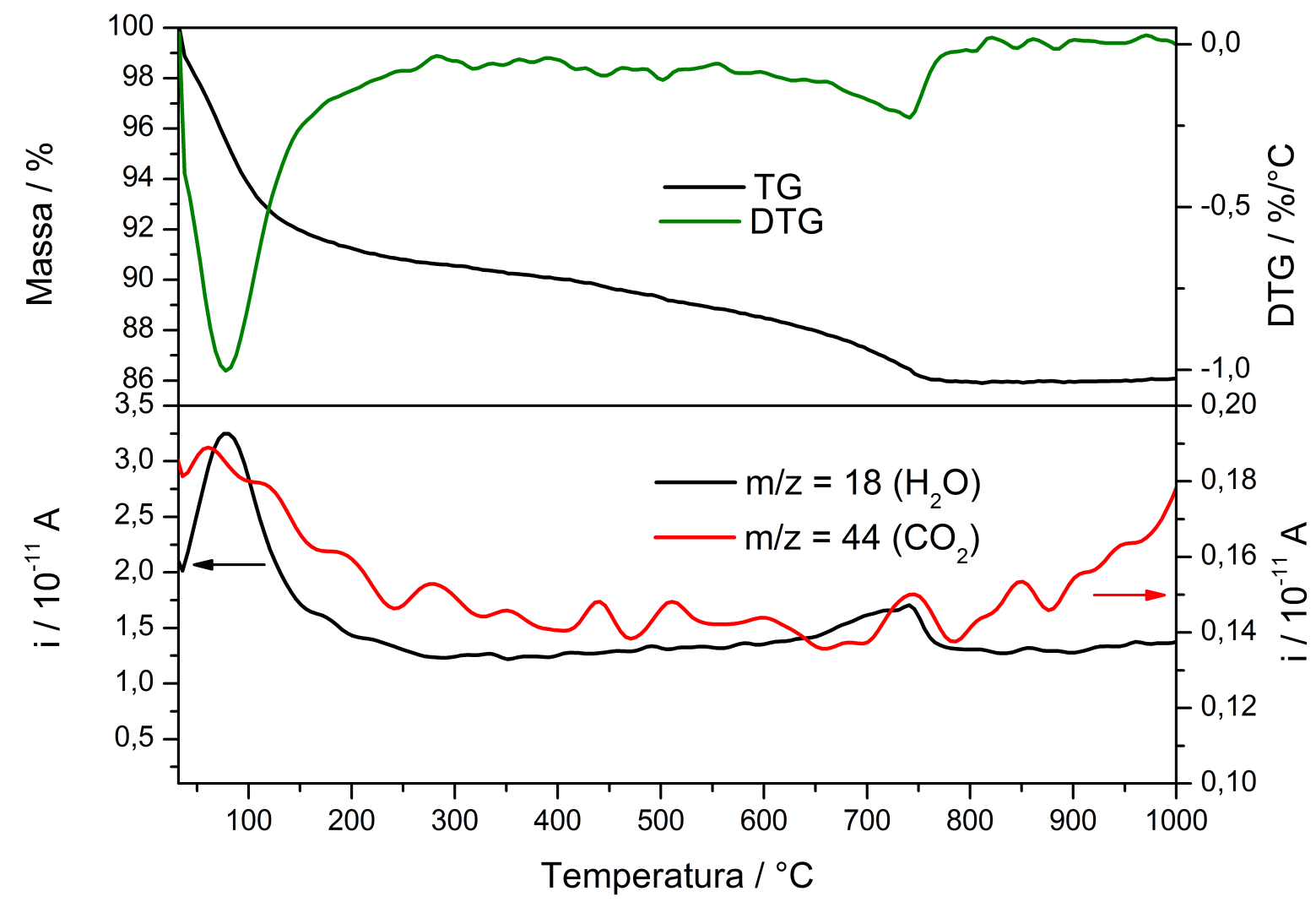

Figura 4.45: Curvas TGA (preto), DTG (verde oliva) e $M S$ (fragmentos $m / z=18$ (preto) e $m / z=44$ (vermelho)) da Laponita $R D$.

A primeira perda de massa (mínimo da curva DTG em $71{ }^{\circ} \mathrm{C}$ ) é atribuída a perda de moléculas de água ligadas mais fracamente à argila. A segunda perda de massa (mínimo da curva DTG em $344^{\circ} \mathrm{C}$ ) pode ser atribuída a perda de água e parte da matéria orgânica, atestada pelos fragmentos $m / z$ igual a 18 e 44, respectivamente. A terceira etapa de perda de massa mais importante, com mínimo na curva de DTG em $556{ }^{\circ} \mathrm{C}$, e responsável pela maior perda de matéria orgânica, é semelhante ao da espécie $\mathrm{Lys}^{+}$(na forma cloridrato; vide Figura 4.6). Já o quarto evento de perda de massa, com mínimo da curva DTG em $755^{\circ} \mathrm{C}$, é devido à desidroxilação das folhas da argila.

A massa residual dessa análise foi de $80,7 \%$ e a partir de $780{ }^{\circ} \mathrm{C}$ não ocorreu mais perda da amostra. O resultado da análise térmica para as amostras LapLysp2 e LapLysp7 encontram-se no Apêndice B. A massa residual dessas duas amostras é semelhante à da LapLysS (isso se deve a maior adsorção de água, pois a intensidade do fragmento com 


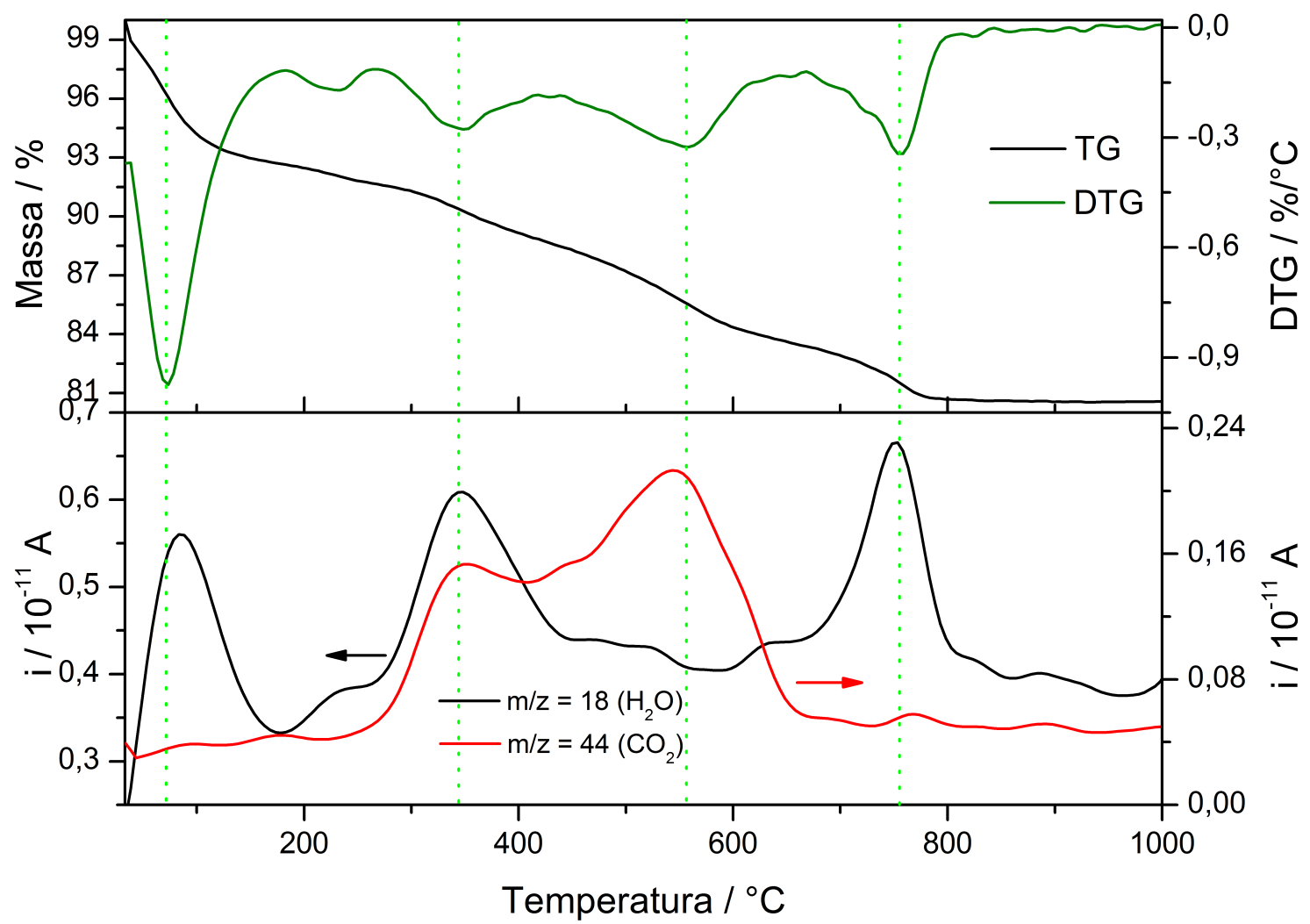

Figura 4.46: Curvas TGA (preto), DTG (verde oliva) e $M S$ (fragmentos $m / z=18$ (preto) e $m / z=44$ (vermelho)) da amostra LapLysS.

$m / z$ igual 44 é menor), porém a curva MS do fragmento com $m / z$ igual a 18 , nessas duas amostras se assemelha à argila pristina.

Ao se observar as curvas MS das amostras CloLysS, VegLysS e LapLysS, percebe-se que para as duas primeiras amostras o fragmento com $m / z$ igual 44 é liberado em temperaturas mais elevadas do que na amostra LapLysS. Isso pode estar ocorrendo devido ao fato da Laponita ter um menor grau de empilhamento e menor tamanho de partícula, fazendo com que as moléculas do aminoácido fiquem mais expostas, facilitando sua decomposição em menores temperaturas.

Para a amostra LapLysS realizou-se a análise química elementar (CHN), que forneceu $2,85 \%$ de porcentagem em massa de carbono. Considerando-se que esse elemento é proveniente somente do aminoácido, a concentração de L-lisina nessa amostra é aproximadamente 5,80\% (ou $40 \mathrm{mmol} / 100 \mathrm{~g}$ de material). Considerando-se a presença de espécies 
Lys $^{+}$nessa amostra, o aminoácido está neutralizando $80 \%$ das cargas negativas da Laponita. Como a carga da superfície externa das argilas é responsável apenas por 5 - $10 \%$ da CTC, as moléculas da L-lisina devem estar na região interlamelar. Para a LapLysS também mediu-se o tamanho médio de partícula que foi igual a 17,65 nm ( $\sigma= \pm 0,22$ e $P D I=0,41)$, um valor maior que o encontrado para a Laponita pristina, isso pode ser devido a uma maior agregação das partículas do material híbrido. O valor de potencial Zeta foi igual a - 49,3 $\mathrm{mV}(\sigma= \pm 6,37)$ também superior ao da argila pristina, mas como é acima de $\pm 30 m V$, continua sendo uma suspensão estável. Todos esses valores foram para uma suspensão $0,1 \%(\mathrm{~m} / \mathrm{v})$ e valor de pH igual a 9,23 .

\subsubsection{L-Argina em Laponita RD}

A Figura 4.47 apresenta os difratogramas de raios X da Laponita RD e dos produtos da interação com o aminoácido L-arginina. Pode-se observar que há um deslocamento do pico $d_{(001)}$ para a amostra LapArgS com $2 \theta=6,43^{\circ}, \mathrm{d}=13,7 \AA$ e para a amostra LapArgp2 com $2 \theta=5,94^{\circ}, \mathrm{d}=14,9 \AA$. Para os sistemas com a Laponita como matriz inorgância, o valor de $d_{(001)}$ é maior do que aqueles observados para os sistemas com Cloisita e Veegum HS com o aminoácido L-arginina.

Como pode ser observado na Figura 4.48, não houve mudanças significativas nos espectros de absorção na região do infravermelho para os produtos das reações entre a argila Laponita RD e o aminoácido L-arginina.

Considerando os valores de $p K_{a 1}(2,17)$ e de $p K_{a 2}(9,04)$ da L-arginina e os valores de pH das suspensões de preparação das amostras Laponita/L-arginina, espera-se que, na amostra LapArgp2, o aminoácido esteja na forma $\left(\mathrm{H}_{2} \mathrm{~N}\right) \mathrm{CN}^{+} \mathrm{H}\left(\mathrm{CH}_{2}\right)_{3}\left(\mathrm{~N}^{+} \mathrm{H}_{3}\right) \mathrm{COO}^{-}$ $\left(\mathrm{Arg}^{+}\right)$. Já nas amostras LapArgp9 e LapArgS, pode haver a interação da argila com as espécies $\mathrm{Arg}^{+}$e/ou $\mathrm{Arg}^{0}$. Os espectros FTIR das três amostras de Laponita/L-arginina não apresentam bandas que possam ser identificadas com o aminoácido. Outras técnicas de caracterização foram empregadas para avaliar a presença ou ausência de arginina nas amostras de Laponita.

Os resultados da análise térmica (Figura 4.49) mostram que a quantidade de aminoá- 


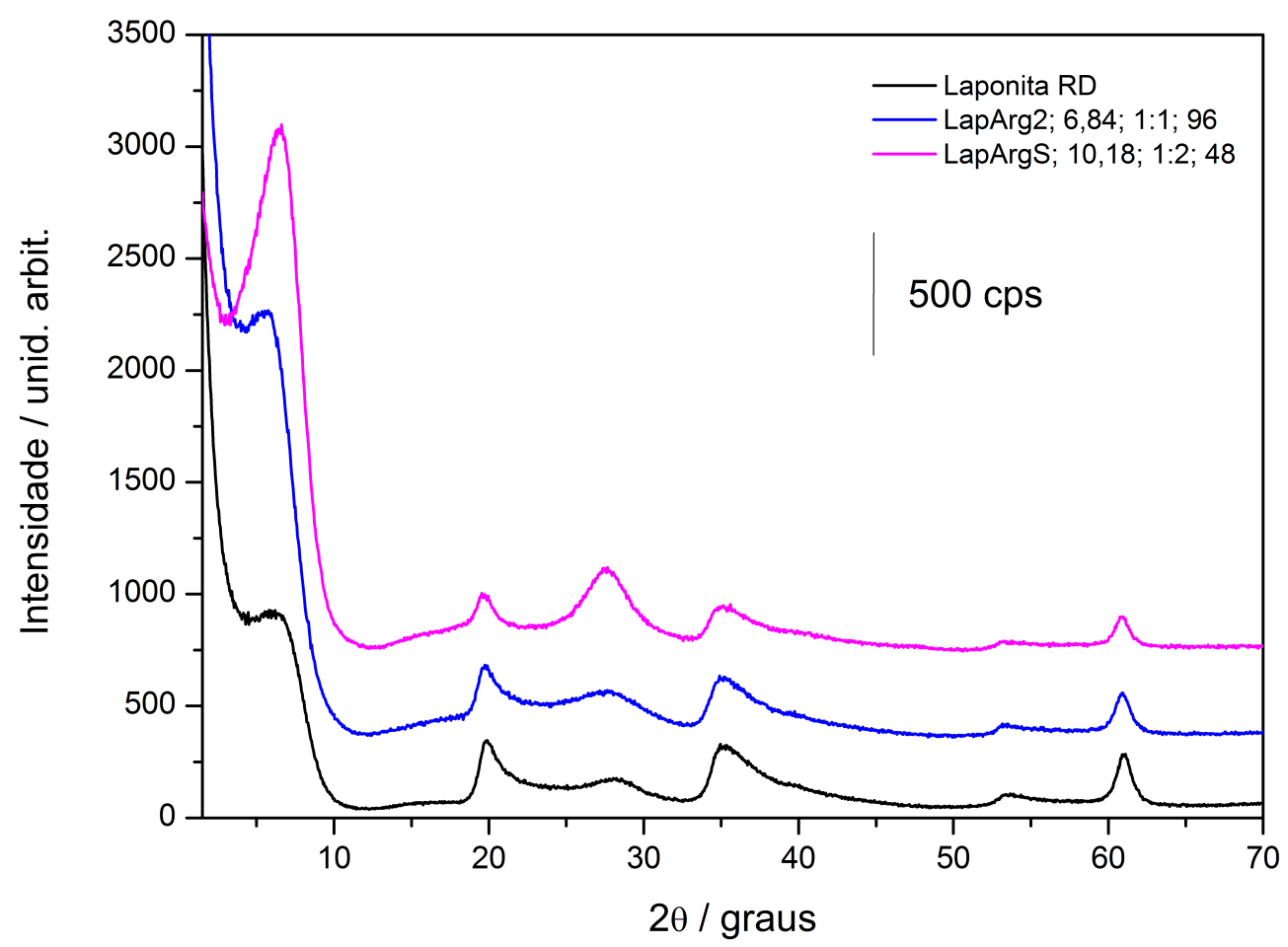

Figura 4.47: Difratogramas de raios $X$ da Laponita $R D$ e dos produtos das reações da Laponita $R D$ com L-Arginina. (Código: Identidade da amostra; pH final de reação; proporção molar de argila:aminoácido; tempo de reação).

cido na amostra LapArgS é maior que nas amostras LapArgp2 e LapArgp9 (resultado encontra-se no Apêndice B), e o perfil de decomposição das três amostras é semelhante entre si e mais uma vez difere dos resultados da L-arginina imobilizados em outras matrizes inorgânicas. Essa amostra também tem o fragmento $\mathrm{m} / \mathrm{z}$ igual 44 sendo liberado em temperaturas mais elevadas que nos outros sistemas. O aminoácido L-arginina pode estar interagindo somente com as bordas da argila e o espaçamento basal $d_{(001)}$ pode ter aumentado somente devido à hidratação dos íons $\mathrm{Na}^{+}$entre as lamelas da Laponita, não sendo a intercalação das moléculas de L-arginina as responsáveis por esse aumento.

A análise química elementar (CHN) para a amostra LapArgS forneceu o valor de 1,57 \% de carbono. Considerando-se que esse elemento é proveniente somente do aminoácido Larginina, a sua concentração nessa amostra é aproximadamente 3,80 \% (ou 21,7 mmol) 100 g). Como a concentração da espécie $\mathrm{Arg}^{+}$nas condições de síntese para essa amostra é apenas 14 vezes maior que a concentração da espécie a $A r g^{0}$, não se pode afirmar que 


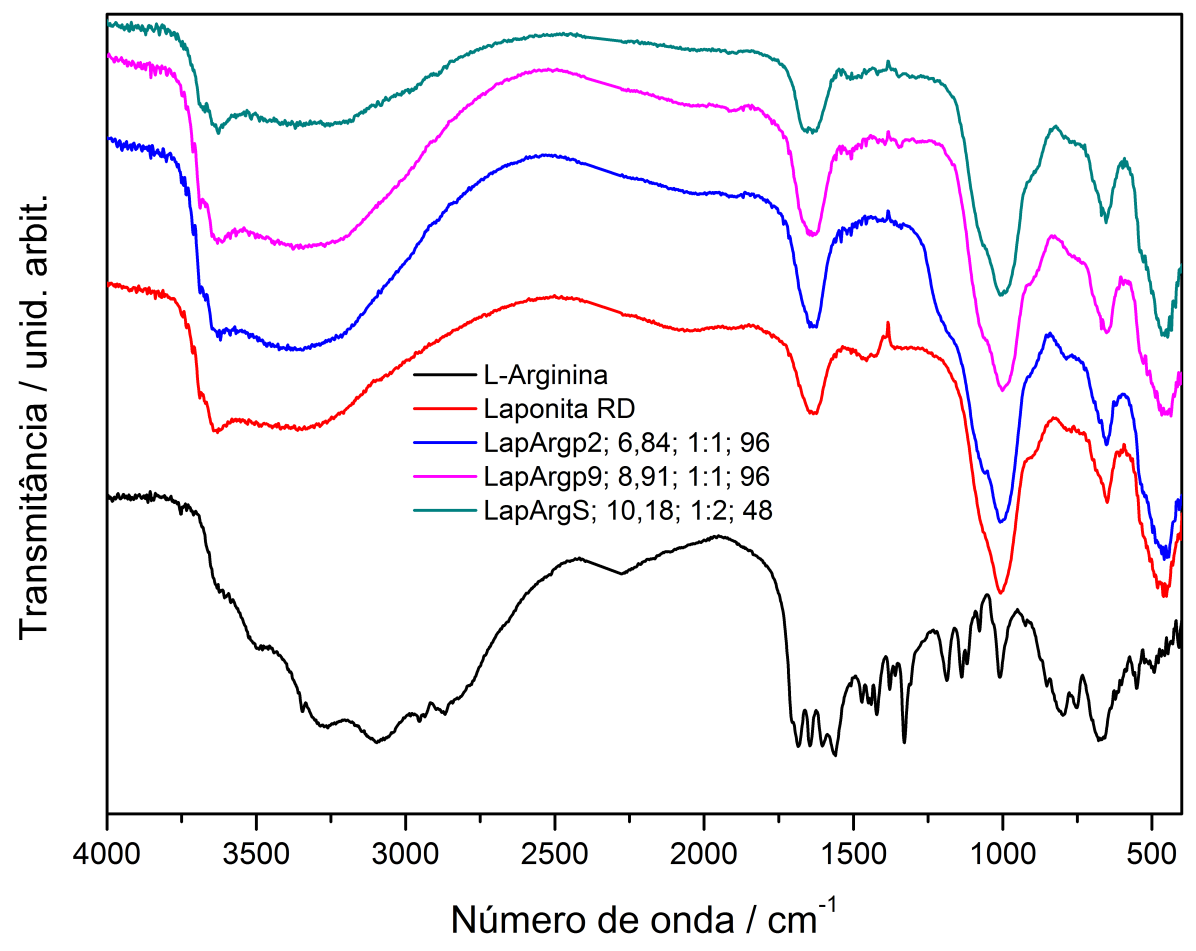

Figura 4.48: Espectros vibracionais na região do Infravermelho da L-Arginina (preto), Laponita RD (vermelho) em suas formas originais e dos produtos de reação. (Código: Identidade da amostra; $p H$ final de reação; proporção molar de argila:aminoácido; tempo de reação).

o aminoácido está neutralizando 43,4 \% das cargas negativas da Laponita. 


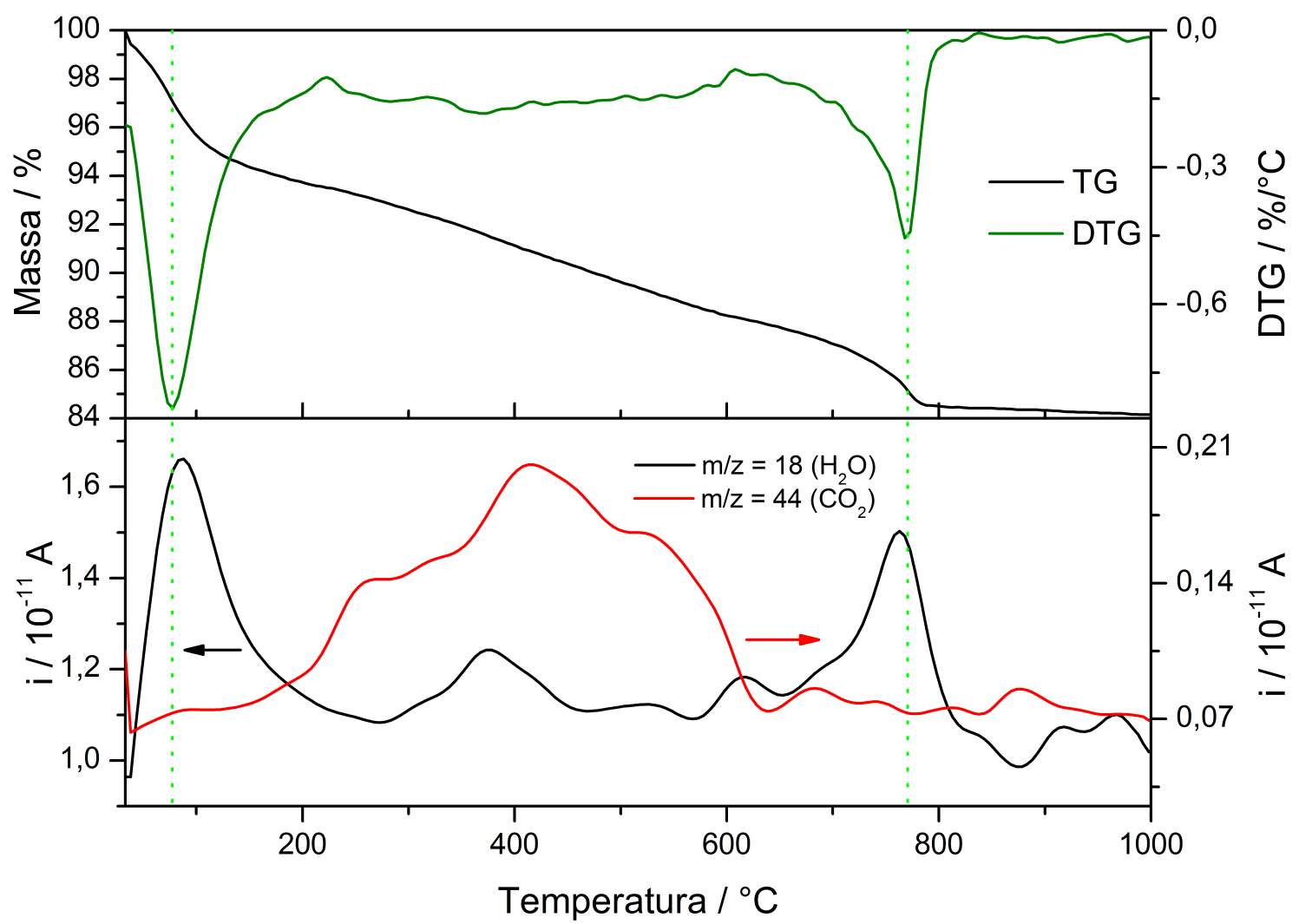

Figura 4.49: Curvas TGA (preto), DTG (verde oliva) e $M S$ (fragmentos $m / z=18$ (preto) $e$ $m / z=44$ (vermelho)) da amostra LapArgS.

\subsubsection{L-Carnosina em Laponita RD}

Ao se realizar os experimentos com a Laponita RD percebeu-se que essa argila não permite o abaixamento do valor de $\mathrm{pH}$ para valores inferiores a 6 , dado que o sistema consome os prótons adicionados (mesmo ao se adicionar uma quantidade significativa de solução de $\mathrm{HCl}$, passadas algumas horas o valor de pH subiu), adotando um comportamento semelhante aos sistemas tampões. Além disso, informações fornecidas pelo fabricante já indicam que a Laponita se dissolve em pH menor que cinco [29].

A Figura 4.50 apresenta o difratograma de raios X da argila Laponita RD e do produto da reação de intercalação com a L-carnosina.

Observa-se que os picos equivalentes, na mesma região, dos diferentes difratogramas estão aproximadamente no mesmo valor de ângulo $2 \theta$, indicando que não há um deslocamento do pico $d_{(001)}$ para região de menor ângulo. 


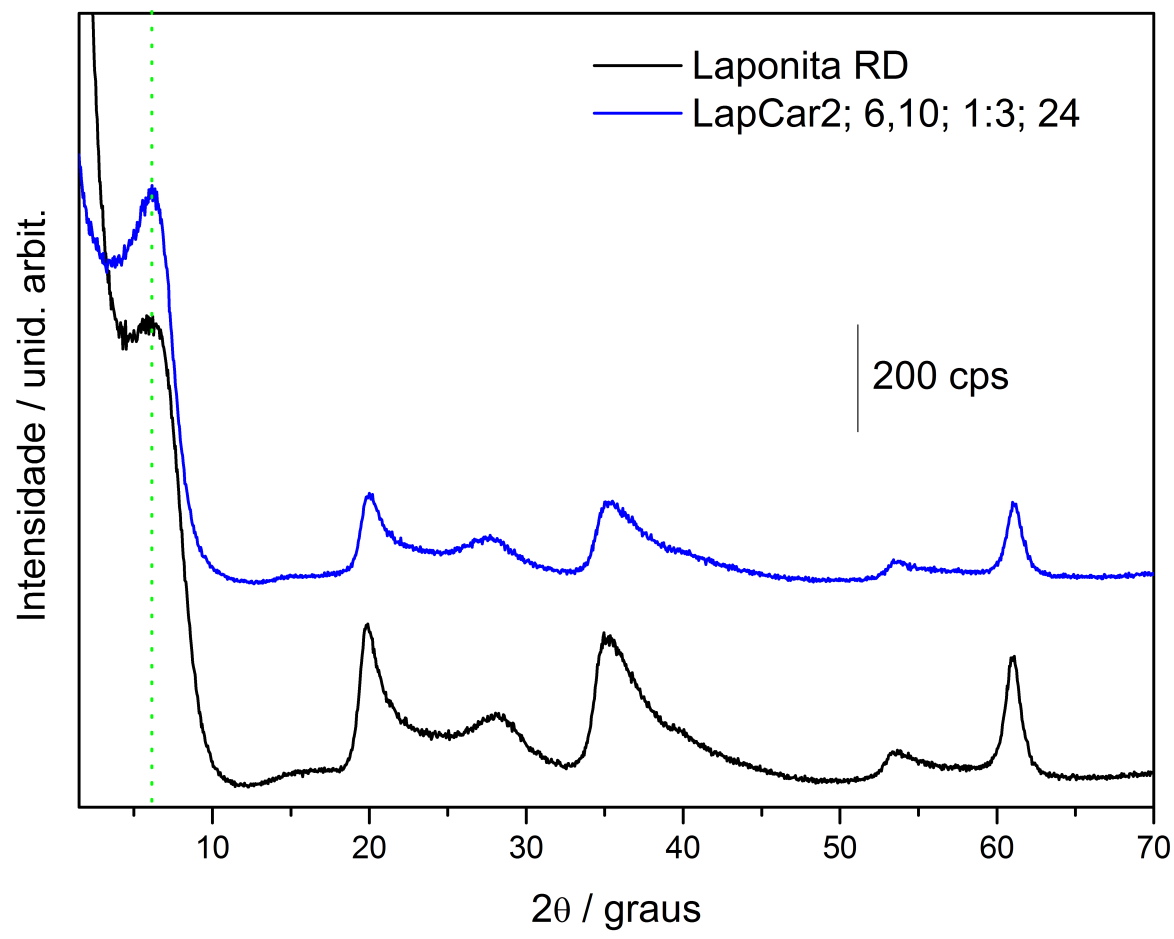

Figura 4.50: Difratogramas de raios $X$ da Laponita $R D$ e dos produtos das reaçôes da Laponita $R D$ com L-Carnosina. (Código: Identidade da amostra; $p H$ final de reação; proporção molar de argila:aminoácido; tempo de reação).

Na Figura 4.51 estão mostrados os espectros vibracionais na região do infravermelho das amostras resultantes da reação de imobilização do dipepítideo L-Carnosina na argila Laponita RD, assim como os espectros da Laponita RD e do aminoácido L-carnosina em suas formas originais.

Nos espectros vibracionais dos produtos, observam-se modificações muito sutis entre as regiões $1800-1400 \mathrm{~cm}^{-1}$. O espectro referente ao produto LapCar2 é o que apresenta maiores modificações. Ao se analisar o procedimento experimental desse produto, observase que a razão molar foi de 1:3 (argila:aminoácido), ou seja, um excesso de três vezes de aminoácido em relação à capacidade de troca catiônica da argila. A reação foi realizada em temperatura ambiente e em $\mathrm{pH}$ igual a 6,10 ; nesse valor de $\mathrm{pH}$ a forma $\mathrm{Car}(+)$ da L-carnosina se encontra com uma concentração 6 vezes maior que a da forma Car(0), ou seja, os grupos imidazol amino estão protonados e o grupo carboxílico, desprotonado.

Esperava-se observar mudanças mais significativas nos espectros no infravermelho dos 


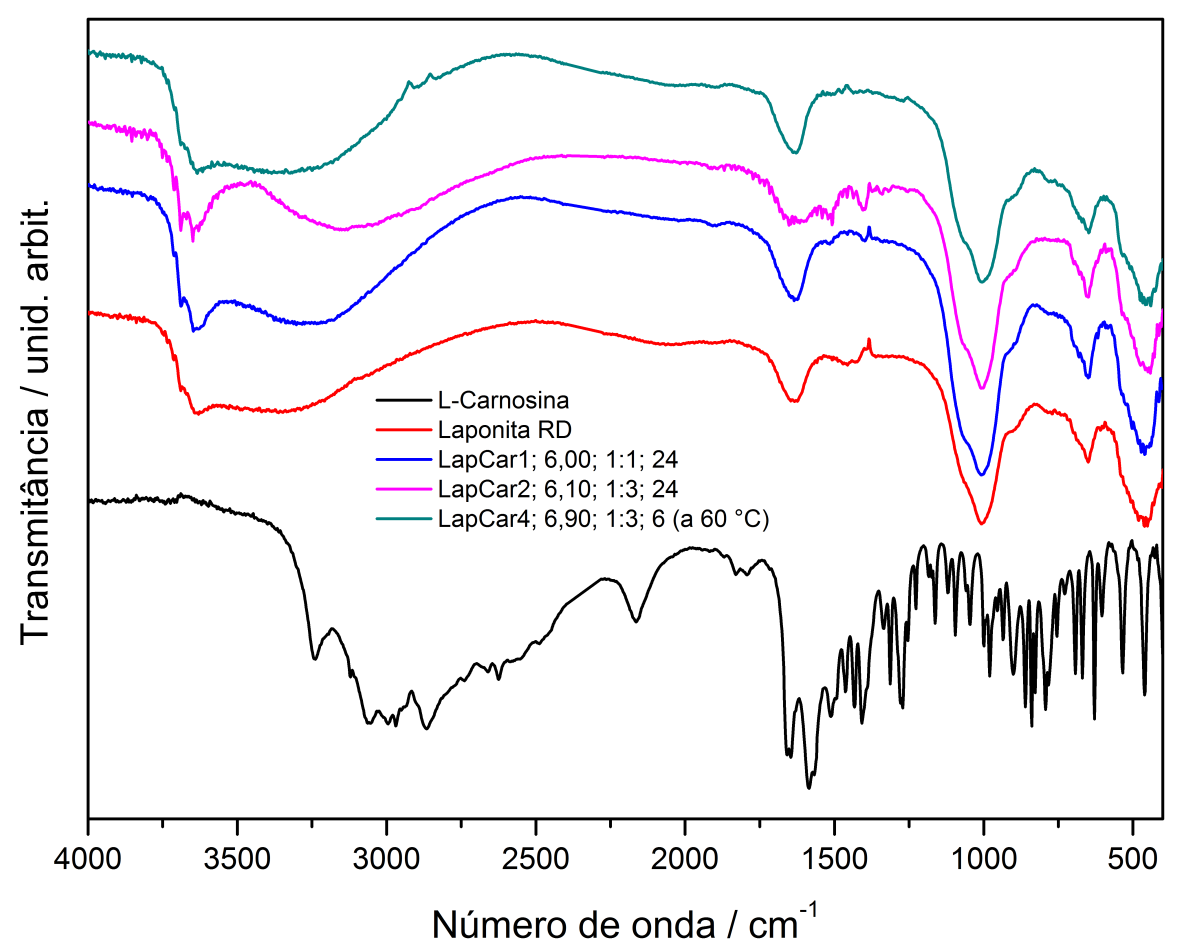

Figura 4.51: Espectros vibracionais na região do Infravermelho da L-Carnosina (preto), Laponita RD (vermelho) em suas formas originais e dos produtos de reação. (Código: Identidade da amostra; pH final de reação; proporção molar de argila:aminoácido; tempo de reação).

produtos das reações de imobilização da L-carnosina na argila, devido às vibrações dos grupos orgânicos do aminoácido. Porém, a intensidade das bandas é muito baixa quando comparada com a dos sistemas de L-carnosina em argilas Cloisita e Veegum HS. Isso indica que a quantidade imobilizada de L-carnosina dever ser muito menor.

Para o sistema constituído de argila Laponita e o aminoácido L-carnosina, foi possível registrar o espectro Raman. As argilas Cloisita e Veegum HS não permitiram o uso dessa técnica vibracional porque apresentam luminescência mesmo quando excitadas com laser no infravermelho próximo (1064 nm). O uso dessa radiação laser (que não promove as transições eletrônicas responsáveis pela luminescência) permitem aumentar a razão sinalruído através do acúmulo de registros e a reduzir os problemas de degradação da amostra pelo laser de excitação [85]. Outra vantagem da espectroscopia Raman em relação à espectroscopia no IR em estudos de materiais híbridos baseados em argilas está no fato das moléculas de água praticamente não apresentarem bandas na região usual de estudo 
$\left(4000-400 \mathrm{~cm}^{-1}\right)$, permitindo a melhor visualização de espécies orgânicas imobilizadas na fase inorgânica.

A Figura 4.52 mostra os espectros Raman da Laponita RD, da carnosina (espécie zwitteriônica) e da amostra LapCar2. As bandas da Laponita RD são encontradas em $1090 \mathrm{~cm}^{-1}(\nu \mathrm{Si}-\mathrm{O}), 772 \mathrm{~cm}^{-1}(\delta \mathrm{OH})$ e $683 \mathrm{~cm}^{-1}\left(\delta M g_{3} \mathrm{OH}\right)[86]$.

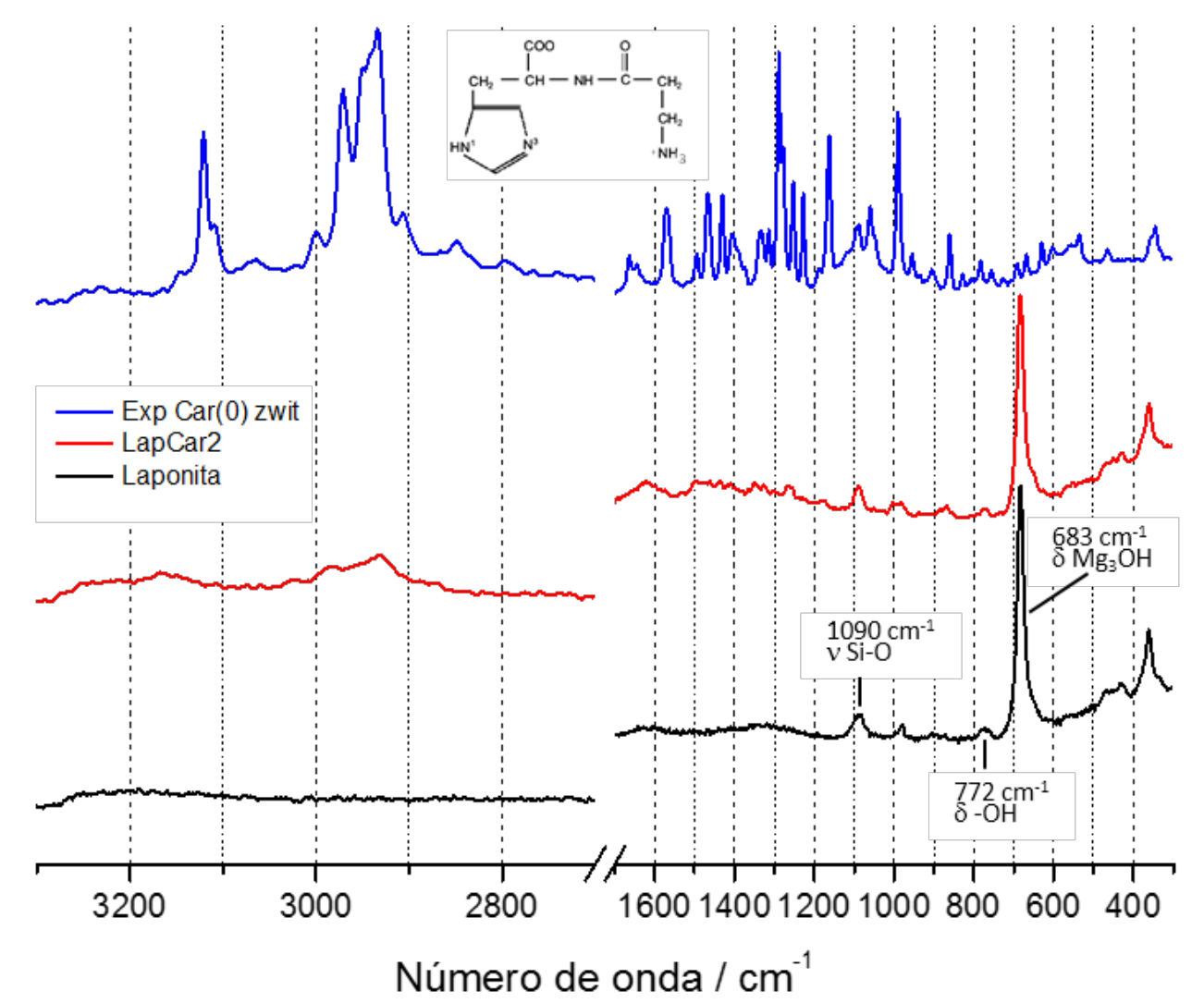

Figura 4.52: Espectros Raman do dipeptídeo L-Carnosina, da Laponita RD e da amostra LapCar2.

Para auxiliar na atribuição das bandas da espécie orgânica, também foram calculados os espectros Raman da L-carnosina em suas várias formas protonadas (Figura 4.53). Embora nos cálculos teóricos as espécies estejam completamente isoladas (ou seja, no vácuo) e na amostra para comparação a espécie esteja em um sólido, os resultados dos cálculos teóricos foram úteis para a atribuição dos espectros. Pode-se observar que o reagente Lcarnosina usado nos experimentos se cristaliza na forma zwitteriônica, abreviada $\operatorname{Car}(0)$. As principais bandas que caracterizam o zwittérion são: 1645 e $1644 \mathrm{~cm}^{-1}(\nu \mathrm{C}=\mathrm{O}$ do grupo amida e $\nu_{a s} \mathrm{COO}^{-}$do grupo carboxilato); 1572, 1497 e $1466 \mathrm{~cm}^{-1}$ ( $\nu$ imidazol desprotonado); $1400 \mathrm{~cm}^{-1}\left(\nu_{s} C O O^{-}\right)$. Como a quantidade de espécie orgânica imobilizada na 
Laponita é baixa, as bandas da L-carnosina podem ser observadas com baixa intensidade no espectro mostrado na Figura 4.53.

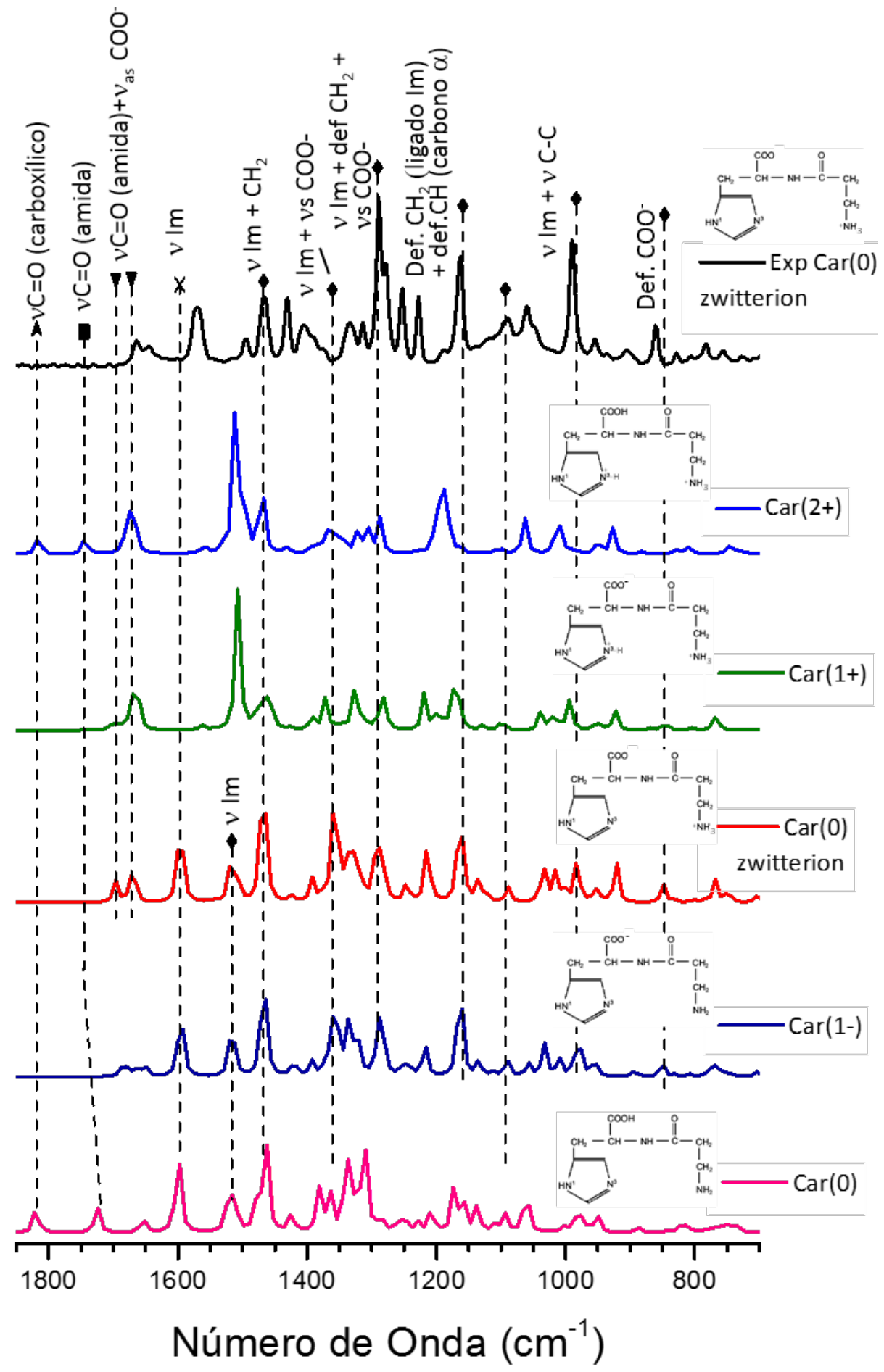

Figura 4.53: Espectros Raman calculados do dipeptídeo L-Carnosina em diferentes graus de protonação e espectro experimental da L-Carnosina sólida (forma zwiteriônica).

Para auxiliar na atribuição, o espectro da amostra LapCar2 foi ampliado na região de $1700-700 \mathrm{~cm}^{-1}$ (Figura 4.54). O perfil espectral da amostra híbrida é semelhante 
ao da espécie zwitteriônica (grupos carboxílico e imidazol desprotonados e grupo amino protonado), mas apresenta deslocamentos interessantes em algumas bandas. As bandas atribuídas aos modos de vibração $\nu \mathrm{C}=\mathrm{O}$ (grupo amida) e $\nu_{a s} C O O^{-}$se deslocam para região de menor energia, sugerindo o estabelecimento de ligações de hidrogênio desses grupos com, provavelmente, os grupos silanol (Si-OH) das arestas da argila.

Os comportamentos distintos das argilas usadas neste trabalho parecem estar relacionados com o fato da Laponita, por ser um material sintético, não apresentar impurezas (inorgânicas ou orgânicas) responsáveis pela luminescência. O uso da espectroscopia Raman na caracterização de espécies imobilizadas em argilas é muito interessante porque essa fase inorgânica apresenta bandas de baixa intensidade (mudanças de polarizabilidade no esqueleto do silicato são pouco pronunciadas), permitindo a visualização das bandas de espécies orgânicas presentes no material. Assim sendo, a forte banda de estiramento Si-O, que domina os espectros vibracionais no IR de argilas na região abaixo de $1100 \mathrm{~cm}^{-1}$, está ausente nos espectros Raman (argilas são espalhadores Raman fracos).

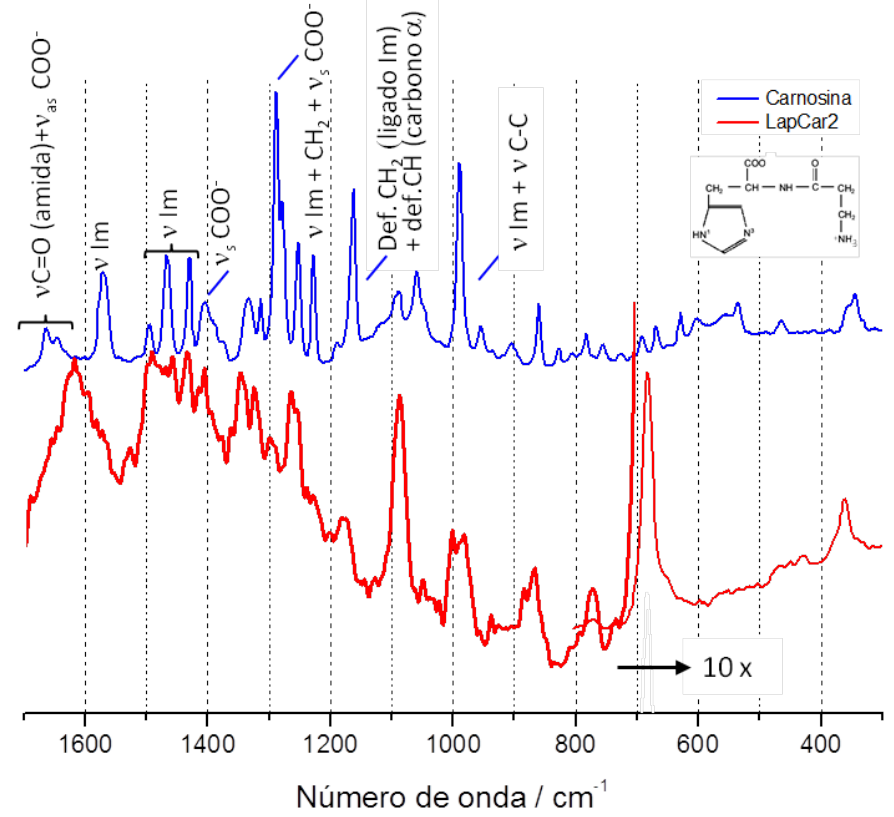

Figura 4.54: Espectros Raman do dipeptídeo L-Carnosina e da amostra LapCar2.

Na Figura 4.55 pode-se observar a curva termogravimétrica e DTG dos produtos das reações de intercalação da Laponita RD com a L-carnosina. A primeira perda de moléculas de água ocorre até a temperatura de $161{ }^{\circ} \mathrm{C}$, com perda de massa de 5,7\%. O segundo 
processo de perda de massa ocorre entre 250 - $660{ }^{\circ} \mathrm{C}$, que pelo espectro de massas pode-se atribuir à perda de água, devido ao fragmento com $m / z$ igual a 18. A perda de massa ao final do registro foi de $6,2 \%$.

As outras curvas são, aparentemente, semelhantes entre si (Apêndice B) e não ultrapassam $8 \%$ de perda de massa. As perdas de massa vão até a temperatura de aproximadamente $770{ }^{\circ} \mathrm{C}$, sendo que a partir dessa temperatura a massa permanece constante em $82,9 \%$.

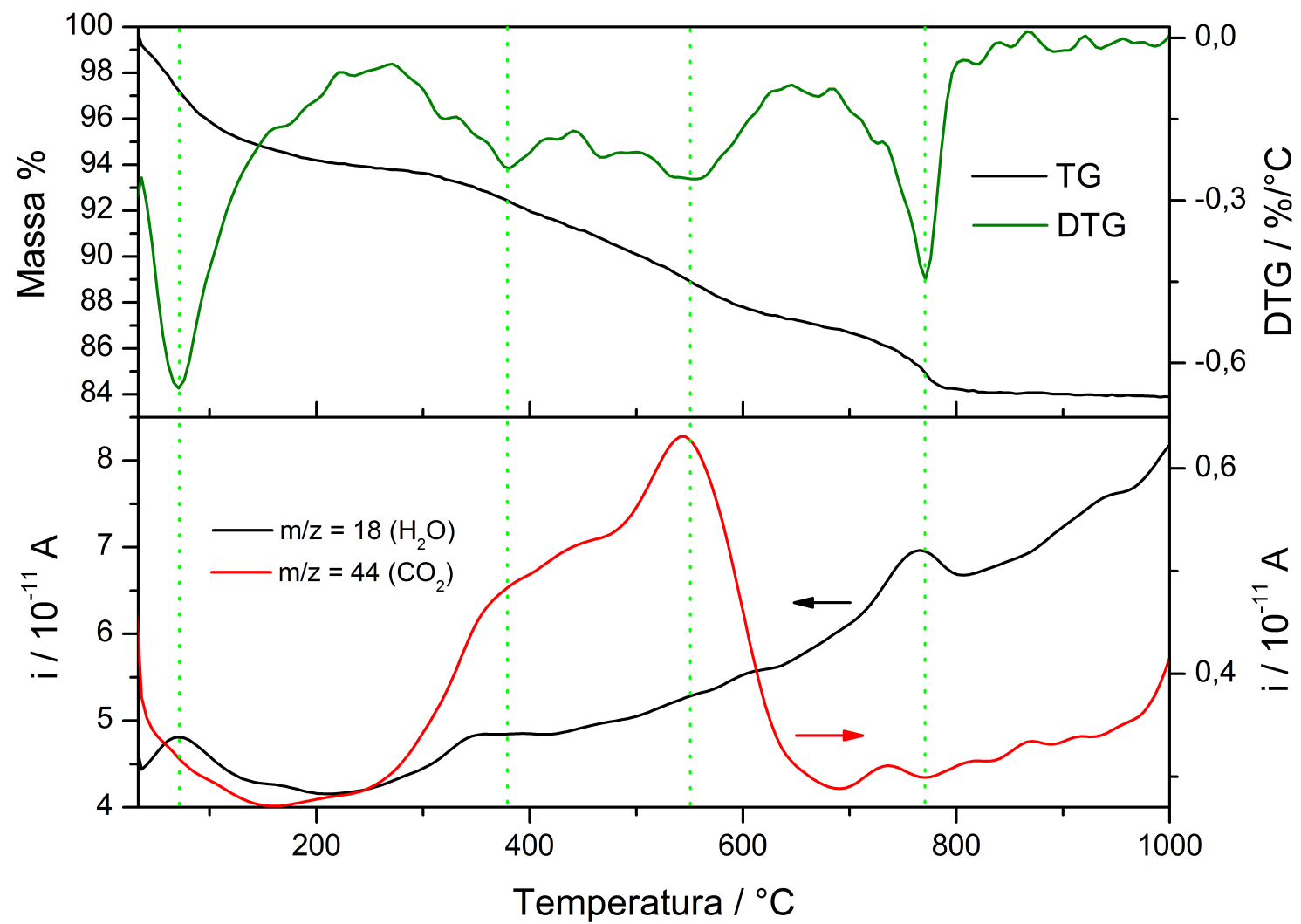

Figura 4.55: Curvas TGA (preto), DTG (verde oliva) e $M S$ (fragmentos $m / z=18$ (preto) $e$ $m / z=44$ (vermelho)) da amostra LapCar2.

Realizou-se a análise química elementar $(\mathrm{CHN})$ para a amostra LapCar2, que forneceu 2,45 de carbono. Considerando-se que esse elemento é proveniente somente do aminoácido, a concentração de L-carnosina na amostra LapCar2 é de aproximadamente 5,15 \% (ou $22,6 \mathrm{mmol} / 100 \mathrm{~g})$.

Em estudos realizados anteriormente por nosso grupo [87] a L-carnosina imobilizada 
na Laponita RD apresentou atividade antimicrobiana, mesmo em baixa concentração no material. Mais estudos serão feitos para um melhor entendimento desse comportamento, pois ainda não há relatos na literatura sobre a imobilização de L-carnosina em hectoritas.

\subsubsection{L-Ornitina em Laponita RD}

Como pode ser visto no difratograma de raios X da amostra LapOrt2 (Figura 4.56), o perfil segue aquele das amostras de Laponita com aminoácidos das reações citadas anteriormente, isto é, sem modificações significativas nos espaçamentos basais. Houve um deslocamento do pico $d_{(001)}$ de $2 \theta=6,14^{\circ}(d=14,4 \AA)$ da Laponita RD para $2 \theta=5,04^{\circ}$ $(\mathrm{d}=17,5 \AA)$ para o produto LapOrt2.

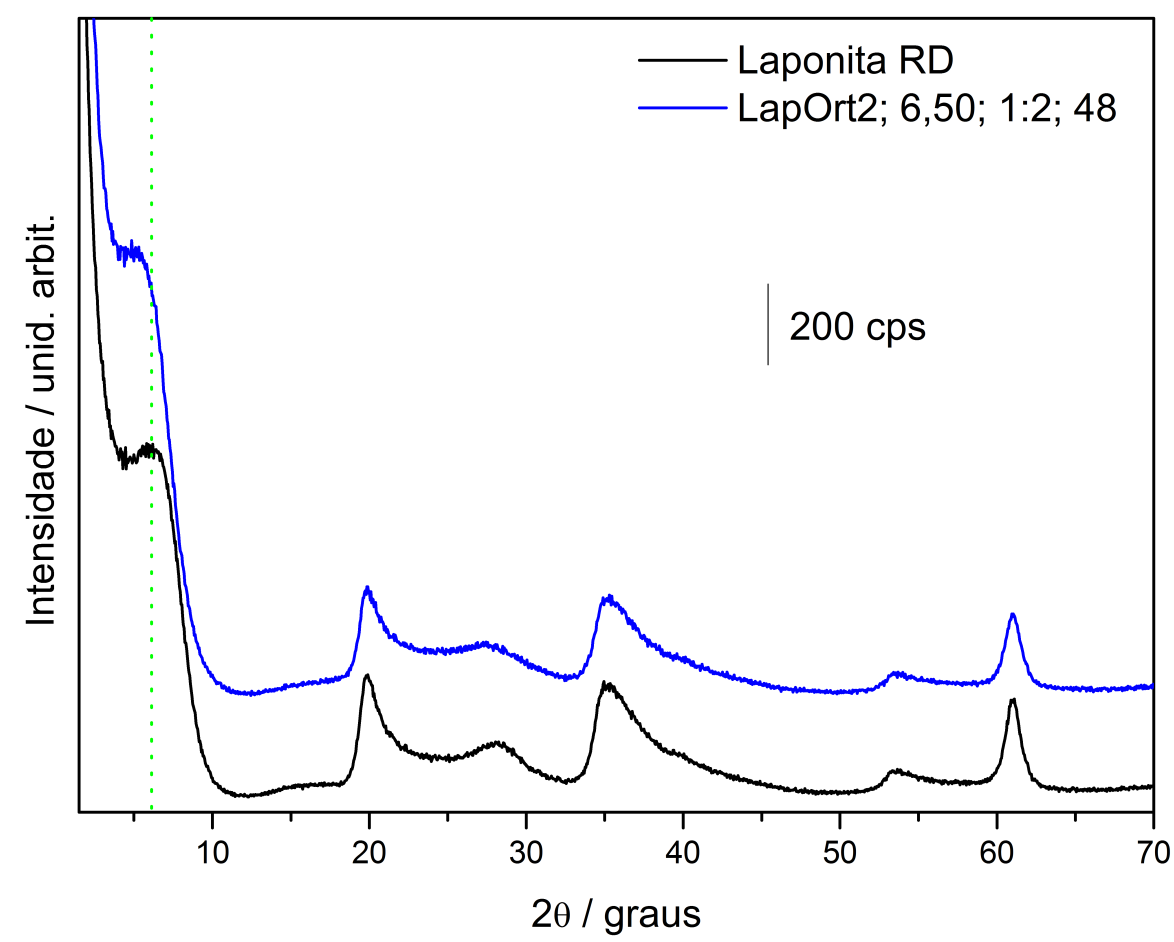

Figura 4.56: Difratogramas de raios $X$ da Laponita $R D$ e dos produtos das reações da Laponita $R D$ com Cloridrato de L-Ornitina. (Código: Identidade da amostra; pH final de reação; proporção molar de argila:aminoácido; tempo de reação).

O espectro vibracional na região do infravermelho do aminoácido L-onitina, na forma cloridrato, da Laponita $\mathrm{RD}$ e dos produtos da reação entre essa argila e o aminoácido encontram-se na Figura 4.57. Pode-se observar que há poucas mudanças no espectro 
vibracional dos produtos em relação à argila pristina.

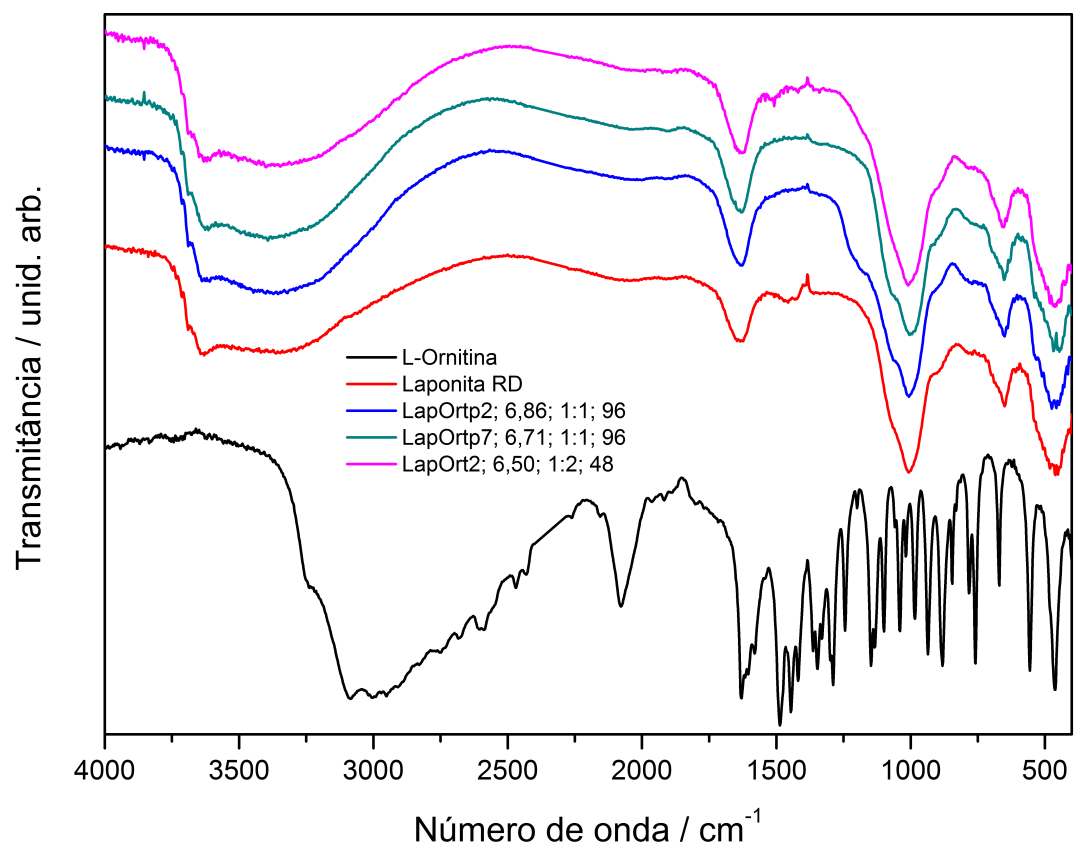

Figura 4.57: Espectros vibracionais na região do Infravermelho do Cloridrato de L-Ornitina (preto), Laponita RD (vermelho) em suas formas originais e dos produtos de reação. (Código: Identidade da amostra; pH final de reação; proporção molar de argila:aminoácido; tempo de reação).

Há bandas de intensidade muito baixas no espectro FTIR da amostra LapOrt2, mas que não permite fazer conclusões acerca da identidade da espécie de L-ornitina imobilizada. Considerando o valor do pH da suspensão de preparação das três amostras mencionadas na Figura 4.57, esperava-se a presença da espécie $\mathrm{Ort}^{+}$.

Os dados de análise térmica da amostra LapOrt2 (Figura 4.58) mostram que o perfil das curvas TGA e MS são semelhantes ao das outras amostras de Laponita com L-lisina e L-arginina. Pela curva DTG, observa-se que há dois processos de perda de massa, assim como para as outras amostras. A massa residual foi de $83 \%$ e na temperatura de aproximadamente $950{ }^{\circ} \mathrm{C}$ não há mais perda de massa. A perda do fragmento com $\mathrm{m} / z$ igual a 18 ocorre em maior intensidade nas temperaturas em torno de $90{ }^{\circ} \mathrm{C}$ e $770{ }^{\circ} \mathrm{C}$ enquanto o fragmento com $m / z$ igual a 44 na temperatura em torno de $500{ }^{\circ} \mathrm{C}$. 


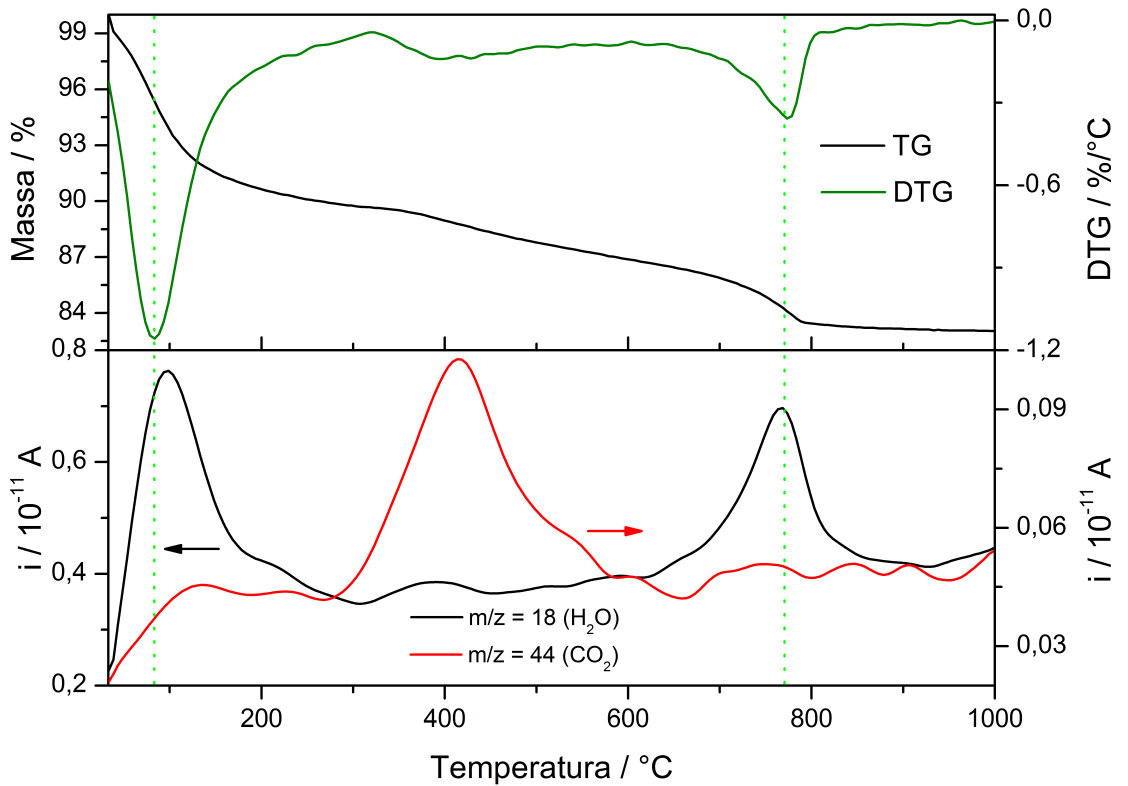

Figura 4.58: Curvas TGA (preto), DTG (verde) e $M S$ (fragmentos $m / z=18$ (preto) e $\mathrm{m} / \mathrm{z}$ = 44 (vermelho)) da amostra LapOrt2. 


\section{Capítulo 5}

\section{CONCLUSÕES}

Para maximizar a interação argila/aminoácido é preciso observar principalmente que (i) o pH deve ser ajustado de modo a gerar espécies positivas (promover a interação eletrostática) e (ii) o baixamento do $\mathrm{pH}$ para valores inferiores a 2 ou 3 podem provocar reações que competem com a intercalação do aminoácido como a intercalação de íons $H^{+}$e a solubilização das argilas, podendo ser o motivo pelo qual não se conseguiu manter o valor do pH da dispersão de Laponita baixo o suficiente para que os aminoácidos estivessem carregados positivamente.

Preparam-se materiais híbridos argila/aminoácido através de reações de troca iônica. Esses novos materiais foram caracterizados por difração de raios X, mas como a distância interlamelar não aumentou significativamente, pois as menores dimensões do aminoácidos eram em torno de $4 \AA$, essa técnica não foi conclusiva para analisar se as moléculas de aminoácido estavam intercaladas ou adsorvidas nas arestas da argila, mas com os dados de análise elementar de carbono e a partir dos cálculos de CTC neutralizada pode-se concluir que o aminoácido está intercalado nas lamelas das argilas.

Os espectros vibracionais na região do infravermelho mostraram mudanças no caso dos novos materiais quando comparados com a argila precursora. Essas mudanças foram atribuídas às vibrações de grupos presentes nas moléculas dos aminoácidos. Resultados de espectrometria de massas acoplada à análise térmica mostram em todos os produtos a presença do fragmento $m / z$ igual a 44, atribuído à decomposição de matéria orgânica.

Para algumas amostras realizou-se o teste com ninidrina e o mesmo atestou a existência 
de aminoácido em todas as amostras em que o teste foi realizado. Logo a matéria orgânica é devida a moléculas de aminoácidos.

Dentre as três matrizes inorgânicas, a que se comportou como um melhor carregador para todos os aminoácidos foi a Cloisita $\mathrm{Na}^{+}$, mas vale lembrar que a matriz inorgânica é um limitante para a quantidade de cátions imobilizados. Os produtos da reação de intercalação dos aminoácidos com as argilas do tipo montmorilonitas apresentam maior quantidade de matéria orgânica do que os materiais sintetizados a partir da argila do tipo hectorita. Esse resultado já era esperado, visto que a CTC da Cloisita $\mathrm{Na}^{+}$e Veegum HS são maiores que a CTC da Laponita RD.

Os estudos de imobilização dos aminoácidos nas argilas permitiram avaliar o grau de acidez de três argilas. A ordem de acidez verificada concorda com aquela já relatada na literatura: montmorilonitas são mais ácidas quando comparadas às hectoritas. Observouse que todos os sistemas montmorilonitas/aminoácidos apresentam o grupo carboxilato protonado mesmo quando preparadas em valores de $\mathrm{pH}$ maiores que seus respectivos valores de $p K_{a 1}$, o que não foi observado para os sistemas hectorita/aminoácidos.

Para o sistema Cloisita/L-lisina o melhor resultado foi a amostra CloLysS, pois além de ser obtido com um menor número de etapas (isto é, não há ajuste de pH),gerando um menor custo, também se obteve uma maior quantidade de aminoácido imobilizado (7,84 \% ou 53,3 mmol/100 g de material), neutralizando 42,4 \% da CTC. Para o sistema argila/L-ornitina, a argila que apresentou melhores resultados foi a Cloisita (amostra CloOrt1 contém 6,2\% de aminoácido ou 46,6 mmol/100 g de material e 50,6 \% de CTC neutralizada).

Ao se comparar os procedimentos experimentais, pode-se concluir que a utilização das razões molares 1:1 e 1:2 (argila:aminoácido) e as pequenas variações de pH da mistura final nem sempre modificam de forma significativa os produtos. Comparando-se os produtos das reações de intercalação da argila Laponita RD com o aminoácido L-carnosina, podese concluir que o procedimento que envolve aquecimento não modifica significativamente o produto (LapCar4), já o procedimento que emprega a maior razão molar (LapCar2) resulta num produto com mais espécies orgânicas intercaladas ou adsorvidas na superfície 
da argila.

Não existem relatos na literatura sobre os sistemas montmorilonitas/L-carnosina, hectorita/L-carnosina, montmorilonita/L-ornitina e hectorita/L-ornitina, sendo relevante o estudo detalhado das interações entre as argilas e esses aminoácidos. 


\section{Capítulo 6}

\section{PERSPECTIVAS FUTURAS}

Os resultados obtidos nesta Dissertação permitem propor estudos posteriores com o objetivo de aprofundar na caracterização estrutural e espectroscópicas dos materiais e iniciar testes de atividade biológica.

Como duas das argilas utilizadas no presente trabalho são de origem natural, podendo conter impurezas de ferro e de minerais, que impossibilitam a realização de alguns estudos (por exemplo, ressonância magnética nuclear de ${ }^{13} \mathrm{C}$ e espectroscopia Raman), sugere-se realizar testes de imobilização dos aminoácidos em argilas sintéticas, livres de impurezas e com composição definida. Os resultados destes trabalho permitem conhecer os melhores parâmetros experimentais para a intercalação de alguns aminoácidos de interesse farmacêutico em argilas.

Algumas estratégias poderiam ser testadas para aumentar o grau de imobilização dos aminoácidos nas argilas. Por exemplo, as argilas poderiam ser pré-intercaladas com metais de transição essenciais para promover a interação, por coordenação do aminoácido.

A L-carnosina possui atividade biológica que merece ser explorada considerando-se a presença de um carregador como as argilas. Estudos futuros poderão avaliar a atividade antioxidante dos materiais híbridos contendo carnosina.

Alguns ensaios realizados por nosso grupo de pesquisa evidenciaram que o material híbrido Laponita/L-carnosina apresenta atividade antimicrobiana. Dessa forma pretendese continuar os estudos deste híbrido visto que esta ainda é uma área pouco explorada. 


\section{Capítulo 7}

\section{REFERÊNCIAS BIBLIOGRÁFICAS}

[1] C. Sanchez, K. J. Shea, and S. Kitagawa. Applications of advanced hybrid organicinorganic nanomaterials: from laboratory to market. Chemical Society Reviews, 40:696-753, 2011. 27, 28, 29, 49

[2] L. A. S. de A. Prado. Materiais híbridos orgânico-inorgânico: Preparação e algumas aplicações. Química Nova, 28:281-288, 2005. 27, 28, 30

[3] A. Domeénech, M. T. Doménech-Carbó, M. Sánchez del Río, M. L. V. de A. Pascual, and E. Lima. Maya blue as a nanostructured polyfunctional hybrid organic-inorganic material: the need to change paradigms. New Journal of Chemistry, 33:2371-2379, 2009. 28

[4] http://www.suapesquisa.com/astecas/imagens_maias.htm. Acessado em 2013. 28

[5] http://www.eie.gr/nhrf/institutes/tpci/researchteams/mspc/mspc-aslmite-en.html. Acessado em 2013. 28

[6] E. Ruiz-Hitzky, P. Aranda, M. Dardera, and G. Rytwobc. Hybrid materials based on clays for environmental and biomedical applications. Journal of Materials Chemistry, 20:9306-9321, 2010. 28, 29, 30, 46

[7] http://www.chemeurope.com/en/encyclopedia/Thixotropy.html. Acessado em 2013. 29

[8] A. C. V. Coelho, P. de S. Santos, and H. de S. Santos. Argilas especiais: Argilas quimicamente modificadas - uma revisão. Química Nova, 30(5):1282-1294, 2007. 29, $35,37,71$

[9] M. Darder, P. Aranda, and E. Ruiz-Hitzky. Bionanocomposites: A new concept of ecological, bioinspired, and functional hybrid materials. Advanced Materials, 19:13091319, 2007. 29, 30

[10] S. Mann. Biomineralization: Principles and Concepts in Bioinorganic Materials Chemistry. Oxford University Press, 2001. 30

[11] G. M. do Nascimento, V. R. L. Constantino, R. Landers, and M. L. A. Temperini. Spectroscopic characterization of polyaniline formed in the presence of montmorillonite clay. Polymer, 47:6131-6139, 2006. 30 
[12] Â. A. Teixeira-Neto, C. M. S. Izumi, M. L. A. Temperini, A. M. da C. Ferreira, and V. R. L. Constantino. Hybrid materials based on smectite clays and nutraceutical anthocyanins from the açaí fruit. European Journal of Inorganic Chemistry, pages 5411-5420, 2012. 30, 72

[13] P. M. Dias, D. L. A. De Faria, and V. R. L. Constantino. Spectroscopic studies on the interaction of tetramethylpyridylporphyrins and cationic clays. Journal of Inclusion Phenomena and Macrocyclic Chemistry, 38:251-266, 2000. 30

[14] P. M. Dias, L. Kinouti, V. R. L. Constantino, A. M. D. C. Ferreira, M. B. Gonçalves, R. R. do Nascimento, H. M. Petrilli, M. Caldas, and R. C. G. Frem. Spectroscopic characterization of schiff base-copper complexes immobilized in smectite clays. Química Nova, 33:2135-2142, 2010. 30

[15] AIPEA (association internationale pour l'etude des argiles). Newsletter, 32, February 1996. 30

[16] P. de S. Santos. Tecnologia de argilas, aplicada às argilas brasileiras. Edgard Blucher, 1975. $30,31,34,35$

[17] C. J. B. Mott. Clay minerals - an introduction. Catalysis Today, 2:199-208, 1988. 31,32

[18] R. A. Schoonheydt and C. T. Johnston. Surface and interface chemistry of clay minerals. Handbook of Clay Science, 1:87-113, 2006. 31, 32, 38, 39, 42

[19] M. G. Neumann, F. Gessner, A. P. P. Cione, R. A. Sartori, and C. C. S. Cavalheiro. Iterações entre corantes e argilas em suspensão aquosa. Quimica Nova, 23(6):818-824, 2000. $31,32,33$

[20] http://education.mrsec.wisc.edu/pmk/pages/montmorillonite.html. Acessado em 2012. 31

[21] P. Komadel, J. Madejová, and J. Bujdák. Preparation and properties of reducedcharge smectites - a review. Clays and Clay Minerals, 53(4):313-334, 2005. 33, 34, 37

[22] T. L. Brown, H. E. LeMay Jr., B. E. Bursten, and J. R. Burdge. Química a ciência central. Pearson, 9 edition, 2005. 33

[23] C. T. Johnston. Sorption of organic compounds on clay minerals: A surface functional group approach. The Clay Minerals Society: CMS Workshop Lectures, 8:2-44, 1996. $33,34,38,39,40$

[24] M. Jaber and J. Miehé-Brendlé. Synthesis, characteriation and applications of 2:1 phyllosilicates and organophyllosilicates: contribution of fluoride to study the octahedral sheet. Microporous and Mesoporous Materials, 107:121-127, 2008. 34

[25] James E. Huheey, Ellen A. Keiter, and Richaard L. Keiter. Inorganic Chemistry: Principles of structure and reactivity. HarperCollinsCollege, 4 edition, 1975. 34

[26] F. Bergaya. History and perspectives of clay science. Latin-American Clay Conference, 2000. 35 
[27] S. Mallakpour and M. Dinari. Preparation and characterization of new organoclays using naural amino acids and closite $\mathrm{Na}^{+}$. Applied Clay Science, 51:353-359, 2011. 35

[28] K. L. Dagnon, S. A., A. Shaito, S. M. Ogbomo, V.e DeLeon, T. D. Golden, M. Rahimi, K. Nguyen, P. S. Braterman, and N. A. D'Souza. Poly (L-lactic acid) nanocomposites with layered double hydroxides functionalized with ibuprofen. Wiley InterScience, 2009. 36

[29] RockWood Additives. Manufacture, structure and chemistry. Laponite: Performance additives, pages 18-20. 36, 128

[30] M. Kowalska, H. Giiler, and D. L. Cocke. Interactions of clay minerals with organic pollutants. The Science of the Total Environment, 141:223-240, 1994. 36

[31] R. A. Schoonheydt, T. Pinnavaia, G. Lagaly, and N. Gangas. Pillared clays and pillared layered solids. Pure and Applied Chemistry, 71:2367-2371, 1999. 37

[32] R. Bradfield. The nature of the acidity of the colloidal clay of acid soils. Journal of the American Chemical Society, 45:2669-2678, 1924. 38

[33] H. He, Q. Tao, J. Zhu, P. Yuan, W. Shen, and S. Yang. Silylation of clay mineral surfaces. Applied Clay Science, 71:15-20, 2013. 38, 39, 42

[34] J. D. Lee. Química inorgânica não tão concisa. Edgard Blucher, 5 edition, 2003. 38

[35] H. He, Q. Tao, J. Zhu, P. Yuan, W. Shen, and S. Yang. Silylation of clay mineral surfaces. Applied Clay Science, 71:15-20, 2013. 42

[36] X. Liu, X. Lu, M. Sprik, J. Cheng, E. J. Meijer, and R. Wang. Acidity of edge surface sites of montmorillonite and kaolinite. Geochimica et Cosmochimica Acta, 117:180-190, 2013. 43

[37] M. Duc, F. Gaboriaud, and F. Thomas. Sensitivity of the acid-base properties of clays to the methods of preparation and measurement. Journal of Colloid and Interface Science, 289:139-147, 2005. 44, 81, 119

[38] M. I. Carretero and M. Pozo. Clay and non-clay minerals in the pharmaceutical industry. Part I. excipients and medical applications. Applied Clay Science, 46:7380, 2009. 44, 45, 46

[39] M. I. Carretero and M. Pozo. Clay and non-clay minerals in the pharmaceutical and cosmetic industries. Part II. active ingredients. Applied Clay Science, 47:171-181, 2010. 45

[40] P. R. Gil, D. Hühn, L. L. del Mercato, D. Sasse, and W. J. Parak. Nanopharmacy: Inorganic nanoscale devices as vectors and active compounds. Pharmacological Research, 62:115-125, 2010. 45, 47

[41] M. E. Sedaghat, M. Ghiaci, H. Aghaei, and S. Soleimanian-Zad. Enzyme immobilization. Part 3. immobilization of L-amylase on Na-bentonite and modified bentonite. Applied Clay Science, 46:125-130, 2009. 45, 47 
[42] R. Slamova, M. Trckova, H. Vondruskova, Z. Zraly, and I. Pavlik. Clay minerals in animal nutrition. Applied Clay Science, 51:395-398, 2011. 45

[43] C. Aguzzi, P. Cerezo, C. Viseras, and C. Caramella. Use of clays as drug delivery systems: Possibilities and limitations. Applied Clay Science, 36:22-36, 2007. 46, 47, 48

[44] F. Si-Shen, M. Lin, A. Panneerselvan, G. CheeWee, and W. Zhou. Poly(lactide)vitamin e derivative/montmorillonite nanoparticle formulations for the oral delivery of docetaxel. Biomaterials, 30:3297, 2009. 46

[45] Z. P. Xua, Q. H. Zeng, G. Q. Lu, and A. B. Yu. Inorganic nanoparticles as carriers for efficient cellular delivery. Chemical Engineering Science, 61:1027-1040, 2006. 47

[46] G. B. Curry, B. K. G. Theng, and H. Zheng. Amino acid distribution in a loesspalaeosol sequence near luochuan, loess plateau, China. Organic Geochemistry, 22:287-298, 1994. 49

[47] X. Ding and S. M. Henrichs. Adsorption and desorption of proteins and polyamino acids by clay minerals and marine sediments. Marine Chemistry, 77:225-237, 2002. 49,50

[48] D. R. Katti, P. Ghosh, S. Schmidt, and K. S. Katti. Mechanical properties of the sodium montmorillonite interlayer intercalated with amino acids. Biomacromolecules, 6:3276-3282, 2005. 49

[49] Y. Xi, R. L. Frost, and H. He. Modification of the surfaces of Wyoming montmorillonite by the cationic surfactants alkyl trimethyl, dialkyl dimethyl, and trialkyl methyl ammonium bromides. Journal of Colloid and Interface Science, 305:150-158, 2007. 49

[50] T. Kollár, I. Pálinkó, and I. Kiricsi. Effect of heat treatment on amino acid intercalated in montmorillonite. Journal of Thermal Analysis and Calorimetry, 79:533-535, 2005. 50

[51] Á. Fudala, I. Pálinkó, and I. Kiricsi. Preparation and characterization of hybrid organic-inorganic composite materials using the amphoteric property of amino acids: Amino acid intercalated layered double hydroxide and montmorillonite. Inorganic Chemistry, 38:4653-4658, 1999. 50

[52] D. L. Nelson and M. M. Cox. Lehninger: Princípios de Bioquímica. Editora Sarvier, 3 edition, 2002. 50, 54, 56

[53] M. J. O’Neil, P. E. Heckelman, C. B. Koch, K. J. Roman, C. M. Kenny, and M. R. D'Arecca. The Merck Index: An encyclopedia of chemicals, drugs, and biologicals. Merck Research Laboratoies, 14, 2006. 51, 52

[54] W. Derave, I. Everaert, S. Beeckman, and A. Baguet. Muscle carnosine metabolism and $\beta$-alanine supplementation in relation to exercise and training. Sports Medicine, 40:247-269, 2010. 51, 52 
[55] M. L. Branham, P. Singh, K. Bisetty, M. Sabela, and T. Govender. Preparation, spectrochemical, and computational analysis of L-Carnosine (2-[(3aminopropanoyl)amino]-3-(1h-imidazol-5- yl)propanoic acid) and its ruthenium (II) coordination complexes in aqueous solution. Molecules, 16:10269-10291, 2011. 51

[56] A. A. Fouad, M. A. Morsy, and W. Gomaa. Protective effect of carnosine against cisplatin-induced nephrotoxicity in mice. Environmental Toxicology and Pharmacology, 25:292-297, 2008. 51, 52

[57] R. Holliday and G. A. McFarland. A role for carnosine in cellular maintenance. Biochemistry (Moscow), 65:843-848, 2000. 51

[58] R. P. Diez and E. J. Baran. A density functional study of some physical properties of carnosine ( $n-\beta$-alanyl-L-histidine). Journal of Molecular Structure (Theochem), 621:245-251, 2003. 51

[59] F. di Pierro, A. Bertuccioli, A. Bressan, and G. Rapacioli. Carnosine-based supplement: Preliminary clinical studies. Nutra Foods, pages 43-47, 2011. 51, 52

[60] G. Takeshi, K. Ken-Ichi, K. Akira, and I. Shunzo. Direct production of L-ornithine from casein by commercial digestive enzymes and in situ activated arginase. Bioprocess and Biosystems Engineering, 33:773, 2010. 53

[61] http://escreta-nh2.blogspot.com.br/2010/12/o -ciclo -da-ornitina.html. Acessado em 2013. 53

[62] S. Ishida, M. Sarada, H. Seki, L. McGirr, A. Lau, and K. Morishita. Genotoxicity and subchronic oral toxicity of L-ornithine monohydrochloride. Regulatory Toxicology and Pharmacology, 67:360-371, 2013. 53

[63] N. Gupta, Y. Jing, N. D. Collie, H. Zhang, and P. Liu. Ageing alters behavioural function and brain arginine metabolism in male sprague-dawley rats. Neuroscience, 226:178-196, 2012. 54

[64] G. Angeli, T. L. de Barros, D. F. L. de Barros, and M. Lima. Investigação dos efeitos da suplementação oral de arginina no aumento de força e massa muscular. Revista Brasileira de Medicina do Esporte, 13:129-132, 2007. 55

[65] D. Coman, J. Yaplito-Lee, and A. Boneh. New indications and controversies in arginine therapy. Clinical Nutrition, 27:489-496, 2008. 55

[66] M. B. Mary, M. Umadevi, and V. Ramakrishnan. Vibrational spectral analysis of L-lysine L-lysinium dichloride nitrate. Spectrochimica Acta Part A, 61:3124-3130, 2005. 55, 73

[67] S. Tsubuku, M. Mochizuki, K. Mawatari, M. Smriga, and T. Kimura. Thirteenweek oral toxicity study of L-Lysine hydrochloride in rats. International Journal of Toxicology, 23:113-118, 2004. 55

[68] D. J. Thein and W. C. Hurt. Lysine as a prophylactic agent in the treatment of recurrent herpes simplex labialis. Oral Medicine, 58:659-666, 1984. 55 
[69] I. A. Silva, J. M. R. Costa, H. S. Ferreira, R. R. Menezes, G. A. Neves, and H. C. Ferreira. Organofilização de argilas bentoníticas com tensoativos não-iônicos visando seu uso em fluidos de perfuração base óleo. Cerâmica, 58:317-327, 2012. 59

[70] C. Aguzzi, C. Viseras, P. Cerezo, S. Rossi, and F. Ferrari. Influence of dispersion conditions of two pharmaceutical grade clays on their interaction with some tetracyclines. Applied Clay Science, 30:79-86, 2005. 59

[71] B. R. Jennings, H. Plummer, W. J. Gloss, and H. G. Jerrard. Size and shape of laponite (type s) synthetic clay particles. Journal of Colloid and Interface Science, 30(1):134-139, 1969. 59

[72] D. M. Moore and R. C. Reynolds Jr. X-Ray Diffraction and the Identification and Analysis of Clay Minerals. Oxford University Press, 2 edition, 1997. 71

[73] F. Bergaya, B.K.G. Theng, and G. Lagaly. Handbook of Clay Science. Elsevier, 1 edition, 2006. 71

[74] B. Hernández, F. Pflüger, N. Derbel, J. de Coninck, and M. Ghomi. Vibrational analysis of amino acids and short peptides in hydrated media. VI. amino acids with positively charged side chains: L-Lysine and L-Arginine. Journal of Physical Chemistry B, 114:1077-1088, 2010. 74

[75] J. Madejová, M. Pentrák, H. Pálková, and P. Komadel. Near-infrared spectroscopy: A powerful tool in studies of acid-treated clay minerals. Vibrational Spectroscopy, 49:211-218, 2009. 74, 103

[76] S. Mukerji and T. Kar. Structural, thermal and spectroscopic investigation of nonlinear optical crystal L-arginine hydrobromide monohydrate. Materials Research Bulletin, 33:619-626, 1998. 85

[77] Z. Durmus, H. Kavas, A. Baykal, H. Sozeri, L. Alpsoy, S.Ü. Çelik, and M.S. Toprak. Synthesis and characterization of L-carnosine coated iron oxide nanoparticles. Journal of Alloys and Compounds, 509:2555-2561, 2011. 89

[78] P. Hohenberg and W. Kohn. Inhomogeneus electron gas. Physical Review, 136(3B):864-871, 1964. 91, 165

[79] W. Kohn and L. J. Sham. Self-consistent equations including exchange and correlation effects. Physical Review, 140(4A):1133-1138, 1965. 91, 165

[80] M. J. Frisch, G. W. Trucks, H. B. Schlegel, G. E.Scuseria, M. A. Robb, and J. Cheeseman R.and G. Scalmani. Gaussian 09. Wallingford CT: Gaussian, 2009. 91, 165

[81] M. Raupach and L. J. Janik. The orientation of ornithine and 6-aminohexanoic acid adsorbed on vermiculite from polarized i.r. atr spectra. Clays and Clay Minerals, 24:127-133, 1976. 96

[82] F. Kanamaru and V. Vand. The crystal structure of a clay-organic complex of 6amino hexanoic acid and vermiculite. The American Mineralogist, 55:1550-1561, 1970. 116 
[83] J. Madejová, J. Bujdák, M. Janek, and P. Komadel. Comparative FT-IR study of structural modifications during acid treatment of dioctahedral smectites and hectorite. Spectrochimica Acta Part A, 54:1397-1406, 1998. 119

[84] M. Janek and G. Lagaly. Proton saturation and rheological properties of smectite dispersions. Applied Clay Science, 19:121-130, 2001. 119

[85] R. L. Frost and P. M. Fredericks. Fourier transform raman spectroscopy of kandite clays. Spectrochimica Acta Part A: Molecular Spectroscopy, 49:667-674, 1993. 130

[86] J. Madejova and P. Komadel. Baseline studies of the clay minerals society source clays: infrared methods. Clays and Clay Minerals, 40:410-432, 2001. 131

[87] G. F. Perotti. Nanocompósitos orgânico-inorgânicos de polímero biodegradável e estruturas lamelares. Tese, Universidade de São Paulo, 17-05-2013. 184 Páginas. 134

[88] C. Lee, W. Yang, and R. G. Parr. Development of the colic-salvetti correlation-energy formula into a functional of the electron density. Physical Review B, 37:785-789, 1988. 165

[89] E. Kaiser, R. L. Colescott, C. D. Bossinger, and P. I. Cook. Color test for detection of free terminal amino groups in solid-phase peptide synthesis. Analytical Biochemistry, 34:595-598, 1970. 168 


\section{Apêndice A}

\section{Condições experimentais empregadas}

\section{nos testes de imobilização de}

\section{aminoácidos em argila}

Tabela A.1: Resumo das condições experimentais para a preparação de amostras com a argila Cloisita $\mathrm{Na}^{+*}$.

\begin{tabular}{|c|c|c|c|c|}
\hline Amostra & Aminoácido & $\begin{array}{c}\text { Proporção } \\
\text { Argila / Aminoácido }\end{array}$ & $\begin{array}{c}\mathrm{pH} \text { (Final } \\
\text { da suspenção) }\end{array}$ & $\begin{array}{c}\text { Tempo de Agitação } \\
\text { (Horas) }\end{array}$ \\
\hline CloLys1 & Lisina & $1: 1$ & 2,66 & 24 \\
\hline CloLys2 & Lisina & $1: 2$ & 2,67 & 24 \\
\hline CloLysp4 & Lisina & $1: 1$ & 4,09 & 24 \\
\hline CloLysp5 & Lisina & $1: 1$ & 5,59 & 24 \\
\hline CloLysp6 & Lisina & $1: 1$ & 6,63 & 24 \\
\hline CloLysS & Lisina & $1: 2$ & 7,52 & 48 \\
\hline CloArg1 & Arginina & $1: 1$ & 3,25 & 24 \\
\hline CloArg2 & Arginina & $1: 2$ & 3,32 & 24 \\
\hline CloArgp4 & Arginina & $1: 1$ & 9,60 & 24 \\
\hline CloArgp5 & Arginina & $1: 1$ & 9,79 & 24 \\
\hline CloArgp6 & Arginina & $1: 1$ & 9,97 & 24 \\
\hline CloArgS & Arginina & $1: 2$ & 9,54 & 48 \\
\hline CloCar1 & Carnosina & $1: 1$ & 3,46 & 24 \\
\hline CloCarp4 & Carnosina & $1: 1$ & 8,01 & 24 \\
\hline CloCarp5 & Carnosina & $1: 1$ & 8,12 & 24 \\
\hline CloCarp6 & Carnosina & $1: 1$ & 8,31 & 24 \\
\hline CloOrtp4 & Ornitina & $1: 1$ & 4,81 & 24 \\
\hline CloOrtp5 & Ornitina & $1: 1$ & 5,74 & 24 \\
\hline CloOrtp6 & Ornitina & $1: 1$ & 6,99 & 24 \\
\hline CloOrt1 & Ornitina & $1: 2$ & 4,25 & 48 \\
\hline
\end{tabular}

*Todos os experimentos foram realizados à temperatura ambiente. 
Tabela A.2: Resumo das condições experimentais para a preparação de amostras com a argila Veegum $H S^{*}$.

\begin{tabular}{ccccc}
\hline Amostra & Aminoácido & $\begin{array}{c}\text { Proporção } \\
\text { Argila / Aminoácido }\end{array}$ & $\begin{array}{c}\mathrm{pH} \text { (Final } \\
\text { da suspenção) }\end{array}$ & $\begin{array}{c}\text { Tempo de Agitação } \\
\text { (Horas) }\end{array}$ \\
\hline VegLysp4 & Lisina & $1: 1$ & 4,32 & 24 \\
\hline VegLysp5 & Lisina & $1: 1$ & 5,00 & 24 \\
\hline VegLysp6 & Lisina & $1: 1$ & 5,55 & 24 \\
\hline VegLysS & Lisina & $1: 2$ & 7,39 & 48 \\
\hline VegArgp4 & Arginina & $1: 1$ & 9,64 & 24 \\
\hline VegArgp5 & Arginina & $1: 1$ & 9,85 & 24 \\
\hline VegArgp6 & Arginina & $1: 1$ & 9,92 & 24 \\
\hline VegArgS & Arginina & $1: 2$ & 9,93 & 48 \\
\hline VegCar4 & Carnosina & $1: 2$ & 4,50 & 42 \\
\hline VegCar5 & Carnosina & $1: 2$ & 5,24 & 42 \\
\hline VegCar6 & Carnosina & $1: 2$ & 3,15 & 42 \\
\hline VegCar7 & Carnosina & $1: 2$ & 5,02 & 42 \\
\hline VegCar8 & Carnosina & $1: 2$ & 2,53 & 24 \\
\hline VegCarp4 & Carnosina & $1: 1$ & 8,07 & 24 \\
\hline VegCarp5 & Carnosina & $1: 1$ & 8,37 & 24 \\
\hline VegCarp6 & Carnosina & $1: 1$ & 8,44 & 24 \\
\hline VegOrtp4 & Ornitina & $1: 1$ & 4,17 & 24 \\
\hline VegOrtp5 & Ornitina & $1: 1$ & 4,95 & 48 \\
\hline VegOrtp6 & Ornitina & $1: 1$ & 5,52 & \\
\hline VegOrt1 & Ornitina & $1: 2$ & 4,18 & 48 \\
\hline * Todos os & exp & & 24 \\
\hline
\end{tabular}

*Todos os experimentos foram realizados à temperatura ambiente.

Tabela A.3: Resumo das condições experimentais para a preparação de amostras com a argila Laponita RD.

\begin{tabular}{cccccc}
\hline Amostra & Aminoácido & $\begin{array}{c}\text { Proporção } \\
\text { Argila / Aminoácido }\end{array}$ & $\begin{array}{c}\mathrm{pH} \text { (Final } \\
\text { da suspenção) }\end{array}$ & $\begin{array}{c}\text { Tempo de Agitação } \\
\text { (Horas) }\end{array}$ & Temperatura \\
\hline LapLysp2 & Lisina & $1: 1$ & 6,82 & 96 & Ambiente \\
\hline LapLysp7 & Lisina & $1: 1$ & 7,61 & 96 & Ambiente \\
\hline LapLysS & Lisina & $1: 2$ & 8,31 & 48 & Ambiente \\
\hline LapArgp2 & Arginina & $1: 1$ & 6,84 & 96 & Ambiente \\
\hline LapArgp9 & Arginina & $1: 1$ & 8,91 & 96 & Ambiente \\
\hline LapArgS & Arginina & $1: 2$ & 10,18 & 48 & Ambiente \\
\hline LapCar1 & Carnosina & $1: 1$ & 6,00 & 24 & Ambiente \\
\hline LapCar2 & Carnosina & $1: 3$ & 6,10 & 24 & Ambiente \\
\hline LapCar3 & Carnosina & $1: 2$ & 6,17 & 24 & Ambiente \\
\hline LapCar4 & Carnosina & $1: 3$ & 6,90 & 6 & $60{ }^{\circ} \mathrm{C}$ \\
\hline LapOrtp2 & Ornitina & $1: 1$ & 6,86 & 96 & Ambiente \\
\hline LapOrtp7 & Ornitina & $1: 1$ & 7,71 & 96 & Ambiente \\
\hline LapOrt1 & Ornitina & $1: 2$ & 6,80 & 24 & Ambiente \\
\hline LapOrt2 & Ornitina & $1: 2$ & 6,50 & 48 & Ambiente \\
\hline
\end{tabular}


Apêndice B

Dados de Análise Térmica acoplados a

Espectrometria de Massas 


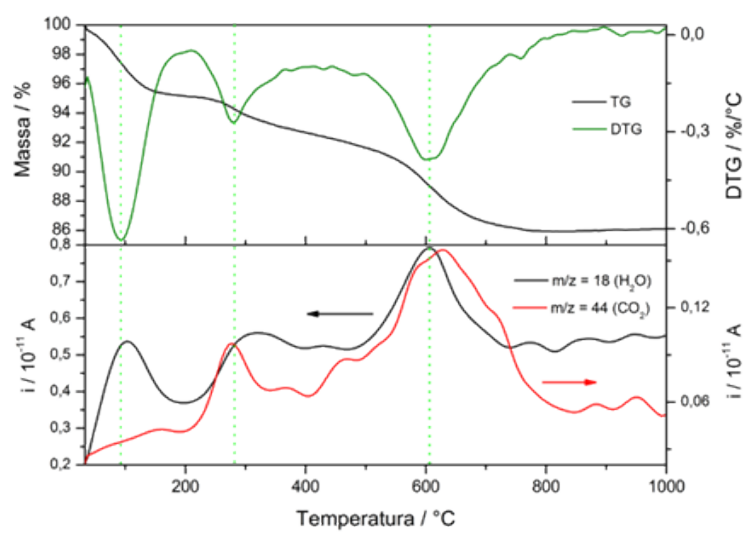

(A)

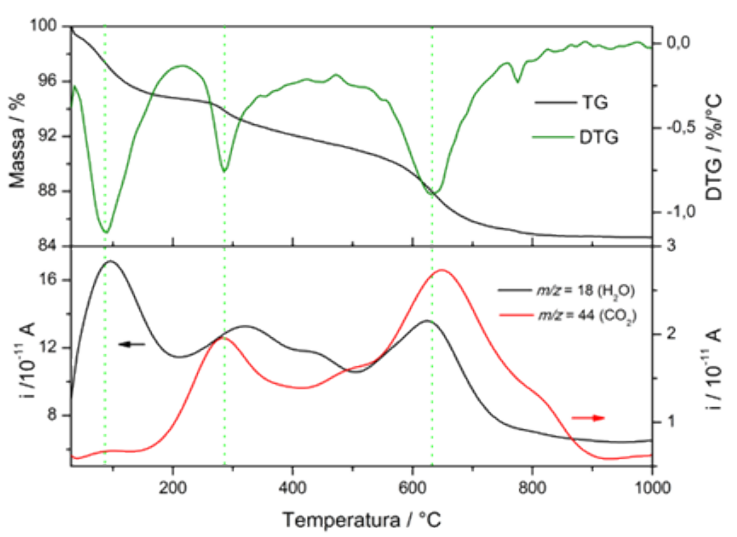

(C)

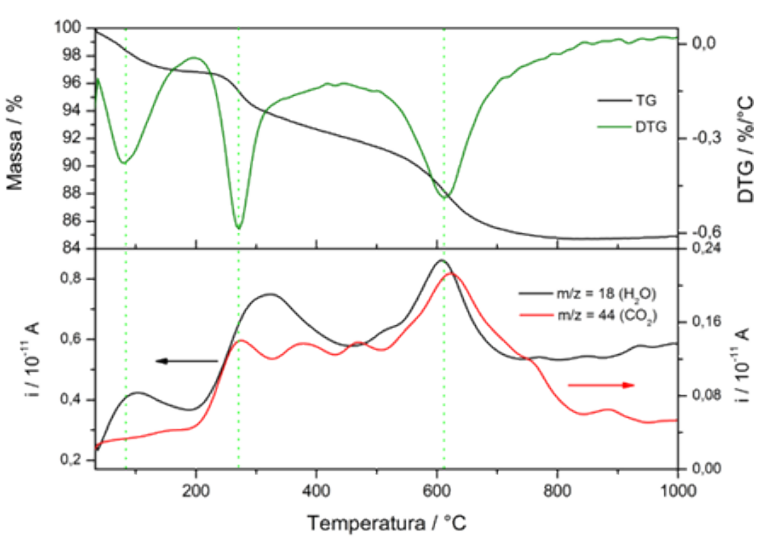

(B)

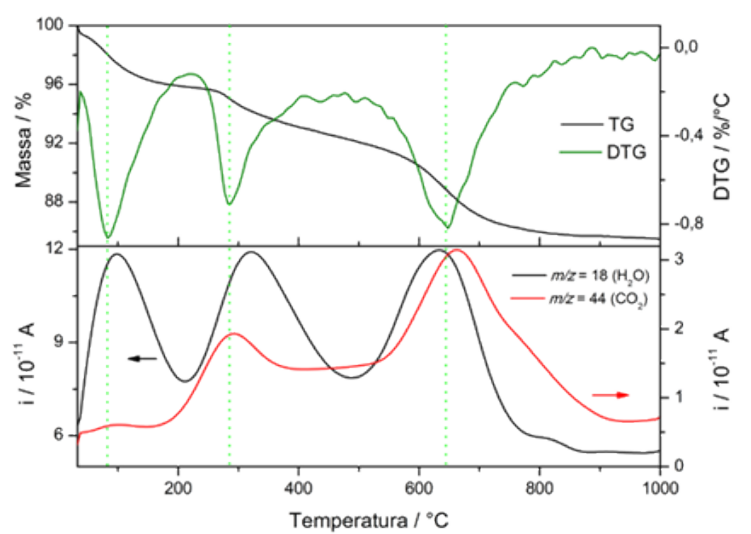

(D)

Figura B.1: Curvas TGA (preto), DTG (verde oliva) e $M S$ (fragmentos $m / z=18$ (preto) $e$ $m / z=44$ (vermelho)) das amostras: A) CloLys2; B) CloLysS; C) CloLysp4; D) CloLysp5. 




(A)

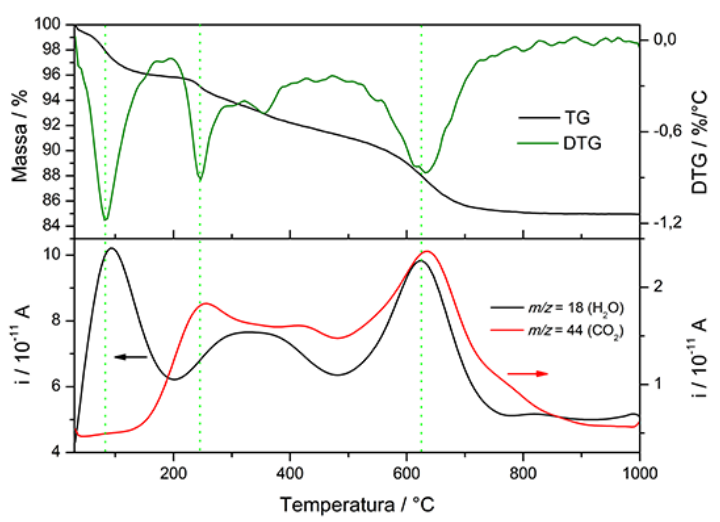

(C)

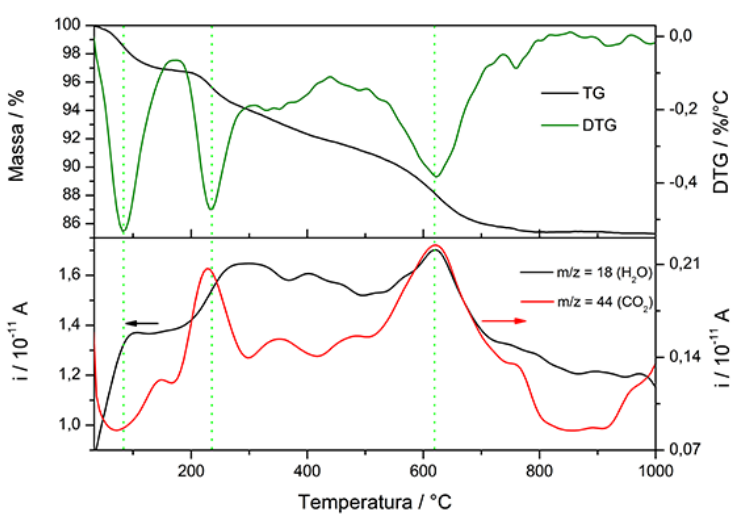

(B)

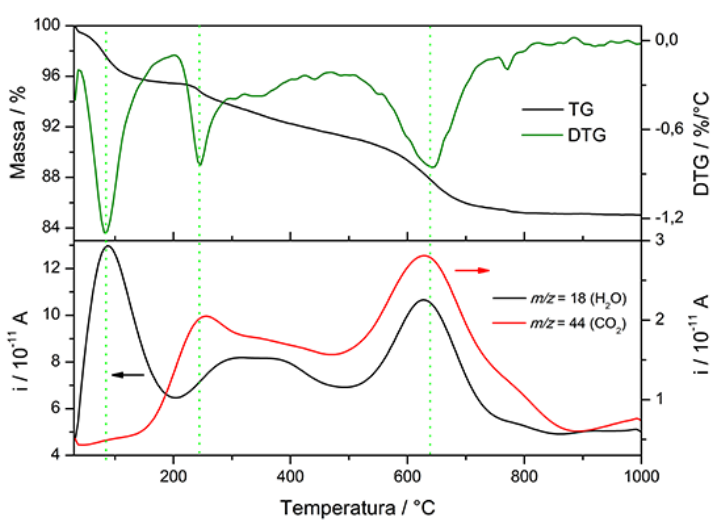

(D)

Figura B.2: Curvas TGA (preto), DTG (verde oliva) e $M S$ (fragmentos $\mathrm{m} / \mathrm{z}=18$ (preto) e $m / z=44$ (vermelho)) das amostras: A) CloArg1; B) CloArgS; C) CloArgp5; D) CloArgp6. 


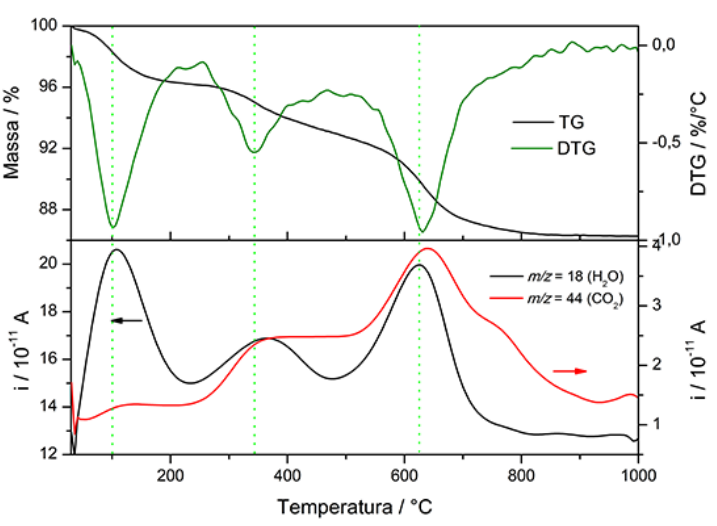

(A)

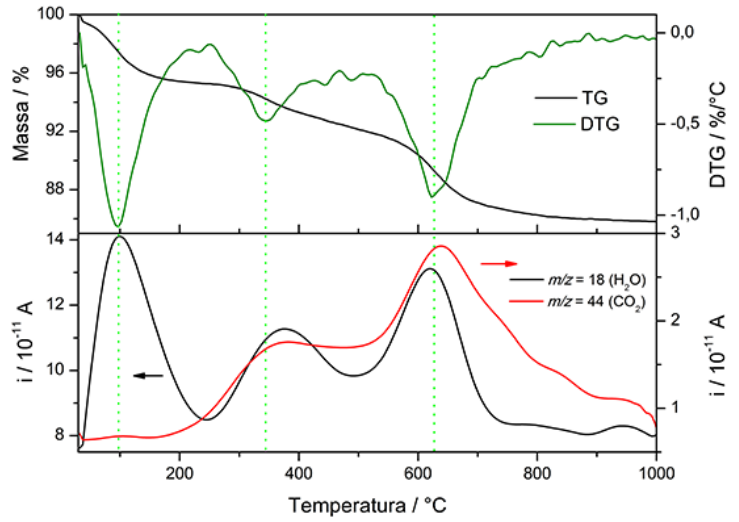

(B)



(C)

Figura B.3: Curvas TGA (preto), DTG (verde oliva) e $M S$ (fragmentos $m / z=18$ (preto) e $m / z=44$ (vermelho)) das amostras: A) CloCarp4; B) CloCarp5; C) CloCarp6. 


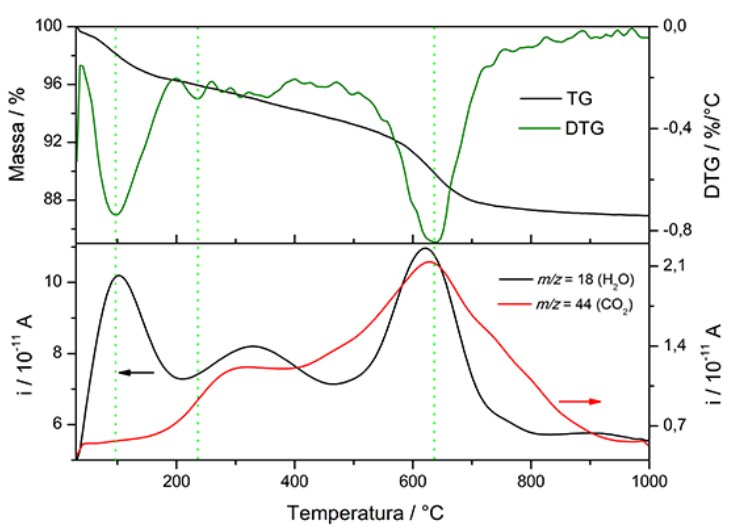

(A)



(B)

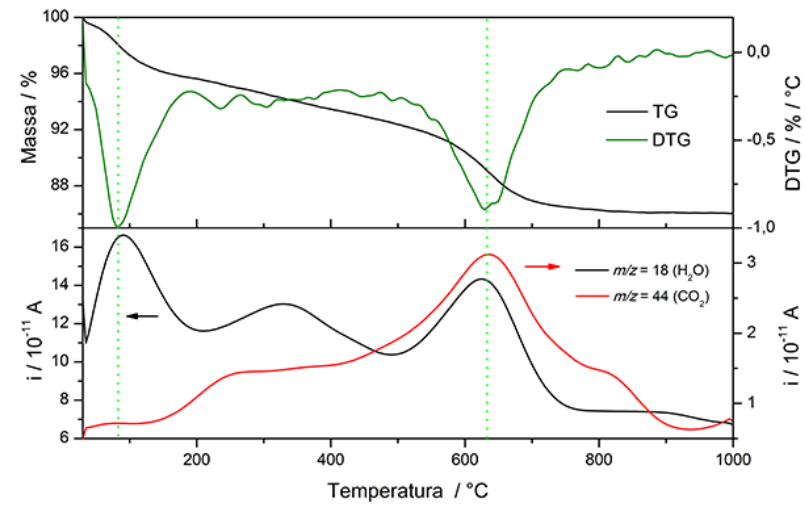

(C)

Figura B.4: Curvas TGA (preto), DTG (verde oliva) e $M S$ (fragmentos $\mathrm{m} / \mathrm{z}=18$ (preto) e $m / z=44$ (vermelho)) das amostras: A) CloOrtp 4; B) CloOrtp5; C) CloOrtp6. 


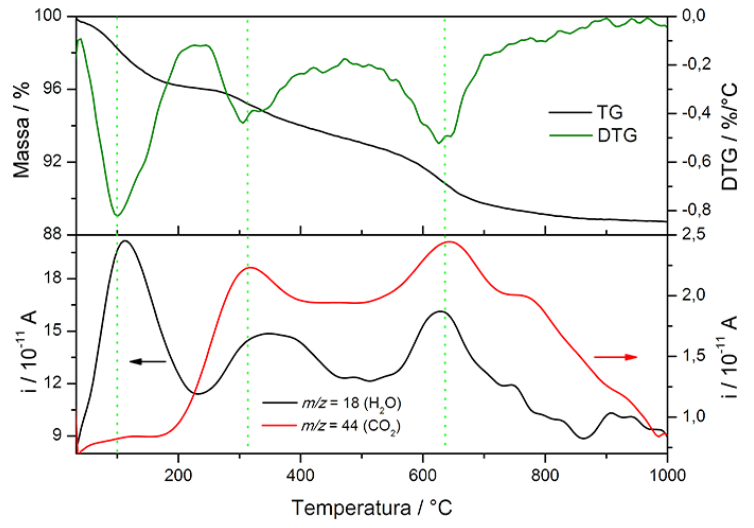

(A)

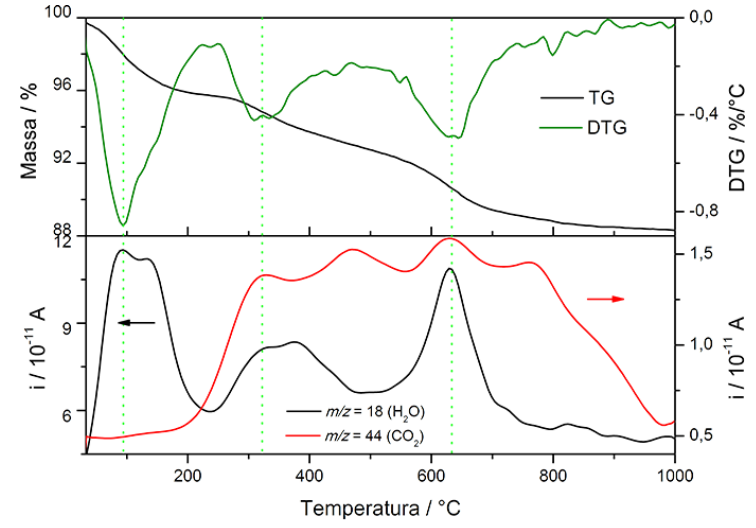

(B)

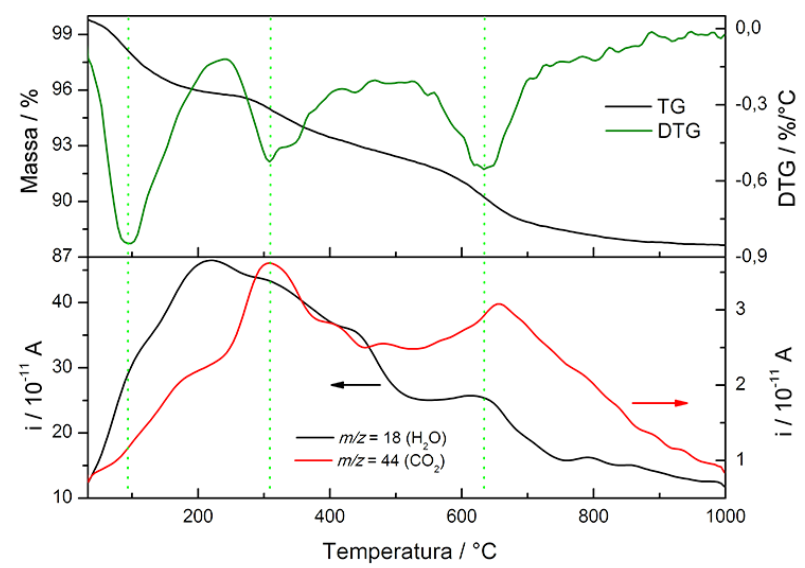

(C)

Figura B.5: Curvas TGA (preto), DTG (verde oliva) e $M S$ (fragmentos $m / z=18$ (preto) e $m / z=44$ (vermelho)) das amostras: A) VegLysp4;B) VegLysp5; C) VegLysp6. 


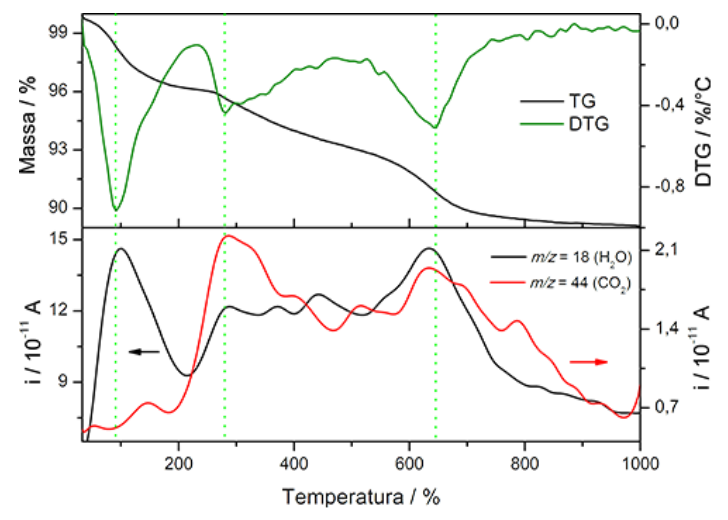

(A)

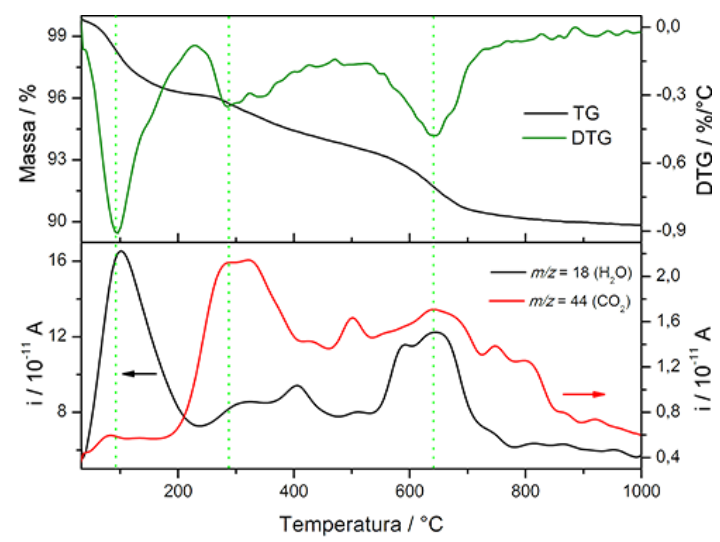

(B)

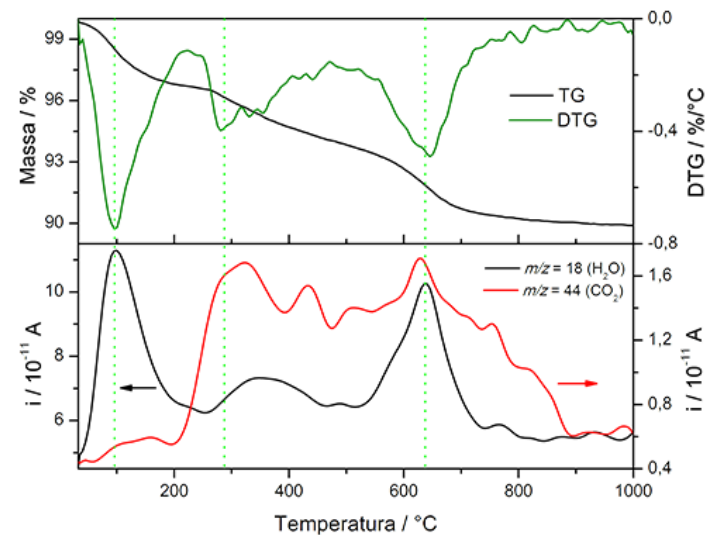

(C)

Figura B.6: Curvas TGA (preto), DTG (verde oliva) e $M S$ (fragmentos $m / z=18$ (preto) e $m / z=44$ (vermelho)) das amostras: A) VegArgp 4; B) VegArgp5; C) VegArgp6. 




(A)

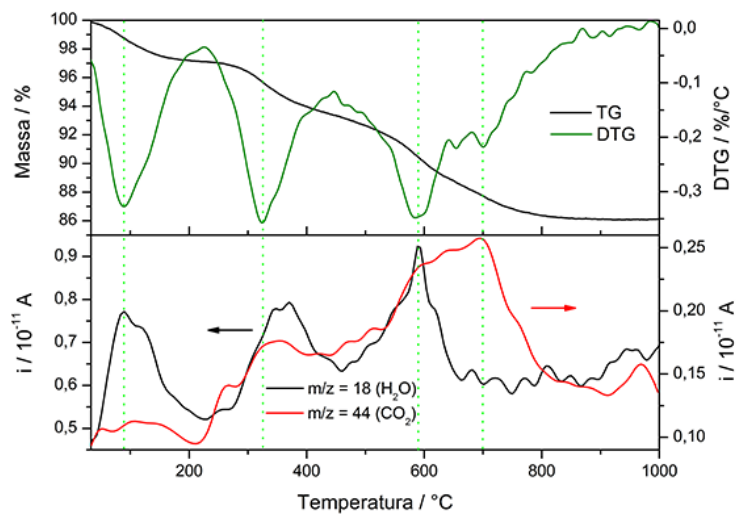

(C)

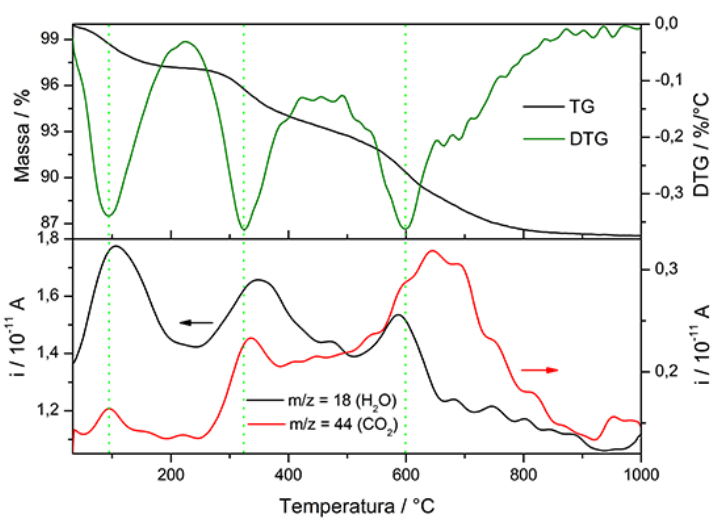

(B)

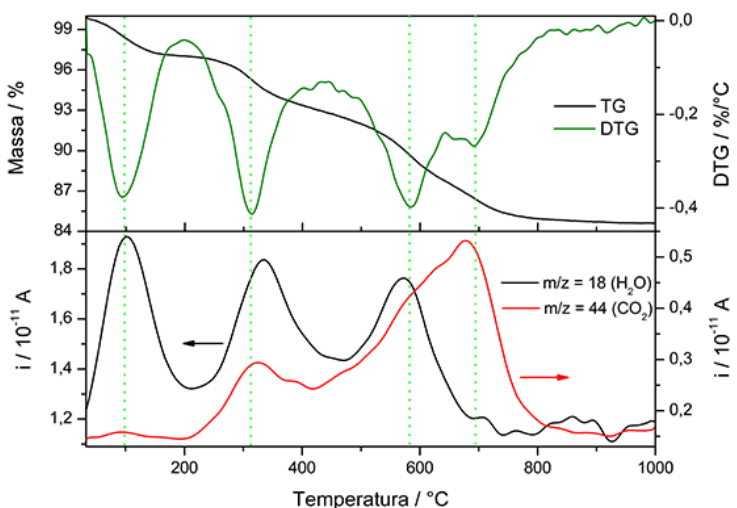

(D)

Figura B.7: Curvas TGA (preto), DTG (verde oliva) e $M S$ (fragmentos $m / z=18$ (preto) e $m / z=44$ (vermelho)) das amostras: A) VegCar4; B) VegCar5; C) VegCar7; D) VegCar8. 


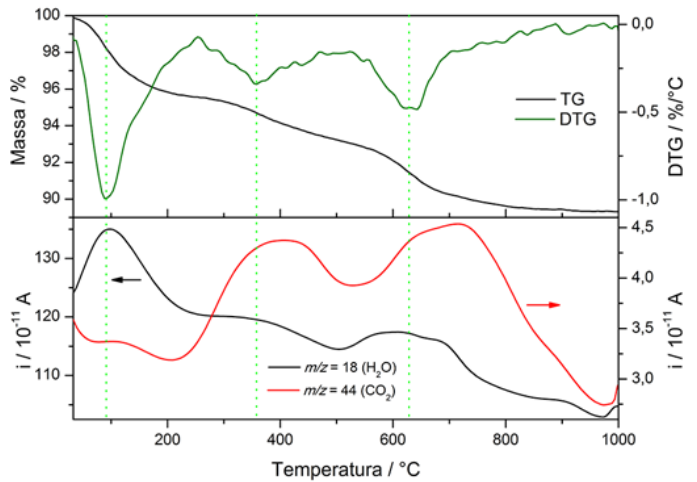

(A)

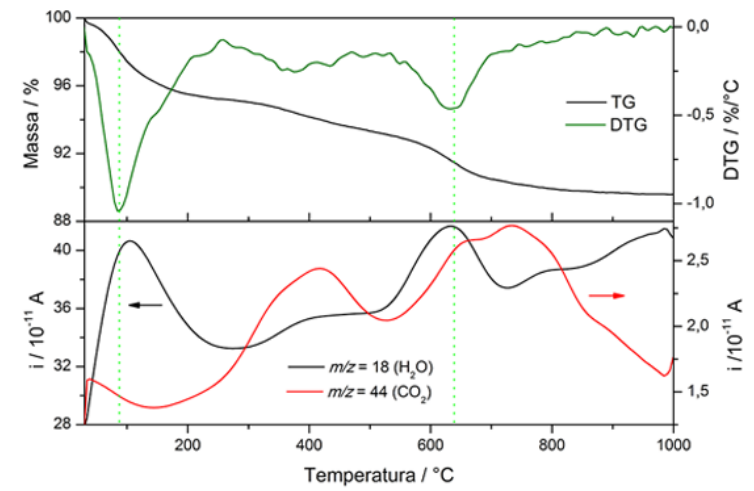

(B)



(C)

Figura B.8: Curvas TGA (preto), DTG (verde oliva) e $M S$ (fragmentos $m / z=18$ (preto) e $m / z=44$ (vermelho)) das amostras: A) VegCarp4; B) VegCarp5; C) VegCarp6. 


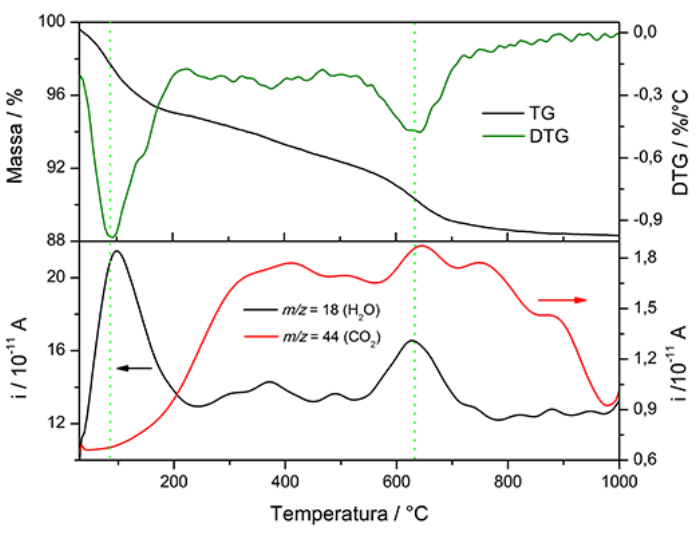

(A)

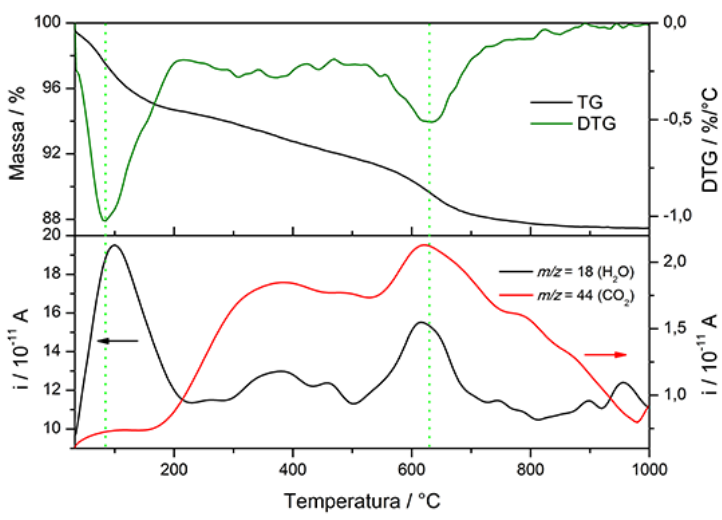

(B)

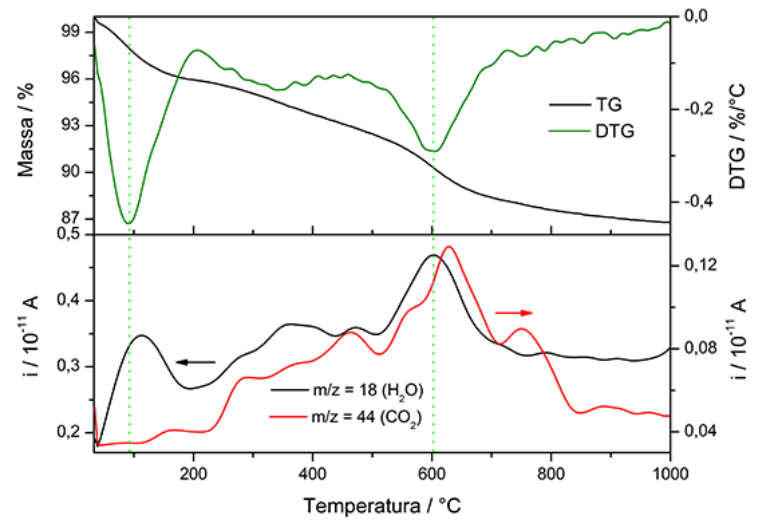

(C)

Figura B.9: Curvas TGA (preto), DTG (verde oliva) e $M S$ (fragmentos $m / z=18$ (preto) e $m / z=44$ (vermelho)) das amostras: A) VegOrtp5; B) VegOrtp6; C) VegOrt1.

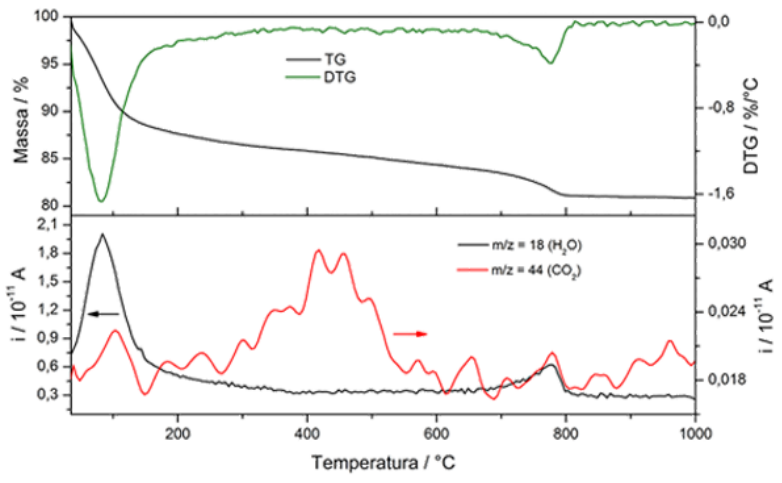

(A)

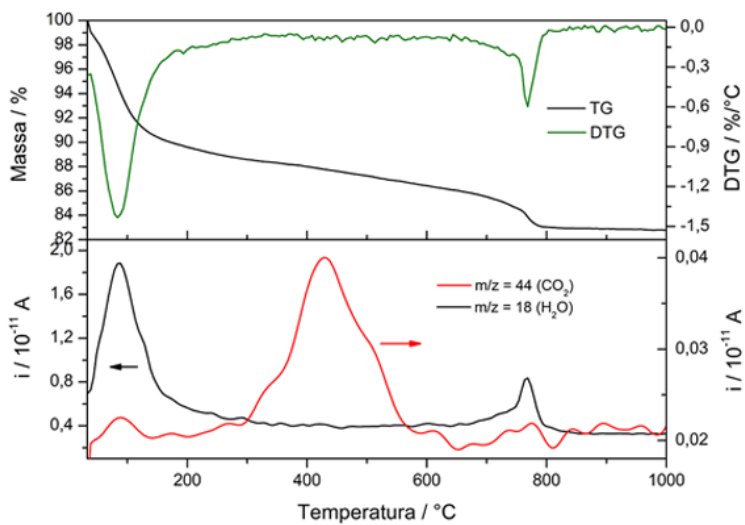

(B)

Figura B.10: Curvas TGA (preto), DTG (verde oliva) e $M S$ (fragmentos $m / z=18$ (preto) e $m / z=44$ (vermelho)) das amostras: A) LapLysp2; B) LapLysp \%. 


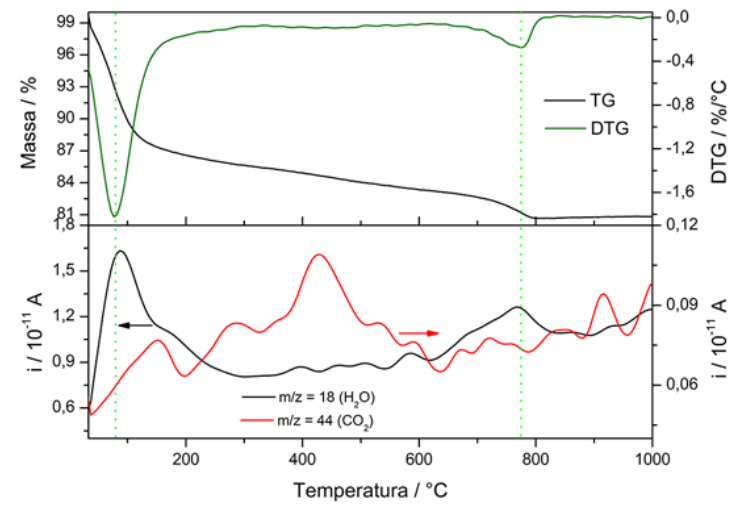

(A)

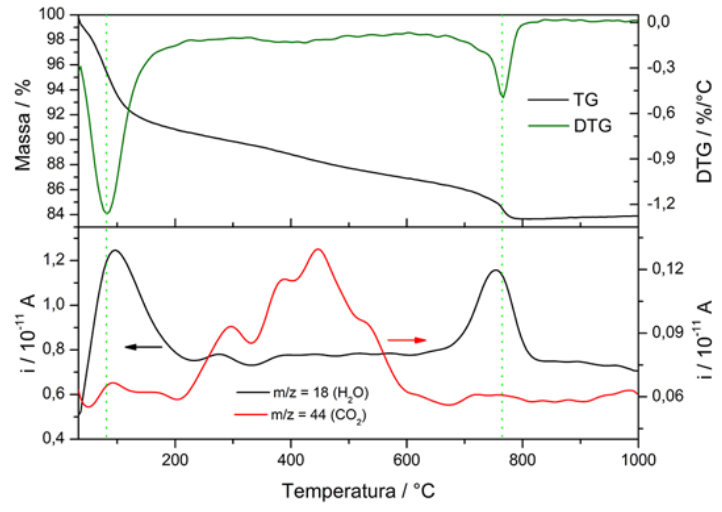

(B)

Figura B.11: Curvas TGA (preto), DTG (verde oliva) e $M S$ (fragmentos $m / z=18$ (preto) e $m / z=44$ (vermelho)) das amostras: A) LapArgp2; B) LapArgp9.

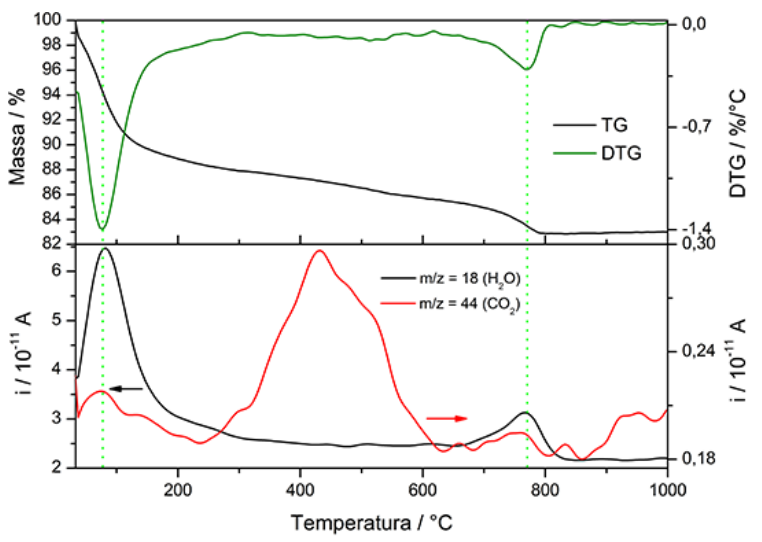

(A)

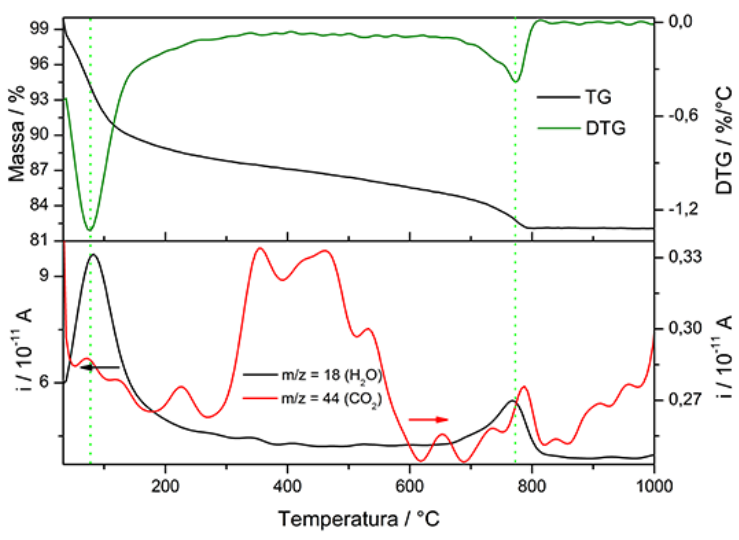

(B)

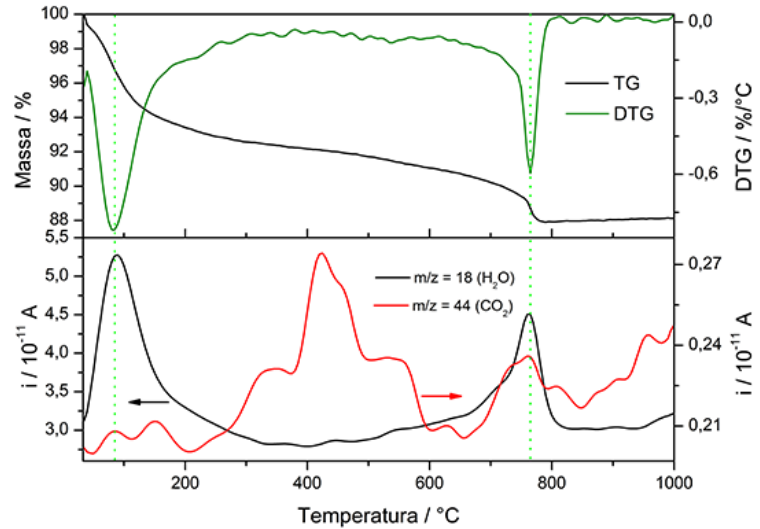

(C)

Figura B.12: Curvas TGA (preto), DTG (verde oliva) e $M S$ (fragmentos $m / z=18$ (preto) e $m / z=44$ (vermelho)) das amostras: A) LapCar1; B) LapCar3; C) LapCar4. 


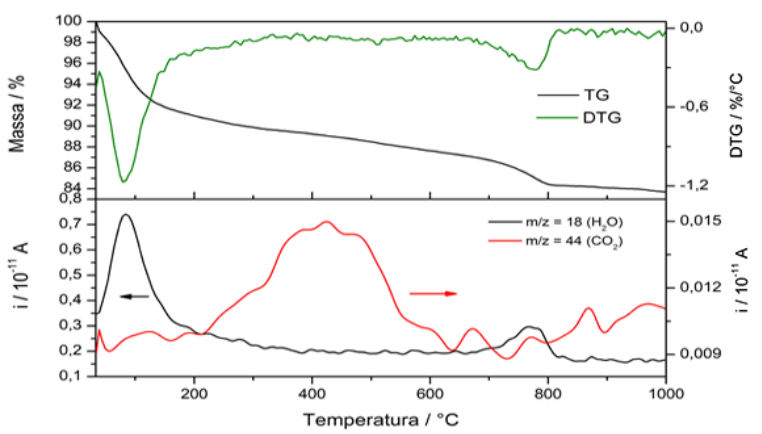

(A)

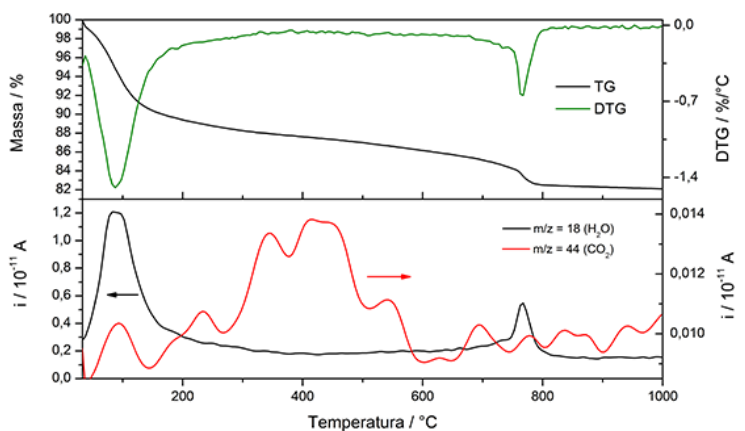

(B)

Figura B.13: Curvas TGA (preto), DTG (verde oliva) e $M S$ (fragmentos $m / z=18$ (preto) $e$ $m / z=44$ (vermelho)) das amostras: A) LapOrtp2; B) LapOrtp\%. 


\section{Apêndice C}

\section{Dados de análise elementar dos}

\section{materiais híbridos argila/aminoácido}

Tabela C.1: Dados de análise elementar dos materiais híbridos argila/L-Lisina.

\begin{tabular}{ccccc}
\hline Amostra & \% C & mmol / $100 \mathrm{~g}$ & $\begin{array}{c}\text { g de aminoácido } \\
100 \mathrm{~g} \text { de material }\end{array}$ & $\begin{array}{c}\text { \% CTC } \\
\text { Neutralizada }\end{array}$ \\
\hline \hline CloLys1 & 2,15 & 29,8 & 4,39 & 32,4 \\
\hline CloLys2 & 2,28 & 31,6 & 4,65 & 34,3 \\
\hline CloLysS & 3,84 & 53,3 & 7,84 & 57,8 \\
\hline VegLysS & 2,62 & 36,4 & 5,35 & 45,4 \\
\hline VegLysp4 & 1,89 & 26,2 & 3,86 & 32,8 \\
\hline LapLysS & 2,85 & 39,6 & 5,82 & 42,4 \\
\hline
\end{tabular}

Tabela C.2: Dados de análise elementar dos materiais híbridos argila/L-Arginina.

\begin{tabular}{lcccc}
\hline Amostra & \% C & mmol / $100 \mathrm{~g}$ & $\begin{array}{c}\text { g de aminoácido } \\
\text { 100 g de material }\end{array}$ & $\begin{array}{c}\text { \% CTC } \\
\text { Neutralizada }\end{array}$ \\
\hline \hline CloArg1 & 2,44 & 33,9 & 5,93 & 36,7 \\
\hline CloArg2 & 2,70 & 37,5 & 6,56 & 40,8 \\
\hline CloArgS & 3,34 & 46,4 & 8,12 & 50,3 \\
\hline VegArgS & 1,94 & 26,9 & 4,71 & 33,6 \\
\hline LapArgS & 1,57 & 21,8 & 3,81 & 43,4 \\
\hline
\end{tabular}


Tabela C.3: Dados de análise elementar dos materiais híbridos argila/L-Carnosina.

\begin{tabular}{ccccc}
\hline Amostra & \% C & mmol / $100 \mathrm{~g}$ & $\begin{array}{c}\text { g de aminoácido } \\
\text { 100 g de material }\end{array}$ & $\begin{array}{c}\text { \% CTC } \\
\text { Neutralizada }\end{array}$ \\
\hline \hline CloCarp4 & 2,29 & 21,2 & 4,81 & 23,0 \\
\hline CloCar1 & 3,37 & 31,2 & 7,08 & 33,9 \\
\hline VegCar1 & 2,52 & 23,3 & 5,29 & 29,1 \\
\hline VegCar5 & 3,31 & 30,6 & 6,95 & 38,3 \\
\hline VegCar6 & 3,54 & 32,8 & 7,44 & 40,9 \\
\hline VegCar7 & 3,25 & 30,1 & 6,83 & 37,6 \\
\hline VegCarp4 & 1,29 & 11,9 & 2,71 & 14,9 \\
\hline LapCar2 & 2,45 & 22,7 & 5,15 & 22,6 \\
\hline LapCar3 & 1,22 & 11,3 & 2,56 & \\
\hline
\end{tabular}

Tabela C.4: Dados de análise elementar dos materiais híbridos argila/L-Ornitina.

\begin{tabular}{lcccc}
\hline Amostra & \% C & mmol / $100 \mathrm{~g}$ & $\begin{array}{c}\text { g de aminoácido } \\
100 \mathrm{~g} \text { de material }\end{array}$ & $\begin{array}{c}\text { \% CTC } \\
\text { Neutralizada }\end{array}$ \\
\hline \hline CloOrt1 & 2,80 & 46,6 & 6,21 & 50,6 \\
\hline VegOrt1 & 1,69 & 28,1 & 3,74 & 35,2 \\
\hline LapOrt1 & 0,93 & 15,5 & 2,06 & 31,0 \\
\hline
\end{tabular}




\section{Anexo A}

\section{Métodos Computacionais}

O mapa de potencial eletrostático dos aminoácidos, observado nas Figuras A.1, foram calculados pelo doutorando e mestre em Física, Filipe Dalmatti Lima, do Instituto de Física da USP (IF-USP), aluno da Professora Doutora Helena Maria Petrilli.

Os cálculos de potencial eletrostático foram obtidos através da teoria do funcional da densidade (DFT) [78] no esquema de Kohn-Sham [79] implementados no código computacional Gaussian 09 [80]. Utilizou-se o conjunto de funções de base 6-311G(d,p) para descrever a função de onda, o funcional B3LYP [88] para descrever os termos de troca e correlação e a aproximação "Polarizable Continuum Model" (PCM) [80] para descrever os efeitos de solvente.

As dimensões teóricas dos aminoácidos a partir da estrutura de menor energia foram calculadas com o programa Accelrys Discovery Studio Visualizer 3.5 e seus valores encontram-se na Figura A.2. 


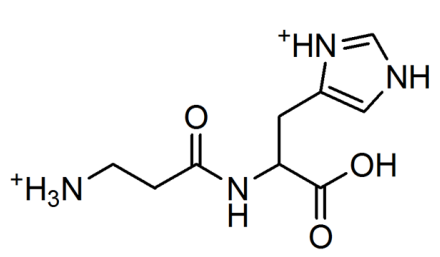<smiles>C=CC=CCCCCCC(=O)NC(Cc1c[nH]c[nH+]1)C(=O)[O-]</smiles>

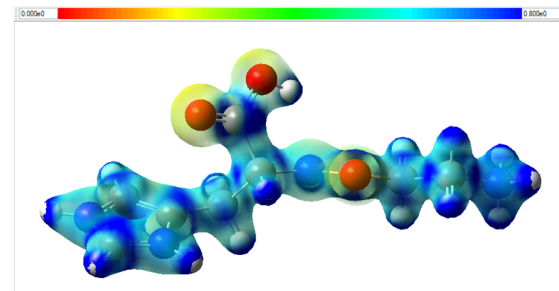

$$
\mathrm{H}^{+} \| \mathrm{pK}_{\mathrm{a} 2}
$$
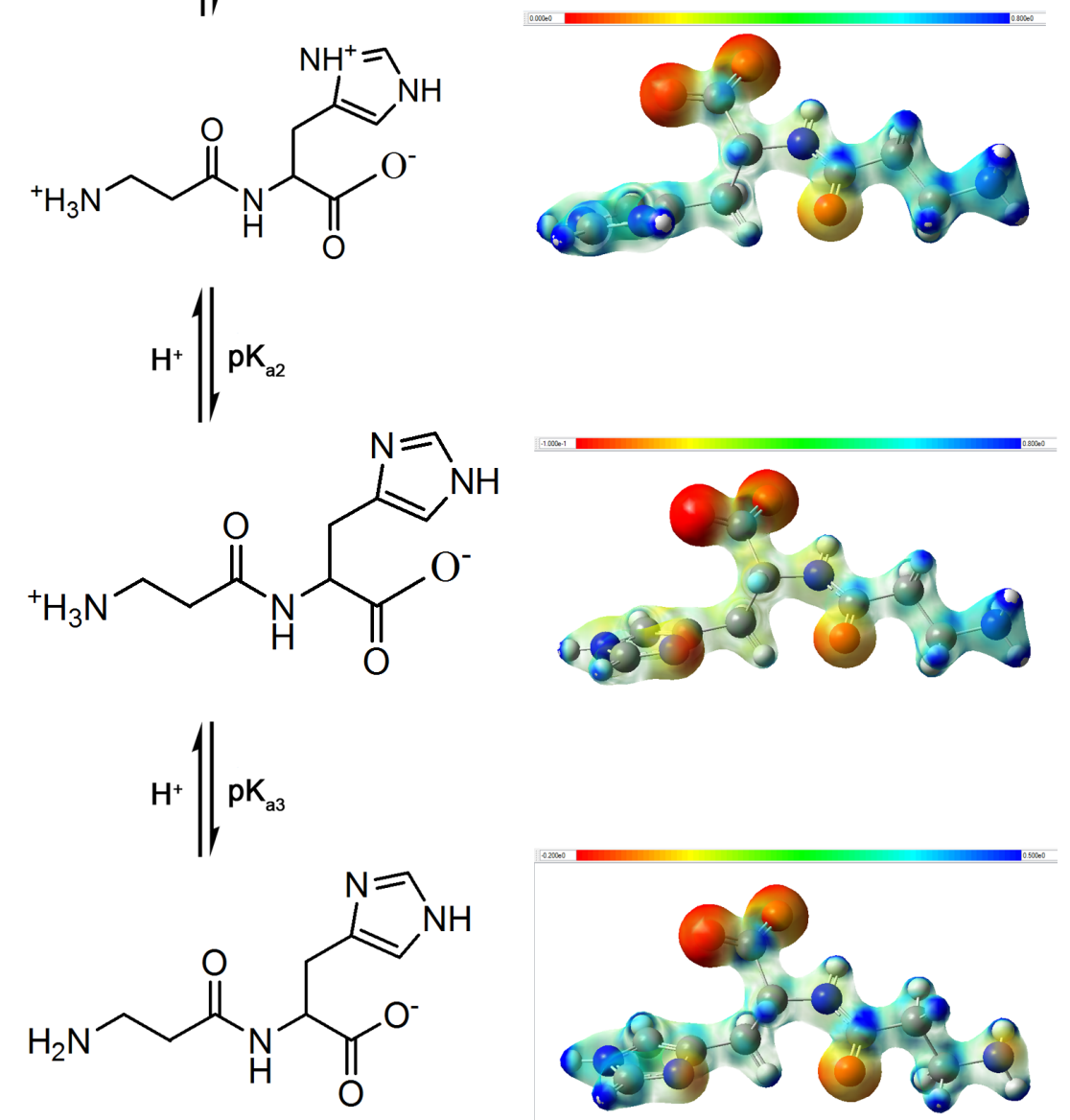

Figura A.1: Mapa de potencial eletrostático para as possíveis formas protonadas do dipeptídeo L-Carnosina. 


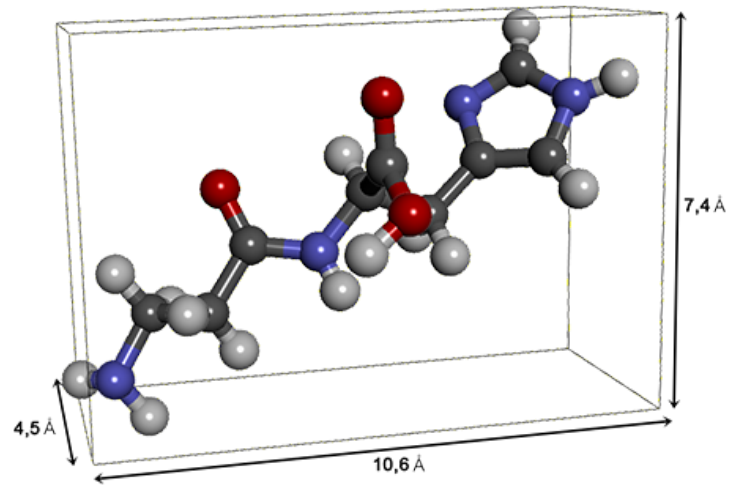

(A)

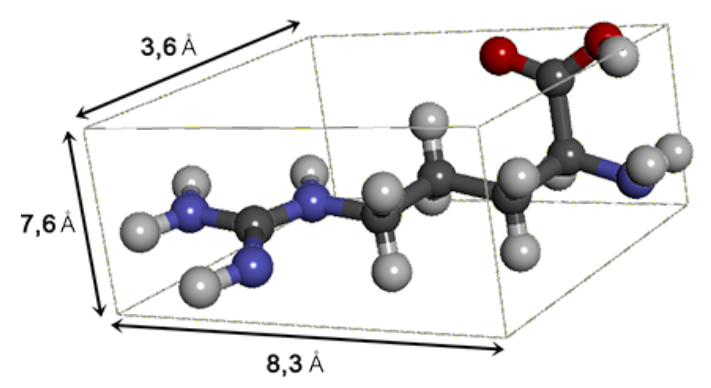

(C)



(B)

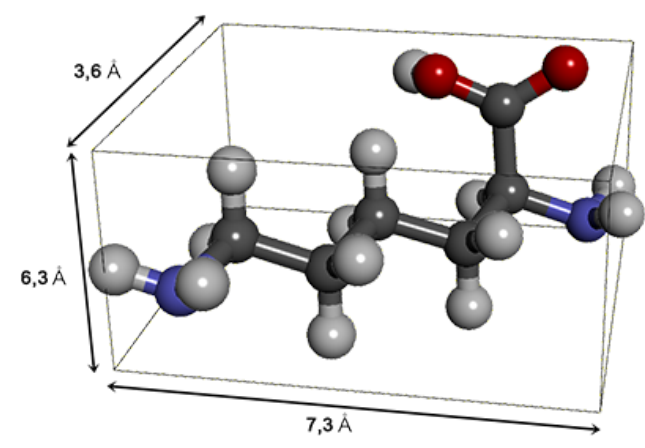

(D)

Figura A.2: Dimensões calculadas do dipeptídeo: A) L-Carnosina; e dos aminoácidos: B) L-Ornitina; C) L-Arginina; D) L-Lisina. 


\section{Anexo B}

\section{Teste da Ninidrina}

O teste de ninidrina [89] das amostras foi realizado no Laboratório de Química de Peptídeos com o auxílio da Professora Doutora Maria Teresa Machini do Departamento de Bioquímica do IQ-USP. Foram empregadas misturas comerciais adquiridas da Applied Biosystems (Foster City/CA, EUA) capazes de revelar a presença (produto azul ou púrpura) ou ausência (nenhum produto; coloração amarela) de grupos amino reativos.

O mecanismo de reação do teste de ninidrina encontra-se na Figura B.1.

A Figura B.2 apresenta uma foto da aparência das amostras após o teste da ninidrina. Pode-se observar que todas as amostras contêm aminoácidos, pois todos os tubos apresentam, com exceção da argila pura, sólidos de coloração azulada para reação da ninidrina com aminoácidos. 

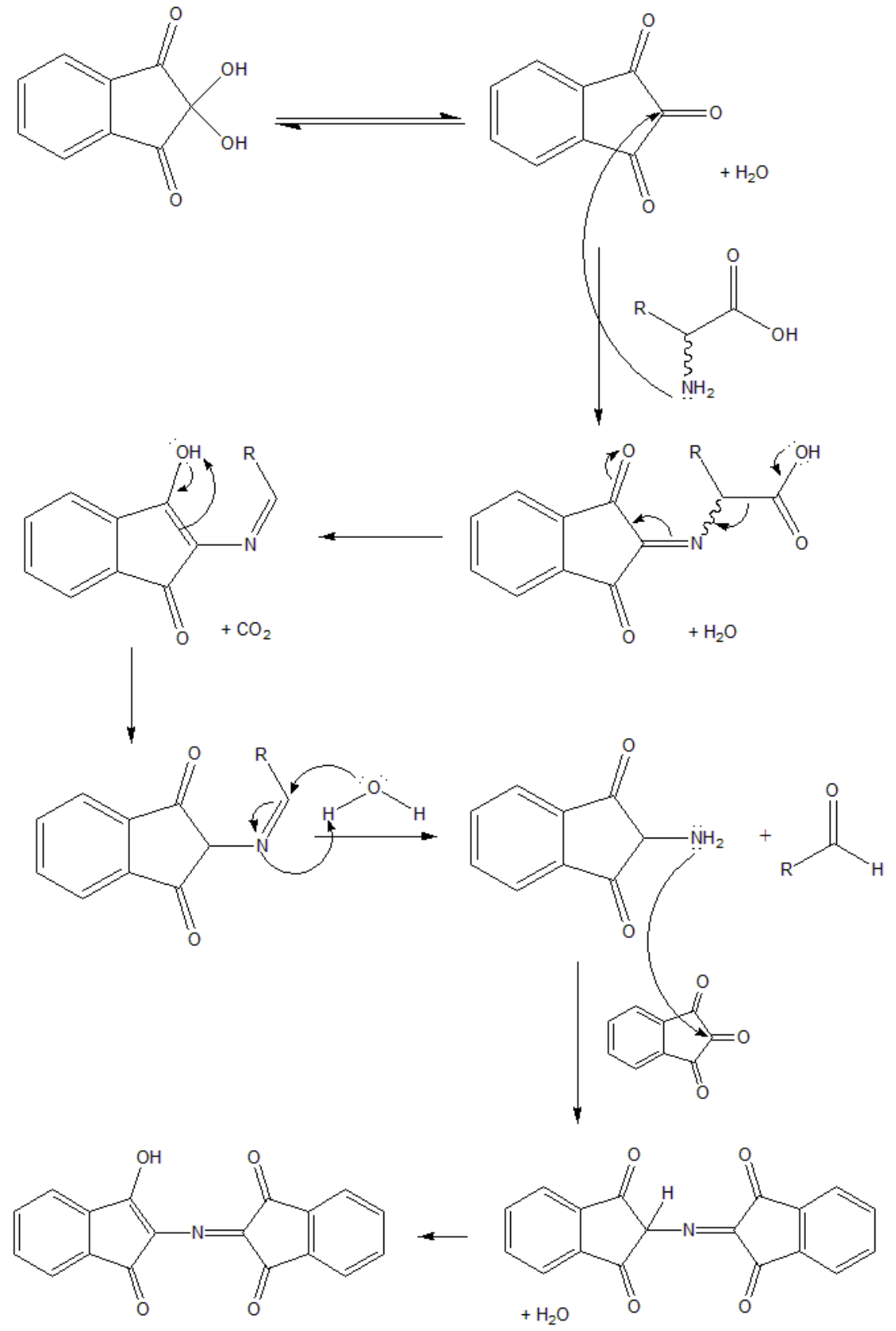

Figura B.1: Mecanismo do teste da ninidrina.

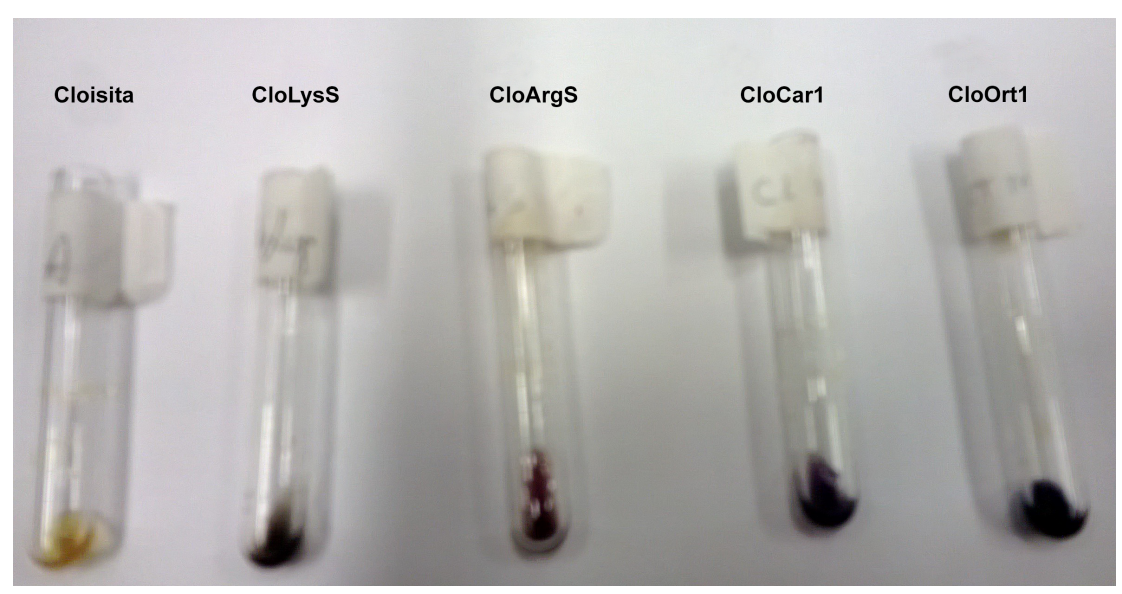

Figura B.2: Teste da ninidrina. 


\section{Anexo C}

\section{Súmula Curricular}

\section{Dados pessoais}

Nome: Ana Paula Mangoni

Filiação: Marques Delci Mangoni e Marilene Carme Marafon Mangoni

Nascimento: 21/08/1987 - São Jorge d'Oeste/PR - Brasil

\section{Endereço profissional}

Universidade de São Paulo, Instituto de Química

Av. Professor Lineu Prestes, 478, Bloco 2 inferior

Butantã - São Paulo

05508-000, SP - Brasil

Endereço eletrônico

e-mail: anapaulamangoni@gmail.com

\section{Formação acadêmica/titulação}

(2011 - 2014) - Mestrado em Química.

Universidade de São Paulo, USP, Sao Paulo, Brasil

Título: Materiais híbridos baseados em argilas catiônicas e espécies com potencial tera- 
pêutico. Orientador: Vera Regina Leopoldo Constantino.

Bolsista do(a): Conselho Nacional de Desenvolvimento Científico e Tecnológico.

(2005 - 2007) - Início da graduação em QUÍMICA (Licenciatura e Bacharelado).

Universidade Federal de Santa Catarina, UFSC, Florianópolis, Brasil

(2008 - 2010) - Conclusão da graduação em QUÍMICA (Licenciatura e Bacharelado).

Universidade Federal do Paraná, UFPR, Curitiba, Brasil

\section{Formação complementar}

2012 - Participação da $6^{\text {a }}$ Escola de Nanociência e Nanotecnologia da UFRJ. Rio de Janeiro, RJ. 20 Horas.

2011 - Curso de curta duração em Acidentes em Laboratórios de Química. Instituto de Química de São Paulo. São Paulo, SP. 2 Horas e 30 Minutos.

2011 - Curso de curta duração em Primeiros Socorros na Parada Cardiorespiratória. Instituto de Química de São Paulo. São Paulo, SP. 5 Horas.

2011 - Curso de curta duração em Filosofia e juízo científico. $2^{\underline{O}}$ Encontro sobre Divulgação e Ensino de Ciências. São Paulo, SP. 4 Horas.

2011 - Curso de curta duração em A importância dos modelos miméticos bioinspirados na química bioinorgânica. Sociedade Brasileira de Química. Florianópolis, SC. 6 Horas.

2010 - Curso de curta duração em Determinação de Estruturas Cristalinas e Mole- 
culares por Difração de Raios X. IV Semana Acadêmica do Setor de Ciências Exatas da Universidade Federal do Paraná. Curitiba, PR. 8 Horas.

2010 - Curso de curta duração em Ressonância Paramagnética Eletrônica. XVIII Encontro de Química da Região Sul. Curitiba, PR. 5 Horas.

2009 - Curso de curta duração em Ciência de interface e sistemas coloidais. XVII Encontro de Química da Região Sul. Rio Grande, RS. 8 Horas.

2009 - Curso de curta duração em Análise Térmica. XVI Semana Acadêmica de Química. Curitiba, PR. 6 Horas.

2009 - Curso de curta duração em Mecânica Quântica e a Revolução do Pensamento Científico. XVI Semana Acadêmica de Química. Curitiba, PR. 6 Horas.

2009 - Curso de curta duração em O Significado Pedagógico da Experimentação no Ensino de Química. XVI Semana Acadêmica do Curso de Química da UFPR. Curitiba, PR. 6 Horas.

2009 - Curso de curta duração em Alfabetização Científica e Tecnológica, Contextualização e abordagem CTS no Ensino de Química: Uma reflexão sobre os conceitos e possibilidades de aplicação. XVI Semana Acadêmica de Química da UFPR. Curitiba, PR. 6 Horas.

2009 - Curso de curta duração em Química de Novos Fertilizantes Visando Ganhos Econômicos e Ambientais. V Workshop Paranaense de Pós-Graduação em Química. Curitiba, PR. 4 Horas.

2008 - Curso de curta duração em Biodiesel. 31ª Reunião Anual da Sociedade Brasi- 
leira de Química. Águas de Lindóia, SP. 6 Horas.

2008 - Curso de curta duração em Ferramentas Multivariadas para Análise Química. XV Semana de Química da UFPR. Curitiba, PR. 6 Horas.

2008 - Curso de curta duração em Jogos em ensino de Química: Formando Professores Divertidos. XIV Encontro Nacional do Ensino de Química. Curitiba, PR. 4 Horas.

2008 - Curso de curta duração em Química Forense. XVI Encontro de Química da região Sul. Blumenau, SC. 5 Horas.

2007 - Curso de curta duração em Qualidade de águas: novos poluentes ,novos desafios. XV Encontro de Química da Região Sul. Ponta Grossa, PR. 5 Horas.

\section{Atuação profissional}

\section{Universidade Federal do Paraná - UFPR}

Vínculo institucional

(2010 - 2011) - Vínculo: Iniciação Científica (IC), Enquadramento funcional: Iniciação Científica (IC) sob a orientação do Professor Antonio Salvio Mangrich, processo 106926/2010-1. Carga horária: 20. Regime: Dedicação exclusiva.

\section{Universidade Federal do Paraná - UFPR}

Vínculo institucional

(2008 - 2010) - Vínculo: Iniciação Científica, Enquadramento funcional: Iniciação Científica (IC) sob a orientação do Professor Antonio Salvio Mangrich, processo 127001/2008-5. Carga horária: 20. Regime: Dedicação exclusiva. Vinculada ao Departamento de Química (UFPR). 


\section{Universidade Federal de Santa Catarina - UFSC}

Vínculo institucional

(2006 - 2007) - Vínculo: Iniciação Científica, Enquadramento funcional: Aluno de Iniciação Científica (PIBIC/CNPq) sob a orientação do professor Bruno Szpoganicz, projeto de pesquisa: Estudo da Afinidade da Melanina por Metais. Carga horária: 20. Regime: Dedicação exclusiva.

\section{Universidade Federal de Santa Catarina - UFSC}

Vínculo institucional

(2006 - 2006) - Vínculo: Iniciação Científica, Enquadramento funcional: Aluno de Iniciação Científica (PIBIC/CNPq) sob a orientação do professor Bruno Szpoganicz, projeto de pesquisa: Estudo da Afinidade da Melanina e Agentes Anti-Melanomas por Íons Metálicos Bivalentes e Trivalentes. Carga horária: 20. Regime: Dedicação exclusiva.

\section{Produção bibliográfica}

\section{Artigos completos publicados em periódicos}

1. REZENDE, E. I. P., MANGRICH, A. S., MANGONi, A. P., SCARPELlini, M., CASELlATO, A., FERNANDEZ, T. L. Estudo espectroscópico de compósito obtido da reação no estado sólido entre um complexo mononuclear de vanádio(IV) e caulinita. Química Nova (Impresso). v. 35, p. 257 - 261, 2012.

2. Cerqueira, S. da C. A., ROMÃO, L. P. C., LUCAS, S. C. O., FRAGA, L. E., SIMÕES, M. L., HAMMER, P., LEAD, J. R., MANGONI, A. P., MANGRICH, A. S. Spectroscopic characterization of the reduction and removal of chromium (VI) by tropical peat and humin. Fuel (Guildford). v. 91, p. 141 - 146, 2012. 
3. RACHinski, S., CARUbelli, A., MAngOni, A. P., MANGRICH, A. S. Pilhas de Combustíveis Microbianas Utilizadas na Produção de Eletricidade a Partir de Rejeitos Orgânicos: Uma Perspectiva de Futuro. Química Nova (Impresso). v. 33, p. $1773-1778,2010$.

\section{Trabalhos apresentados em eventos}

1. MANGOni, Ana Paula, CONSTANTINO, V. R. L. Immobilization of L-Lysine Amino Acid Into Natural Montmorillonite Clay. XV International Clay Conference. Rio de Janeiro, RJ, 2013.

2. MANGOni, Ana Paula, CONSTANTINO, V. R. L. Intercalation of L-carnosine into Veegum HS clay. IV International Workshop on Layered Materials. Campinas, SP, 2012.

3. MAnGOni, Ana Paula, REZEnde, E. I. P., BATISTA, M. G. de F, MANGRICH, A. S. Biocarvão que sequestra carbono no solo e complexa íons metálicos nutrientes de plantas. XVIII Encontro de Química da Região Sul. Curitiba, PR, 2010.

4. MANGONI, Ana Paula, MANGRICH, A. S. Biocarvão que sequestra carbono no solo e complexa íons metálicos nutrientes de plantas. $18^{\circ}$ Evento de Iniciação Científica da Universidade Federal do Paraná. Curitiba, PR, 2010.

5. CERqueirA, S. C. A., ROMAO, L. P. C., MAngOni, Ana Paula, REZEndE, E. I. P., MANGRICH, A. S. Caracterização Espectroscópica da Redução e Remoção de Cromo (VI) por Turfa Tropical e sua Fração Humina. XI Jornada Brasileira de Ressonância Magnética. Curitiba, PR, 2010.

6. MAngOni, Ana Paula, REZEnde, E. I. P., MANGRICH, A. S., CASELATTO, A., FERNANDEZ, T. L., SCARPELLINI, M. Ressonância Paramagnética Eletrônica (RPE) no Estudo de Mistura Sólida de Complexo de Vanádio com Caulinita. XI Jornada Brasileira de Ressonância Magnética. Curitiba, PR, 2010. 
7. MANGRICH, A. S., NOVOTNY, E. H., VElloso, M. H. R., REZENDE, E. I. P., MANGONI, Ana Paula, MESSERSCHMIDT, I. Preparação de "biochar"imitando


de Química. Águas de Lindóia, SP, 2010.

8. MAngOni, Ana Paula, MANGRICH, A. S., RIBEIRO, R. R. Nova Terra Preta de Índios da Amazônia obtida por pirólise a partir da torta de mamona. XVII Encontro de Química da Região Sul. Rio Grande, RS, 2009.

9. MANGONI, Ana Paula, MANGRICH, A. S., RIBEIRO, R. R. Preparação de húmus de pirólise a partir de torta de biodiesel. 17º Evento de Iniciação Científica da Universidade Federal do Paraná. Curitiba, PR, 2009.

10. MAngOni, Ana Paula, SZPOGAnICZ, B., SCHU, A., NASS, F. Estudo do Fungibiopolímero Micoton: um novo composto para a remoção do cromo hexavalente em águas residuais. 30 a Reunião Anual da Sociedade Brasileira de Química. Águas de Lindóia, SP, 2007.

11. MAngOni, Ana Paula, SCHU, A., SZPOGAnICZ, B. Estudos da Afinidade da Melanina pelo Íon Mn(II). XV Encontro de Química da Região Sul. Ponta Grossa, PR, 2007.

12. MAngOni, Ana Paula, SZPOGAnICZ, B. Estudos da Afinidade da Melanina e Agentes Anti-Melanomas por Íons Metálicos Bivalentes e Trivalentes. XVI Seminário de Iniciação Científica da UFSC. Florianópolis, SC, 2006.

13. MAngOni, Ana Paula, SZPOGAniCZ, B., SCHU, Â. Estudos de Equilíbrio de Complexos de Cobre. 14 ${ }^{\mathrm{O}}$ SBQ Sul. Erechim, RS, 2006. 


\section{Participação em eventos}

1. Workshop em Nanobiotechnologia - Polímeros Avançados, Sistemas de Liberação, Curativos e Engenharia de Tecidos. Realizado no Instituto de Pesquisas Energéticas e Nucleares. São Paulo, SP, 2013. 24 Horas.

2. XV International Clay Conference. Rio de Janeiro, RJ, 2013.

3. IV International Workshop on Layered Materials. Campinas, SP, 2012.

4. Post Workshop School in Advanced Characterization Techniques of Layered Materials, 2012.

5. USP Conferences on Nanotechnology. São Paulo, SP, 2011.

6. 28 $8^{\text {a }}$ Semana da Química - Ano Internacional da Química: celebrando as conquistas da Química para Humanidade. São Paulo, SP, 2011.

7. $2^{\mathrm{O}}$ Encontro sobre Divulgação e Ensino de Ciências. São Paulo, SP, 2011. 20 Horas.

8. III Encontro da Pós-Graduação do Instituto de Química da Universidade de São Paulo. São Paulo, SP, 2011.

9. USP Conference - Chemistry and Earth Sciences. São Paulo, SP, 2011.

10. $34^{\mathrm{a}}$ Reunião Anual da Sociedade Brasileira de Química. Florianópolis, SC, 2011.

11. XVIII Encontro de Química da Região Sul, Curitiba, PR, 2010.

12. IV Semana Acadêmica do Setor de Ciências Exatas da Universidade Federal do Paraná. Curitiba, PR, 2010.

13. XVII Encontro de Química da Região Sul. Rio Grande, RS, 2009.

14. V Workshop Paranaense de Pós-Graduação em Química. Curitiba, PR, 2009.

15. XVI Semana de Química da UFPR. Curitiba, PR, 2009. 20 Horas. 
16. XIV Encontro Nacional de Ensino de Química. Curitiba, PR, 2008.

17. $31^{\text {a }}$ Reunião Anual da Sociedade Brasileira de Química. Aguas de Lindóia, SP, 2008.

18. XV Semana de Química da UFPR. Curitiba, PR, 2008. 20 Horas.

19. XVI Encontro de Química da Região Sul: A Química como Ciência, Educação e Tecnologia. Blumenau, SC, 2008. 30 Horas.

20. XV Encontro de Química da Região Sul. Ponta Grossa, PR, 2007. 30 Horas.

21. XIV Encontro de Química da Região Sul: Química na Sociedade: significados e implicações. Erechim, RS, 2006.

22. XIII Encontro de Química da Região Sul. Florianópolis, SC, 2005.

23. I Semana da Física - Ano Mundial da Física na UFSC. Florianópolis, SC, 2005. 14 Horas.

\section{Organização de evento}

1. 1. MANGONI, Ana Paula. XVIII Encontro de Química da Região Sul, Curitiba, PR, 2010. 